\title{
Interconnecting PV on New York City's Secondary Network Distribution System
}

Technical Report NREL/TP-7A2-46902

November 2009

K. Anderson, M. Coddington, K. Burman, S. Hayter, B. Kroposki, and A. Watson 


\section{Interconnecting PV on New York City's Secondary Network Distribution System}

K. Anderson, M. Coddington, K. Burman, S. Hayter, B. Kroposki, and A. Watson

Prepared under Task No. PVC9.92GA

\section{Technical Report} NREL/ TP-7A2-46902

November 2009

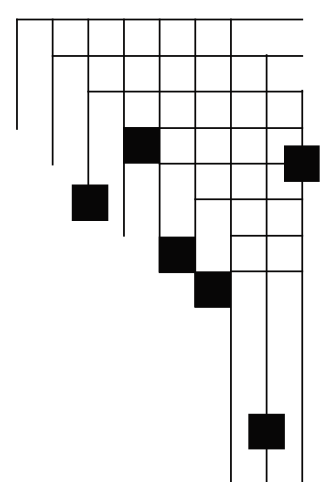




\section{NOTICE}

This report was prepared as an account of work sponsored by an agency of the United States government. Neither the United States government nor any agency thereof, nor any of their employees, makes any warranty, express or implied, or assumes any legal liability or responsibility for the accuracy, completeness, or usefulness of any information, apparatus, product, or process disclosed, or represents that its use would not infringe privately owned rights. Reference herein to any specific commercial product, process, or service by trade name, trademark, manufacturer, or otherwise does not necessarily constitute or imply its endorsement, recommendation, or favoring by the United States government or any agency thereof. The views and opinions of authors expressed herein do not necessarily state or reflect those of the United States government or any agency thereof.

Available electronically at http://www.osti.gov/bridge

Available for a processing fee to U.S. Department of Energy and its contractors, in paper, from:

U.S. Department of Energy

Office of Scientific and Technical Information

P.O. Box 62

Oak Ridge, TN 37831-0062

phone: 865.576 .8401

fax: 865.576 .5728

email: mailto:reports@adonis.osti.gov

Available for sale to the public, in paper, from:

U.S. Department of Commerce

National Technical Information Service

5285 Port Royal Road

Springfield, VA 22161

phone: 800.553 .6847

fax: 703.605.6900

email: orders@ntis.fedworld.gov

online ordering: http://www.ntis.gov/ordering.htm 


\section{Report Contents}

1.0 Photovoltaic Deployment Analysis for New York City

2.0 A Briefing for Policy Makers on Connecting PV to a Network Grid

3.0 Technical Review of Concerns and Solutions to PV Interconnection in New York City

4.0 Utility Application Process Review

5.0 Conclusion

6.0 Glossary

ES-i 


\section{Executive Summary}

The U.S. Department of Energy (DOE) has teamed with cities across the country through the Solar America Cities (SAC) partnership program to help reduce barriers and accelerate implementation of solar energy. The New York City SAC team is a partnership between the City University of New York (CUNY), the New York City Mayor's Office of Long-term Planning and Sustainability, and the New York City Economic Development Corporation (NYCEDC). The New York City SAC team is working with DOE's National Renewable Energy Laboratory (NREL) and Con Edison, the local utility, to develop a roadmap for photovoltaic (PV) installations in the five boroughs. The city set a goal to increase its installed PV capacity from 1.1 MW in 2005 to 8.1 MW by 2015 (the maximum allowed in 2005). A key barrier to reaching this goal, however, is the complexity of the interconnection process with the local utility. Unique challenges are associated with connecting distributed PV systems to secondary network distribution systems (simplified to "networks" in this report).

Although most areas of the country use simpler radial distribution systems to distribute electricity, larger metropolitan areas like New York City typically use networks to increase reliability in large load centers. Unlike the radial distribution system, where each customer receives power through a single line, a network uses a grid of interconnected lines to deliver power to each customer through several parallel circuits and sources. This redundancy improves reliability, but it also requires more complicated coordination and protection schemes that can be disrupted by energy exported from distributed PV systems. Currently, Con Edison studies each potential PV system in New York City to evaluate the system's impact on the network, but this is time consuming for utility engineers and may delay the customer's project or add cost for larger installations. City leaders would like to streamline this process to facilitate faster, simpler, and less expensive distributed PV system interconnections.

\section{The DOE/NREL Four-Part Study}

To assess ways to improve the interconnection process, NREL conducted a four-part study with support from DOE. The NREL team then compiled the final reports from each study into this report. In Section 1-PV Deployment Analysis for New York City-we analyze the technical potential for rooftop PV systems in the city. This analysis evaluates potential PV power production in ten Con Edison networks of various locations and building densities (ranging from high density apartments to lower density single family homes). Next, we compare the potential power production to network loads to determine where and when PV generation is most likely to exceed network load and disrupt network protection schemes. The results of this analysis may assist Con Edison in evaluating future PV interconnection applications and in planning future network protection system upgrades. This analysis may also assist other utilities interconnecting PV systems to networks by defining a method for assessing the technical potential of PV in the network and its impact on network loads.

Section 2-A Briefing for Policy Makers on Connecting PV to a Network Grid - presents an overview intended for nontechnical stakeholders. This section describes the issues associated with interconnecting PV systems to networks, along with possible solutions. 
Section 3-Technical Review of Concerns and Solutions to PV Interconnection in New York City - summarizes common concerns of utility engineers and network experts about interconnecting PV systems to secondary networks. This section also contains detailed descriptions of nine solutions, including advantages and disadvantages, potential impacts, and road maps for deployment.

Section 4-Utility Application Process Review-looks at utility interconnection application processes across the country and identifies administrative best practices for efficient PV interconnection.

\section{Summary of Findings}

Section 1 finds that if PV systems were fully deployed to cover all suitable roof space in New York City, PV generation could exceed network load in six of the ten networks. Figure ES-1 shows an example of network load and predicted PV generation in one network. The figure illustrates that PV generation exceeds network load in the spring months, resulting in energy exported to the network and possible disruption of network protection equipment.

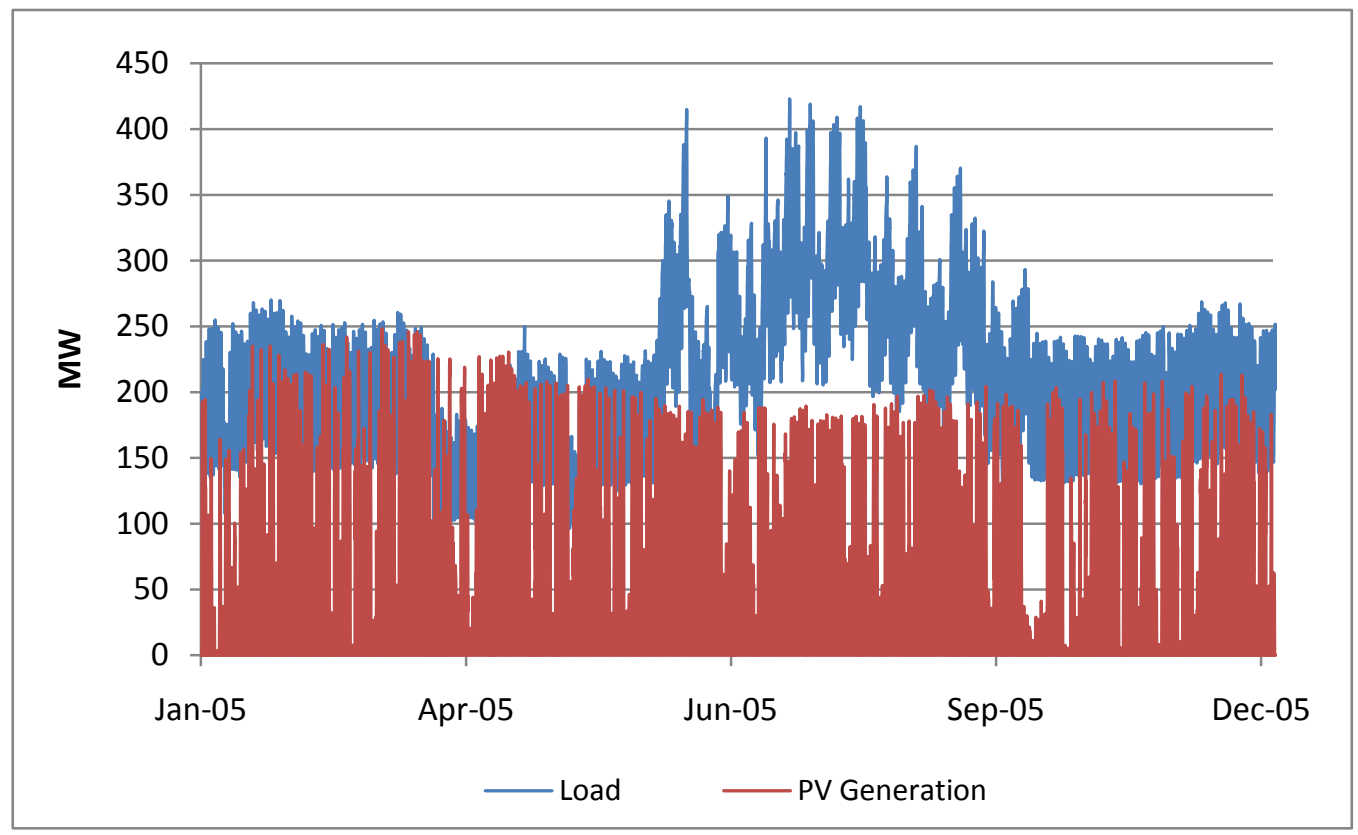

Figure ES-1. PV generation and network load

Table ES-1gives results for all ten networks. The fourth column shows the annual maximum percent of network load met by PV-generated electricity (called "PV generation" in this report) under full PV deployment. A value greater than 100 means that PV generation surpasses network load, resulting in a net export of electricity from the network. Although PV generation can significantly exceed network loads at times (by as much as two times in the Maspeth network, for example), its contribution to the network's overall energy requirements is much lower because energy generation is limited to daylight hours. In general, the networks with the highest amount of rooftop space per person export the most electricity. Generally, these networks serve the outer boroughs, where there are more single-family homes and office buildings with fewer stories. 
Table ES-1. Network Analysis Results

\begin{tabular}{lcccc} 
Network Name & Location & $\begin{array}{c}\text { Total PV Size } \\
(\text { MW AC) }\end{array}$ & $\begin{array}{c}\text { Percent of Load } \\
\text { Met by PV (Annual } \\
\text { Maximum; } \%)^{\mathrm{a}}\end{array}$ & $\begin{array}{c}\text { Energy } \\
\text { Penetration } \\
(\%)^{\mathrm{b}}\end{array}$ \\
\hline Bay Ridge & Brooklyn & 96.20 & 104.22 & 14.73 \\
Central Bronx & Brooklyn & 58.08 & 44.52 & 6.42 \\
Cooper & Bronx & 75.25 & 112.21 & 17.18 \\
Flushing & Manhattan & 25.73 & 27.17 & 3.76 \\
Fox Hill & Queens & 223.17 & 163.35 & 18.80 \\
Herald & Staten Island & 97.51 & 142.26 & 18.94 \\
Maspeth & Manhattan & 1.29 & 4.31 & 0.45 \\
Southeast Bronx & Bueens & 188.61 & 203.72 & 26.70 \\
Sutton & Bronx & 115.85 & 157.65 & 16.41 \\
\hline
\end{tabular}

${ }^{\text {a }}$ Percent of load met by PV (annual maximum) $=$ PV power generation/load $\times 100 \%$, for annual maximum hour ${ }^{\mathrm{b}}$ Energy penetration $=$ annual PV energy generation/annual energy consumption $\times 100 \%$

The amount of energy exported varies by time of year, day of week, and time of day. Exporting is highest during the spring months because PV generation is above average and loads are low. PV generation peaks in the spring because the PV array tilt angle (equal to the site's latitude) best matches the medium sun angle that occurs in the spring and fall. The fall and winter months experience less (although still significant) exporting, and the summer months export little electricity because network loads are higher. More electricity is exported on weekends than on weekdays, particularly in industrial networks where loads drop when businesses close on the weekends.

Over the course of a day, exporting is most likely to occur between 9:00 a.m. and 1:00 p.m., peaking at 11:00 a.m. PV generation is highest at midday, when the sun is directly over the south-facing arrays. The low midday load also contributes to high exporting. In general, the PV arrays reduce load significantly for about 8 hours in the morning and afternoon, but have no effect on nighttime loads. Because the peak load occurs in the evening in most networks, the PV systems reduce peak load in only three of the ten networks. In the others, the utility's required generating capacity remains the same. 
Because many PV arrays in the New York area are flat-mounted, we conducted additional analysis to evaluate how the results would change for flat-mounted PV arrays. We found that total annual PV power generation decreases, with production in the summer remaining about the same, spring and fall production dropping somewhat, and winter production falling significantly. The annual maximum percent of load met by PV changes very little (although the day on which it occurred shifts from early to late spring). Total net exporting hours are significantly reduced, with exporting completely eliminated in all months except May.

This analysis evaluated the effects of full PV deployment, with all suitable roof space covered in PV arrays. Although it is unlikely that full PV deployment will ever be realized, some effects on network systems are seen even at low deployment levels.

Section 2 describes the technical concerns associated with interconnecting distributed PV to network systems. Power exported from individual systems can disrupt protection and coordination schemes essential to the reliable operation of the network. At higher deployments, distributed PV systems can present challenges for load forecasting and power system planning, increase potential for unintentional islands, and cause power quality problems like voltage flicker. We end Section 2 by briefly summarizing potential solutions for these issues.

Section 3 looks at nine solutions in more detail. We find that the most common way to prevent disruption to networks from distributed PV systems is to ensure that they do not export power to the network. This can be achieved by sizing systems so that they never produce more power than is consumed at the site or by adding hardware (reverse power relays [RPRs], minimum import relays [MIRs], or dynamically controlled inverters [DCIs]) that prevents power from exporting. DCIs show the most promise because they reduce PV output without taking the PV system offline altogether and do not require manual resets, which reduces lost output for the system owner. DCI costs, which are minimal compared to RPR and MIR technologies, would not be cost-prohibitive for smaller systems. In the future, smart grid technologies will facilitate interconnection of exporting PV systems through better communication and control of network protection equipment and PV systems.

In Section 4, we review the administrative interconnection processes of utilities across the country and identify ways to streamline the distributed generation application process. This review suggests that making application documents available online and using an online tracking system (where homeowners and contractors can look up their application status) reduces wait time. In addition, compiling a qualified equipment list and a qualified contractor list makes information on acceptable equipment and trusted contractors readily available, decreasing review time. Finally, training and outreach programs for both contractors and homeowners help to improve the quality of the applications submitted.

\section{Future Research}

To increase understanding of the effects of distributed PV systems on networks, we recommend further research in the following areas:

- Identify system-level impacts of high PV penetration in networks: Although the effects of individual PV system connections to networks have been comprehensively 
examined, little is known about how the entire system is affected at high penetrations of $\mathrm{PV}$.

- Identify maximum penetration levels in network systems: PV penetration levels of $20 \%$ to $30 \%$ are generally considered to be the maximum level allowable in radial distribution systems before changes to the system are necessary. The maximum allowable penetration level on a network system, however, is unclear. Additional research is necessary for establishing maximum acceptable penetration levels in both area and spot networks.

- Improve modeling of distributed generation in network systems: Current modeling solutions do not adequately address the system impacts of distributed generation in network systems. Additional research and development should be directed at improving modeling solutions for network systems.

- Develop smart grid technologies: Future smart grid technologies may offer intelligent monitoring and control of PV systems that will allow better integration into network systems. Research and development of smart grid technologies, with a particular focus on their applicability in network systems, should continue. 


\subsection{Photovoltaic Deployment Analysis for New York City}

This study evaluated the technical potential of rooftop photovoltaics (PV) in ten New York City networks. To determine the maximum technical PV potential for each network, analysts from the U.S. Department of Energy's (DOE) National Renewable Energy Laboratory (NREL) assessed suitable roof space and estimated the power that could be produced if all suitable space were covered with PV arrays. PV power levels were then compared to actual hourly load levels in each network. The results of the study, presented in this section, are intended to help New York City and its utility, Con Edison, plan for increased PV deployment on the city's secondary network distribution system by showing where and when PV-generated electricity (called "PV generation" in this report) is most likely to exceed network load and disrupt network protection schemes. The results may assist Con Edison in evaluating future PV interconnection applications and planning future network protection system upgrades. This study might also help other utilities that are interconnecting PV systems to networks by defining a method for assessing the technical potential of PV in the network and its impact on network loads. 


\section{Contents}

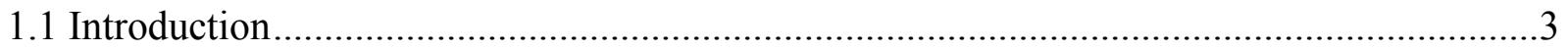

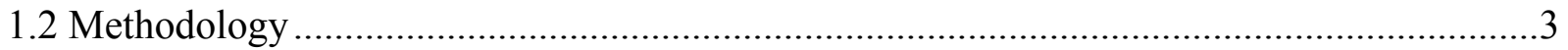

1.2.1 Analyzing the Building Type Composition of Each Network Area .......................... 4

1.2.2 Analyzing the Suitable Roof Space in Each Building Type Category ...................... 5

1.2.3 Calculating the Suitable Roof Space and Maximum Capacity of PV in Each

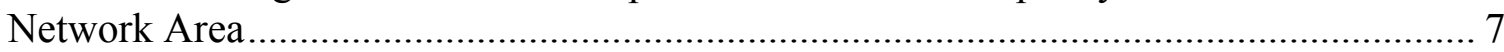

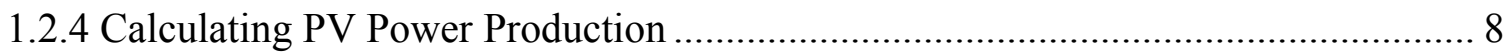

1.2.5 Comparing PV Electricity Production to Network Loads ........................................ 9

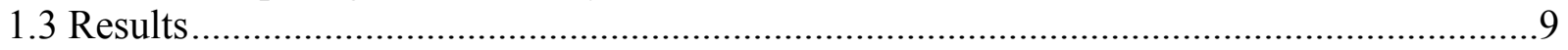

1.3.1 Percent of Network Area Covered by PV ......................................................... 10

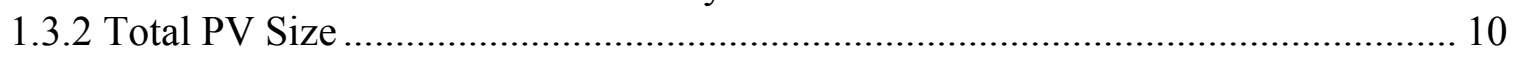

1.3.3 Percent of Load Met by PV (Annual Maximum) ................................................ 10

1.3.4 Capacity Penetration ......................................................................................... 10

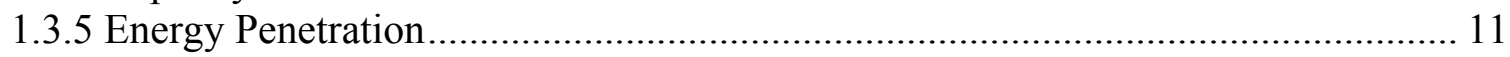

1.3.6 Network Load and PV Generation under Full PV Deployment .............................. 11

1.3.7 Maximum Export Day under Full PV Deployment................................................. 16

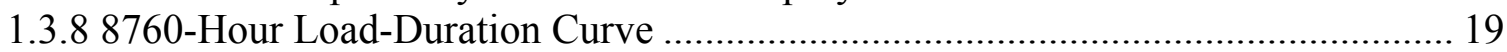

1.3.9 8760-Hour Load-Duration Curve, Top 100 Hours ................................................ 23

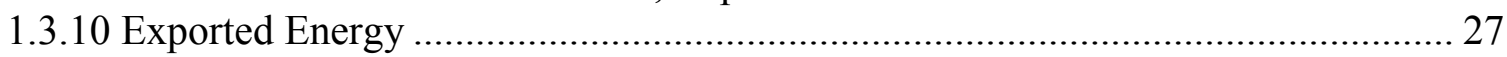

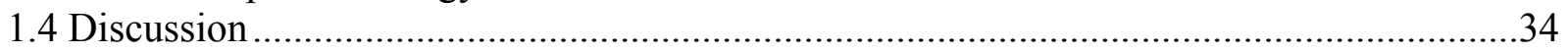

1.5 Sources of Error

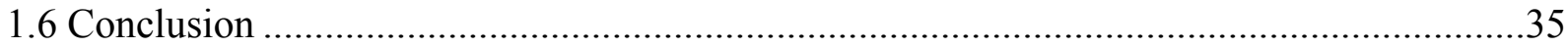

Appendix 1-A: Network PV Deployment Percentage and PV Capacity Calculations .......... 37

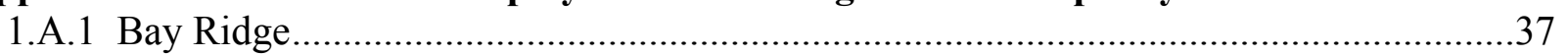

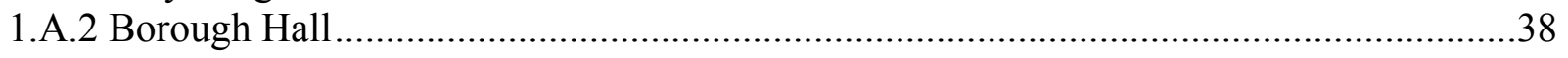

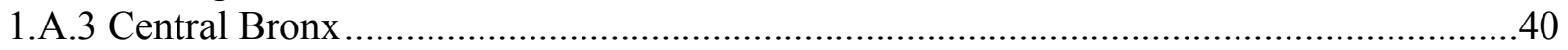

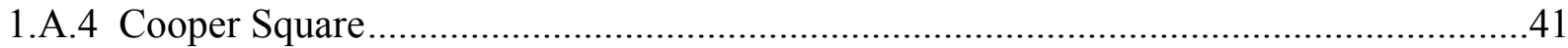

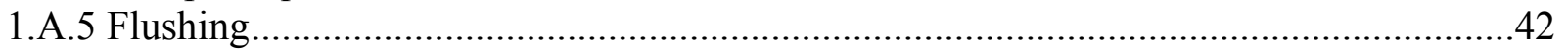

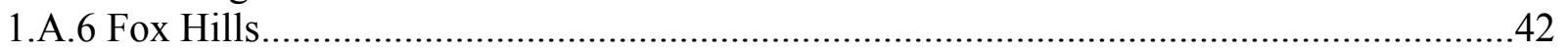

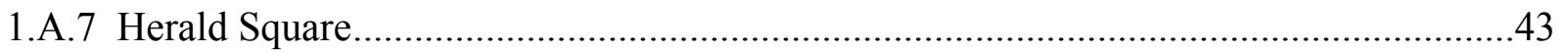

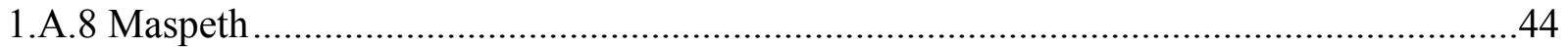

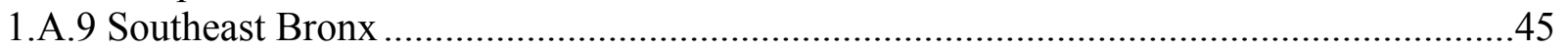

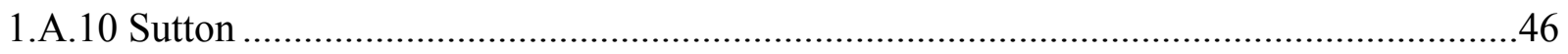

Appendix 1-B: PV Generation for Flat-Mounted Arrays............................................................... 47

Appendix 1-C: Individual Building Analysis ..........................................................................5 54

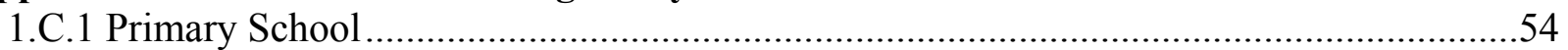

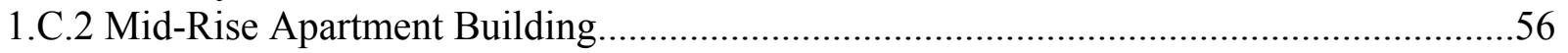

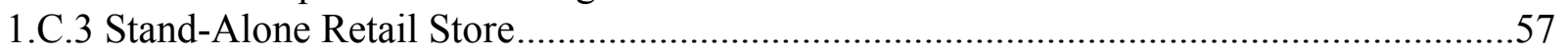

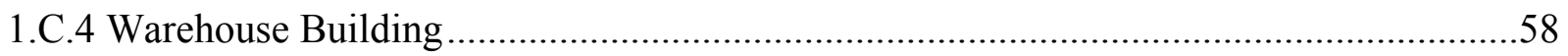

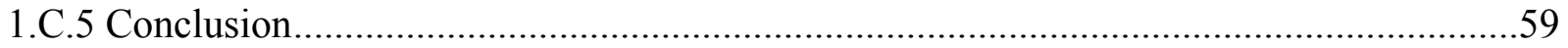




\subsection{Introduction}

Although most areas of the country use simpler radial distribution systems to distribute electricity, larger metropolitan areas like New York City typically use more complicated secondary network distribution systems (referred to as "networks" in this report) to increase reliability in large load centers. Unlike the radial distribution system, where each customer receives power through a single line, a network uses a grid of interconnected lines to deliver power to each customer through several parallel circuits and sources. This redundancy improves reliability, but also requires protective devices called "network protectors" (NPs) that prevent power from back-feeding from one transformer through another. Network protector operation can be disrupted by energy exported to the network from distributed generation. At current levels of distributed PV deployment, PV generation is so small compared to network loads that any electricity exported to the network is consumed by nearby loads. At higher levels of deployment, however, PV could generate enough electricity to back-feed through network protectors, potentially causing these devices to open unnecessarily, which would reduce network reliability.

To assess PV generation at high deployment levels and the effect it might have on the network, an NREL team conducted a study to evaluate the technical potential of rooftop PV in ten New York City networks. We selected the particular networks to study because they represent a cross section of all of New York City's 62 networks.

We determined the maximum technical PV potential for each network by assessing suitable roof space and estimating the power that could be produced if all suitable space were covered with PV arrays. Next, we compared the PV generation levels to actual hourly load levels in each network. We found that if PV systems were fully deployed to cover all suitable roof space in New York City, PV generation could exceed network load in six of the ten networks. This would be most likely to occur at midday during spring weekends in the lower density outer boroughs.

It is important to note that we performed this analysis at the macro level, comparing total loads and total PV generation across entire networks. Although this allowed us to estimate net energy exported from the network as a whole, network protectors operate within the network and will respond to more localized energy exporting. To predict the effects of exporting PV energy on individual network protectors, a more detailed study at the individual building level is required.

\subsection{Methodology}

With support from DOE, the NREL team analyzed ten Con Edison networks to determine the maximum technical PV deployment possible in each network area. We used NREL's In My Backyard (IMBY) tool to estimate the amount of roof space suitable for PV arrays in each network area. ${ }^{1}$ Based on the suitable area and an average PV power density, we determined the total capacity of rooftop PV. Based on this capacity and on site weather

\footnotetext{
${ }^{1}$ For more information on IMBY, see http://www.nrel.gov/eis/imby/.
} 
data, we calculated hourly PV production, then compared these data to actual hourly load levels in each network. Finally, we analyzed the data in more depth to determine in which hours PV generation exceeded network load, and by how much. The subsections that follow outline the analysis steps in detail.

\subsubsection{Analyzing the Building Type Composition of Each Network Area}

Because the percentage of total network area available for PV varies by building type and density, we examined satellite images to determine the building composition of each network. Some areas were homogenous, with similar building types and densities across much of the network. In other networks, building types varied significantly. In nonhomogenous networks, we broke down the total built area into categories by building type, building density, and, for the warehouses, availability of rooftop space (see Table 11). We estimated roof-space availability based on visible rooftop obstructions. The blue areas on the rooftops in the example images in Table 1-1 represent potential PV arrays for the selected block.

Table 1-1. Building Categories

\begin{tabular}{ll}
$\begin{array}{l}\text { Building } \\
\text { Category }\end{array}$ & \multicolumn{1}{c}{ Description } \\
\hline $\begin{array}{l}\text { Low- } \\
\text { Density }\end{array}$ & $\begin{array}{l}\text { Includes widely spaced single-family } \\
\text { homes (generally found on the outskirts } \\
\text { of the outer boroughs), as well as } \\
\text { widely spaced high-rise apartment } \\
\text { buildings. Less than 50\% of the total } \\
\text { land area is occupied by buildings. }\end{array}$ \\
&
\end{tabular}

High- Includes closely spaced or attached Density single-family homes, multifamily units, Residential and apartment buildings. More than $50 \%$ of the total land area is occupied by buildings.

Low- Includes large, low commercial Density buildings with wide expanses of roof Warehouse space. Less than $50 \%$ of the total land (Poor area is occupied by buildings, and less Availability) than $20 \%$ of the roof space is available for PV.
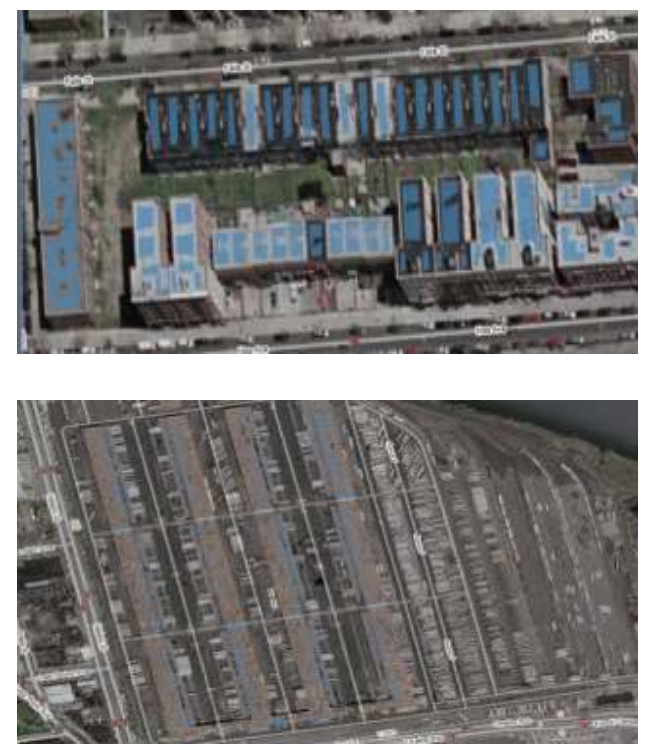


\begin{tabular}{ll}
\hline Low- & Includes large, low commercial \\
Density & buildings with wide expanses of roof \\
Warehouse & space. Less than 50\% of the total land \\
(Good & area is occupied by buildings, and more \\
Availability) & $\begin{array}{l}\text { than 20\% of the roof space is available } \\
\text { for PV. }\end{array}$
\end{tabular}

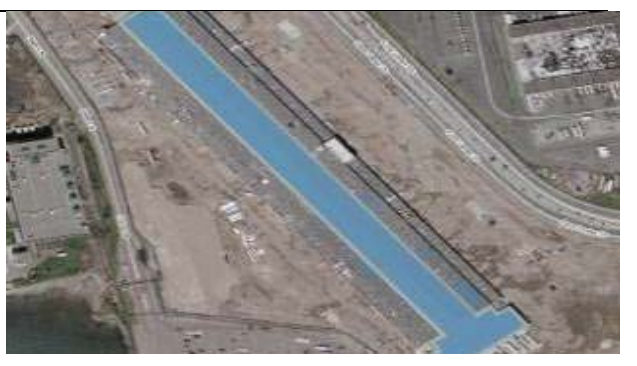

High- Includes large, low commercial

Density buildings with wide expanses of roof

Warehouse space. More than $50 \%$ of the total land

(Poor area is occupied by buildings, and less

Availability) than $20 \%$ of the roof space is available for PV.

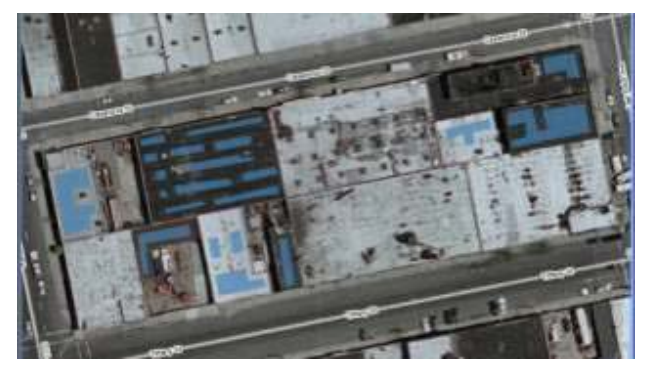
High- Includes large, low commercial Density buildings with wide expanses of roof Warehouse space. More than $50 \%$ of the total land (Good area is occupied by buildings, and more Availability) than $20 \%$ of the roof space is available for PV.

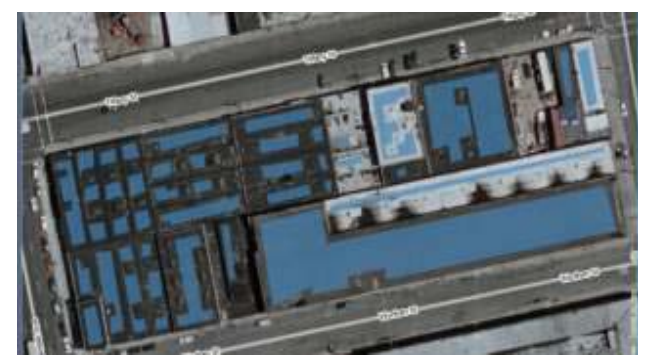

High- Includes closely spaced high-rise Density buildings, found mainly in Manhattan. High-Rise

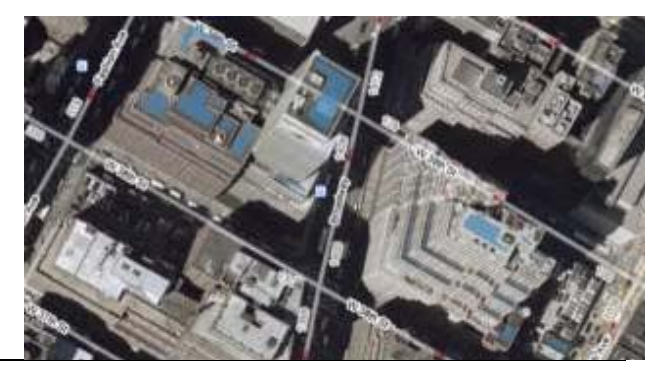

For example, in analyzing the satellite imagery of the Bay Ridge network, we found that the area is made up of $80 \%$ high-density residential buildings; $4 \%$ low-density warehouse (poor availability) buildings; 5\% low-density warehouse (good availability) buildings; $5 \%$ high-density warehouse (poor availability) buildings; and 6\% high-density warehouse (good availability) buildings.

These percentages represent the percent of the total network area (\%TNA) attributed to each building category. Appendix 1-A contains details of building categories in each network area. We estimate that the building composition percentages are $\pm 2 \%$ accurate.

\subsubsection{Analyzing the Suitable Roof Space in Each Building Type Category}

We used IMBY to perform a detailed analysis of $10 \%$ of the area in each building category in each network to estimate the amount of roof space suitable for PV in that 
sample area. ${ }^{2}$ Roofs were covered to the maximum extent practical, taking into consideration the following factors:

- Rooftop obstructions preventing PV placement

- Shading by rooftop obstructions, parapets, nearby buildings, or trees

- Walkway space required around obstructions and PV panels for access and safety

- Roof aspect - east, south, and west-facing roofs were covered; north-facing roofs were avoided.

Visible rooftop maintenance conditions were evaluated as well (see Appendix 1-A), but we included rooftop space regardless of condition to assess the maximum amount of available space.

Using IMBY, we estimated the suitable space on each rooftop in the sample area (accurate to within $\pm 10 \%$ ). Next, we summed the suitable areas on each rooftop to calculate the total suitable space in the sample area and compared this value to the size of the entire sample area. This allowed us to estimate the PV deployment percentage (PVD\%): the percentage of the sample area that could be covered in PV arrays (see Equation 1-1). That percentage was assumed to be equal to the percentage calculated for its sample area. We estimate that this is $5 \%$ to $15 \%$ accurate, depending on the size of the sample area (larger sample areas including many buildings are more accurate) and the variation in the building category (less varied categories are more accurate).

$$
\begin{aligned}
& \text { PV deployment percentage }(P V D \%)_{\text {Sample Area } A}= \\
& \frac{\sum\left(\text { Array area }_{1}, \text { array area }_{2}, \ldots \text { array area }_{N}\right)}{\text { Sample area } A} \times 100 \%
\end{aligned}
$$

For example, if a 1,000- $\mathrm{m}^{2}$ sample area contained five buildings, and the IMBY analysis found that each had $10 \mathrm{~m}^{2}$ of suitable roof space, the PVD\% would be

$$
\operatorname{PVD} \%=(10+10+10+10+10) / 1000 \times 100 \%=5 \% .
$$

Appendix 1-A contains PVD\% details in each building category for each network.

\footnotetext{
${ }^{2}$ IMBY estimates the size of a polygon drawn on a Google map satellite image. Based on this size and an average power density, it then estimates electricity production using the PVWatts performance model (for more information on PVWatts, see http:/www.nrel.gov/rredc/pvwatts/). IMBY is typically used to estimate the size and potential electricity production of a PV array or wind turbine at an individual home or business. In this study, we used it to estimate the size of PV arrays over a large area.
} 


\subsubsection{Calculating the Suitable Roof Space and Maximum Capacity of PV in Each Network Area}

To estimate the overall network PV deployment percentage, we multiplied the PVD\% figures calculated in each building category (see Section 1.2.2) by the corresponding \%TNA figures (see Section 1.2.1 and Equation 1-2).

$$
\begin{aligned}
& P V \text { deployment percentage }(P V D \%)_{n e t w o r k}= \\
& {\left[\left(P V D \%_{1}\right) \times\left(\% T N A_{1}\right)+\left(P V D \%_{2}\right) \times\left(\% T N A_{2}\right)+\ldots+\right.} \\
& \left.\left(P V D \%_{n}\right) \times\left(\% T N A_{n}\right)\right] / 100
\end{aligned}
$$

For example, the PVD\% and \%TNA for each building category in the network (see Table $1-2$ ) can be multiplied as follows to calculate the network PVD\%:

$$
\mathrm{PVD}_{\text {Network }}=[10 \times 50+5 \times 20+15 \times 30] / 100=10.5 \% .
$$

This number represents the maximum percentage of the total network area that could be covered in PV arrays, assuming that all suitable roof space was used.

Table 1-2. PVD\% and \%TNA for Sample Network Building Categories

\begin{tabular}{lcc}
\hline \multicolumn{1}{c}{ Building Category } & PVD\% & \%TNA \\
\hline High-Density Residential & 10 & 50 \\
$\begin{array}{l}\text { High-Density Warehouse (Poor } \\
\text { Availability) }\end{array}$ & 5 & 20 \\
$\begin{array}{l}\text { High-Density Warehouse (Good } \\
\text { Availability) }\end{array}$ & 15 & 30 \\
\hline
\end{tabular}

To calculate the total area of the PV arrays in a network at full PV deployment, we multiplied the size of the total network area by the network PVD\%. Using the resulting value, we applied a power density of $0.1 \mathrm{~kW} \mathrm{DC} / \mathrm{m}^{2}$ to calculate the total capacity (in kilowatts) of PV in the network (see Equation 1-3). In reality, this power density will vary by $\pm 15 \%$, depending on individual module characteristics.

$$
P V \text { capacity }_{\text {network }}=\text { total network area } \times P V D \% \times 0.1 \mathrm{kWDC} / \mathrm{m}^{2}
$$

For example, if a network had an area of $10 \mathrm{~km}^{2}\left(10,000,000 \mathrm{~m}^{2}\right)$ and a PVD $\%$ of $10.5 \%$, the network's PV capacity would be

$$
\text { PV capacity }=10,000,000 \mathrm{~m}^{2} \times 0.105 \times 0.1 \mathrm{~kW} \mathrm{DC} / \mathrm{m}^{2}=105 \mathrm{MW} \text { DC. }
$$

The AC capacity is calculated by multiplying by a DC-to-AC derate factor of 0.77 . For the example given here, the AC capacity would be $105 \times 0.77=81 \mathrm{MW}$ AC. 


\subsubsection{Calculating PV Power Production}

We used IMBY's solar estimator to model the PV power on an hourly basis for 2005 annual data. IMBY made use of Perez Satellite Solar Resource Data (satellite-derived, high-resolution data from visible channel images from geostationary satellites) ${ }^{3}$ and PVWatts (as the PV performance model) to estimate hourly AC power production for a crystalline silicon PV system. Using the 2005 Perez weather data from New York City, the solar estimator calculated the solar radiation incident on the PV array and the PV cell temperature for each hour of the year. The DC power for each hour was calculated from the PV system DC rating and the incident solar radiation, and then corrected for the PV cell temperature. The AC power for each hour was calculated by multiplying the DC power by the overall DC-to-AC derate factor and adjusting for inverter efficiency as a function of load. The PV power production estimate is accurate to within $10 \%$ to $12 \% .{ }^{4}$

We made the following assumptions in calculating power generated from the PV arrays:

- The overall DC-to-AC derate factor was 0.77. This is the standard derate factor assumed in PVWatts. It accounts for losses from the components of the PV system, including inverter and transformer, mismatch, diodes and connections, DC wiring, AC wiring, soiling, system availability, shading, sun-tracking, and age.

- All PV arrays were assumed to be fixed (not tracking the sun). Sun-tracking arrays could generate between $25 \%$ and $40 \%$ more electricity.

- The PV array tilt angle was equal to the site's latitude $\left(40.8^{\circ} \mathrm{N}\right)$. This normally maximizes annual energy production. Increasing the tilt angle favors energy production in the winter; decreasing the tilt angle favors energy production in the summer. A tilt angle equal to the site's latitude will favor energy production in the spring and fall. In this case, because Con Edison sees its minimum loads in spring and fall, maximizing PV production for spring and fall allowed us to analyze maximum energy exporting. Because many New York area PV systems are flat-mounted, we also analyzed one network with a PV array tilt angle equal to zero (flat-mounted). Appendix 1-B contains this analysis for comparison.

- The $\mathbf{P V}$ array azimuth angle was $180^{\circ}$ (south-facing). This normally maximizes energy production.

- The installed nominal operating temperature was $45^{\circ} \mathrm{C}$. This is the PVWatts default.

- The power degradation resulting from temperature was $0.5 \% /{ }^{\circ} \mathrm{C}$. This is the PVWatts default.

- The angle-of-incidence (reflection) losses for a glass PV module cover were calculated as presented by King and colleagues. ${ }^{5}$

\footnotetext{
${ }^{3}$ Perez R.; Ineichen, P; Moore, K.; Kmiecik, M.; Chain, C., George, R.; Vignola, F. "A New Operational Satellite-to-Irradiance Model." Solar Energy; Vol. 73 (5), 2002; 307-317.

${ }^{4}$ See http://www.nrel.gov/rredc/pvwatts/interpreting_results.html.

${ }^{5}$ King, D; Kratochvil, J; Boyson, W. "Field Experience with a New Performance Characterization Procedure for Photovoltaic Arrays." Presented at the Second World Conference and Exhibition on Photovoltaic Solar Energy Conversion, July 6-10, 1998.
} 


\subsubsection{Comparing PV Electricity Production to Network Loads}

We compared the predicted PV production under full PV deployment to actual 2005 Con Edison network loads. The next section gives the results of this comparison.

\subsection{Results}

PV generation under full PV deployment was compared to network loads for the ten network areas. The results for each network are presented in Table 1-3 and in the graphs that follow. We discuss these results in more detail in Section 1.4.

Table 1-3. Network Analysis Results

\begin{tabular}{|c|c|c|c|c|c|}
\hline $\begin{array}{c}\text { Network Name } \\
\text { (Borough) }\end{array}$ & $\begin{array}{l}\text { Percent } \\
\text { of } \\
\text { Network } \\
\text { Area } \\
\text { Covered } \\
\text { by PV } \\
(\%)^{\mathrm{a}} \\
\end{array}$ & $\begin{array}{c}\text { Total PV } \\
\text { Size } \\
(\mathrm{MW} \\
\mathrm{AC})^{\mathrm{b}} \\
\end{array}$ & $\begin{array}{l}\text { Percent of } \\
\text { Load Met by } \\
\text { PV (Annual } \\
\text { Maximum; \%) }\end{array}$ & $\begin{array}{c}\text { Capacity } \\
\text { Penetration } \\
(\%)^{d}\end{array}$ & $\begin{array}{c}\text { Energy } \\
\text { Penetration } \\
(\%)^{\mathrm{e}} \\
\end{array}$ \\
\hline Central Bronx (Bronx) & 10.16 & 75.25 & 112.21 & 68.73 & 17.18 \\
\hline Bay Ridge (Brooklyn) & 10.12 & 96.20 & 104.22 & 48.87 & 14.73 \\
\hline Borough Hall (Brooklyn) & 9.60 & 58.08 & 44.52 & 23.52 & 6.42 \\
\hline Southeast Bronx (Bronx) & 8.66 & 115.85 & 157.65 & 57.69 & 16.41 \\
\hline Cooper (Manhattan) & 7.91 & 25.73 & 27.17 & 11.94 & 3.76 \\
\hline Maspeth (Queens) & 7.18 & 188.61 & 203.72 & 85.80 & 26.70 \\
\hline Herald (Manhattan) & 6.94 & 1.29 & 4.31 & 1.35 & 0.45 \\
\hline Flushing (Queens) & 5.64 & 223.17 & 163.35 & 58.67 & 18.80 \\
\hline Sutton (Manhattan) & 3.84 & 1.85 & 3.04 & 1.32 & 0.40 \\
\hline Fox Hill (Staten Island) & 2.99 & 97.51 & 142.26 & 53.18 & 18.94 \\
\hline \multicolumn{6}{|c|}{$\begin{array}{l}{ }^{\mathrm{a}} \text { Percent of network area covered by PV: Calculated as shown in Section } 1.2 .3 \\
\mathrm{~b} \text { Total PV size }=\text { size of PV array covering entire network } \times \text { percent of network area covered by PV } \\
{ }^{\mathrm{c}} \text { Percent of load met by PV (annual maximum) }=\text { PV power generation/load } \times 100 \text {, for annual maximum } \\
\text { hour (coincident). Coincident means the PV generation and load occur during the same hour. } \\
\mathrm{d} \text { Capacity penetration }=\text { annual peak PV power generation/annual peak load } \times 100 \text { (noncoincident). } \\
\text { Noncoincident means the PV generation and load occur during different hours. } \\
\text { e Energy penetration = annual PV energy generation/annual energy consumption } \times 100\end{array}$} \\
\hline
\end{tabular}




\subsubsection{Percent of Network Area Covered by PV}

The second column in Table 1-3 shows the percent of the total network land area that could be covered with PV arrays under full PV deployment (PVD\%). This number is based on our analysis of the $10 \%$ sample area, and varies from $3 \%$ to $10 \%$, depending on the density of buildings in the network area. The higher density networks have more buildings per square foot and therefore more rooftop space, which allows for larger amounts of PV per square foot. The lower density networks have fewer buildings per square foot and therefore a lower percentage of rooftop space available for PV arrays. For example, the high-density Bay Ridge, Borough Hall, Central Bronx, and Southeast Bronx networks have higher PVD\%. The lower density Flushing, Fox Hill, and Maspeth networks have lower PVD\%. Manhattan networks (Sutton, Herald, and Cooper) are an exception to this rule - even though they are high density, they tend to have low to medium PVD\% because rooftop equipment and shading from neighboring high-rise buildings leave little space available for PV arrays.

\subsubsection{Total PV Size}

The third column in Table 1-3 shows the cumulative size of all PV systems in the network - in megawatts of alternating current power - under full PV deployment. This is the amount of power that could be produced by PV if all suitable rooftop space were covered (see Equation 1-4).

Total PV size $=$ size of PV array covering entire network $\times$ percent of network area covered by $P V$

\subsubsection{Percent of Load Met by PV (Annual Maximum)}

The fourth column in Table 1-3 shows the maximum percent of network load supplied by PV-generated electricity, calculated as shown in Equation 1-5. It represents the one maximum hour during the year - in all other hours, the percentage will be lower. This hour is different for each network, but generally occurs at midday during the spring. A value greater than 100 shows that PV generation surpasses network load, meaning that there is a net export of electricity from the network. Note that these are coincident power generation and load values.

$$
\begin{aligned}
& \text { Percent of load met by PV (Annual Maximum })= \\
& {\left[\frac{\text { Maximum hour PV power generation }(\mathrm{kW})}{\text { Maximum hour load }(\mathrm{kW})}\right] \times 100}
\end{aligned}
$$

\subsubsection{Capacity Penetration}

The values in the fifth column in Table 1-3 are calculated by dividing the annual peak PV power generation (the PV generation during the 1 hour of the year when PV generation is at its highest) by the annual peak network load (the load during the 1 hour of the year when load is at its highest; see Equation 1-6). It is similar to "percent of load met by $\mathrm{PV}$ (annual maximum)" in that it is a measure of how much of the load is being generated 
by PV. In this case, however, the generation and load values are noncoincident. Capacity penetration is a value commonly used by utilities in the peak hour report to evaluate the impact of distributed generation on network loads.

Capacity penetration percentage $=$

$\left[\frac{\text { Annual peak PV power generation }(\mathrm{kW})}{\text { Annual peak load }(\mathrm{kW})}\right] \times 100$

\subsubsection{Energy Penetration}

The last column in Table 1-3 shows the percent of annual network energy needs met by annual PV energy generation, calculated as shown in Equation 1-7. We see that even though PV energy production (in kilowatt-hours or megawatt-hours) may significantly surpass network loads in a single hour, it makes a much smaller contribution to total annual energy use.

$$
\begin{aligned}
& \text { Energy penetration percentage }= \\
& {\left[\frac{\text { Annual PV energy generation }(\mathrm{kWh})}{\text { Annual energy consumption }(\mathrm{kWh})}\right] \times 100}
\end{aligned}
$$

We developed graphs to further illuminate the impact of PV generation in each network under full PV deployment. Each network has an associated graph that illustrates the following:

- $\quad$ Network load and PV generation under full PV deployment

- Maximum export day under full PV deployment

- 8760-hour load-duration curve

- 8760-hour load-duration curve, top 100 hours

- Exported energy by month, day, and time.

\subsubsection{Network Load and PV Generation under Full PV Deployment}

Figures 1-1 through 1-10 chart the 2005 load and PV generation (under full deployment) for each network. They show how PV generation compares to loads over the course of the year, including how often PV generation surpasses load (if at all), and when. Because we were comparing PV generation to hourly loads (in megawatts), we used PV power generation (in megawatts) rather than energy generation (in megawatt-hours).

From these graphs, we see that PV generation potential varies significantly between networks. In Herald and Sutton, for example, PV generation never approaches network load levels. In the Maspeth network, on the other hand, PV generation exceeds network loads throughout much of the year. In six of the ten evaluated networks, if PV arrays were fully deployed, they would sometimes generate more energy than the network could 
use. In general, the most likely areas to experience exporting are those with the highest amount of rooftop space per person. In areas of dense high-rise buildings (like Manhattan), where many people live or work under one roof, space available for PV arrays is small, and the energy they produce will be small compared to the load generated by all the people under that roof. In a residential area like Staten Island, however, people mainly live in single-family homes and office buildings tend to have only a few stories. Because there is a much larger amount of roof space per person, PV can generate a much higher percent of the minimum load.

Figures 1-1 through 1-10 also show that, because the PV arrays are tilted at an angle equal to the site's latitude $\left(40.8^{\circ} \mathrm{N}\right)$, PV power output is greatest in the spring and fall. This tilt angle favors power production in the spring and fall because it best matches the medium sun angle that occurs during those seasons (halfway between the low winter sun and high summer sun). Note that this is different from energy production. Energy production (measured in megawatt hours) would peak in the summer months, when more daylight hours will result in more energy produced, even though less energy is produced per hour.

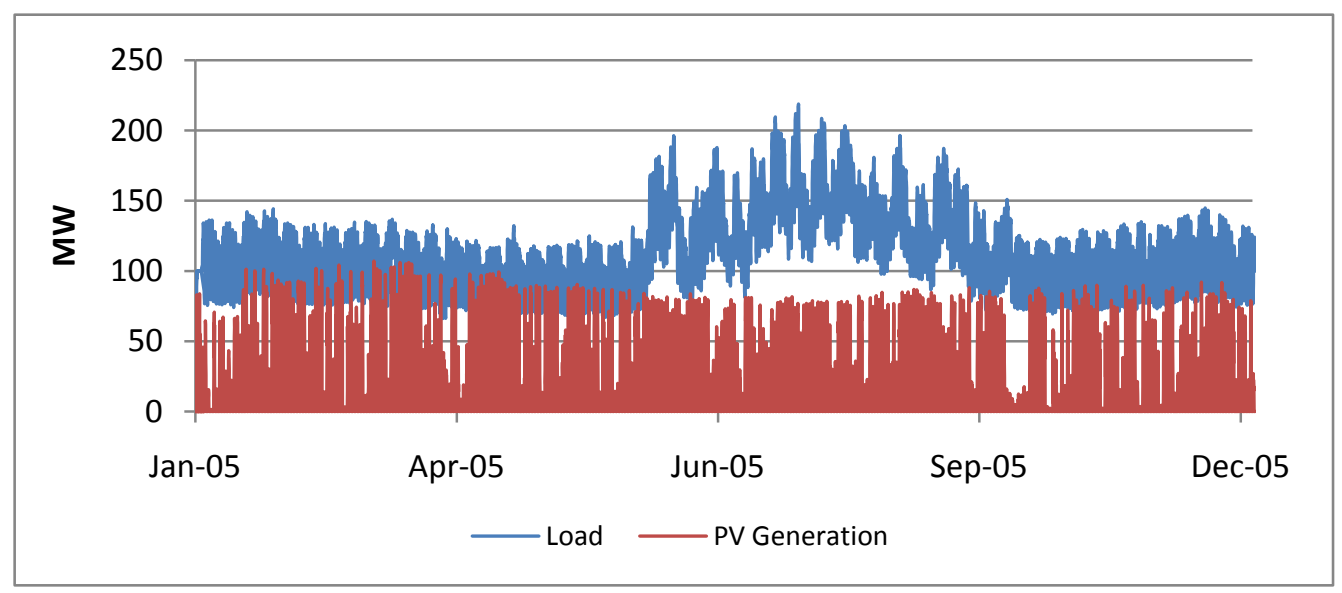

Figure 1-1. Bay Ridge network load and maximum PV generation under full PV deployment 


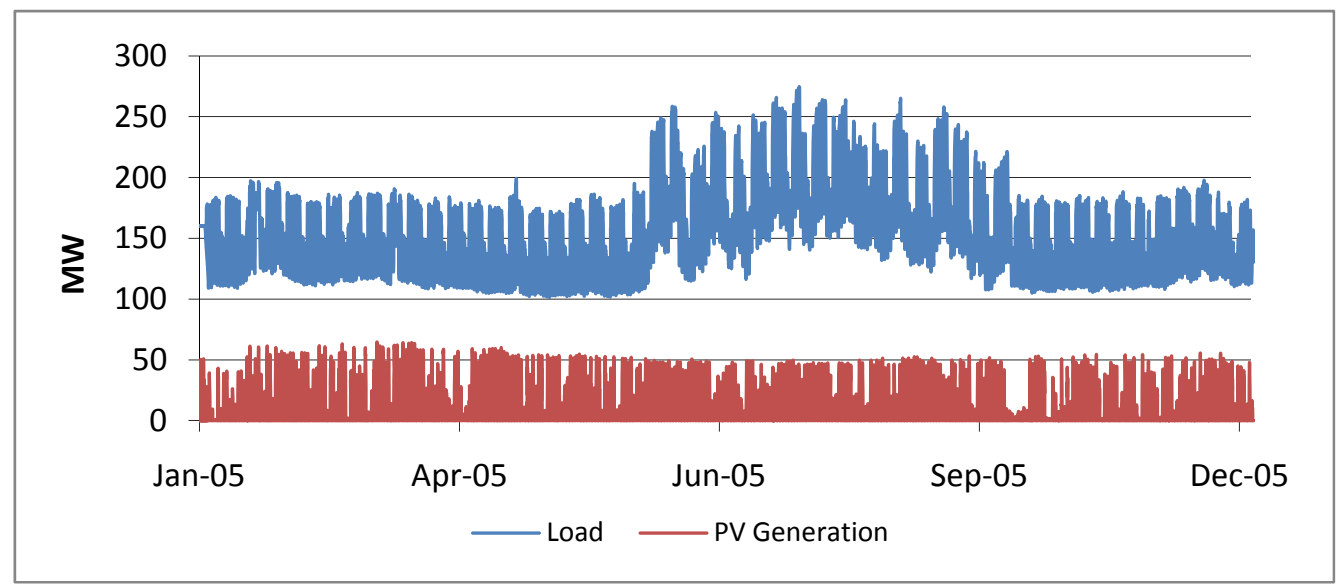

Figure 1-2. Borough Hall network load and maximum PV generation under full PV deployment

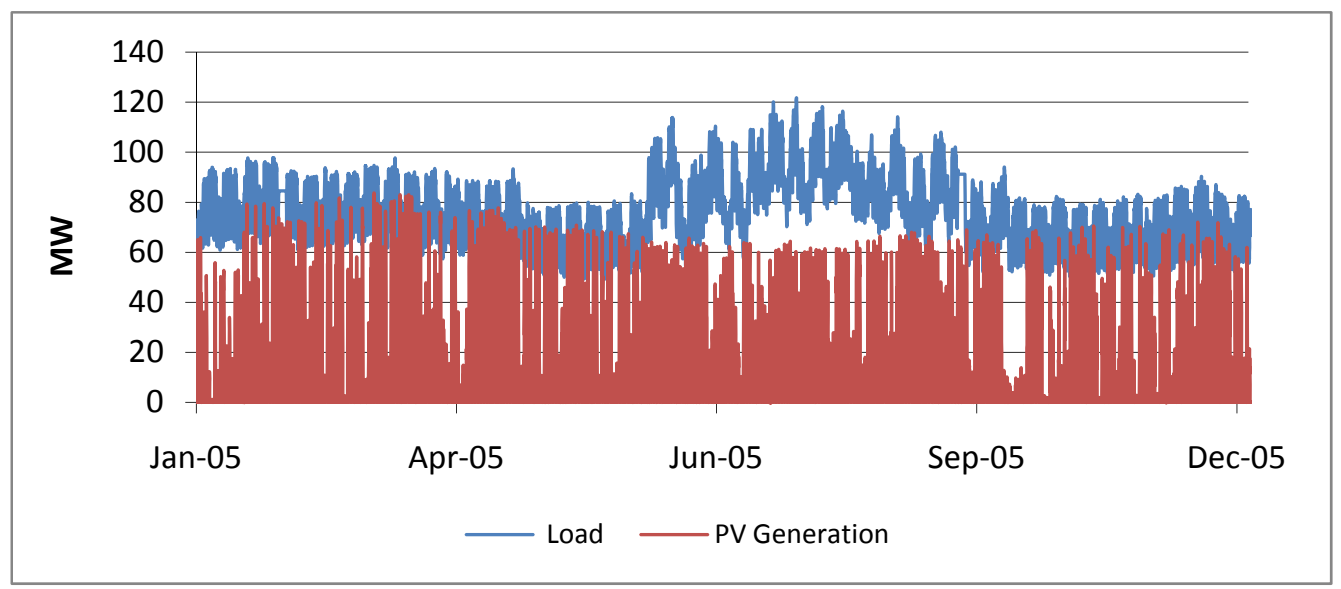

Figure 1-3. Central Bronx network load and maximum PV generation under full PV deployment

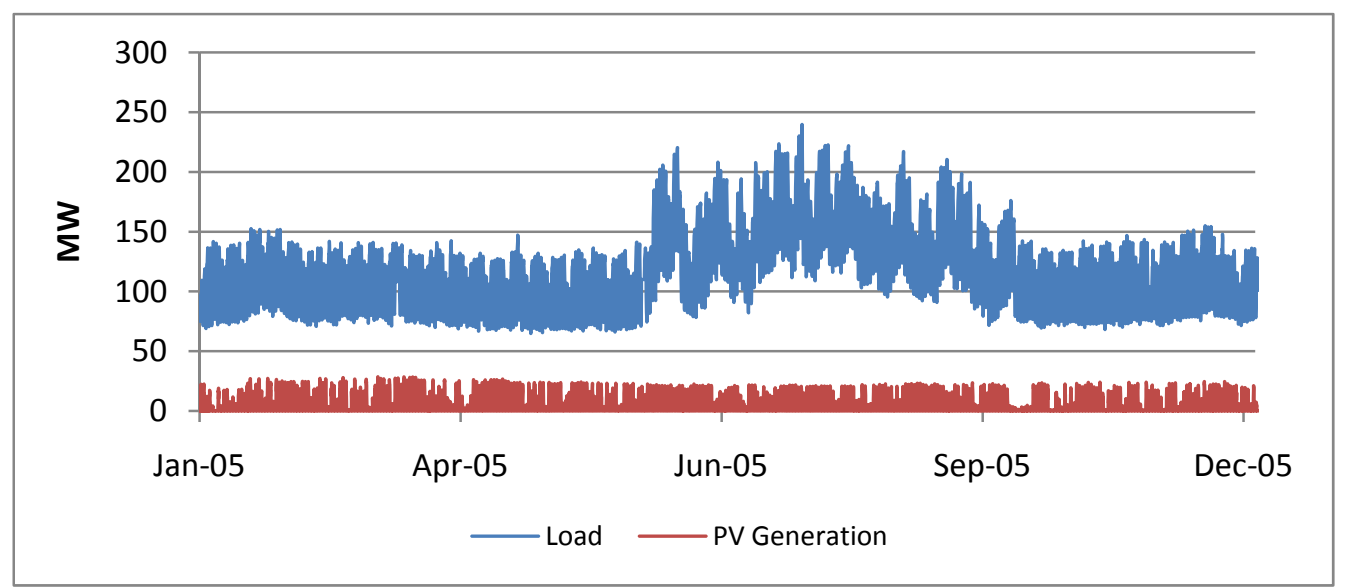

Figure 1-4. Cooper network load and maximum PV generation under full PV deployment 


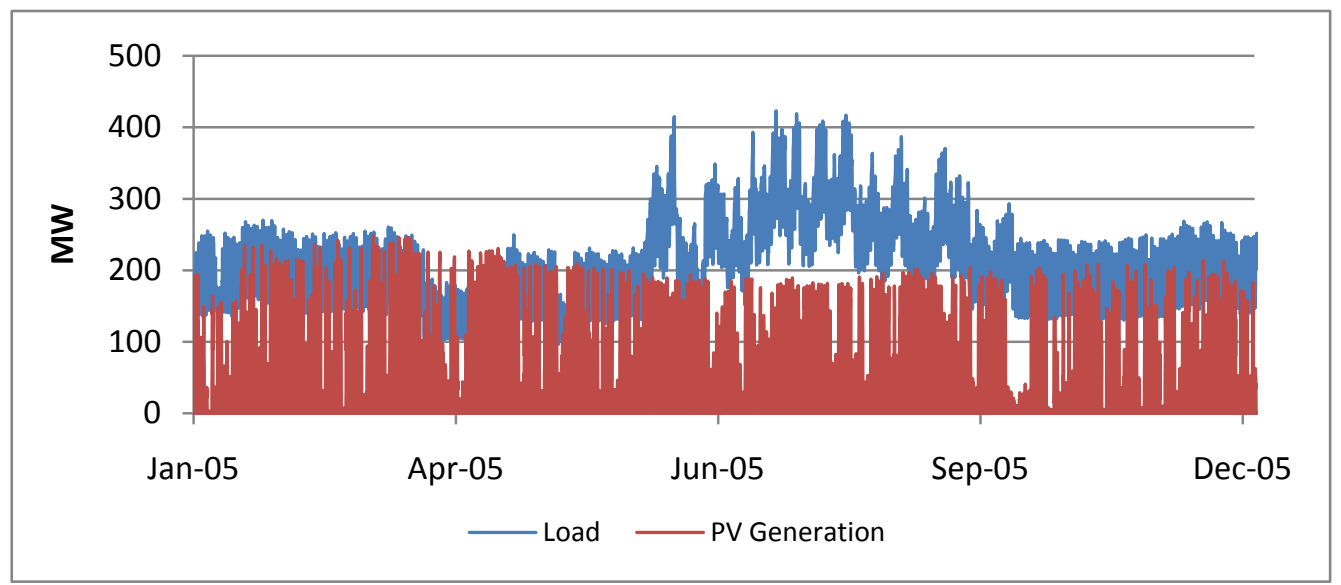

Figure 1-5. Flushing network load and maximum PV generation under full PV deployment

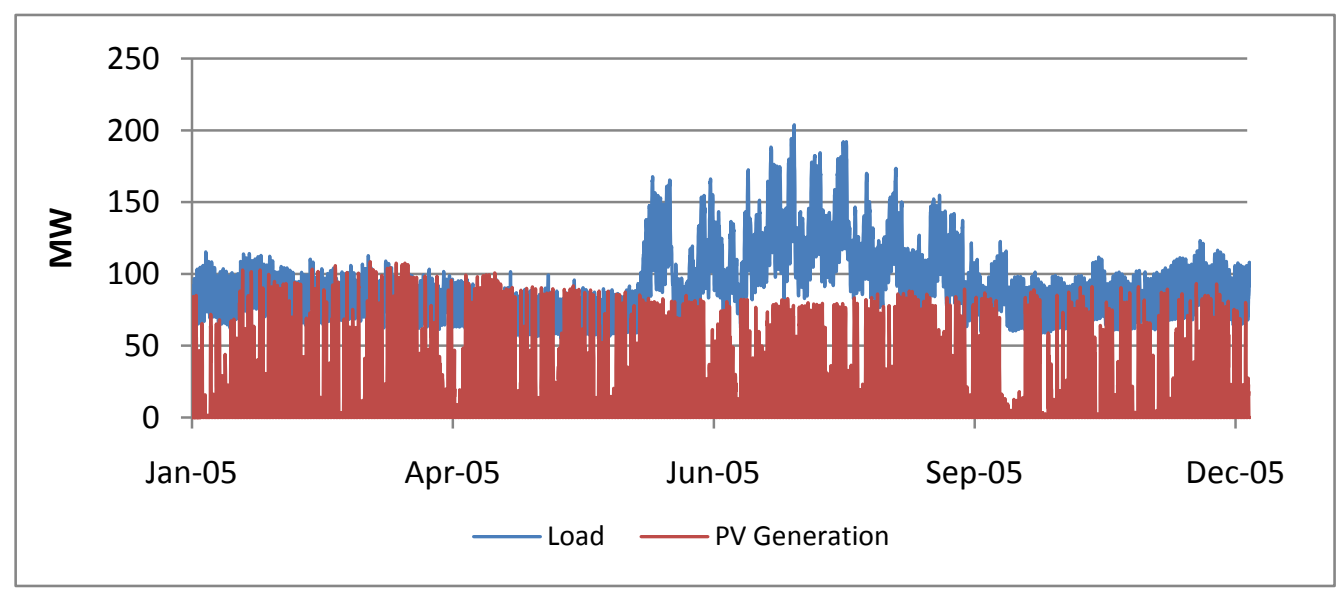

Figure 1-6. Fox Hill network load and maximum PV generation under full PV deployment

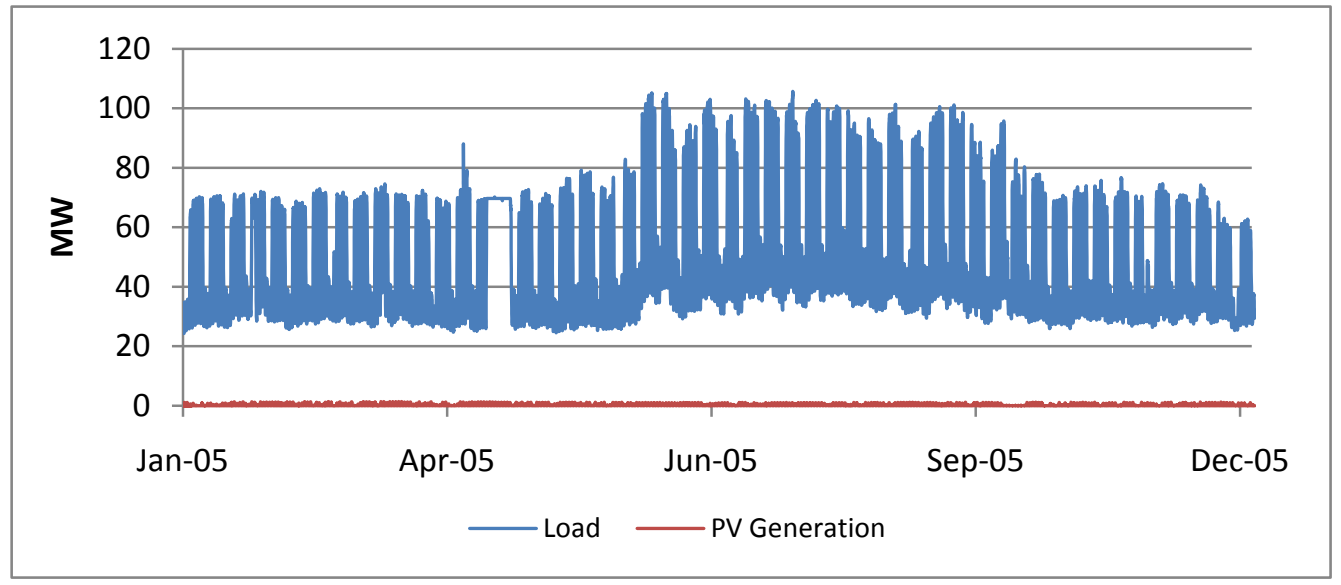

Figure 1-7. Herald network load and maximum PV generation under full PV deployment 


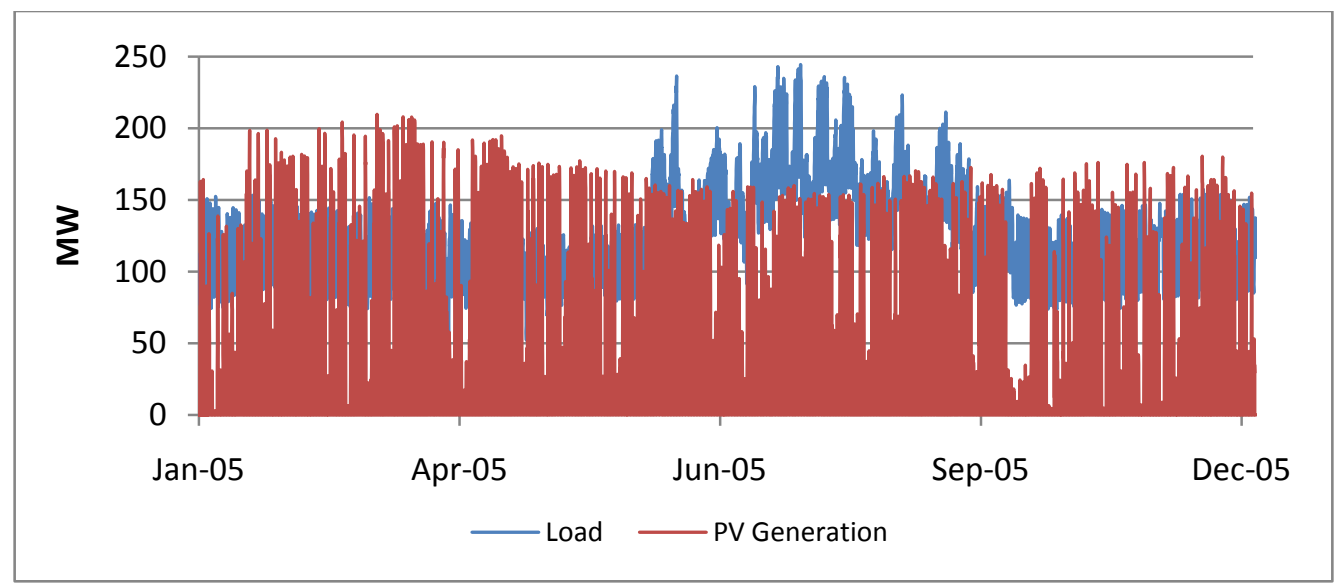

Figure 1-8. Maspeth network load and maximum PV generation under full PV deployment

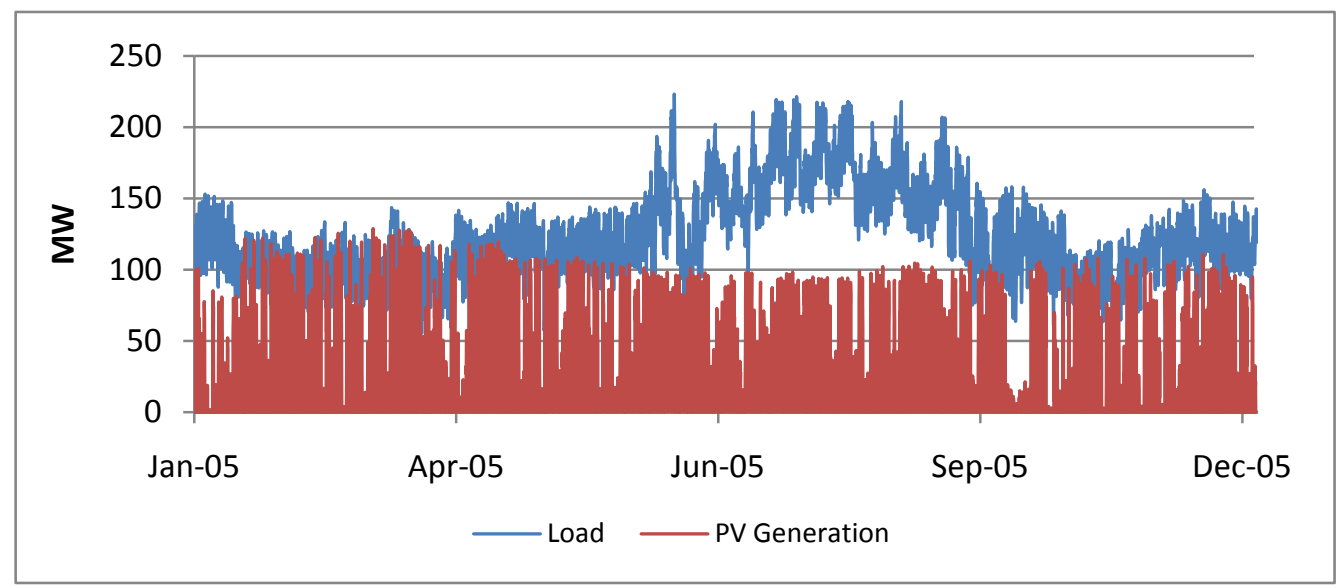

Figure 1-9. Southeast Bronx network load and maximum PV generation under full PV deployment

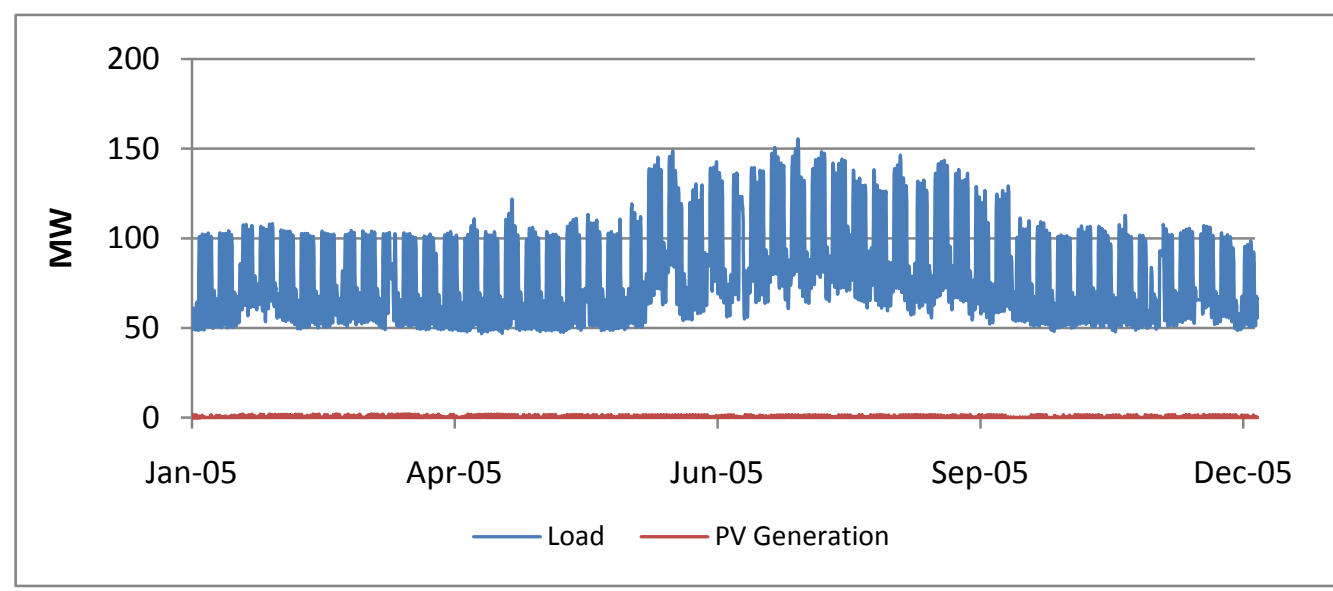

Figure 1-10. Sutton network load and maximum PV generation under full PV deployment 


\subsubsection{Maximum Export Day under Full PV Deployment}

Figures 1-11 through 1-20 offer a detailed look at the day during which the maximum export hour occurs (or, for nonexporting networks, the day when PV generation levels come closest to load levels). These graphs show the load and PV generation over 24 hours and illustrate how PV generation reduces load, at what times of day the reduction occurs, and by how much. (Reduced load is equal to load minus PV generation.) When the reduced load dips below $0 \mathrm{MW}$, energy is exported to the network. We used hourly data to make these comparisons.

From these graphs we see that PV generation can reduce load significantly in the morning and afternoon (between 7 a.m. and 4 p.m.), but it has no effect on evening loads. In general, PV generation results in a smooth dip in reduced load, but passing clouds can create abrupt decreases in PV generation, resulting in a more jagged curve (see Figure 119).

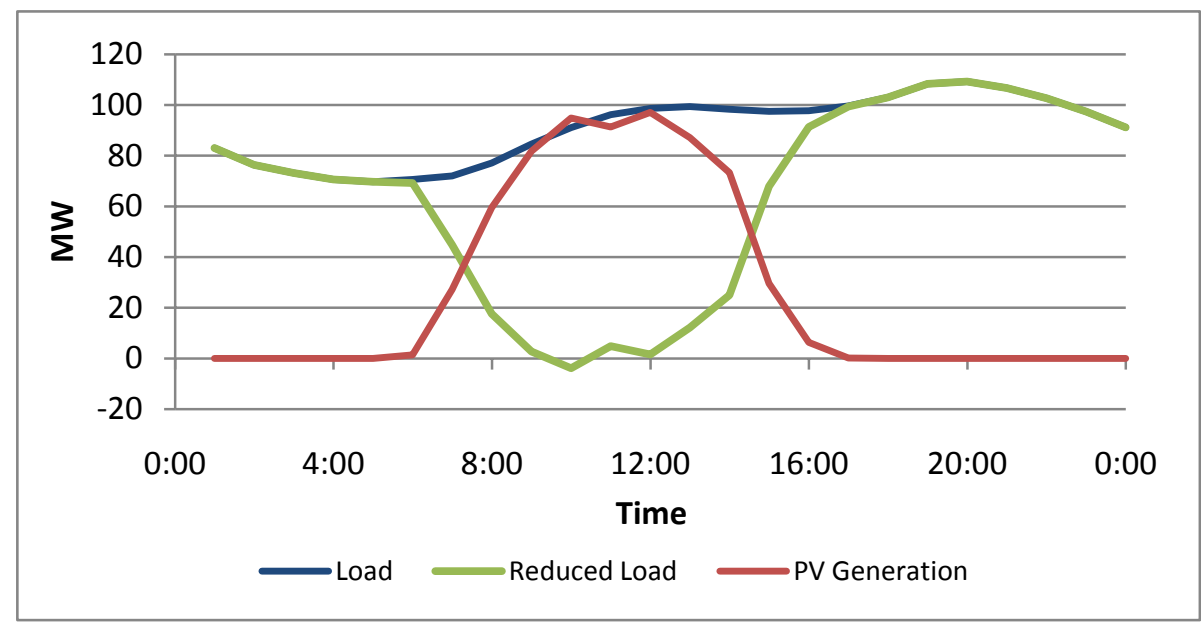

Figure 1-11. Bay Ridge maximum export day, March 26, 2005

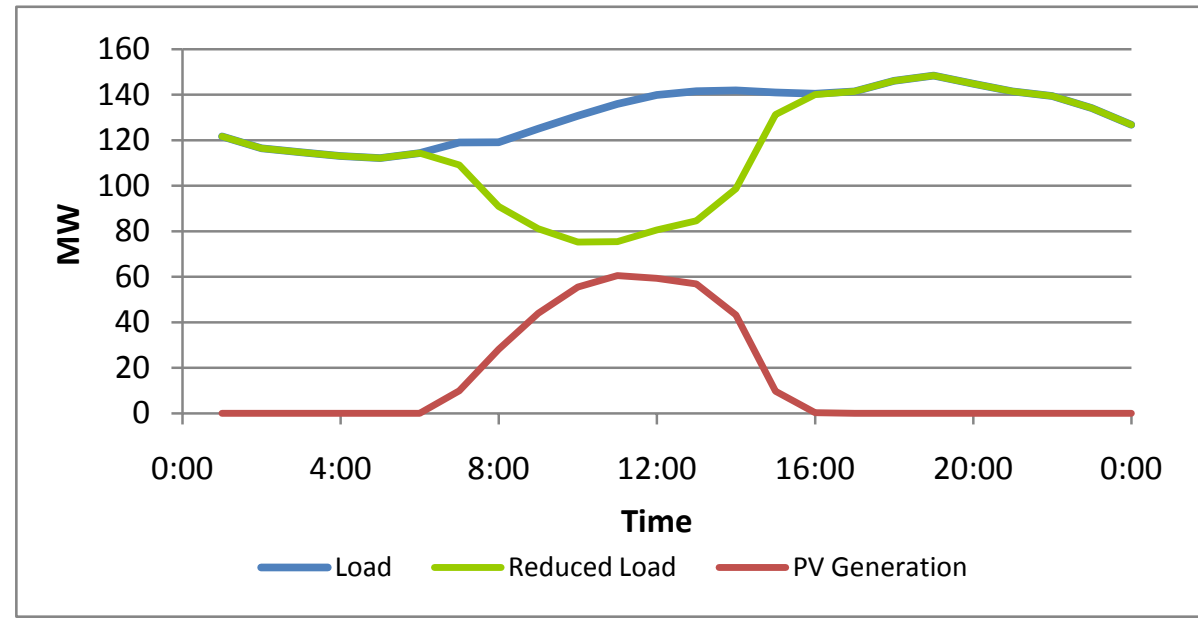

Figure 1-12. Borough Hall maximum export day, February 13, 2005 


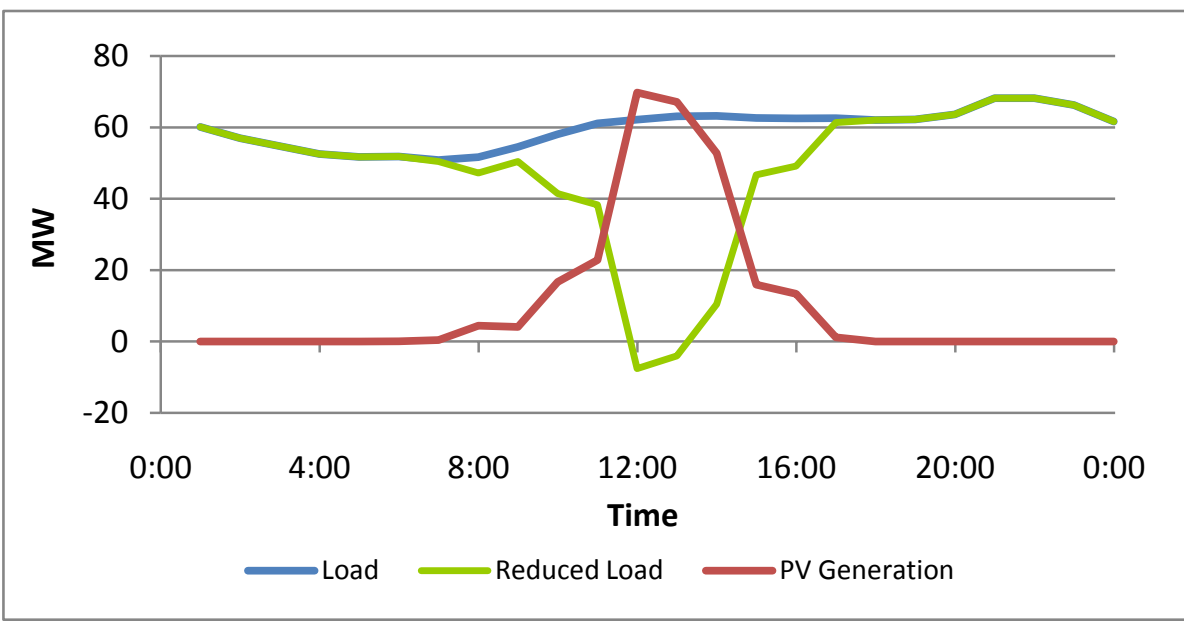

Figure 1-13. Central Bronx maximum export day, May 1, 2005

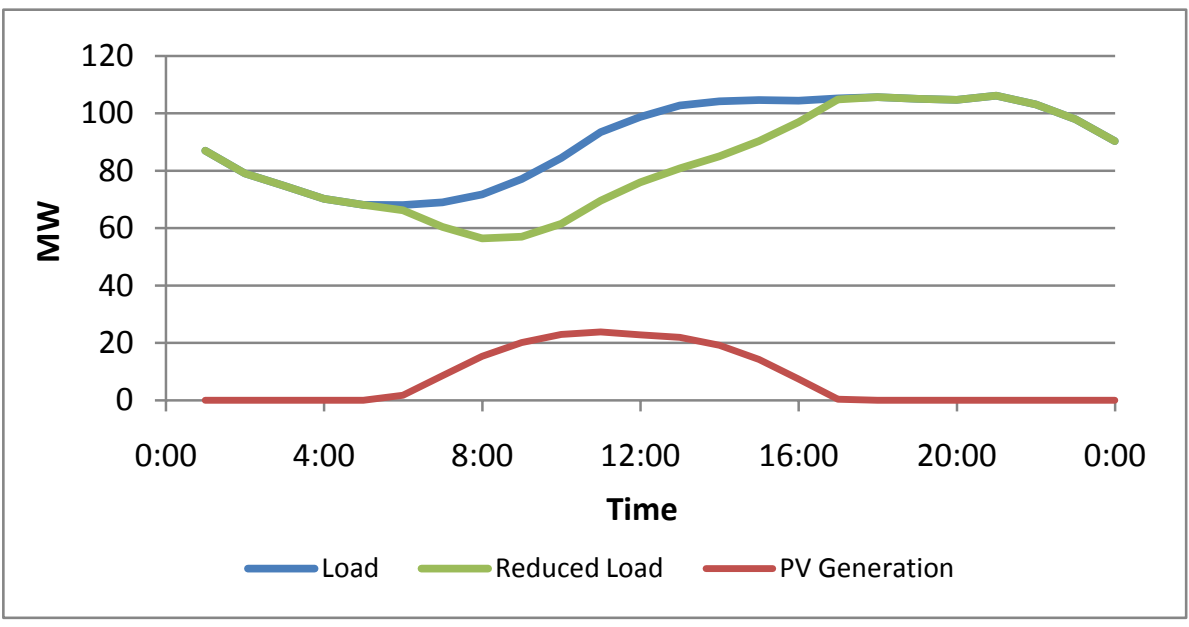

Figure 1-14. Cooper maximum export day, April 10, 2005

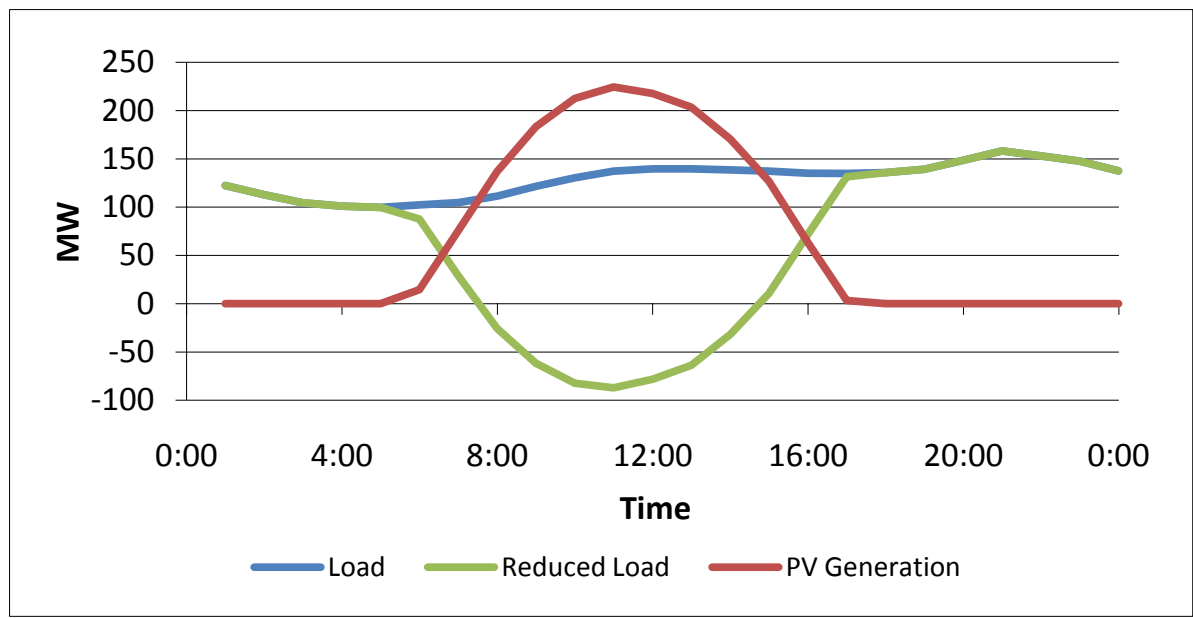

Figure 1-15. Flushing maximum export day, April 9, 2005 


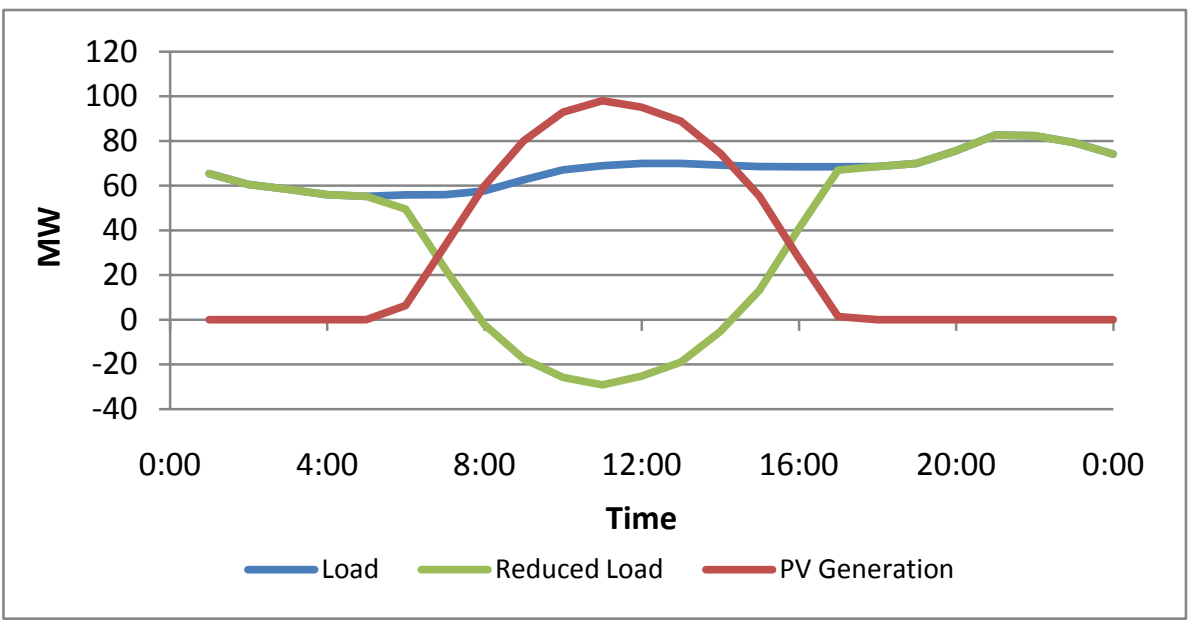

Figure 1-16. Fox Hill maximum export day, April 9, 2005

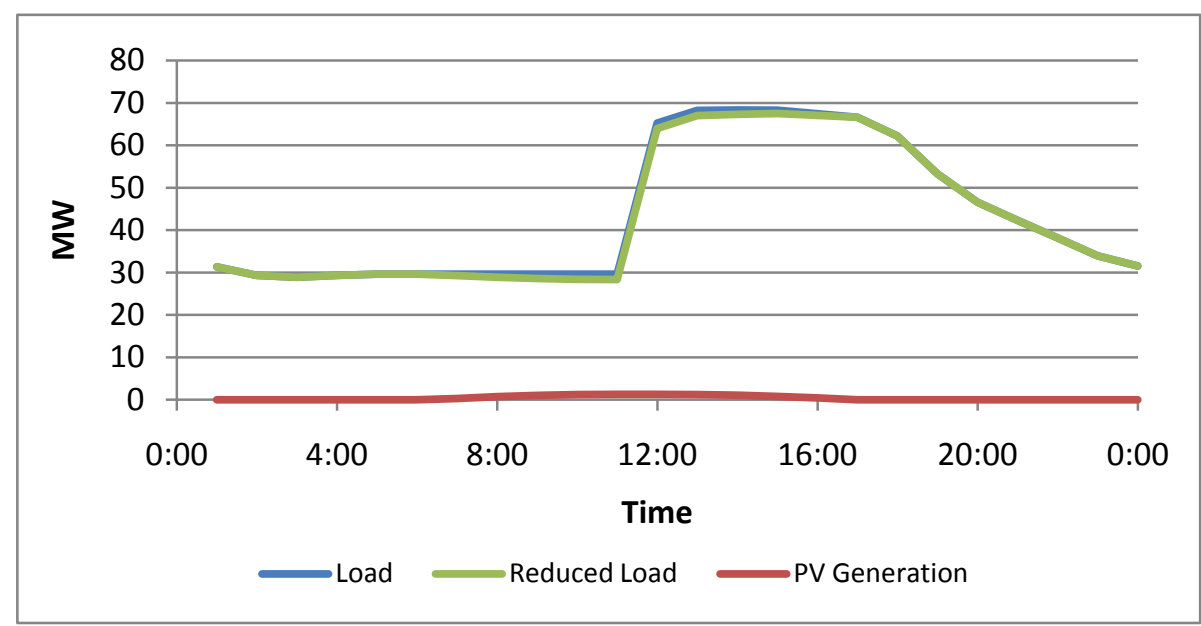

Figure 1-17. Herald maximum export day, March 18, 2005

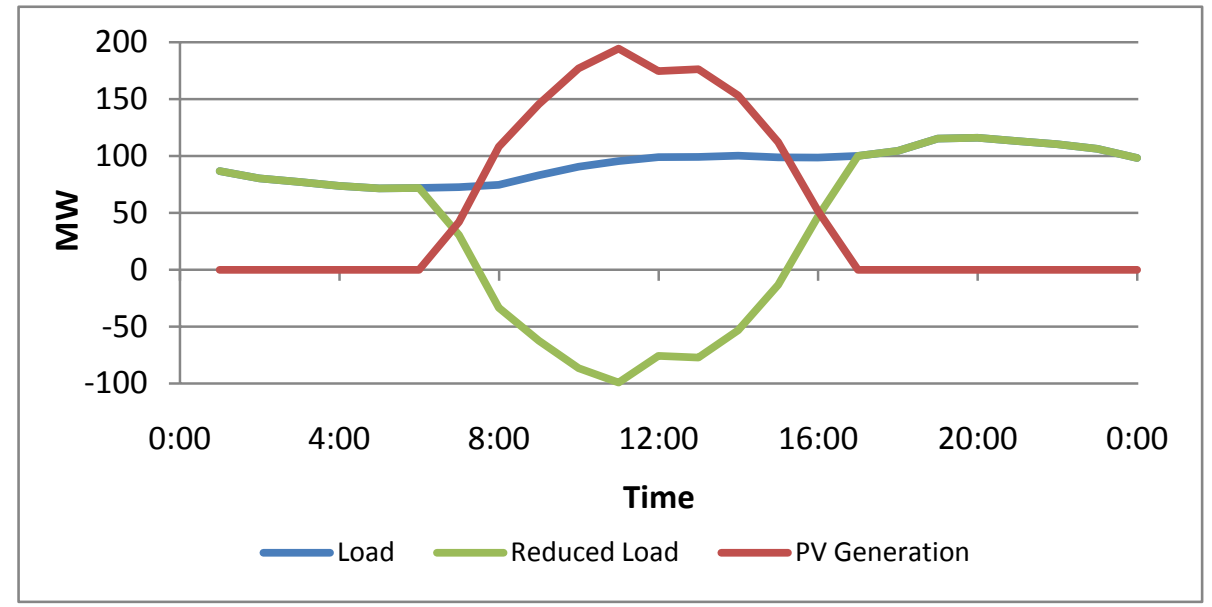

Figure 1-18. Maspeth maximum export day, February 27, 2005 


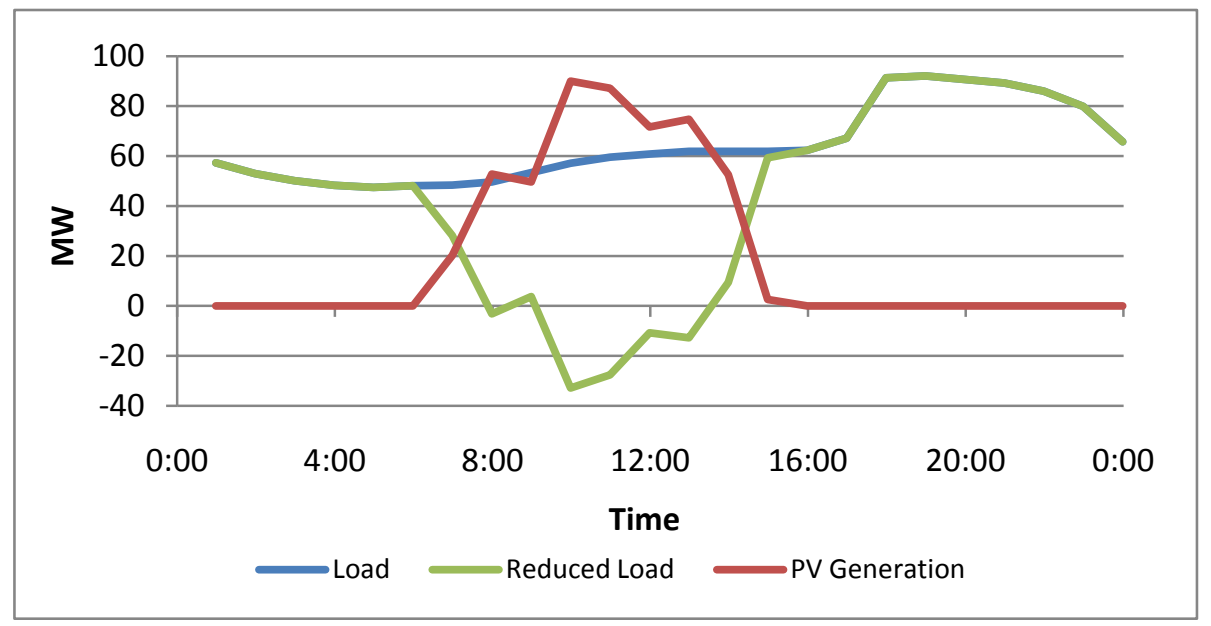

Figure 1-19. Southeast Bronx maximum export day, November 13, 2005

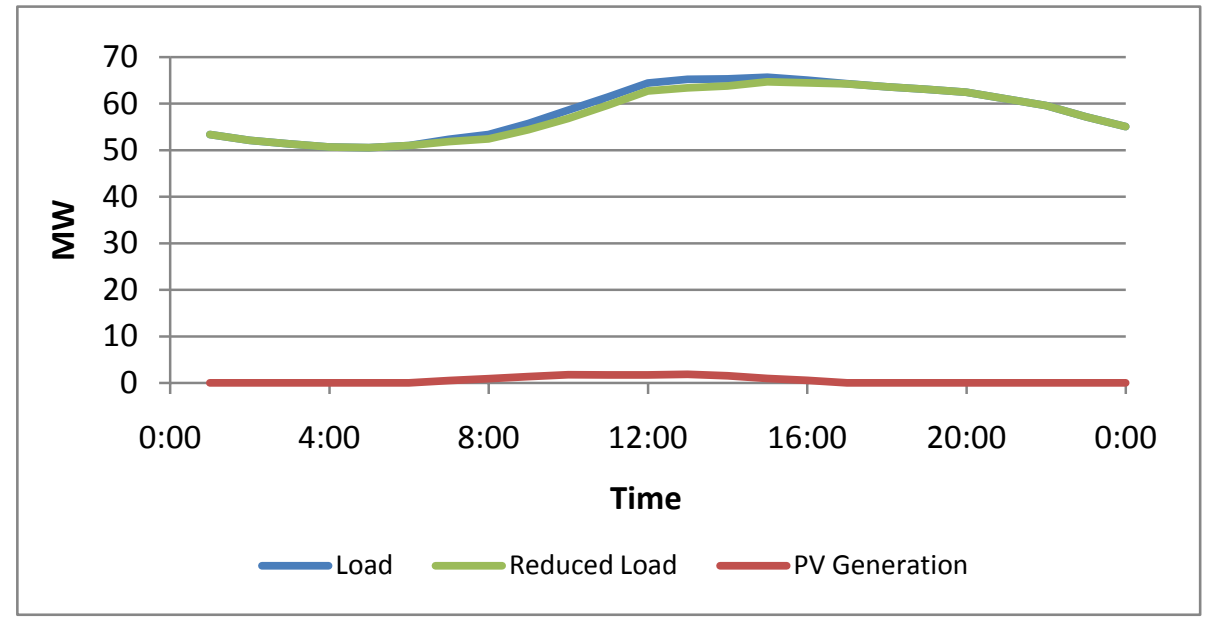

Figure 1-20. Sutton maximum export day, March 13, 2005

\subsubsection{0-Hour Load-Duration Curve}

Figures 1-21 through 1-30 plot the 8760-hour load values over the course of the year, sorted in descending order, and the 8760-hour reduced-load (load minus PV generation) values, also sorted in descending order. The right side of the graphs show us how many hours per year PV energy exports to the grid under full deployment (export occurs when the reduced load line dips below $0 \mathrm{MW}$ ). Each figure also notes the percentage of full deployment and capacity of PV that would reduce net exporting hours to zero. 


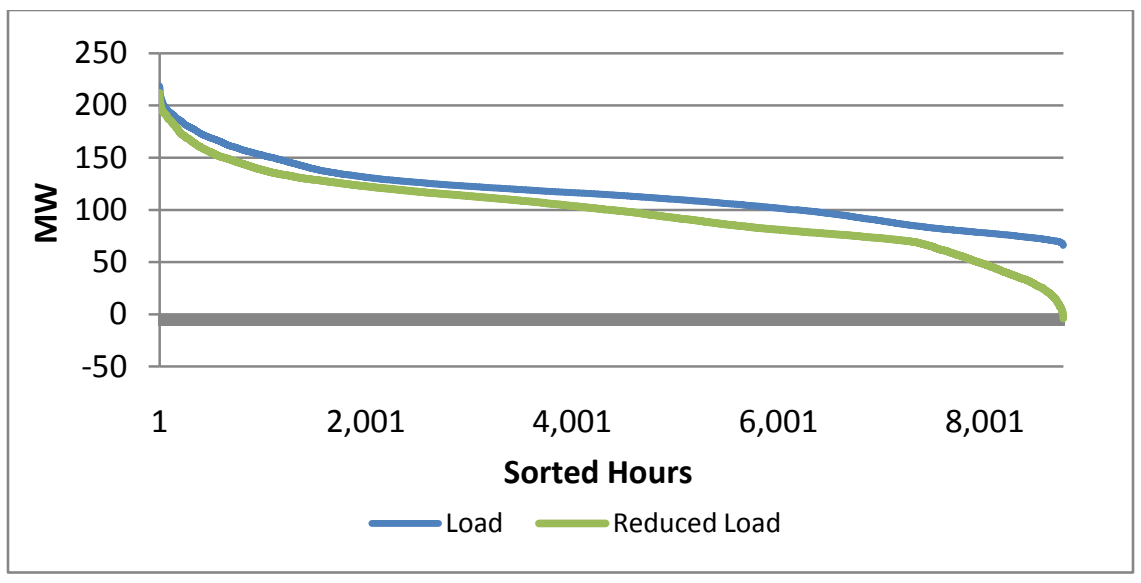

Note: Under full deployment, there is one hour net exporting. To reduce exported hours to zero, limit deployment to $95.96 \%$ of full deployment (92.31 MW).

Figure 1-21. Bay Ridge 8760-hour load-duration curve

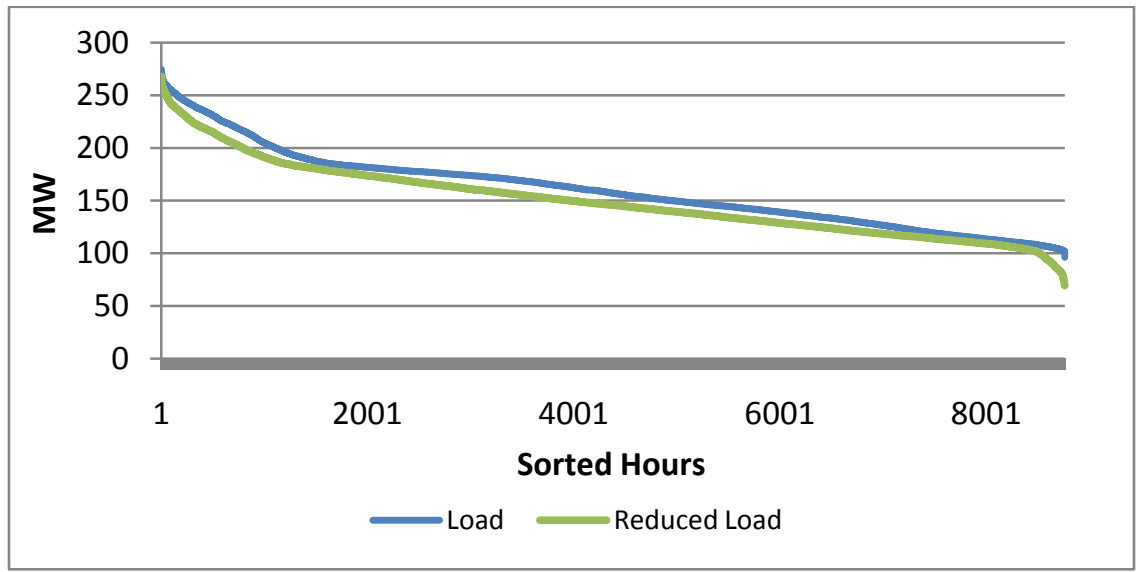

Note: Under full deployment, there are 0 hours net exporting.

Figure 1-22. Borough Hall 8760-hour load-duration curve

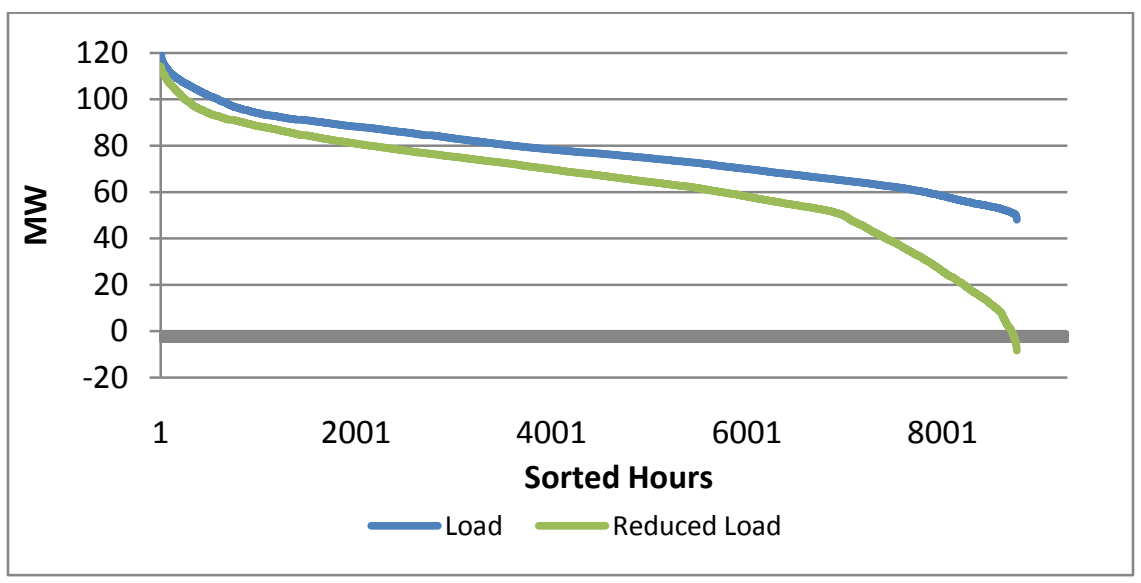

Note: Under full deployment, there are 53 hours net exporting. To reduce exported hours to zero, limit deployment to $89.12 \%$ of full deployment (67.06 MW).

Figure 1-23. Central Bronx 8760-hour load-duration curve 


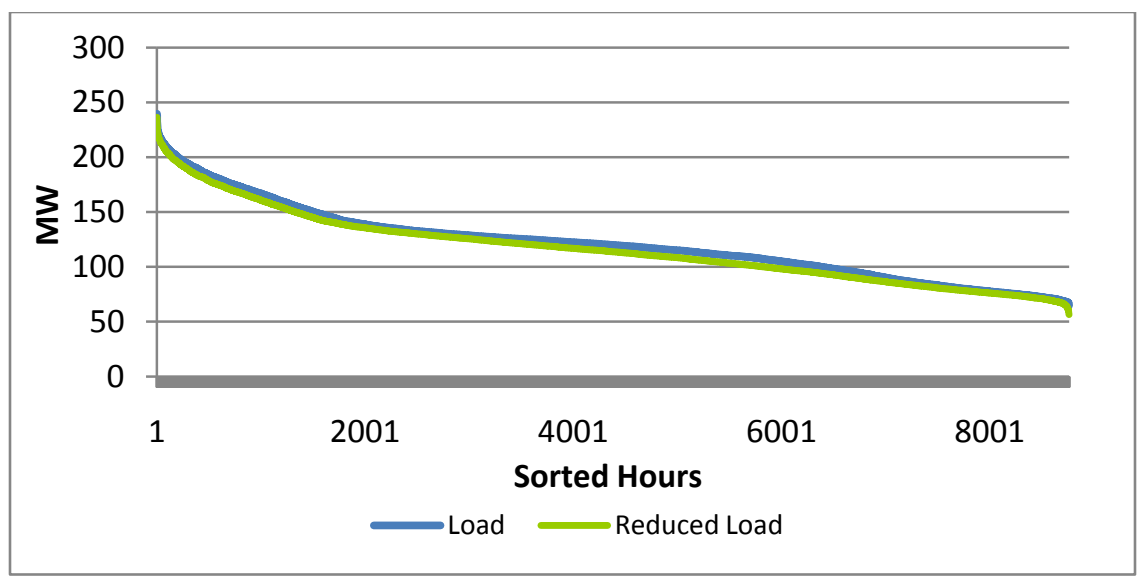

Note: Under full deployment, there are zero hours net exporting.

Figure 1-24. Cooper 8760-hour load-duration curve

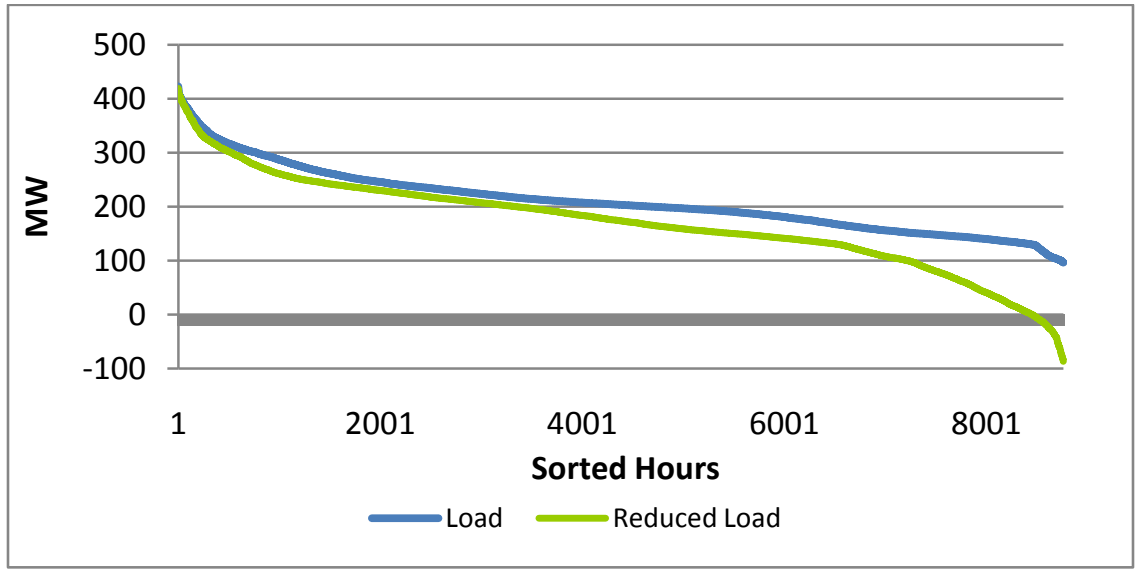

Note: Under full deployment, there are 313 hours net exporting. To reduce exported hours to zero, limit deployment to $61.22 \%$ of full deployment (136.62 MW).

Figure 1-25. Flushing 8760-hour load-duration curve

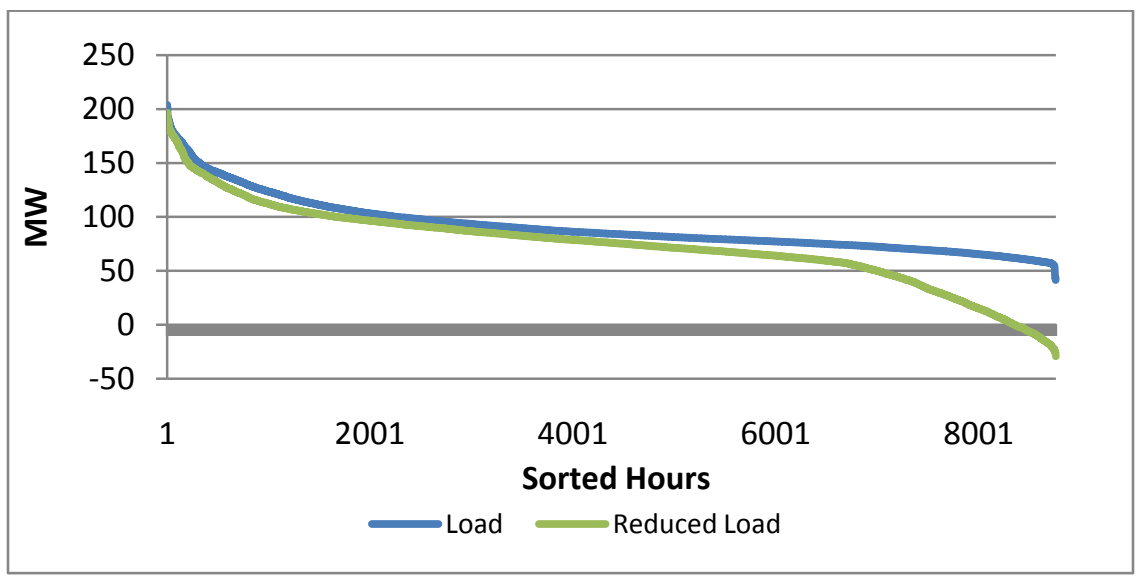

Note: Under full deployment, there are 406 hours net exporting. To reduce exported hours to zero, limit deployment to $70.29 \%$ of full deployment (68.54 MW).

Figure 1-26. Fox Hill 8760-hour load-duration curve 


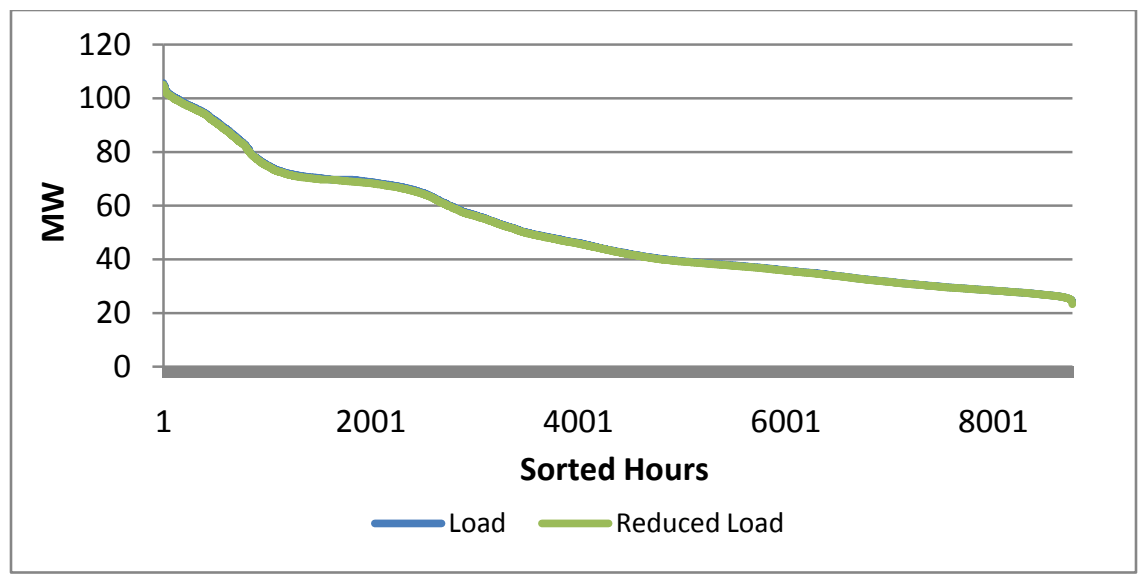

Note: Under full deployment, there are zero hours net exporting.

Figure 1-27. Herald 8760-hour load-duration curve

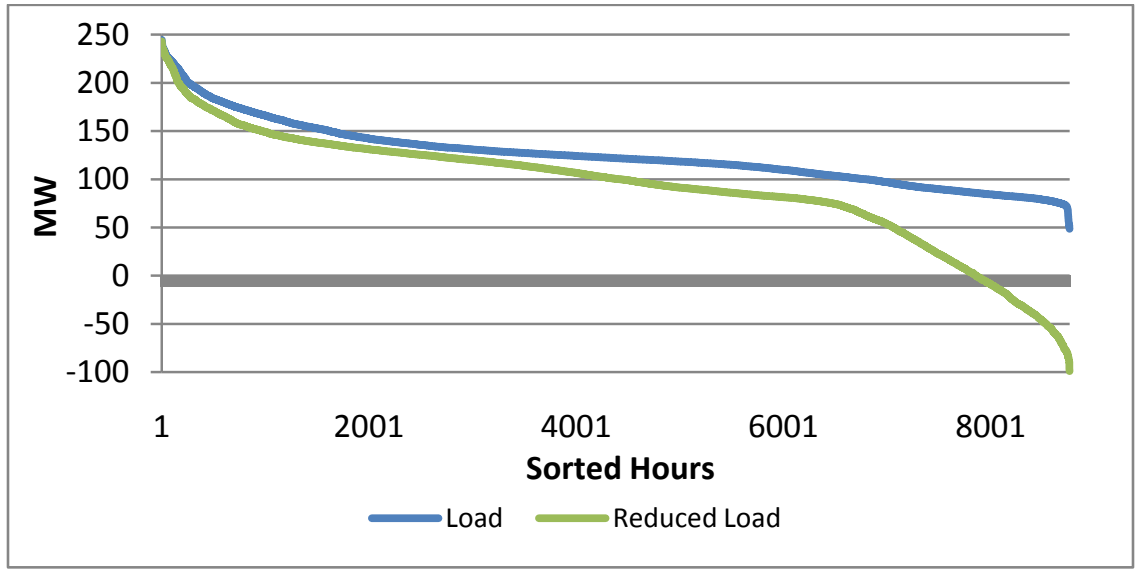

Note: Under full deployment, there are 901 hours net exporting. To reduce exported hours to zero, limit deployment to $49.09 \%$ of full deployment (92.58 MW).

Figure 1-28. Maspeth 8760-hour load-duration curve

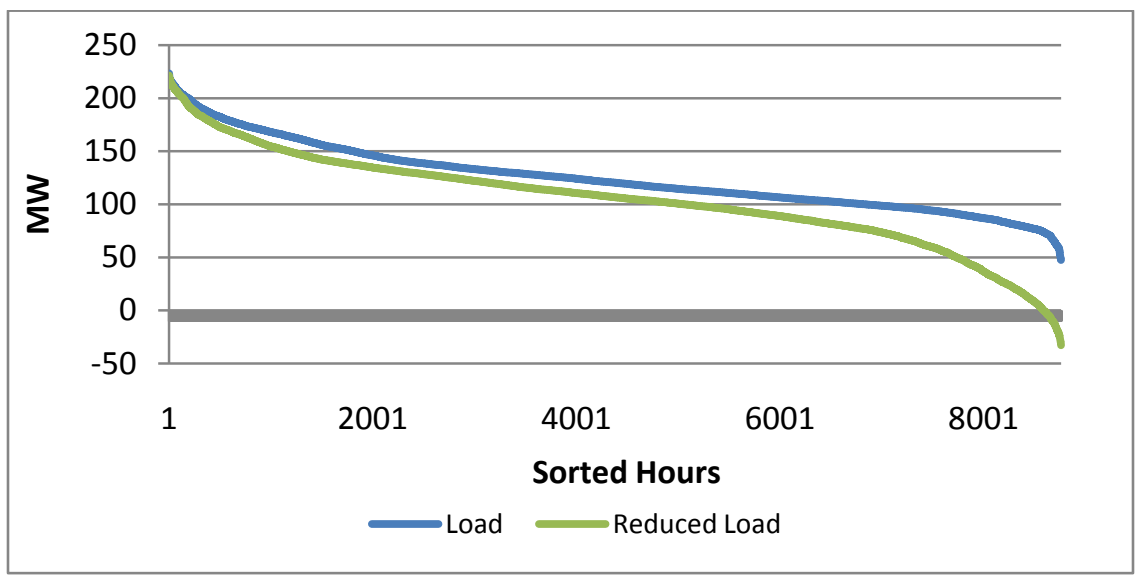

Note: Under full deployment, there are 173 hours net exporting. To reduce exported hours to zero, limit deployment to $63.43 \%$ of full deployment (73.48 MW).

Figure 1-29. Southeast Bronx 8760-hour load-duration curve 


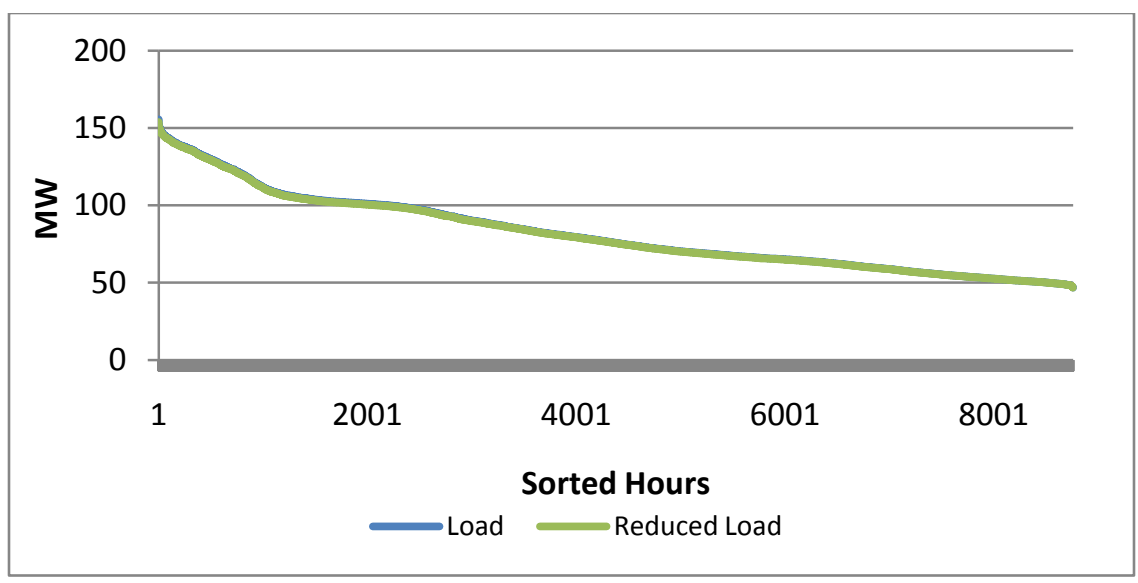

Note: Under full deployment, there are zero hours net exporting.

Figure 1-30. Sutton 8760-hour load-duration curve

\subsubsection{0-Hour Load-Duration Curve, Top 100 Hours}

Figures 1-31 through 1-40 zoom in on the top 100 hours of the 8760-hour load-duration curve, allowing us to see if the PV generation reduces peak loads. (The reduced load line has a lower maximum load value than the load line if PV reduces peak loads.) Peak load reduction is beneficial because it would allow the utility to reduce overall generation capacity and relieve network equipment (e.g., substations, feeders, and transformers).

The load-duration curves for the top 100 hours show that PV systems reduce peak load only slightly in most networks. Central Bronx sees the biggest reduction, at $4.68 \%$ of peak load. Bay Ridge and Borough Hall each see about a $1.75 \%$ reduction. In the remaining networks, peak load is reduced by less than $1 \%$. This is because peak load occurs later in the day in most networks, when PV systems are not producing power. Even though the PV-generated electricity can significantly exceed network loads at times (as much as double the load in the Maspeth network), its contribution to the network's overall energy requirements is much lower, because energy generation is limited to daylight hours.

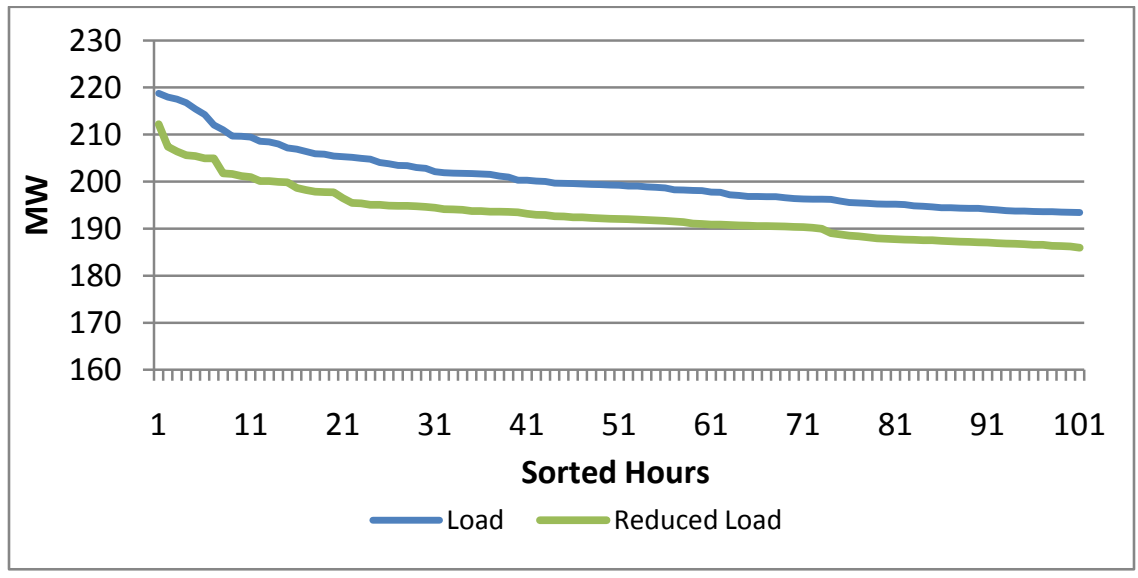

Figure 1-31. Bay Ridge 8760-hour load-duration curve, top 100 hours 


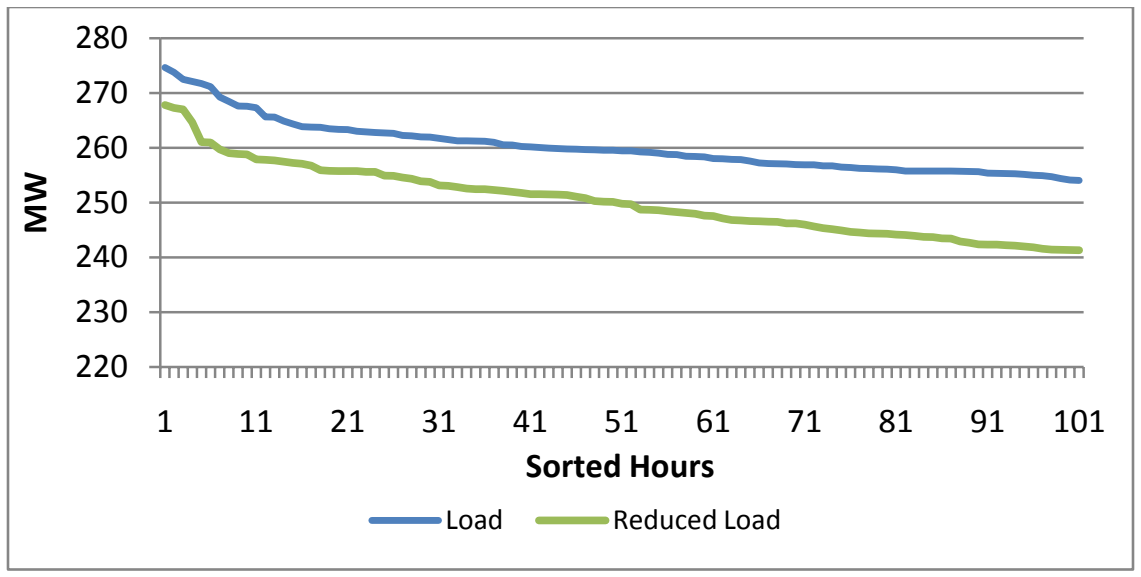

Figure 1-32. Borough Hall 8760-hour load-duration curve, top 100 hours

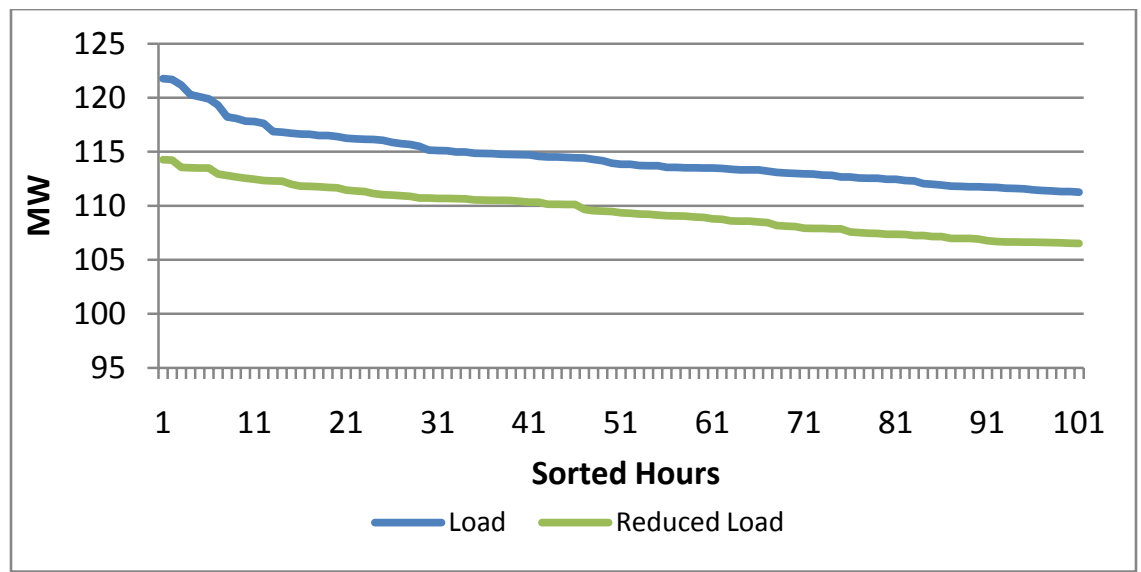

Figure 1-33. Central Bronx 8760-hour load-duration curve, top 100 hours

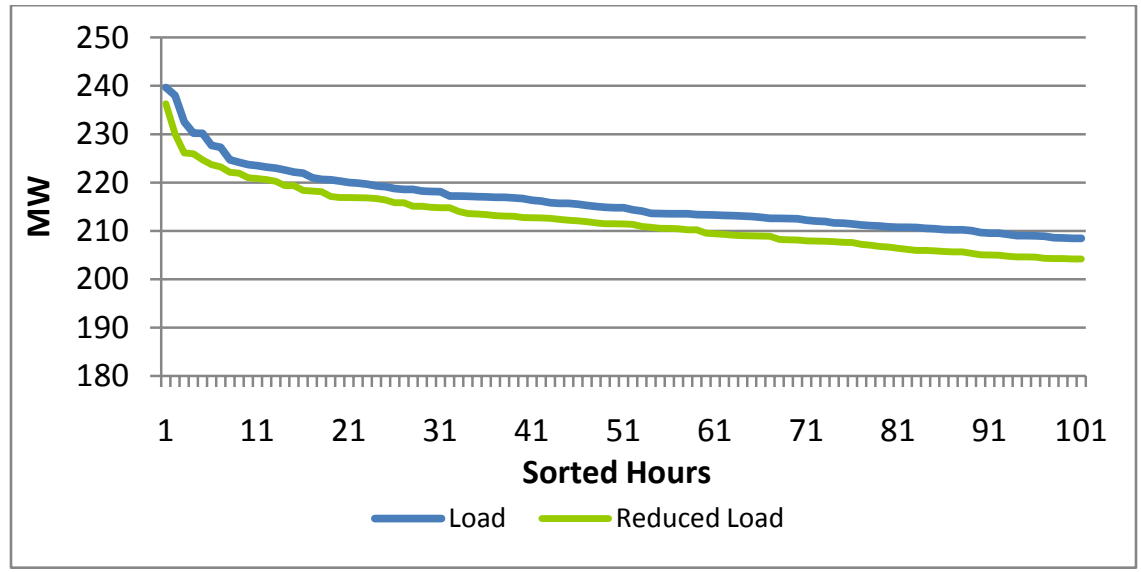

Figure 1-34. Cooper 8760-hour load-duration curve, top 100 hours 


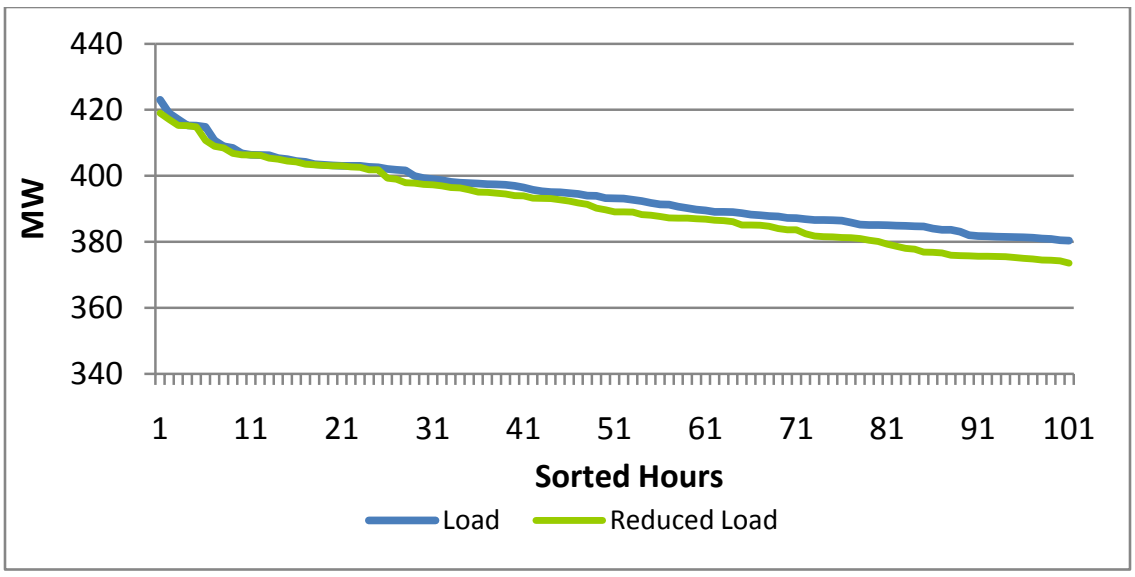

Figure 1-35. Flushing 8760 -hour load-duration curve, top 100 hours

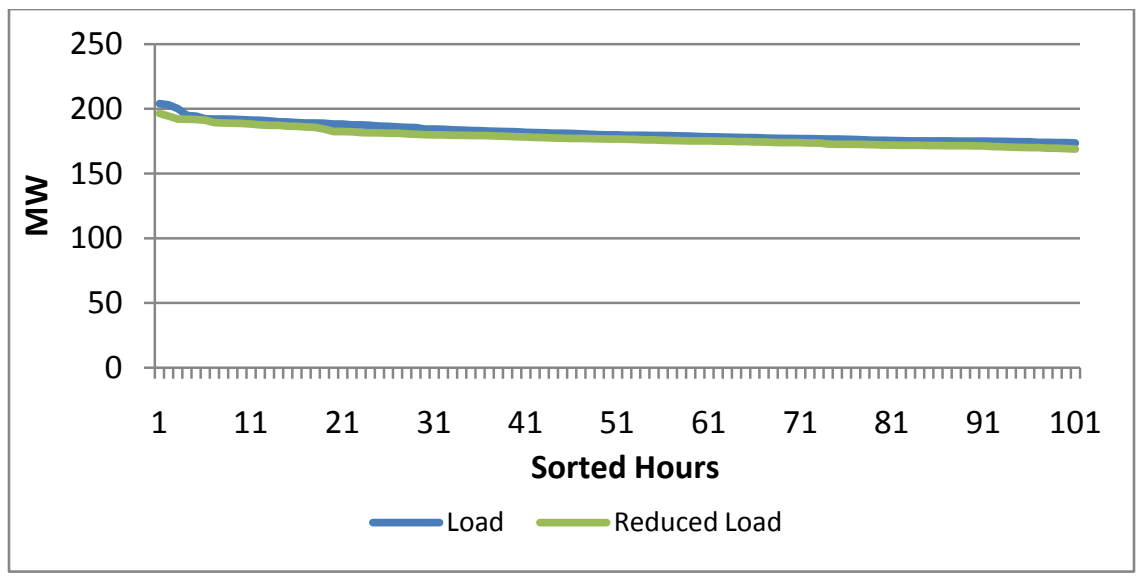

Figure 1-36. Fox Hill 8760-hour load-duration curve, top 100 hours

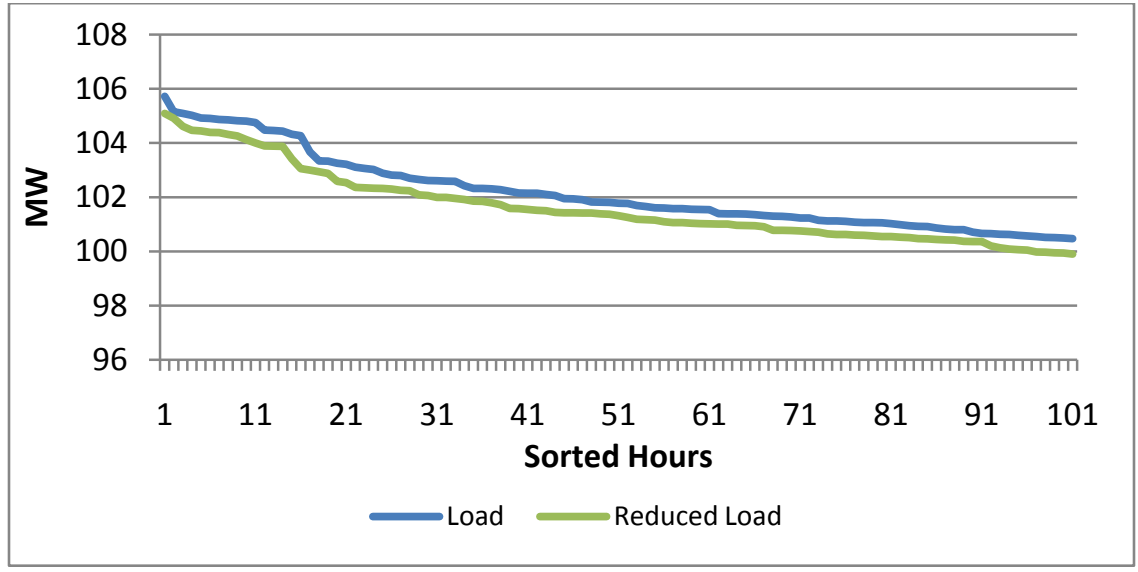

Figure 1-37. Herald 8760-hour load-duration curve, top 100 hours 


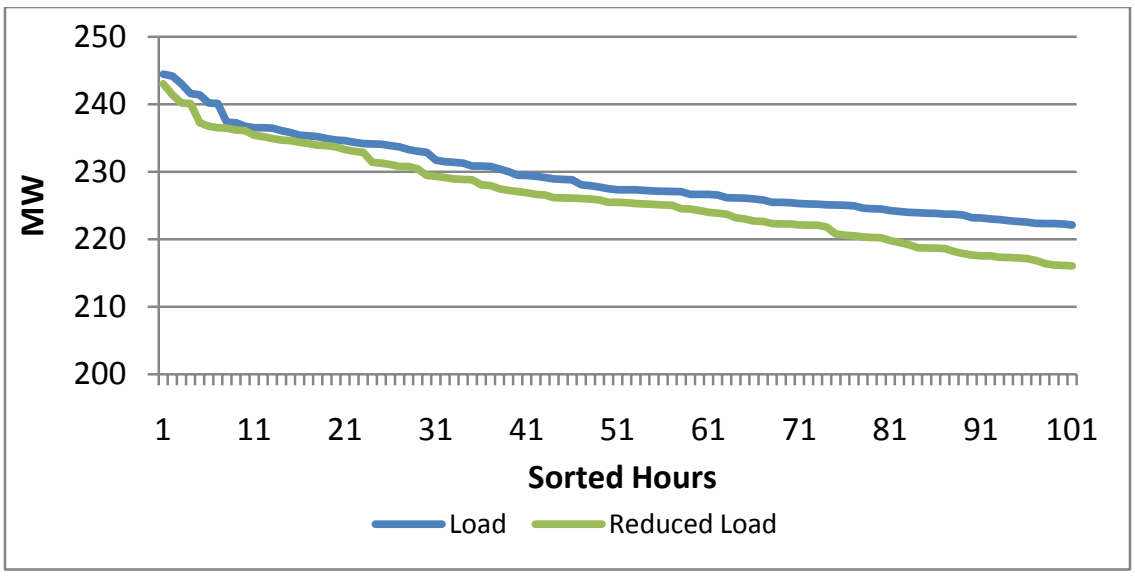

Figure 1-38. Maspeth 8760-hour load-duration curve, top 100 hours

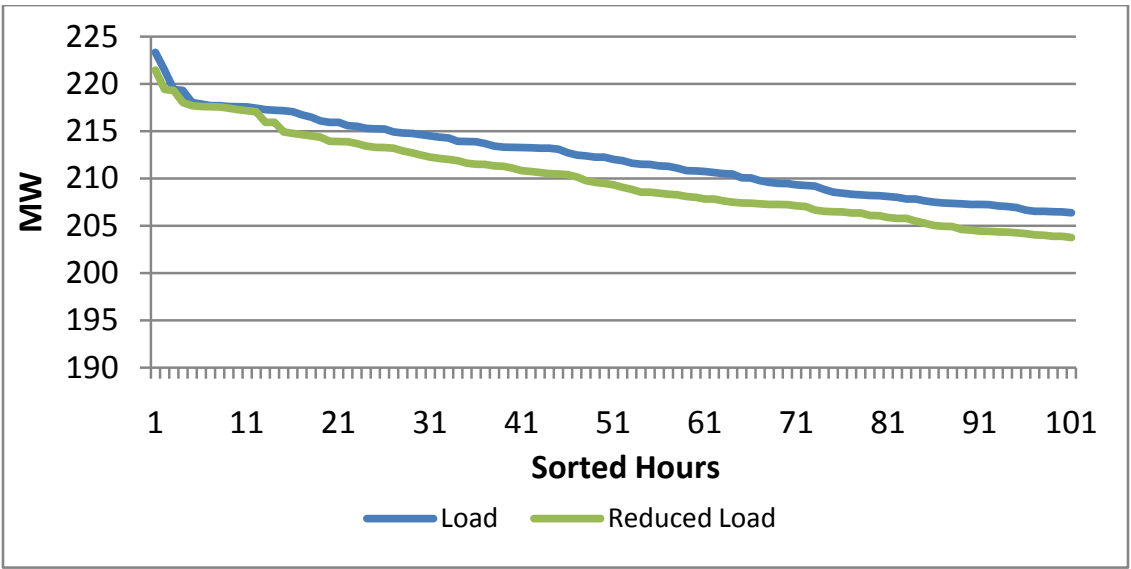

Figure 1-39. Southeast Bronx 8760-hour load-duration curve, top 100 hours

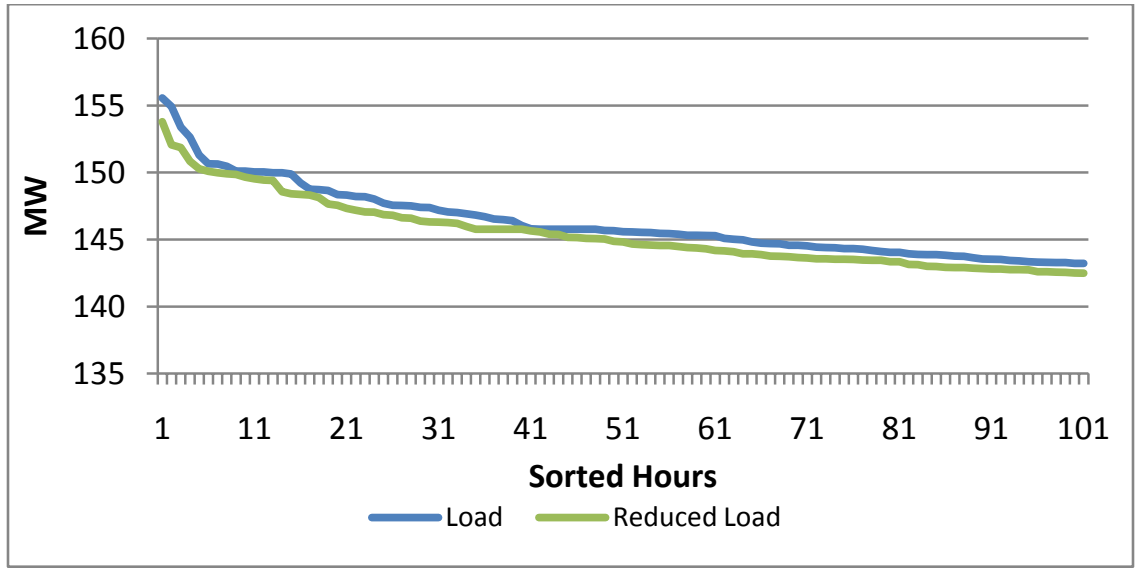

Figure 1-40. Sutton 8760-hour load-duration curve, top 100 hours 


\subsubsection{Exported Energy}

Figures 1-41 through 1-76 give more detail on when energy is exported to the grid. They show which times of the day, days of the week, and months of the year are most likely to experience exporting energy. The graphs show this information in two ways - the amount of energy exported per year (in megawatt-hours) and the number of hours per year during which energy is exported. Note that we include these graphs only for the six networks that export energy.

Figures 1-41 through 1-52 show energy exported by month. These graphs show that the most likely time of year for PV energy exporting to the grid is the spring (March-May). This can be attributed to good PV generation (almost as high as the peak summer energy generation) and low loads. The fall and winter months experience less (although still significant exporting), and the summer months see little exporting because of higher network loads.

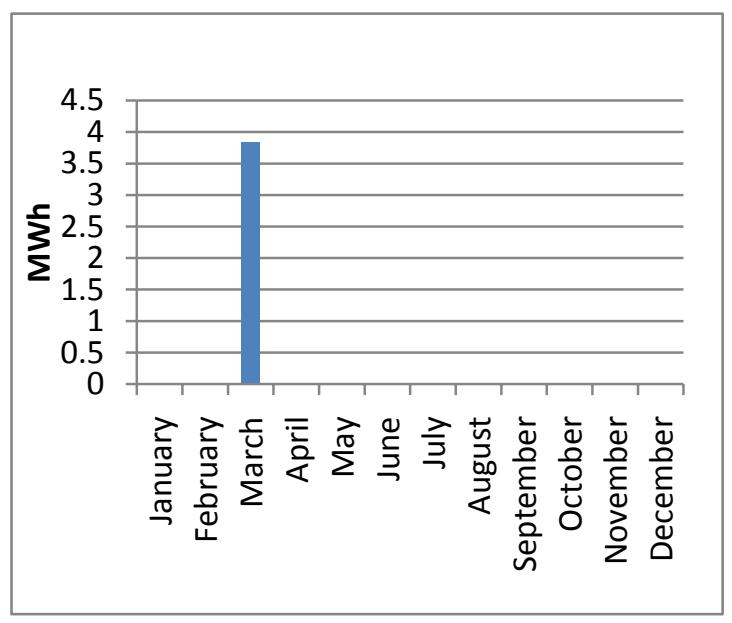

Figure 1-41. Bay Ridge amount of energy exported by month

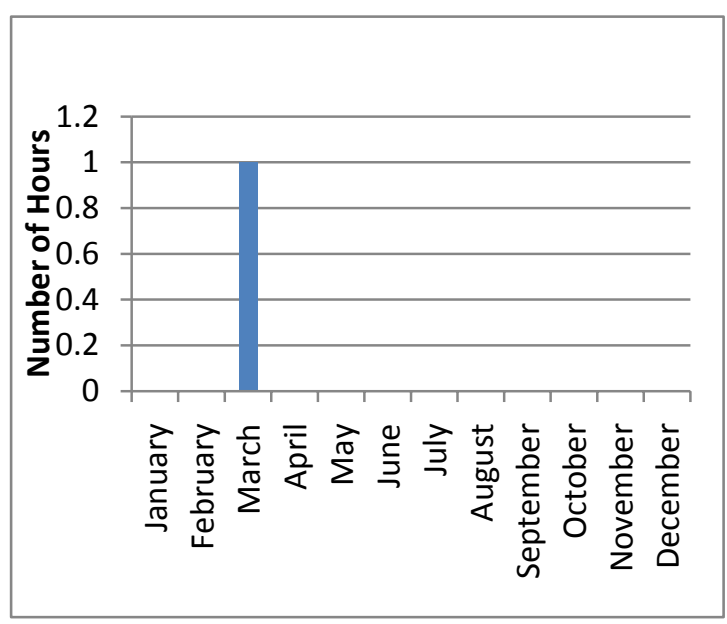

Figure 1-42. Bay Ridge number of hours of energy exported by month 


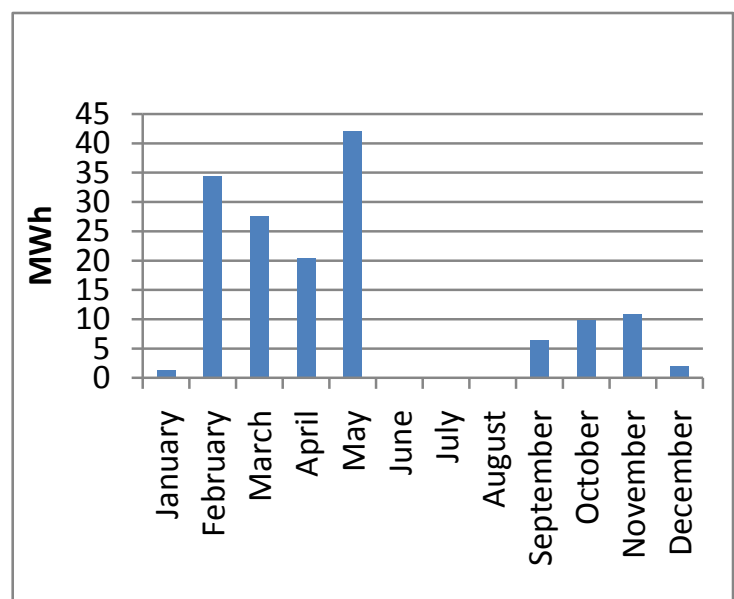

Figure 1-43. Central Bronx amount of energy exported by month

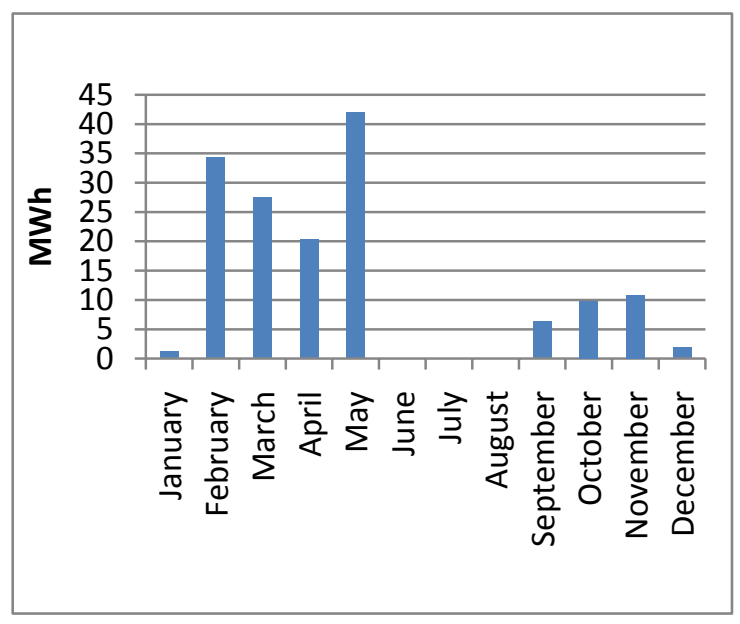

Figure 1-45. Flushing amount of energy exported by month

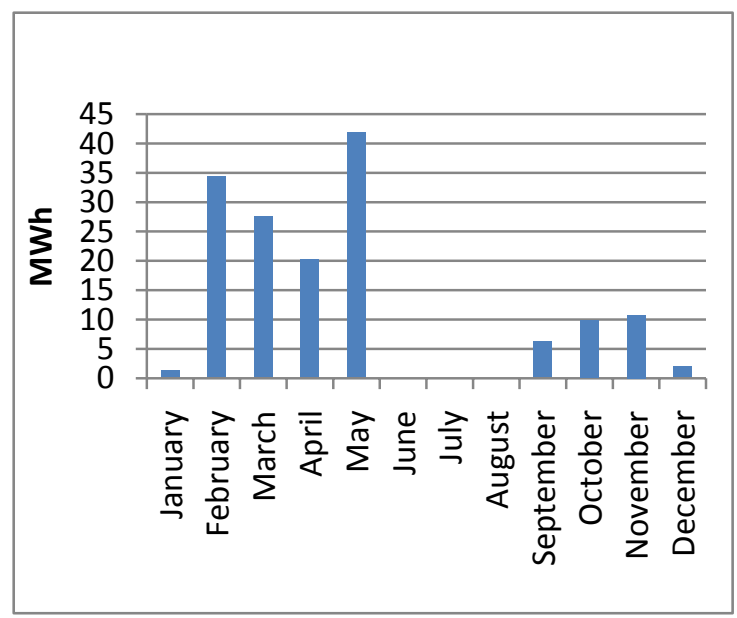

Figure 1-47. Fox Hill amount of energy exported by month

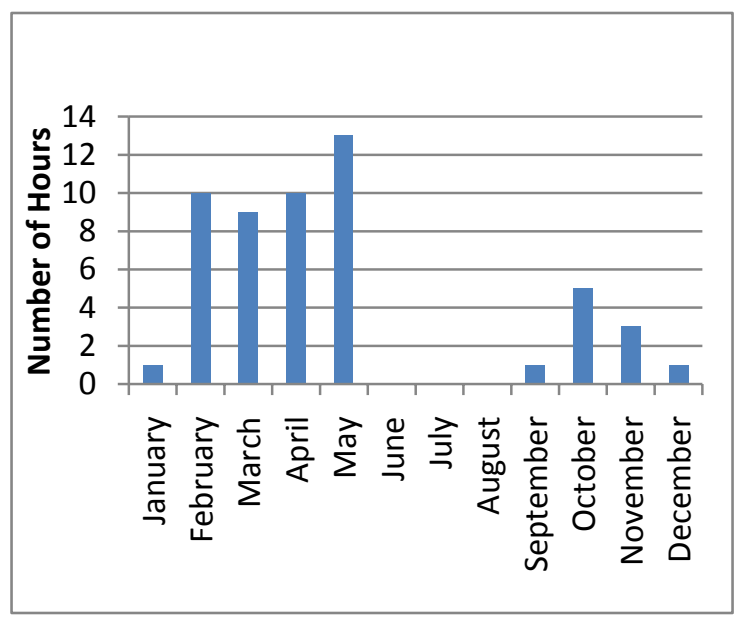

Figure 1-44. Central Bronx number of hours of energy exported by month

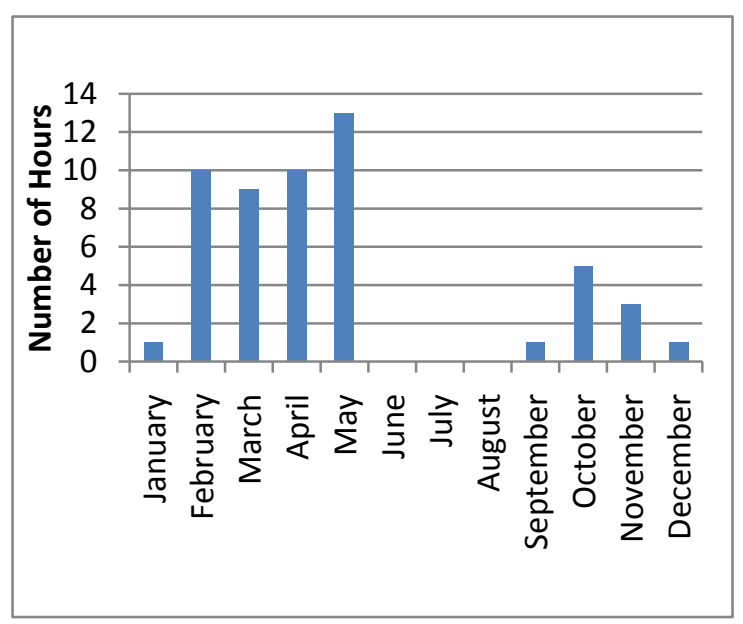

Figure 1-46. Flushing number of hours of energy exported by month

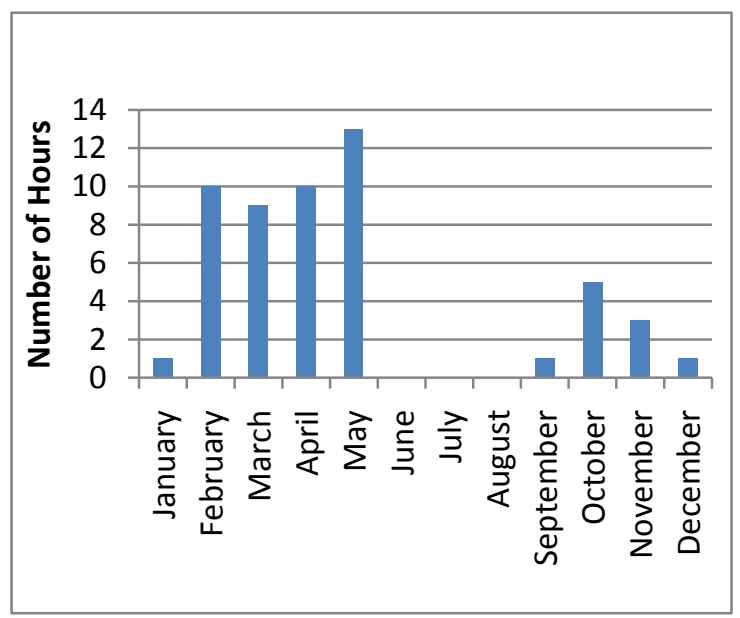

Figure 1-48. Fox Hill number of hours of energy exported by month 


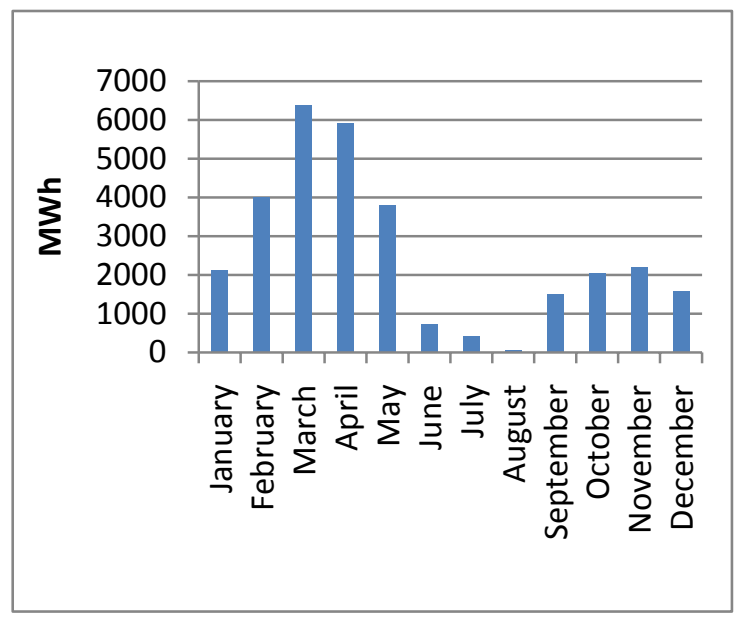

Figure 1-49. Maspeth amount of energy exported by month

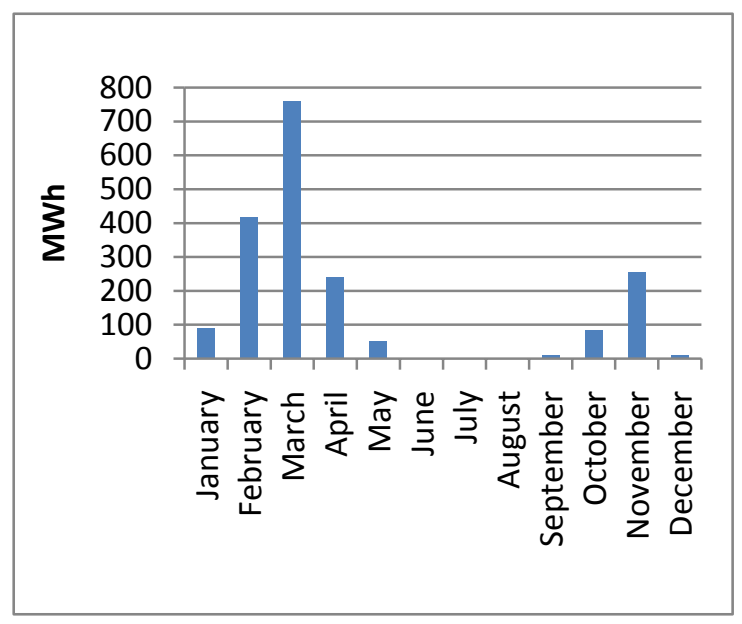

Figure 1-51. Southeast Bronx amount of energy exported by month

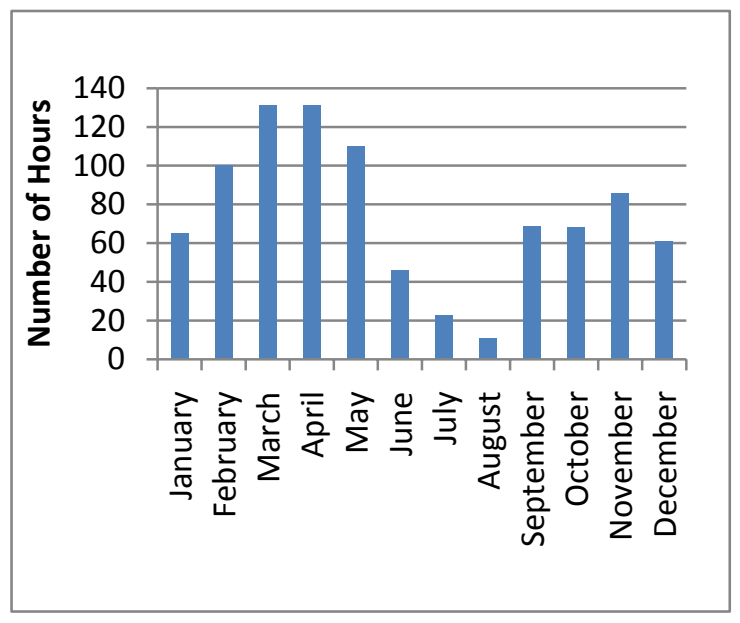

Figure 1-50. Maspeth number of hours of energy exported by month

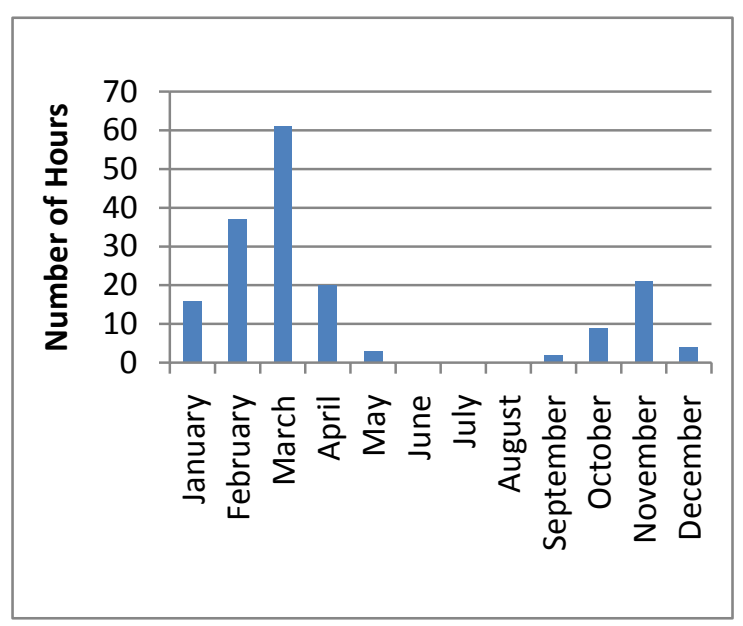

Figure 1-52. Southeast Bronx number of hours of energy exported by month

Figures 1-53 through 1-64 show that Saturdays and Sundays are the most common days of the week for energy to export to the grid. In the more industrial networks like Southeast Bronx and Central Bronx, the increase in export on the weekends is significant (at least twice the weekday export level). In the more residential networks like Fox Hill and Flushing, the increase is less significant. This is likely because the residential loads are fairly consistent over the course of the week, but industrial loads drop on the weekends when businesses close. 


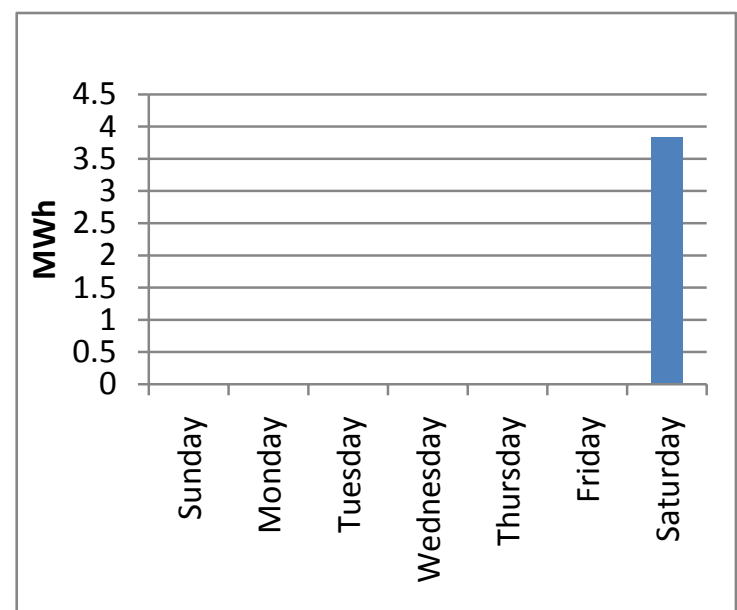

Figure 1-53. Bay Ridge amount of energy exported by day

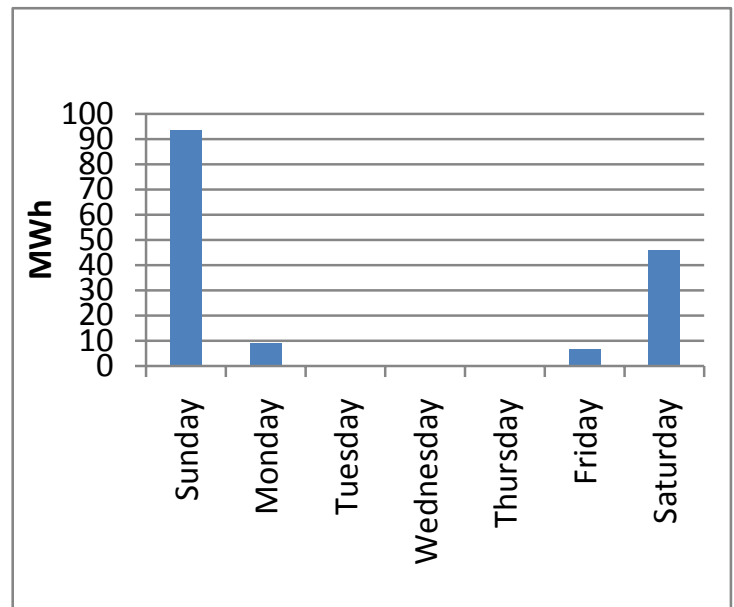

Figure 1-55. Central Bronx amount of energy exported by day

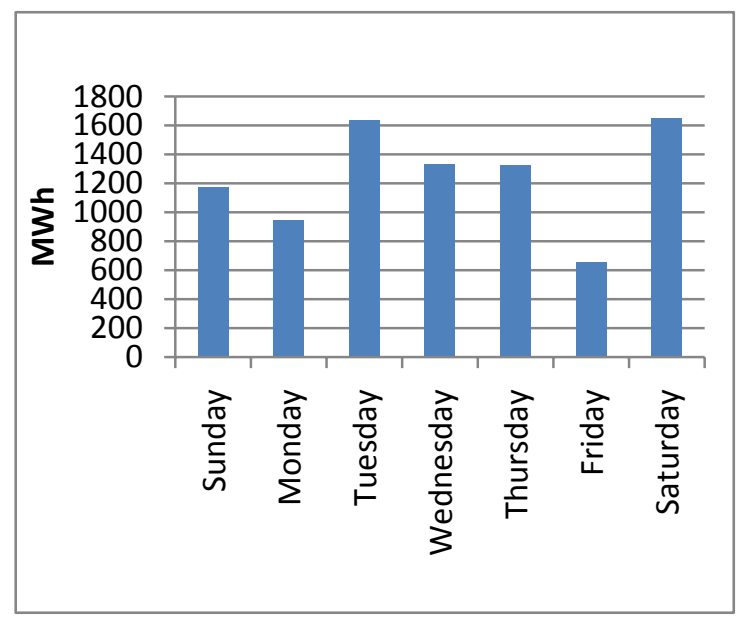

Figure 1-57. Flushing amount of energy exported by day

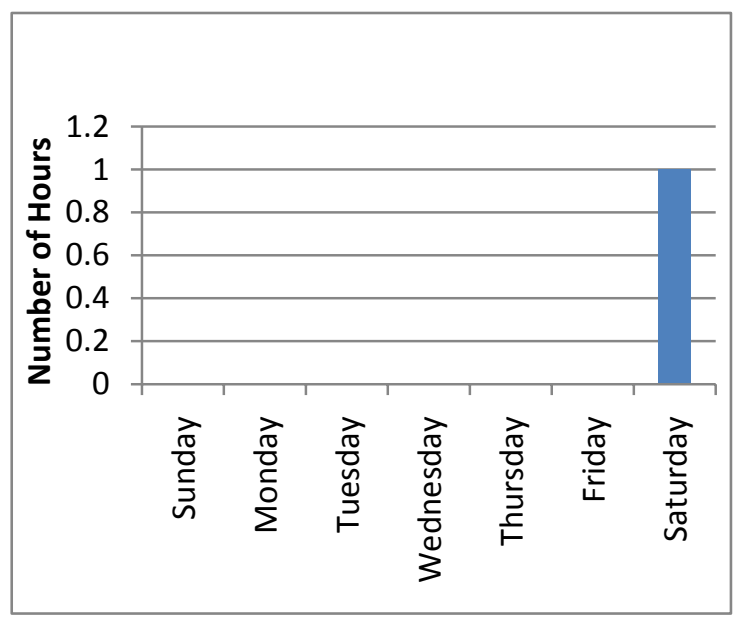

Figure 1-54. Bay Ridge number of hours of energy exported by day

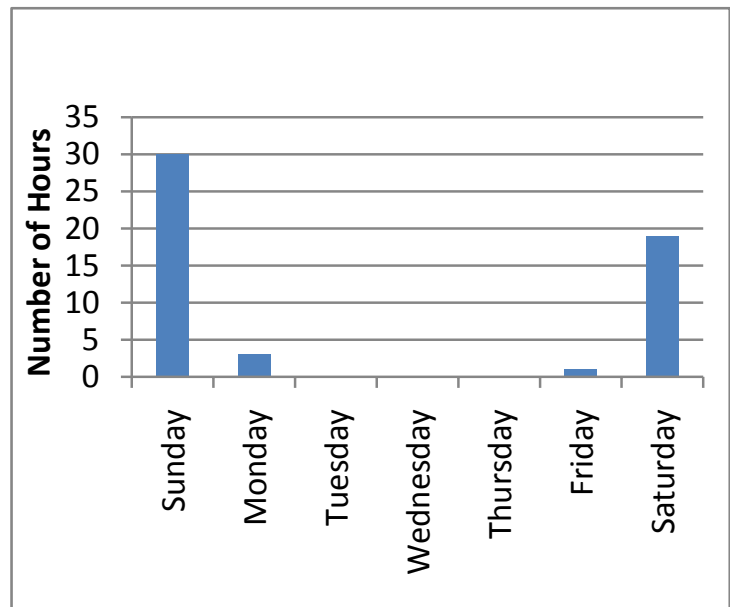

Figure 1-56. Central Bronx number of hours of energy exported by day

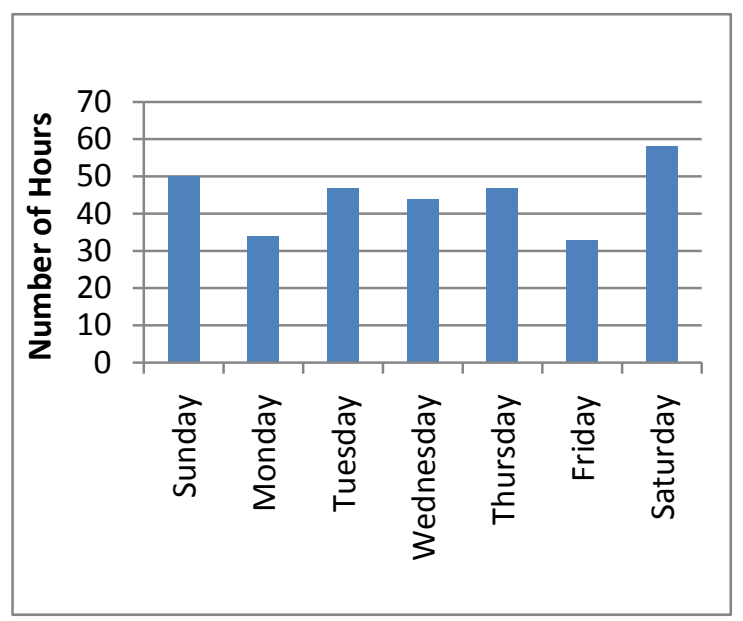

Figure 1-58. Flushing number of hours of energy exported by day 


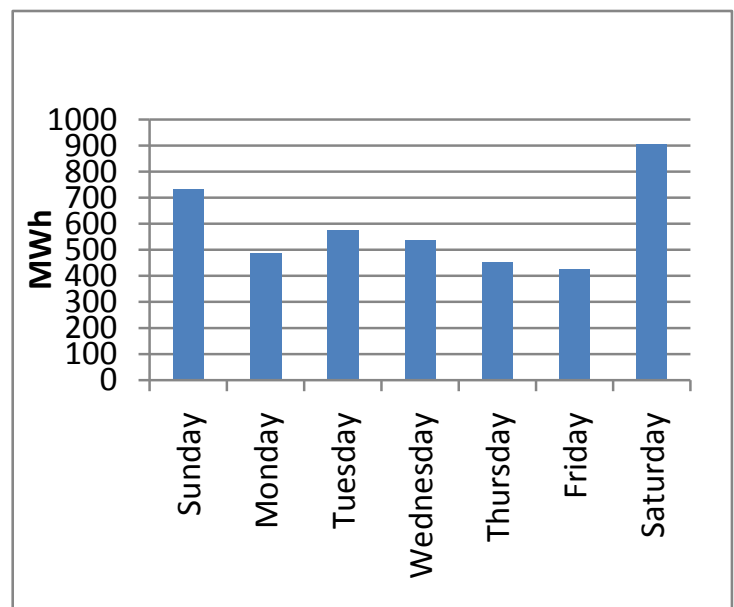

Figure 1-59. Fox Hill amount of energy exported by day

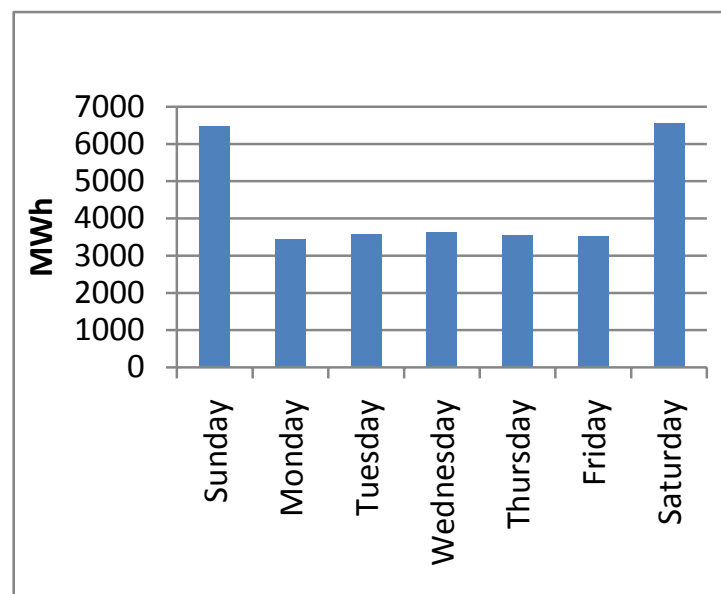

Figure 1-61. Maspeth amount of energy exported by day

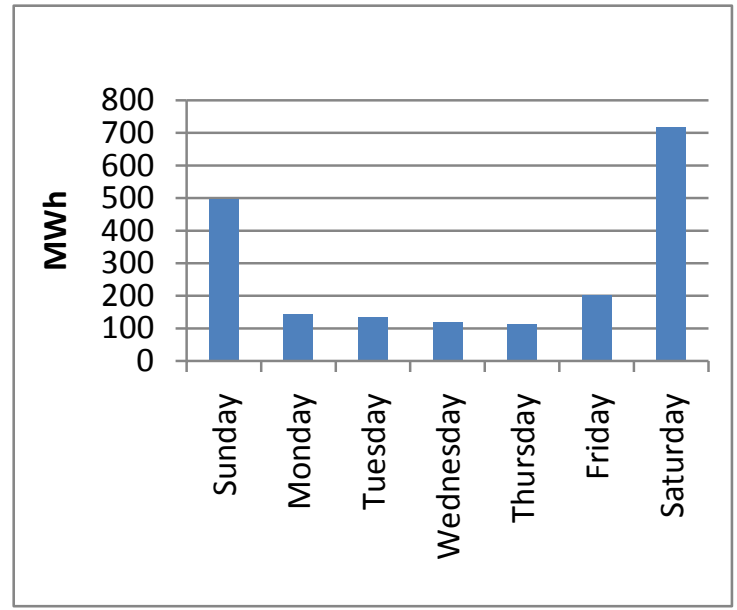

Figure 1-63. Southeast Bronx amount of energy exported by day

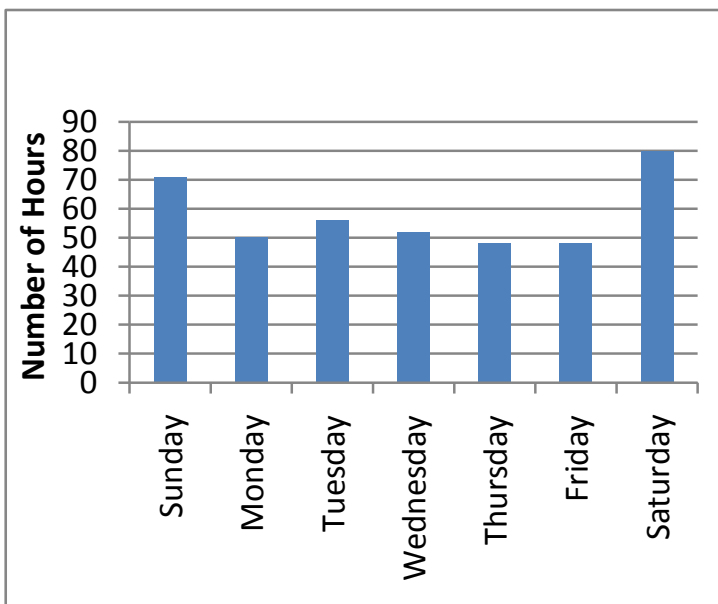

Figure 1-60. Fox Hill number of hours of energy exported by day

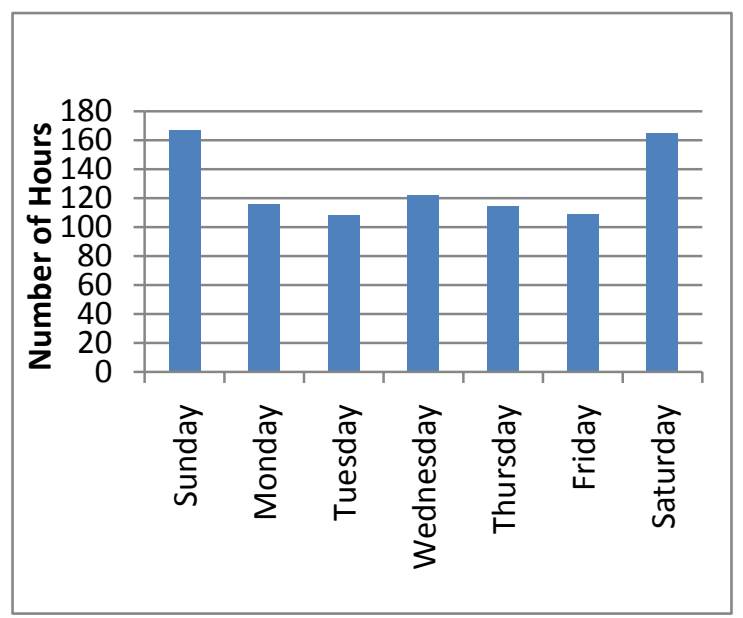

Figure 1-62. Maspeth number of hours of energy exported by day

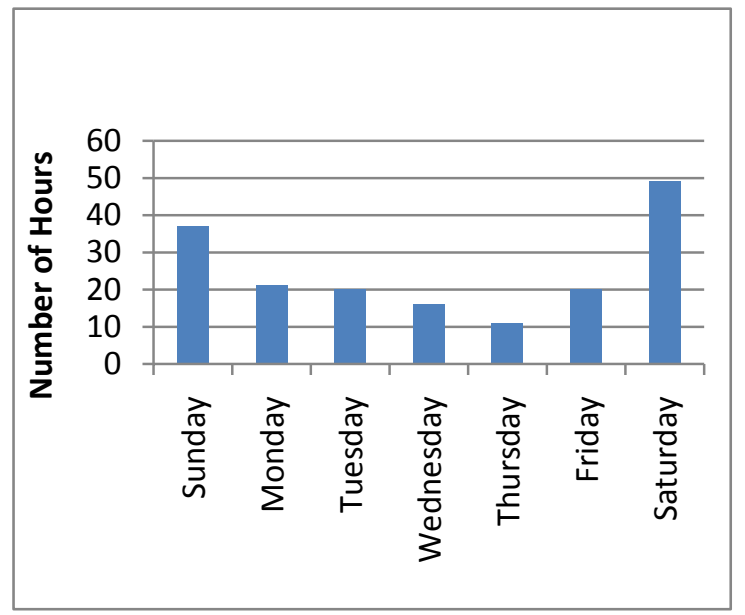

Figure 1-64. Southeast Bronx number of hours of energy exported by day 
Figures 1-65 through 1-76 show that over the course of a day, exporting is most likely to occur between 9:00 a.m. and 1:00 p.m. (although it can start as early as 8:00 a.m. and go as late as 3:00 p.m.), peaking at 11:00 a.m. This is because PV generation is highest at midday, when the sun is directly over the south-facing arrays. The low midday load also contributes to high exporting.

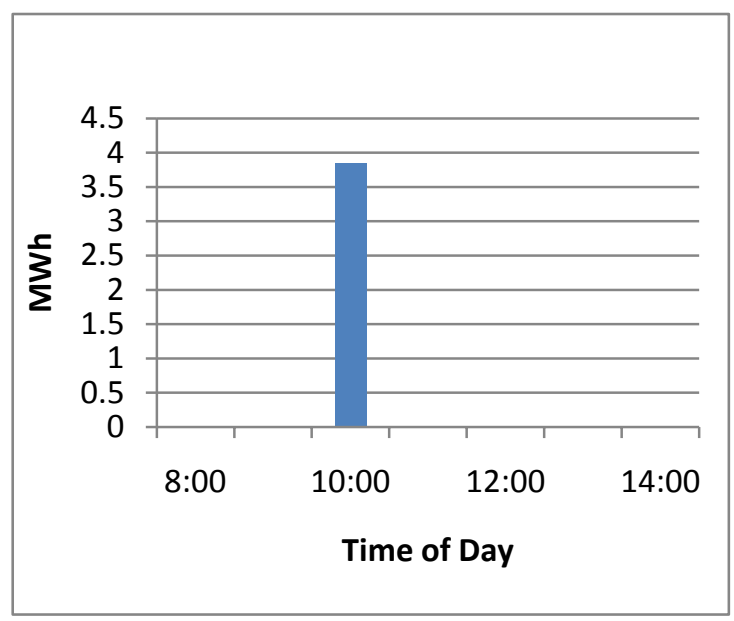

Figure 1-65. Bay Ridge amount of energy exported by time of day

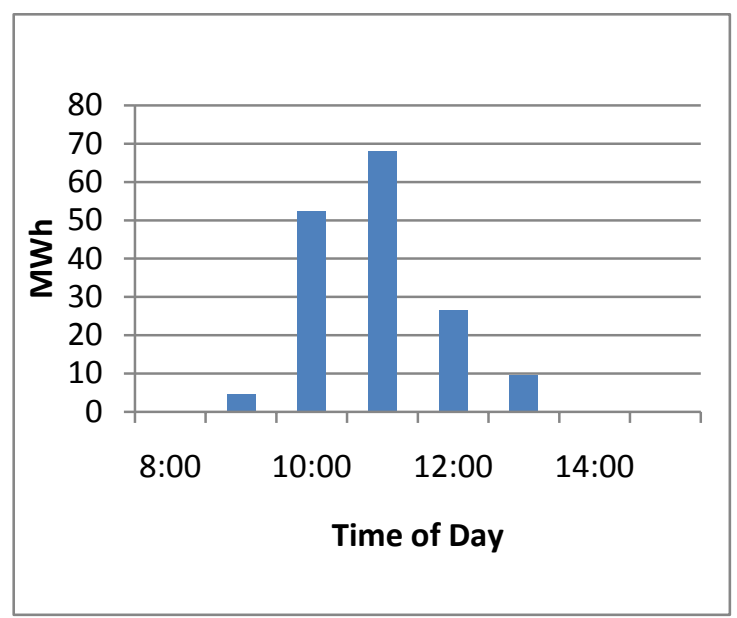

Figure 1-67. Central Bronx amount of energy exported by time of day

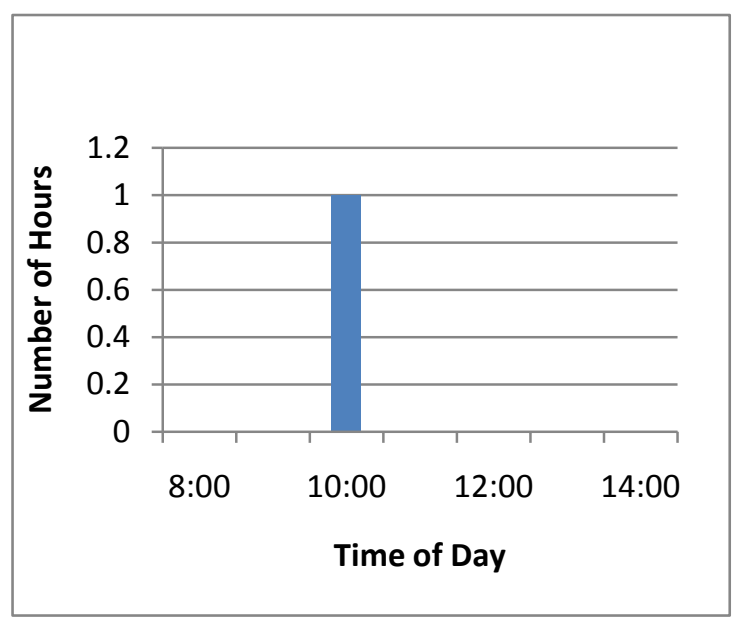

Figure 1-66. Bay Ridge number of hours of energy exported by time of day

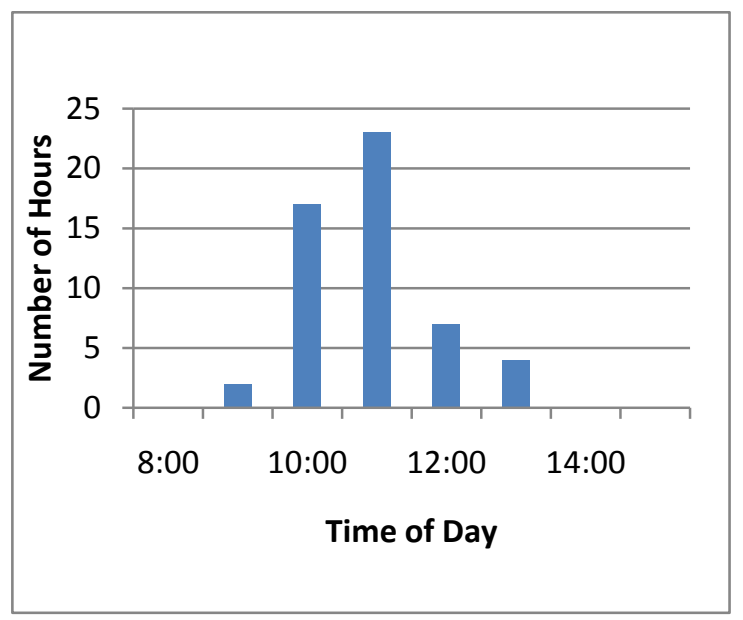

Figure 1-68. Central Bronx number of hours of energy exported by time of day 


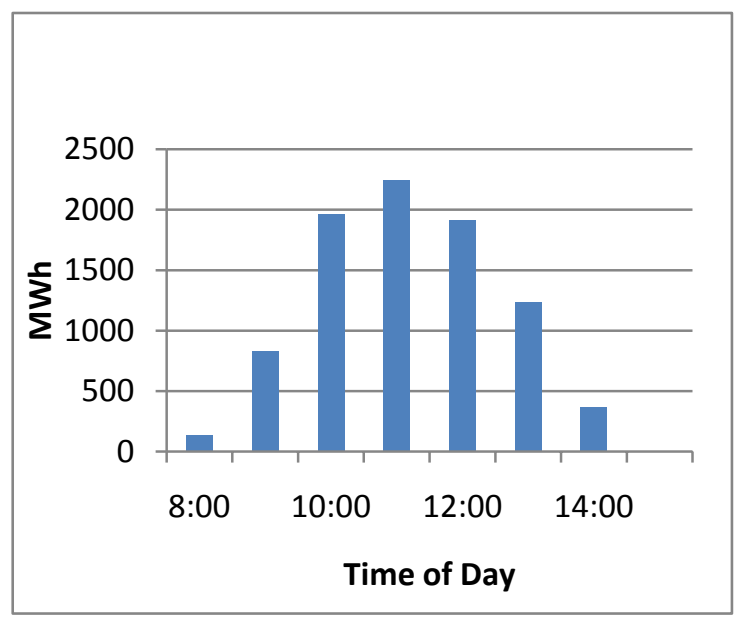

Figure 1-69. Flushing amount of energy exported by time of day

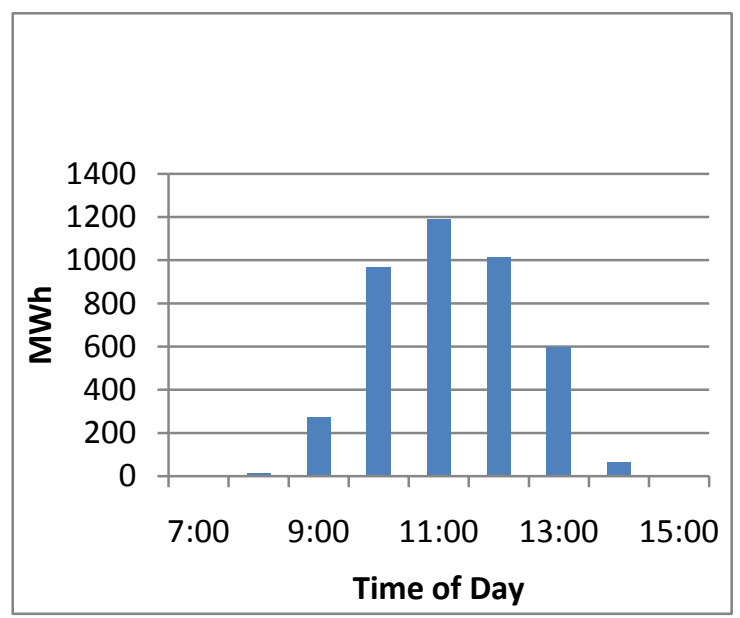

Figure 1-71. Fox Hill amount of energy exported by time of day

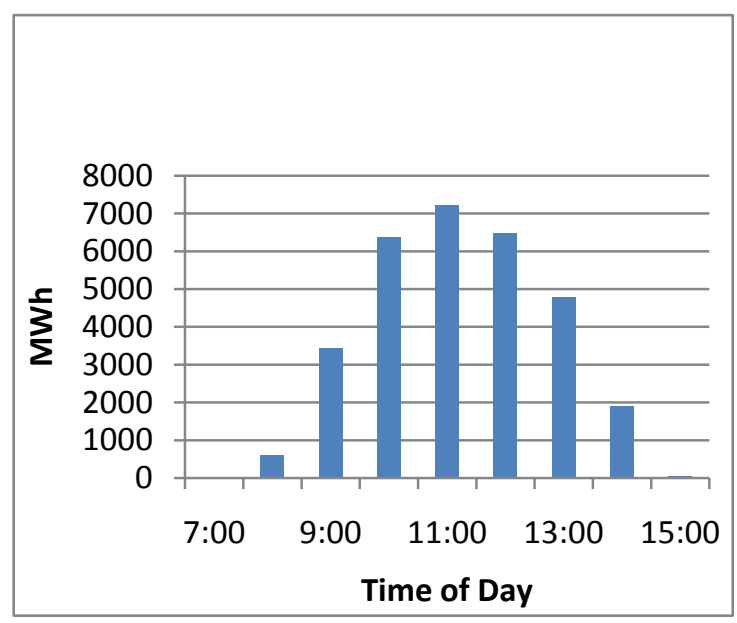

Figure 1-73. Maspeth amount of energy exported by time of day

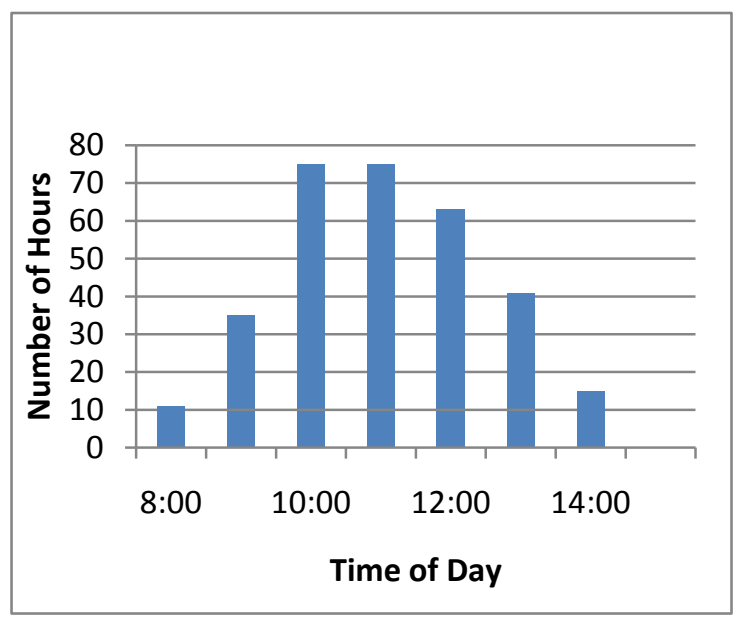

Figure 1-70. Flushing number of hours of energy exported by time of day

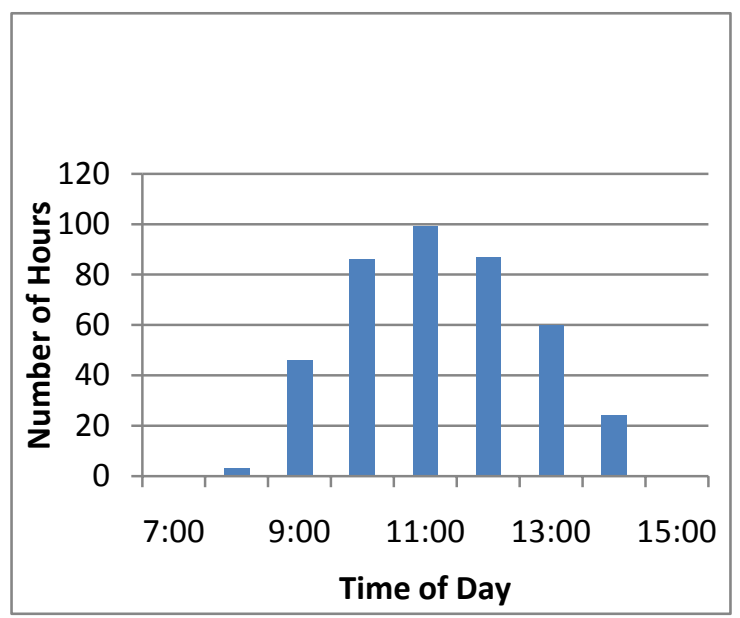

Figure 1-72. Fox Hill number of hours of energy exported by time of day

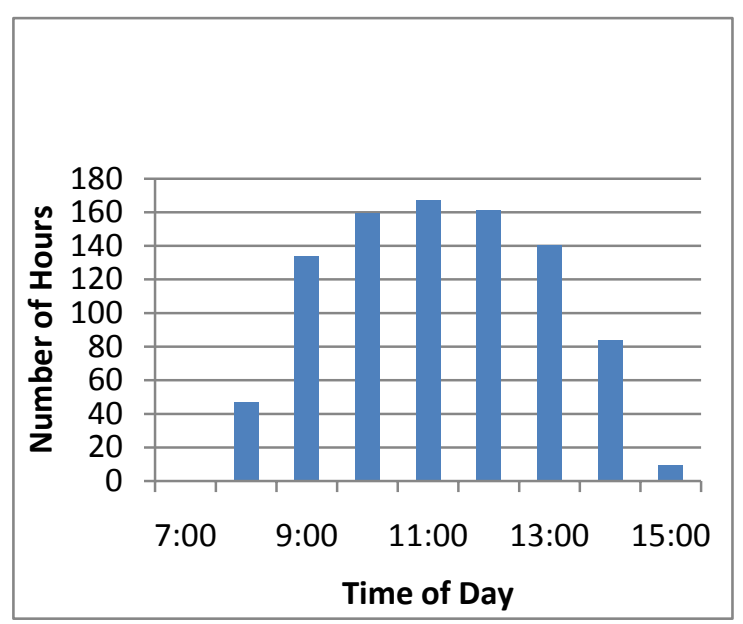

Figure 1-74. Maspeth number of hours of energy exported by time of day 


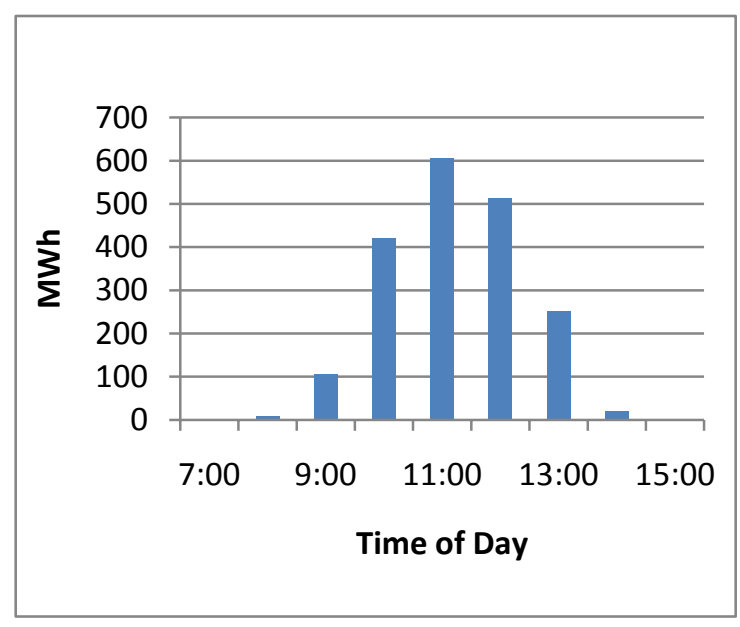

Figure 1-75. Southeast Bronx amount of energy exported by time of day

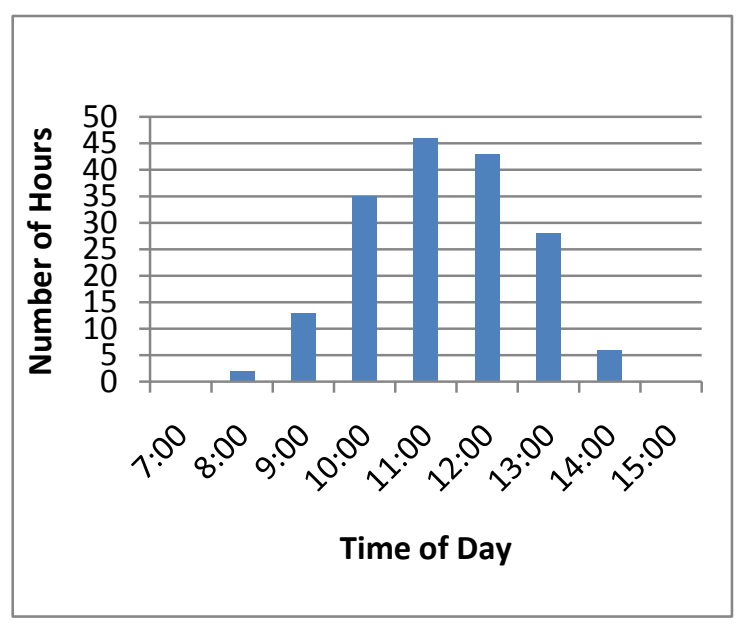

Figure 1-76. Southeast Bronx number of hours of energy exported by time of day

\subsection{Discussion}

We can also use the results of this analysis to determine the size of PV array that would generate a given percentage of the network load. Table 1-4 shows the PV array size that would generate $20 \%, 50 \%$, or $100 \%$ of the network load during the year's annual maximum export hour. Because these PV array sizes are based on the maximum export hour, the percentage of network load generated by the PV array during all other hours will be lower.

Table 1-4. PV Array Sizes to Generate Percentage of Network Load during Maximum Export Hour

\begin{tabular}{lcccc}
\hline \multirow{2}{*}{ Network } & $\begin{array}{c}\text { Maximum PV Size } \\
\text { Based on Available } \\
\text { Roof Space (MW }\end{array}$ & \multicolumn{3}{c}{$\begin{array}{c}\text { PV Array Size to Generate Percentage of } \\
\text { Network Load (MW AC) }\end{array}$} \\
\cline { 3 - 5 } & AC) & $20 \%$ & $50 \%$ & $100 \%$ \\
\hline Bay Ridge & 96.20 & 18.46 & 46.15 & 92.31 \\
Borough Hall & 58.08 & 26.09 & 65.23 & 130.46 \\
Central Bronx & 75.25 & 13.41 & 33.53 & 67.06 \\
Cooper & 25.73 & 18.94 & 47.35 & 94.71 \\
Flushing & 223.17 & 27.32 & 68.31 & 136.62 \\
Fox Hill & 97.51 & 13.71 & 34.27 & 68.54 \\
Herald & 1.29 & 5.98 & 14.95 & 29.90 \\
Maspeth & 188.61 & 18.52 & 46.29 & 92.58 \\
Southeast Bronx & 115.85 & 14.70 & 36.74 & 73.48 \\
Sutton & 1.85 & 12.15 & 30.37 & 60.75 \\
\hline
\end{tabular}

Even though we evaluated only ten networks in this study, the results can be used to estimate PV generation in other networks in the New York area. An estimate of the percent of the network area that could be covered by PV arrays can be drawn from a similar network. In general, a dense area of buildings with fewer stories (such as in 
Brooklyn or the Bronx) will have the highest percent coverage, around $8 \%$ to $10 \%$. A dense area of taller buildings (like Manhattan) will have a lower percent coverage, around $4 \%$ to $8 \%$. Tall buildings tend to shade neighboring roof space and typically have a higher percentage of their own rooftops occupied by rooftop equipment (and therefore unavailable for PV). Lower density areas (such as in Staten Island and Queens) will also have lower percent coverages, between $3 \%$ and $7 \%$, because there is less rooftop space per square foot of land area. Lower density areas also tend to have buildings with fewer stories and more trees, making rooftops in these areas more susceptible to shading.

If the size of the network area (in square meters) is known, we can estimate PV generation from Equation 1-8:

$$
\begin{aligned}
& \text { PV Power }(\mathrm{kW} A C)= \\
& \text { Area of Network }\left(\mathrm{m}^{2}\right) \times \text { Percent of Network Area Covered by PV } \\
& \times 0.1 \mathrm{kWDC} / \mathrm{m}^{2} \times 0.77 \mathrm{~kW} A C / \mathrm{kWDC}
\end{aligned}
$$

This equation assumes a DC-to-AC derate factor of 0.77 and a power density of $0.1 \mathrm{~kW}$ $\mathrm{DC} / \mathrm{m}^{2}$. The percent of network area covered by PV can be estimated by comparing the building density and composition of the network area to the networks evaluated in this study, and using a corresponding percentage from the second column in Table 1-3.

\subsection{Sources of Error}

There are two main sources of error in this analysis:

- Sample area estimate: We estimated the PV array size for each sample area by drawing arrays on rooftops in a satellite image. Because of limits in the satellite image resolution, these drawings are only an estimate of the maximum PV array size possible, accurate to within 10\%. Further, IMBY estimates the rating of each array based on the rule of thumb that the DC rating of the system in kilowatts is one-tenth the area of the array in square meters. This estimate is accurate to within $15 \%$.

- Extrapolation of sample area to network area: Although we chose the sample areas to represent particular building categories within a given network area as closely as possible, there is variation within each building category, and the sample areas are not likely to be an exact match. The sample areas are estimated to be accurate within $5 \%$ and $15 \%$, depending on the size of the sample area (larger sample areas including many buildings are more accurate) and the variation in the building category (less varied categories are more accurate).

\subsection{Conclusion}

In this analysis, the NREL team evaluated ten New York area networks to determine the maximum PV deployment possible in each network. Electricity generation from those PV systems was then compared to the network load. We found that under full PV 
deployment, PV generation would sometimes exceed network load and export to the grid in six of the ten networks. The networks with the highest amount of rooftop space per person experienced the most exporting. These were generally lower density networks in the outer boroughs, made up of more single-family homes and office buildings with fewer stories. The amount of energy exported varied by time of year, day of week, and time of day. Exporting was highest during the spring months, but also significant in fall and winter. Weekends experienced greater exporting than weekdays, particularly in industrial networks. On days that exporting occurred, it was consistently highest at 11:00 a.m. 


\section{Appendix 1-A: Network PV Deployment Percentage and PV Capacity Calculations}

In this appendix, we present more detail on how we calculated network PV deployment percentages and total PV capacities. To represent the varied building types and rooftop availability, we first divided each network into different building categories. Then we chose $10 \%$ of the area for each building category, for detailed evaluation of PV deployment potential. Next, we evaluated rooftops in each sample area using NREL's In My Backyard (IMBY) tool to estimate the maximum PV deployment percentage (PVD\%) in each building category.

By multiplying each building category's PVD\% by the percent of total network area (\%TNA) it represents, and summing across all five building categories, we calculated an overall network PVD\%. We then multiplied the overall network PVD\% by the network area and a power density of $0.1 \mathrm{~kW} \mathrm{DC} / \mathrm{m}^{2}$ to calculate the total capacity of $\mathrm{PV}$ in the network.

For each network, we give results for current roof conditions (in which some rooftops are avoided because of poor maintenance) and well-maintained conditions (in which no rooftops are avoided because of poor maintenance). Note that the PV generation presented in the main body of the report assumes well-maintained conditions.

Sections 1.A.1 through 1.A.10 describe each network.

\section{A.1 Bay Ridge}

The Bay Ridge network is located in Brooklyn. It is of particular interest in the PV deployment analysis because the warehouses in its Sunset Park neighborhood, along the New York Upper Bay between 20th and 60th Streets, have large expanses of available roof space.

Our analysis of satellite images showed that the network consists of two distinct types of neighborhoods: residential and warehouse. Although the residential neighborhoods are very similar to one another, generally consisting of brownstones with comparable rooftop areas, maintenance conditions, and shading, the warehouses are not as homogenous. The size and density of buildings vary, along with the state of their rooftops. Some rooftops have many obstructions that make PV panels impractical. Others appear to be in poor repair.

To represent the varied building types and rooftop availability, we divided the network into different building categories. Table 1-A-1 presents the \%TNA and PVD\% for each building category, along with the resulting overall network PVD\% and total network PV capacity. 
Table 1-A-1. Bay Ridge PV Deployment Percentage and PV Capacity Calculations

\begin{tabular}{|c|c|c|c|c|}
\hline \multirow{2}{*}{$\begin{array}{l}\text { Building } \\
\text { Category }\end{array}$} & \multirow{2}{*}{ Sample Area } & \multirow{2}{*}{ \%TNA } & \multicolumn{2}{|c|}{ PVD\% } \\
\hline & & & $\begin{array}{c}\text { Current } \\
\text { Rooftop } \\
\text { Conditions } \\
\end{array}$ & $\begin{array}{c}\text { Well- } \\
\text { Maintained } \\
\text { Conditions } \\
\end{array}$ \\
\hline $\begin{array}{l}\text { High-Density } \\
\text { Residential }\end{array}$ & $\begin{array}{l}\text { Bounded by 3rd Avenue on } \\
\text { the west, Fort Hamilton } \\
\text { Parkway on the east, } 61 \text { st } \\
\text { Street on the south, and } \\
\text { 53rd Street on the north }\end{array}$ & 80.04 & 9.83 & 10.08 \\
\hline $\begin{array}{l}\text { Low-Density } \\
\text { Warehouse } \\
\text { (Poor } \\
\text { Availability) }\end{array}$ & $\begin{array}{l}\text { Bounded by the Upper New } \\
\text { York Bay on the west, 1st } \\
\text { Avenue on the east, 56th } \\
\text { Street on the south, and } \\
\text { 54th Street on the north }\end{array}$ & 3.72 & 2.14 & 4.50 \\
\hline $\begin{array}{l}\text { Low-Density } \\
\text { Warehouse } \\
\text { (Good } \\
\text { Availability) }\end{array}$ & $\begin{array}{l}\text { Bounded by the Upper New } \\
\text { York Bay on the west, 2nd } \\
\text { Avenue on the east, 63rd } \\
\text { Street on the south, and } \\
\text { 58th Street on the north }\end{array}$ & 4.91 & 8.17 & 8.17 \\
\hline $\begin{array}{l}\text { High-Density } \\
\text { Warehouse } \\
\text { (Poor } \\
\text { Availability) }\end{array}$ & $\begin{array}{l}\text { Bounded by } 2 \text { nd Avenue on } \\
\text { the west, 3rd Avenue on the } \\
\text { east, } 37 \text { th Street on the } \\
\text { south, and 33rd Street on } \\
\text { the north }\end{array}$ & 4.98 & 6.69 & 10.00 \\
\hline $\begin{array}{l}\text { High-Density } \\
\text { Warehouse } \\
\text { (Good } \\
\text { Availability) }\end{array}$ & $\begin{array}{l}\text { Bounded by the Upper New } \\
\text { York Bay on the west, 3rd } \\
\text { Avenue on the east, 22nd } \\
\text { Street on the south, and } \\
\text { 19th Street on the north }\end{array}$ & 6.35 & 15.51 & 15.51 \\
\hline \multicolumn{2}{|c|}{ Overall PV Deployment Percentage } & & 9.67 & 10.12 \\
\hline \multicolumn{2}{|c|}{ Total Capacity (kW DC) } & & 119,383 & 124,932 \\
\hline \multicolumn{2}{|c|}{ Total Capacity (kW AC) } & & 91,925 & 96,198 \\
\hline
\end{tabular}

Based on the number of installations in each sample area, we estimate full deployment at approximately 36,000 individual installations.

\section{A.2 Borough Hall}

The Borough Hall network is found at the north end of Brooklyn, neighboring the Bay Ridge network. Our analysis of satellite images showed that the network consists of three distinct types of neighborhoods: residential, warehouse, and high-rise. Within these three neighborhoods, the residential and warehouse areas can be further broken down by 
density and rooftop availability. Table 1-A-2 presents the \%TNA and PVD\% for each building category, along with the resulting overall network PVD\% and total network PV capacity.

Because the building types and densities in the Borough Hall network are very similar to those in Bay Ridge, we applied the PV deployment percentages calculated for the Bay Ridge network to the five equivalent Borough Hall categories. PV deployment percentages for the remaining two categories, low-density residential and high-rise buildings, have been drawn from similar neighborhoods in the Central Bronx and Herald networks, respectively.

Table 1-A-2. Borough Hall PV Deployment Percentage and PV Capacity Calculations

\begin{tabular}{|c|c|c|c|c|}
\hline \multirow[b]{2}{*}{ Building Category } & \multirow[b]{2}{*}{ Sample Area } & \multirow[b]{2}{*}{ \%TNA } & \multicolumn{2}{|c|}{ PVD\% } \\
\hline & & & $\begin{array}{c}\text { Current } \\
\text { Rooftop } \\
\text { Conditions }\end{array}$ & $\begin{array}{c}\text { Well- } \\
\text { Maintained } \\
\text { Conditions }\end{array}$ \\
\hline Low-Density Residential & See Table 1-A-3 & 7.07 & 5.07 & 5.32 \\
\hline $\begin{array}{l}\text { High-Density } \\
\text { Residential }\end{array}$ & See Table 1-A-1 & 37.75 & 9.83 & 10.08 \\
\hline $\begin{array}{l}\text { Low-Density } \\
\text { Warehouse (Poor } \\
\text { Availability) }\end{array}$ & See Table 1-A-1 & 3.26 & 2.14 & 4.50 \\
\hline $\begin{array}{l}\text { Low-Density } \\
\text { Warehouse (Good) } \\
\text { Availability }\end{array}$ & See Table 1-A-1 & 16.95 & 8.17 & 8.17 \\
\hline $\begin{array}{l}\text { High-Density } \\
\text { Warehouse (Poor } \\
\text { Availability) }\end{array}$ & See Table 1-A-1 & 18.88 & 6.69 & 10.00 \\
\hline $\begin{array}{l}\text { High-Density } \\
\text { Warehouse (Good } \\
\text { Availability) }\end{array}$ & See Table 1-A-1 & 10.30 & 15.51 & 15.51 \\
\hline High-Density High-Rise & See Table 1-A-7 & 5.78 & 6.94 & 6.94 \\
\hline Overall PV Deployment F & ercentage & & 8.79 & 9.60 \\
\hline Total Capacity (kW DC) & & & 69,029 & 75,423 \\
\hline Total Capacity (kW AC) & & & 53,152 & 58,076 \\
\hline
\end{tabular}

We estimate full deployment at approximately 12,000 individual installations. 


\section{A.3 Central Bronx}

The Central Bronx network is of particular interest in the PV deployment analysis because the warehouses in the network's Hunt's Point neighborhood (along the Bronx River east of the Sheridan Expressway) are thought to be prime locations for large PV systems.

Our analysis of satellite images showed that the network consists of two distinct types of neighborhoods: residential and warehouse. The residential neighborhoods can be further divided into areas of high-density and low-density buildings. The warehouse areas can be grouped by building density and the availability of their rooftops. Table 1-A-3 presents the \%TNA and PVD\% for each building category, along with the resulting overall network PVD\% and total network PV capacity.

Table 1-A-3. Central Bronx PV Deployment Percentage and PV Capacity Calculations

\begin{tabular}{|c|c|c|c|c|}
\hline \multirow{2}{*}{$\begin{array}{l}\text { Building } \\
\text { Category }\end{array}$} & \multirow[b]{2}{*}{ Sample Area } & \multirow[b]{2}{*}{ \%TNA } & \multicolumn{2}{|c|}{ PVD\% } \\
\hline & & & $\begin{array}{c}\text { Current } \\
\text { Rooftop } \\
\text { Conditions }\end{array}$ & $\begin{array}{c}\text { Well- } \\
\text { Maintained } \\
\text { Conditions }\end{array}$ \\
\hline $\begin{array}{l}\text { Low-Density } \\
\text { Residential }\end{array}$ & $\begin{array}{l}\text { Bounded by Trinity Avenue } \\
\text { on the west, Tinton Avenue } \\
\text { on the east, E 163rd Street } \\
\text { on the south, and E 165th } \\
\text { Street on the north }\end{array}$ & 6.40 & 5.07 & 5.32 \\
\hline $\begin{array}{l}\text { High-Density } \\
\text { Residential }\end{array}$ & $\begin{array}{l}\text { Bounded by Prospect } \\
\text { Avenue and Westchester } \\
\text { Avenue on the west, } \\
\text { Southern Boulevard on the } \\
\text { east and south, and E 163rd } \\
\text { Street on the north }\end{array}$ & 52.82 & 11.91 & 12.16 \\
\hline $\begin{array}{l}\text { Low-Density } \\
\text { Warehouse } \\
\text { (Poor } \\
\text { Availability) }\end{array}$ & $\begin{array}{l}\text { Bounded by Halleck Street } \\
\text { on the west, Avenue F on } \\
\text { the east, Food Center Drive } \\
\text { on the south, and the Bronx } \\
\text { River on the north }\end{array}$ & 17.57 & 2.84 & 5.30 \\
\hline $\begin{array}{l}\text { Low-Density } \\
\text { Warehouse } \\
\text { (Good } \\
\text { Availability) }\end{array}$ & $\begin{array}{l}\text { Bounded by Halleck Street } \\
\text { on the west, Food Center } \\
\text { Drive on the north and east, } \\
\text { and the Bronx River on the } \\
\text { south }\end{array}$ & 14.69 & 7.75 & 7.75 \\
\hline $\begin{array}{l}\text { High-Density } \\
\text { Warehouse } \\
\text { (Poor } \\
\text { Availability) }\end{array}$ & $\begin{array}{l}\text { Bounded by Tiffany Street } \\
\text { on the west, Manida Street } \\
\text { on the east, Oak Point } \\
\text { Avenue on the south, and } \\
\text { Randall Avenue on the } \\
\text { north }\end{array}$ & 5.74 & 6.30 & 11.43 \\
\hline
\end{tabular}




\begin{tabular}{|c|c|c|c|c|}
\hline $\begin{array}{l}\text { High-Density } \\
\text { Warehouse } \\
\text { (Good } \\
\text { Availability) }\end{array}$ & $\begin{array}{l}\text { Bounded by Worthen Street } \\
\text { on the west, Tiffany Street } \\
\text { on the east, Oak Point } \\
\text { Avenue on the south, and } \\
\text { Truxton Street on the north }\end{array}$ & 2.80 & 22.87 & 23.84 \\
\hline \multicolumn{3}{|c|}{ Overall PV Deployment Percentage } & 9.25 & 10.16 \\
\hline \multicolumn{3}{|c|}{ Total Capacity (kW DC) } & 89,046 & 97,722 \\
\hline \multicolumn{3}{|c|}{ Total Capacity (kW AC) } & 68,565 & 75,246 \\
\hline
\end{tabular}

We estimate full deployment at approximately 15,000 individual installations.

\section{A.4 Cooper Square}

The Cooper Square network is located in Manhattan's East Village. Our analysis of satellite images shows that it is largely made up of high-density residences and businesses, with lower density buildings near the East River. Rooftops are in fairly good condition, although some need maintenance. There are few trees shading rooftops, but there are significant areas of shading resulting from the height of nearby buildings. There are no warehouses in this network. Table 1-A-4 presents the \%TNA and PVD\% for each building category, along with the resulting overall network PVD\% and total network PV capacity.

Table 1-A-4. Cooper Square PV Deployment Percentage and PV Capacity Calculations

\begin{tabular}{|c|c|c|c|c|}
\hline \multirow{2}{*}{$\begin{array}{l}\text { Building } \\
\text { Category }\end{array}$} & \multirow[b]{2}{*}{ Sample Area } & \multirow[b]{2}{*}{$\%$ TNA } & \multicolumn{2}{|c|}{ PVD\% } \\
\hline & & & $\begin{array}{c}\text { Current } \\
\text { Rooftop } \\
\text { Conditions }\end{array}$ & $\begin{array}{c}\text { Well- } \\
\text { Maintained } \\
\text { Conditions }\end{array}$ \\
\hline $\begin{array}{l}\text { Low-Density } \\
\text { Residential }\end{array}$ & $\begin{array}{l}\text { Bounded by Pitt Street on } \\
\text { the west, Columbia Street } \\
\text { on the east, Grand Street on } \\
\text { the south, and Stanton } \\
\text { Street on the north }\end{array}$ & 27.61 & 4.33 & 4.58 \\
\hline $\begin{array}{l}\text { High-Density } \\
\text { Residential/ } \\
\text { Business }\end{array}$ & $\begin{array}{l}\text { Bounded by Bowery on the } \\
\text { west, Clinton Street on the } \\
\text { east, Delancey Street on the } \\
\text { south, and E Houston Street } \\
\text { on the north }\end{array}$ & 72.39 & 8.93 & 9.18 \\
\hline \multicolumn{2}{|c|}{ Overall PV Deployment Percentage } & & 7.66 & 7.91 \\
\hline \multicolumn{2}{|c|}{ Total Capacity (kW DC) } & & 32,363 & 33,418 \\
\hline \multicolumn{2}{|c|}{ Total Capacity (kW AC) } & & 24,919 & 25,732 \\
\hline
\end{tabular}

We estimate full deployment at approximately 7,000 individual installations. 


\section{A.5 Flushing}

The Flushing network is located in Queens. Our analysis of satellite images shows that it is a residential area, consisting mainly of single-family homes. There are several large parks and golf courses, and the New York Mets' Citi Field (and its associated parking lots) is located here as well. With the exception of these open spaces, the building density is fairly uniform. Rooftops are generally well-maintained, with a fair amount of shading from the area's many trees. Because the network density and building types are uniform, we evaluated the built area of the network in one sample area. Table 1-A-5 presents the $\%$ TNA and PVD\% for each building category, along with the resulting overall network PVD\% and total network PV capacity.

Table 1-A-5. Flushing PV Deployment Percentage and PV Capacity Calculations

\begin{tabular}{|c|c|c|c|c|}
\hline \multirow{2}{*}{$\begin{array}{l}\text { Building } \\
\text { Category }\end{array}$} & \multirow[b]{2}{*}{ Sample Area } & \multirow[b]{2}{*}{ \%TNA } & \multicolumn{2}{|c|}{ PVD\% } \\
\hline & & & $\begin{array}{c}\text { Current } \\
\text { Rooftop } \\
\text { Conditions }\end{array}$ & $\begin{array}{c}\text { Well- } \\
\text { Maintained } \\
\text { Conditions }\end{array}$ \\
\hline Built Area & $\begin{array}{l}\text { Bounded by Whitestone } \\
\text { Expressway on the west, } \\
\text { Clearview Expressway on } \\
\text { the east, 35th Avenue on } \\
\text { the south, and } 26 \text { th Avenue } \\
\text { on the north }\end{array}$ & 79.72 & 6.83 & 7.08 \\
\hline Open Space & Not applicable & 20.28 & 0 & 0 \\
\hline \multicolumn{2}{|c|}{ Overall PV Deployment Percentage } & & 5.44 & 5.64 \\
\hline \multicolumn{2}{|c|}{ Total Capacity (kW DC) } & & 279,601 & 289,835 \\
\hline \multicolumn{2}{|c|}{ Total Capacity (kW AC) } & & 215,293 & 223,173 \\
\hline
\end{tabular}

We estimate full deployment at approximately 65,000 individual installations.

\section{A.6 Fox Hills}

The Fox Hills network is located on Staten Island. Our analysis of satellite images shows that it is a residential area, consisting mainly of single-family homes. There are several large parks and golf courses, with open space making up 31\% of the network area. There are small pockets of wooded areas with more widely spaced homes, and a few blocks of denser high-rise buildings, but overall building density is uniform. Rooftops are wellmaintained, but there is a significant amount of shading from the area's many trees.

Because the network density and building types are uniform, we evaluated the built area of the network in one sample area. Table 1-A-6 presents the \%TNA and PVD\% for each building category, along with the resulting overall network PVD\% and total network PV capacity. 
Table 1-A-6. Fox Hills PV Deployment Percentage and PV Capacity Calculations

\begin{tabular}{|c|c|c|c|c|}
\hline \multirow{2}{*}{$\begin{array}{l}\text { Building } \\
\text { Category }\end{array}$} & \multirow[b]{2}{*}{ Sample Area } & \multirow[b]{2}{*}{ \%TNA } & \multicolumn{2}{|c|}{ PVD\% } \\
\hline & & & $\begin{array}{c}\text { Current } \\
\text { Rooftop } \\
\text { Conditions }\end{array}$ & $\begin{array}{c}\text { Well- } \\
\text { Maintained } \\
\text { Conditions }\end{array}$ \\
\hline Built Area & $\begin{array}{l}\text { Bounded by Todt Hill Road } \\
\text { on the west, Seaside } \\
\text { Boulevard on the east, } \\
\text { Midland Avenue on the } \\
\text { south, and Seaview Avenue } \\
\text { on the north }\end{array}$ & 68.76 & 4.10 & 4.35 \\
\hline Open Space & Not applicable & 31.24 & 0 & 0 \\
\hline \multicolumn{2}{|c|}{ Overall PV Deployment Percentage } & & 2.82 & 2.99 \\
\hline \multicolumn{2}{|c|}{ Total Capacity (kW DC) } & & 119,435 & 126,635 \\
\hline \multicolumn{2}{|c|}{ Total Capacity (kW AC) } & & 91,965 & 97,509 \\
\hline
\end{tabular}

We estimate full deployment at approximately 40,000 individual installations.

\section{A.7 Herald Square}

The Herald Square network is located in the center of Manhattan. Our analysis of satellite images shows that it is made up solely of high-density high-rise buildings. Rooftops are in good condition, and even though some are covered with rooftop equipment, large spaces are also available for PV. There is some shading from the tall buildings nearby. The small size of this network (11 square blocks) allowed us to evaluate $100 \%$ of the network area (instead of the 10\% sample we completed for larger networks). Table 1-A-7 presents the overall network PVD\% and total network PV capacity.

Table 1-A-7. Herald Square PV Deployment Percentage and PV Capacity Calculations

\begin{tabular}{lcc}
\hline & \multicolumn{2}{c}{ PVD\% } \\
\cline { 2 - 3 } & $\begin{array}{c}\text { Current Rooftop } \\
\text { Conditions }\end{array}$ & $\begin{array}{c}\text { Well-Maintained } \\
\text { Conditions }\end{array}$ \\
\hline Overall PV Deployment Percentage & 6.69 & 6.94 \\
Total Capacity (kW DC) & 1,612 & 1,673 \\
Total Capacity (kW AC) & 1,242 & 1,288 \\
\hline
\end{tabular}

We estimate full deployment at approximately 60 individual installations. 


\section{A.8 Maspeth}

The Maspeth network is located on the west side of Queens. Our analysis of satellite images shows that it is mainly a high-density residential area, made up of closely spaced single-family homes and attached brownstones. There are also small pockets of lower density residential areas, and some warehouse buildings. In general, the rooftops appear to be in good repair, although there is some room for maintenance. There is little shading from trees or other buildings. Open space (mainly cemeteries) makes up a large section of the network as well. Table 1-A-8 presents the \%TNA and PVD\% for each building category, along with the resulting overall network PVD\% and total network PV capacity. Availability on warehouse building rooftops is uniform throughout the network, so they are not separated into good and poor availability categories.

Table 1-A-8: Maspeth PV Deployment Percentage and PV Capacity Calculations

\begin{tabular}{|c|c|c|c|c|}
\hline \multirow{2}{*}{$\begin{array}{l}\text { Building } \\
\text { Category }\end{array}$} & \multirow[b]{2}{*}{ Sample Area } & \multirow[b]{2}{*}{ \%TNA } & \multicolumn{2}{|c|}{ PVD\% } \\
\hline & & & $\begin{array}{c}\text { Current } \\
\text { Rooftop } \\
\text { Conditions }\end{array}$ & $\begin{array}{c}\text { Well- } \\
\text { Maintained } \\
\text { Conditions }\end{array}$ \\
\hline $\begin{array}{l}\text { Low-Density } \\
\text { Residential }\end{array}$ & $\begin{array}{l}\text { Bounded by Ascan Avenue } \\
\text { on the west, Puritan Avenue } \\
\text { on the east, Kessel Street } \\
\text { on the south, and Greenway } \\
\mathrm{N} \text { on the north }\end{array}$ & 2.45 & 3.44 & 3.44 \\
\hline $\begin{array}{l}\text { High-Density } \\
\text { Residential }\end{array}$ & $\begin{array}{l}\text { Bounded by } 69 \text { th Street on } \\
\text { the west, Queens Boulevard } \\
\text { on the east, the Long Island } \\
\text { Expressway on the south, } \\
\text { and } 51 \text { st Avenue on the } \\
\text { north }\end{array}$ & 56.68 & 9.40 & 9.65 \\
\hline $\begin{array}{l}\text { Low-Density } \\
\text { Warehouse }\end{array}$ & $\begin{array}{l}\text { Bounded by Highway } 278 \\
\text { on the west, } 50 \text { th Street on } \\
\text { the east, } 55 \text { th Avenue on } \\
\text { the south, and } 54 \text { th Road on } \\
\text { the north }\end{array}$ & 2.97 & 5.91 & 6.91 \\
\hline $\begin{array}{l}\text { High-Density } \\
\text { Warehouse }\end{array}$ & $\begin{array}{l}\text { Bounded by } 47 \text { th and 48th } \\
\text { Streets on the west, Rust } \\
\text { Street on the east, Grand } \\
\text { Avenue on the south, and } \\
\text { Maspeth Avenue on the } \\
\text { north }\end{array}$ & 10.28 & 12.83 & 13.83 \\
\hline Open Space & Not applicable & 27.62 & 0 & 0 \\
\hline \multicolumn{2}{|c|}{ Overall PV Deployment Percentage } & & 6.91 & 7.18 \\
\hline \multicolumn{2}{|c|}{ Total Capacity (kW DC) } & & 235,596 & 244,947 \\
\hline \multicolumn{2}{|c|}{ Total Capacity (kW AC) } & & 181,409 & 188,610 \\
\hline
\end{tabular}

We estimate full deployment at approximately 40,000 individual installations. 


\section{A.9 Southeast Bronx}

Our analysis of satellite images shows that the Southeast Bronx network is mainly a residential area of high-density single-family homes, but there are also some lower density apartment buildings, a few warehouse buildings, and some small areas of parkland. In general, the residential area rooftops appear to be in good repair, although there is some room for maintenance. There is little shading from trees or other buildings. Table 1-A-9 presents the \%TNA and PVD\% for each building category, along with the resulting overall network PVD\% and total network PV capacity. For the warehouse areas, we drew estimates of PV deployment from similar areas in the neighboring Central Bronx network.

Table 1-A-9. Southeast Bronx PV Deployment Percentage and PV Capacity Calculations

\begin{tabular}{|c|c|c|c|c|}
\hline \multirow{2}{*}{$\begin{array}{l}\text { Building } \\
\text { Category }\end{array}$} & \multirow[b]{2}{*}{ Sample Area } & \multirow[b]{2}{*}{ \%TNA } & \multicolumn{2}{|c|}{ PVD\% } \\
\hline & & & $\begin{array}{c}\text { Current } \\
\text { Rooftop } \\
\text { Conditions }\end{array}$ & $\begin{array}{c}\text { Well- } \\
\text { Maintained } \\
\text { Conditions }\end{array}$ \\
\hline $\begin{array}{l}\text { Low-Density } \\
\text { Residential }\end{array}$ & $\begin{array}{l}\text { Bounded by Unionport Road } \\
\text { on the west, Purdy Street } \\
\text { and Olmstead Avenue on } \\
\text { the east, St. Raymond } \\
\text { Avenue and Starling } \\
\text { Avenue on the south, and } \\
\text { Tremont Avenue on the } \\
\text { north }\end{array}$ & 11.51 & 6.13 & 6.13 \\
\hline $\begin{array}{l}\text { High-Density } \\
\text { Residential }\end{array}$ & $\begin{array}{l}\text { Bounded by the Hutchinson } \\
\text { River Parkway on the west, } \\
\text { the Bruckner Expressway } \\
\text { on the east, E Tremont } \\
\text { Avenue on the south, and } \\
\text { Westchester Avenue on the } \\
\text { north }\end{array}$ & 78.94 & 8.06 & 8.31 \\
\hline $\begin{array}{l}\text { Low-Density } \\
\text { Warehouse }\end{array}$ & See Table 1-A-3 & 2.52 & 7.75 & 7.75 \\
\hline $\begin{array}{l}\text { High-Density } \\
\text { Warehouse }\end{array}$ & See Table 1-A-3 & 5.26 & 22.87 & 22.87 \\
\hline Open Space & Not applicable & 1.77 & 0 & 0 \\
\hline \multicolumn{2}{|c|}{ Overall PV Deployment Percentage } & & 8.47 & 8.66 \\
\hline \multicolumn{2}{|c|}{ Total Capacity (kW DC) } & & 147,025 & 150,452 \\
\hline \multicolumn{2}{|c|}{ Total Capacity (kW AC) } & & 113,209 & 115,848 \\
\hline
\end{tabular}

We estimate full deployment at approximately 40,000 individual installations. 


\section{A.10 Sutton}

The Sutton network is located on the east side of midtown Manhattan. Our analysis of satellite images shows that it contains primarily large high-rise buildings and a few brownstones. The building density is high. Rooftops are in good condition, but most are covered with rooftop equipment, leaving little room for PV. There is significant shading from the tall buildings nearby.

Because the network density and building types are fairly uniform, we did not divide this network into building categories. Instead, we selected one sample area for detailed evaluation of PV deployment potential. Table 1-A-10 presents the overall network PVD\% and total network PV capacity.

Table 1-A-10. Sutton PV Deployment Percentage and PV Capacity Calculations

\begin{tabular}{lccc}
\hline \multicolumn{1}{c}{ Sample Area } & \%TNA & \multicolumn{2}{c}{ PVD\% } \\
\cline { 3 - 4 } & & $\begin{array}{c}\text { Current } \\
\text { Rooftop } \\
\text { Conditions }\end{array}$ & $\begin{array}{c}\text { Well- } \\
\text { Maintained } \\
\text { Conditions }\end{array}$ \\
\hline $\begin{array}{l}\text { Bounded by 55th Street on the } \\
\text { north, 54th Street on the south, }\end{array}$ & 100 & 3.59 & 3.84 \\
$\begin{array}{l}\text { 5th Avenue on the west, and } \\
\text { the East River on the east }\end{array}$ & & 3.59 & 3.84 \\
$\begin{array}{l}\text { Overall PV Deployment Percentage } \\
\text { Total Power (kW DC) }\end{array}$ & 2,244 & 2,400 \\
Total Power (kW AC) & & 1,728 & 1,848 \\
\hline
\end{tabular}

We estimate full deployment at approximately 400 individual installations. 


\section{Appendix 1-B: PV Generation for Flat-Mounted Arrays}

Our analysis assumed that all PV arrays were tilted at $40.8^{\circ} \mathrm{N}$ (equal to the latitude of the site). This maximizes annual energy production and favors energy production in the spring and fall. Because Con Edison sees its minimum loads in spring and fall, maximizing PV production for spring and fall gives us maximum energy exporting. Many PV arrays in the New York Area, however, are flat-mounted. As a result, we conducted additional analysis for one network (Central Bronx) to show how results can be expected to change for flat-mounted PV arrays.

As shown in Table 1-B-1, the percent of network area covered by PV and total PV size remain the same. Changing the angle of the PV arrays, though, affects the annual maximum percent of load met by PV, the capacity penetration, and the energy penetration.

Table 1-B-1. Comparison of $0^{\circ}$ and $40.8^{\circ}$ PV Array Tilt Angles, Central Bronx Network

\begin{tabular}{|c|c|c|c|c|c|}
\hline $\begin{array}{l}\text { PV Array Tilt } \\
\text { Angle }\end{array}$ & $\begin{array}{c}\text { Percent of } \\
\text { Network } \\
\text { Area } \\
\text { Covered by } \\
\text { PV }(\%)^{\mathrm{a}} \\
\end{array}$ & $\begin{array}{c}\text { Total PV } \\
\text { Size } \\
(\mathrm{MW} \mathrm{AC})^{\mathrm{b}} \\
\end{array}$ & $\begin{array}{c}\text { Percent of } \\
\text { Load Met by } \\
\text { PV }(\text { Annual } \\
\text { Maximum; \%) }\end{array}$ & $\begin{array}{c}\text { Capacity } \\
\text { Penetration } \\
(\%)^{\mathrm{d}}\end{array}$ & $\begin{array}{c}\text { Energy } \\
\text { Penetration } \\
(\%)^{\mathrm{e}} \\
\end{array}$ \\
\hline $40.8^{\circ}$ Tilt & 10.16 & 75.25 & 112.21 & 68.73 & 17.18 \\
\hline $0^{\circ}$ Tilt & 10.16 & 75.25 & 110.28 & 55.48 & 14.46 \\
\hline
\end{tabular}

${ }^{\mathrm{a}}$ Percent of network area covered by PV: Calculated as shown in Section 1.2.3

${ }^{\mathrm{b}}$ Total PV size $=$ size of PV array covering entire network $\times$ percent of network area covered by PV

${ }^{\mathrm{c}}$ Percent of load met by PV (annual maximum) $=$ PV power generation/load $\times 100$, for annual maximum hour (coincident)

${ }^{\mathrm{d}}$ Capacity penetration $=$ annual peak PV power generation/annual peak load $\times 100$ (noncoincident)

${ }^{\mathrm{e}}$ Energy penetration $=$ annual $\mathrm{PV}$ energy generation/annual energy consumption $\times 100$

The annual maximum percent of load met by PV changes very little. The day on which it occurs shifts toward the summer (from May 1 to May 29), because a flat-mounted array will produce the most energy around the summer solstice when the sun is highest in the sky. This is helpful in mid-summer, when New York sees its highest annual loads. But near-maximum amounts of energy are also produced in late spring, when New York experiences its lowest annual loads. The annual maximum percent of load met by PV, then, is not reduced much for a flat-mounted array.

The capacity penetration and energy penetration show more significant reductions (about $19 \%$ and $16 \%$, respectively). Capacity penetration is calculated by dividing the annual peak PV power generation by the annual peak network load (noncoincident). Although the annual peak network load has not changed, the annual peak PV power generation is reduced at a $0^{\circ}$ tilt angle. (Optimum tilt angles for the New York area vary between $25.8^{\circ}$ and $55.8^{\circ}$, depending on the season in which you want maximum PV generation.) Lower 
angles are better for summer generation, medium angles for spring and fall, and higher angles for winter production. A $0^{\circ}$ tilt angle is not optimum at any time of year. Energy penetration is calculated by dividing annual PV generation by annual energy consumption. Again, although energy consumption has not changed, the annual PV generation is reduced at this tilt angle. These lower values indicate that less energy will be exported over the course of the year. The effect of changing the PV array tilt angle is further shown in the graphs that follow.

Figure 1-B-1 shows how the PV generation curve changes when the tilt angle is adjusted to $0^{\circ}$. PV generation remains about the same in the summer (albeit with a slight decrease), but is reduced more in the spring and fall and significantly reduced in the winter. This is because a flat-mounted PV array will see the most direct sunlight during the summer, when the sun is highest in the sky. As the sun moves lower in the sky during the spring and fall, and reaches its lowest point in winter, the PV array will receive much less direct sunlight. Although it seems surprising that summer generation also decreases, this is explained by the tilt angle. An optimum tilt angle for summer production is about $15^{\circ}$ less than latitude, or $25.8^{\circ}$. Because the $0^{\circ}$ tilt is further from the optimum summer angle than the $40.8^{\circ}$ tilt, summer production is slightly reduced.

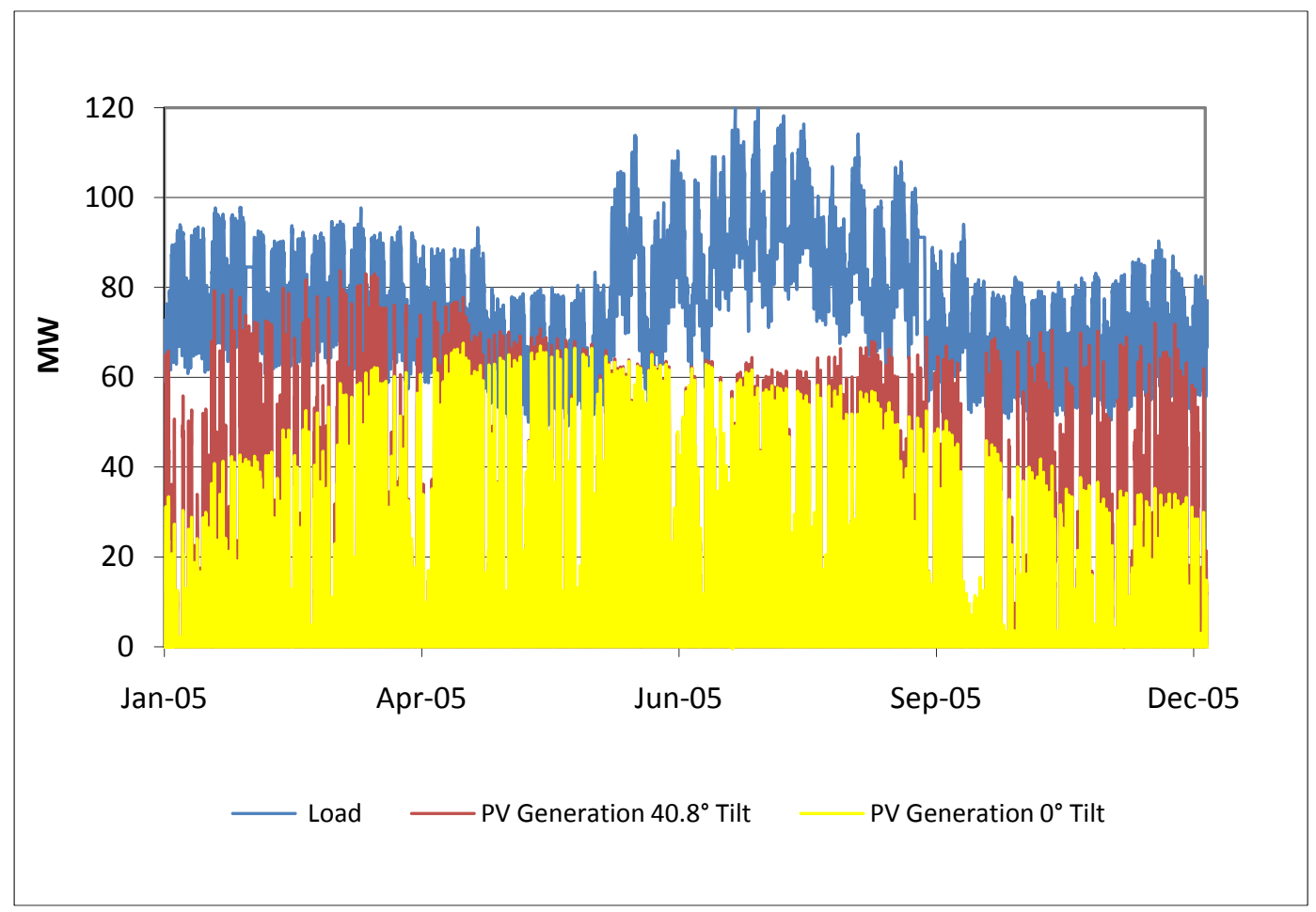

Figure 1-B-1. Central Bronx network load and PV generation under full deployment: Comparison of $40.8^{\circ}$ and $0^{\circ}$ tilt angles 
Figures 1-B-2 and 1-B-3 show the maximum export days under full PV deployment for $40.8^{\circ}$ and $0^{\circ}$ tilt angles. The jagged shape of the $0^{\circ}$ tilt angle curve, which is caused by partly cloudy conditions, demonstrates the intermittent nature of PV power. At a $40.8^{\circ}$ degree tilt, the maximum export day occurs closer to the spring solstice (on May 1). At a $0^{\circ}$ degree tilt, the maximum export day is May 29, closer to the summer solstice. In both cases, the load is reduced by about the same amount.

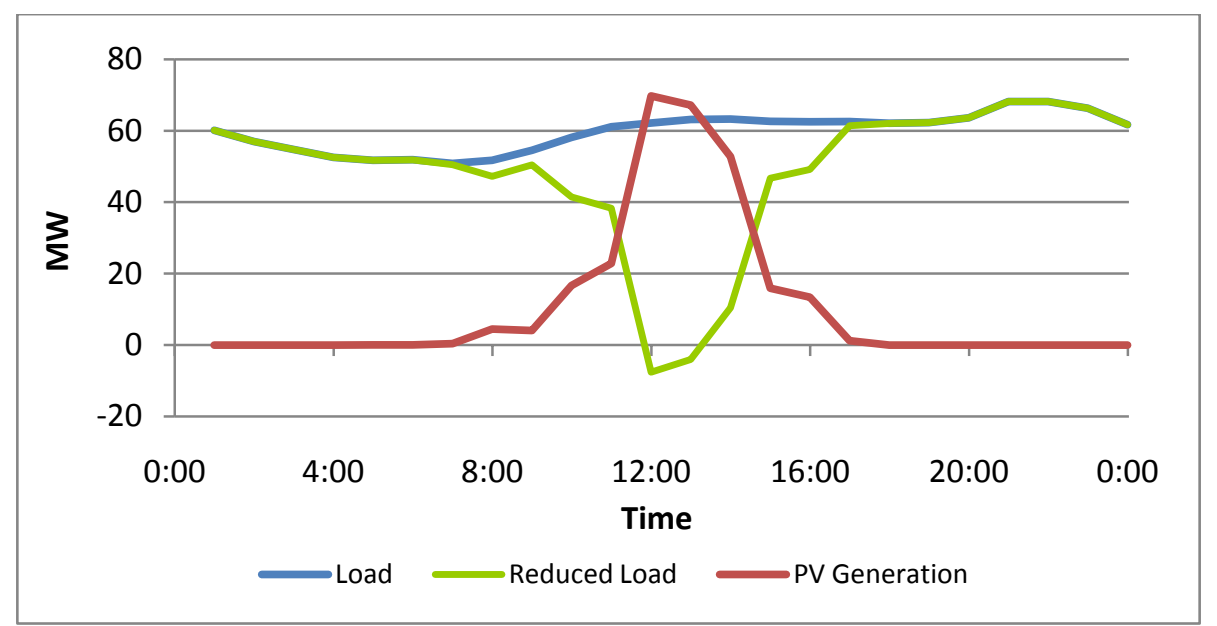

Figure 1-B-2. Maximum export day under full PV deployment: $40.8^{\circ}$ tilt angle (May 1)

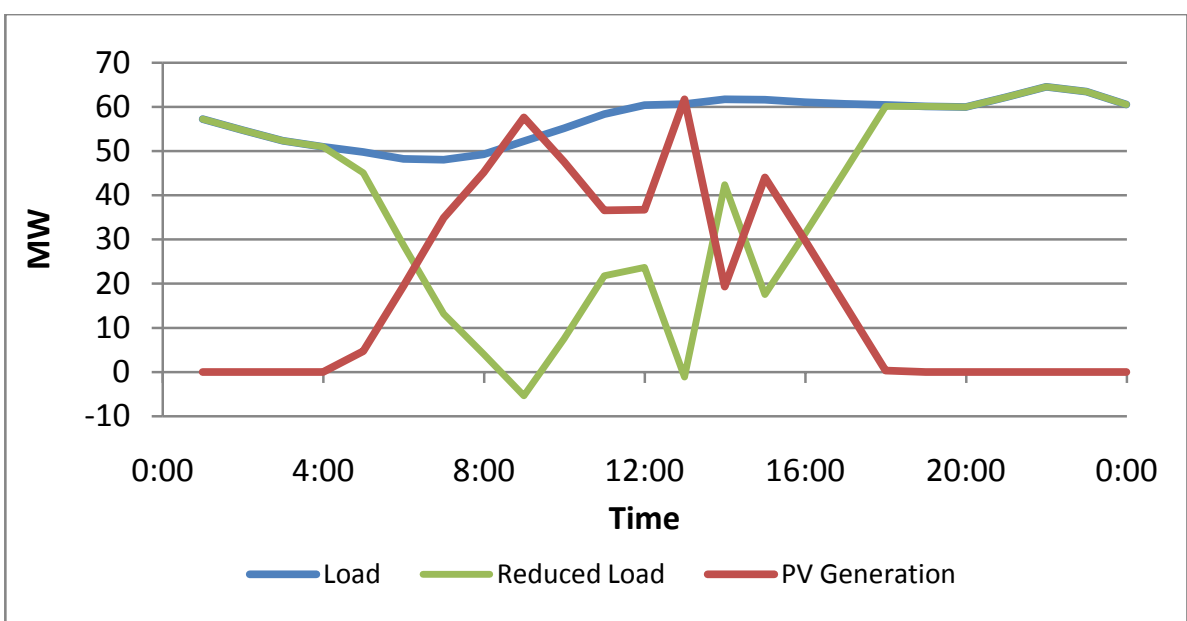

Figure 1-B-3. Maximum export day under full PV deployment: $0^{\circ}$ tilt angle (May 29) 
Figures 1-B-4 and 1-B-5 compare the load-duration curves for $40.8^{\circ}$ and $0^{\circ}$ tilt angles. The full 8760-hour curve shows that changing the tilt angle from $40.8^{\circ}$ and $0^{\circ}$ results in 43 fewer net exporting hours. Therefore, a slightly higher percentage of full deployment can be reached before a net export of energy occurs. The curve of the top 100 hours shows that PV arrays tilted at $40.8^{\circ}$ and $0^{\circ}$ produce equal reductions in peak load.

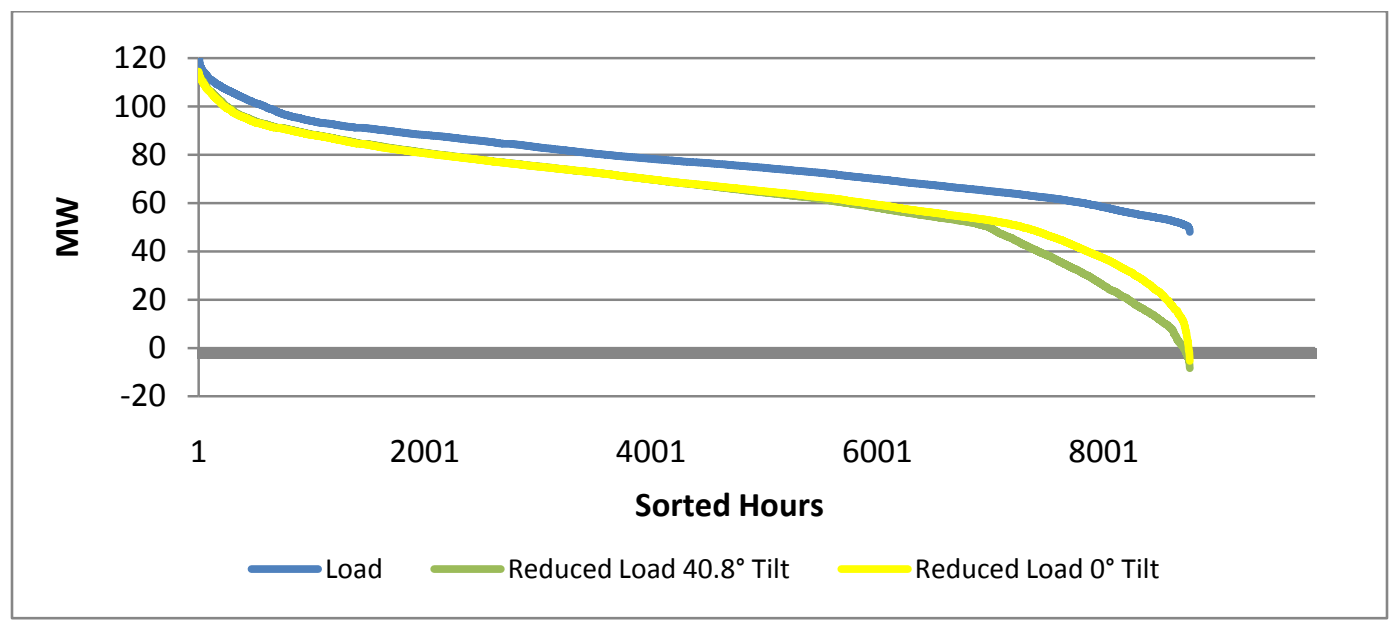

Note: Under full deployment, at $0^{\circ}$ tilt, there are 10 hours net exporting. To reduce exported hours to zero, limit deployment to $90.8 \%$ of full deployment $(68.23 \mathrm{MW})$. At $40^{\circ}$ tilt, there are 53 hours net exporting.

To reduce exported hours to zero, limit deployment to $89.12 \%$ of full deployment (67.06 MW).

Figure 1-B-4. 8760-hour load-duration curve: Comparison of $0^{\circ}$ and $40.8^{\circ}$ tilt angles

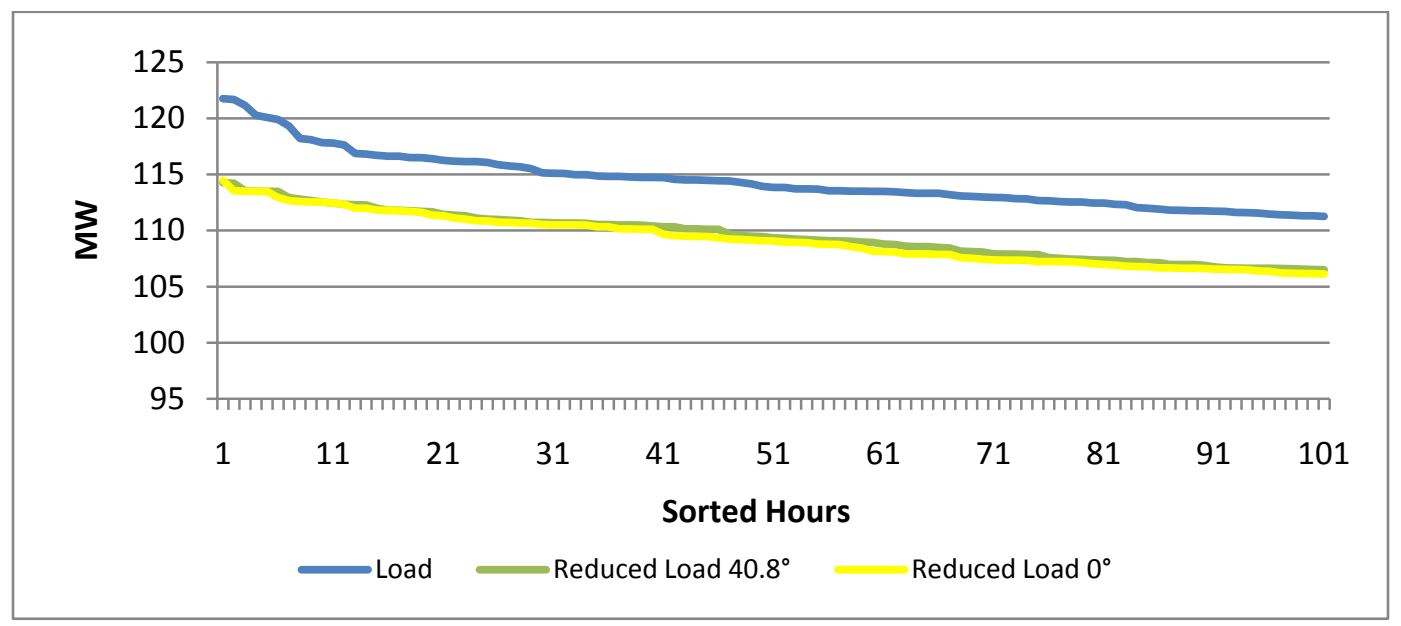

Figure 1-B-5. Top-100-hour load-duration curve: Comparison of $0^{\circ}$ and $40.8^{\circ}$ tilt angles 
Figures 1-B-6 through 1-B-11 give more details on how much net energy is exported to the grid and when, for PV arrays at $40.8^{\circ}$ and $0^{\circ}$ tilt angles.

Figures 1-B-6 and 1-B-7 show that reducing the tilt angle from $40.8^{\circ}$ to $0^{\circ}$ significantly reduces net exporting energy at all times of day, with the greatest reductions seen between 10 a.m. and 1 p.m..

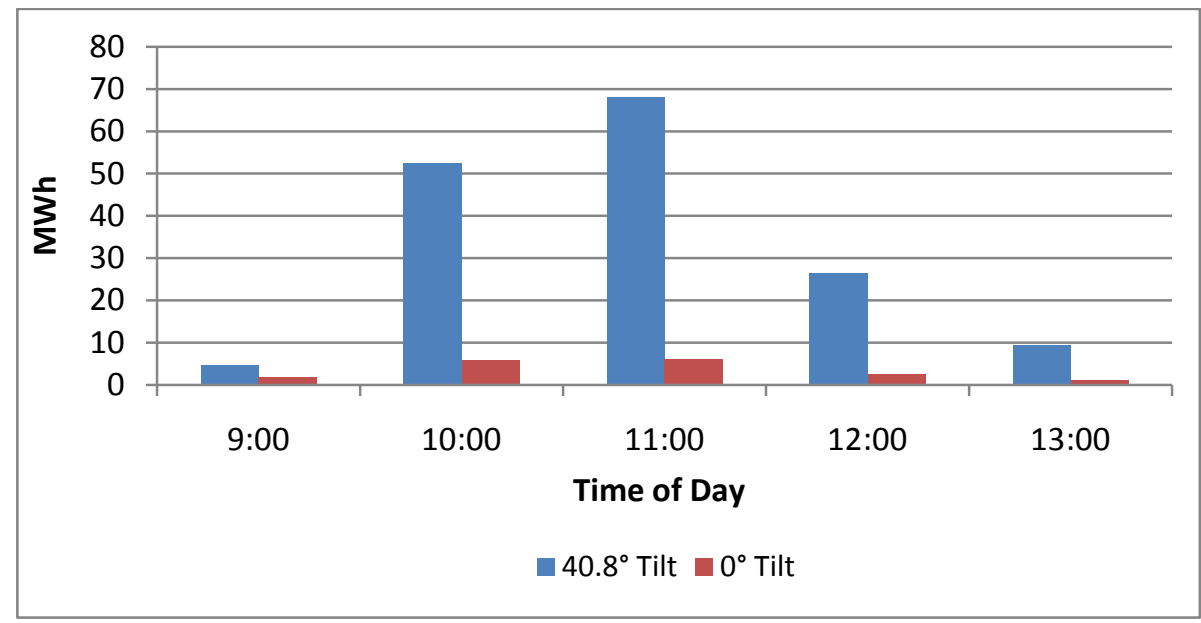

Figure 1-B-6. Amount of energy exported by time of day: Comparison of $40.8^{\circ}$ and $0^{\circ}$ tilt angles

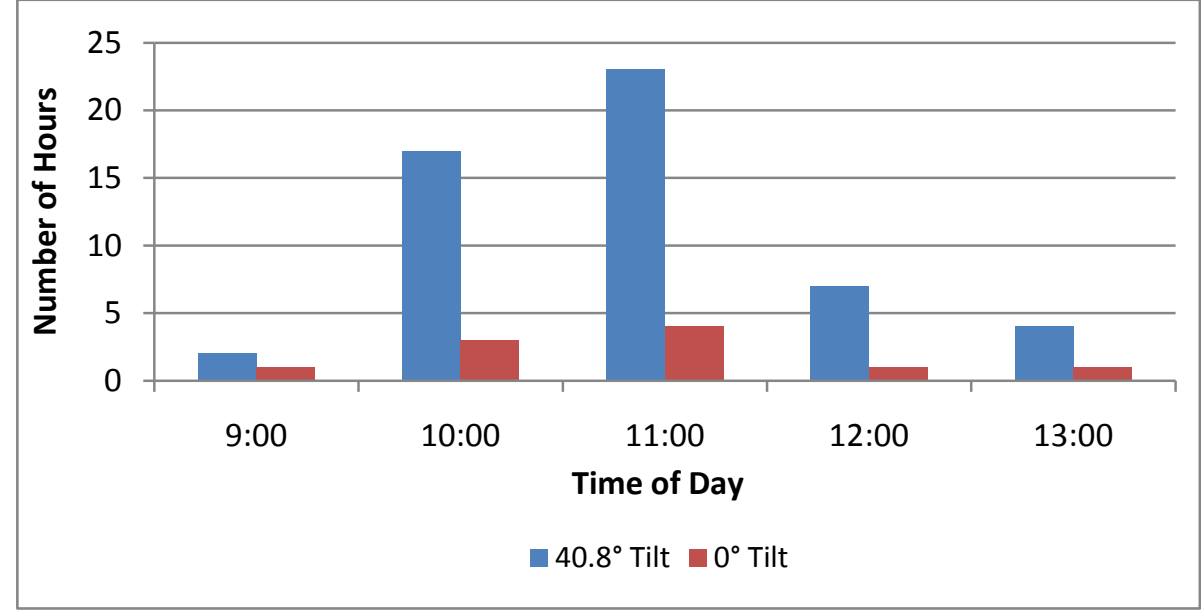

Figure 1-B-7. Number of hours of energy exported by time of day: Comparison of $40.8^{\circ}$ and $0^{\circ}$ tilt angles 
Figures 1-B-8 and 1-B-9 show that reducing the tilt angle from $40.8^{\circ}$ to $0^{\circ}$ significantly reduces net exporting energy throughout the week.

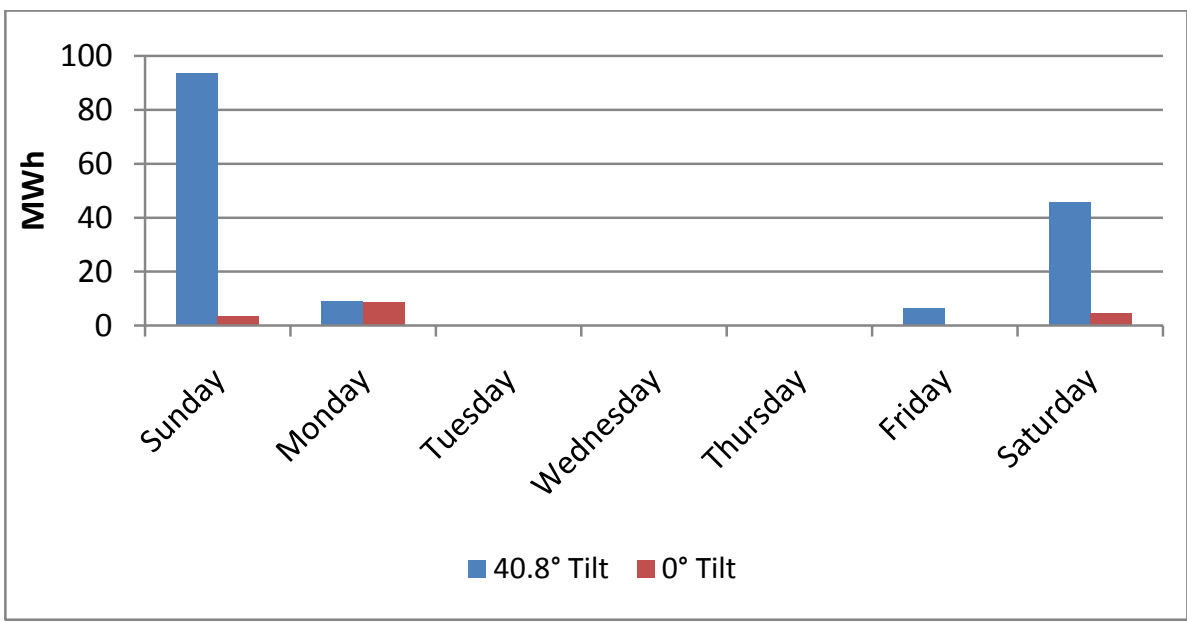

Figure 1-B-8. Amount of energy exported by day of week: Comparison of $40.8^{\circ}$ and $0^{\circ}$ tilt angles

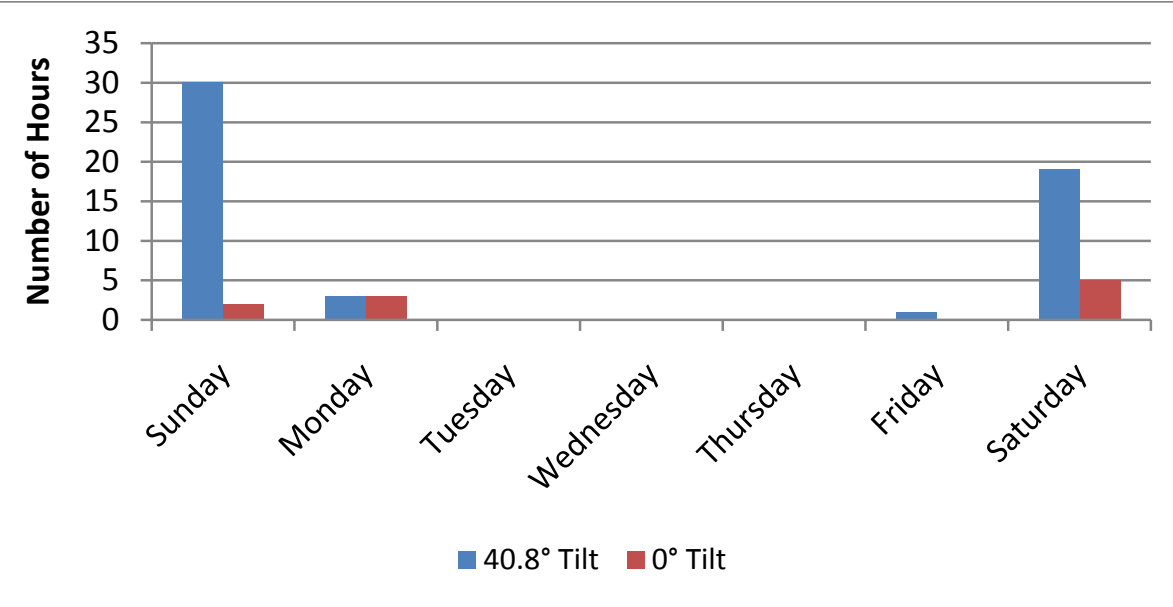

Figure 1-B-9. Number of hours of energy exported by day of week: Comparison of $40.8^{\circ}$ and $0^{\circ}$ tilt angles 
Figures 1-B-10 and 1-B-11 show that reducing the tilt angle from $40.8^{\circ}$ to $0^{\circ}$ significantly reduces the amount of energy exported and the number of hours of energy exported throughout the year. It also changes the monthly distribution of exporting energy. PV arrays tilted at $40.8^{\circ}$ have two peaks (a higher one in spring and a lower one in fall). PV arrays tilted at $0^{\circ}$ show one peak in late spring/early summer.

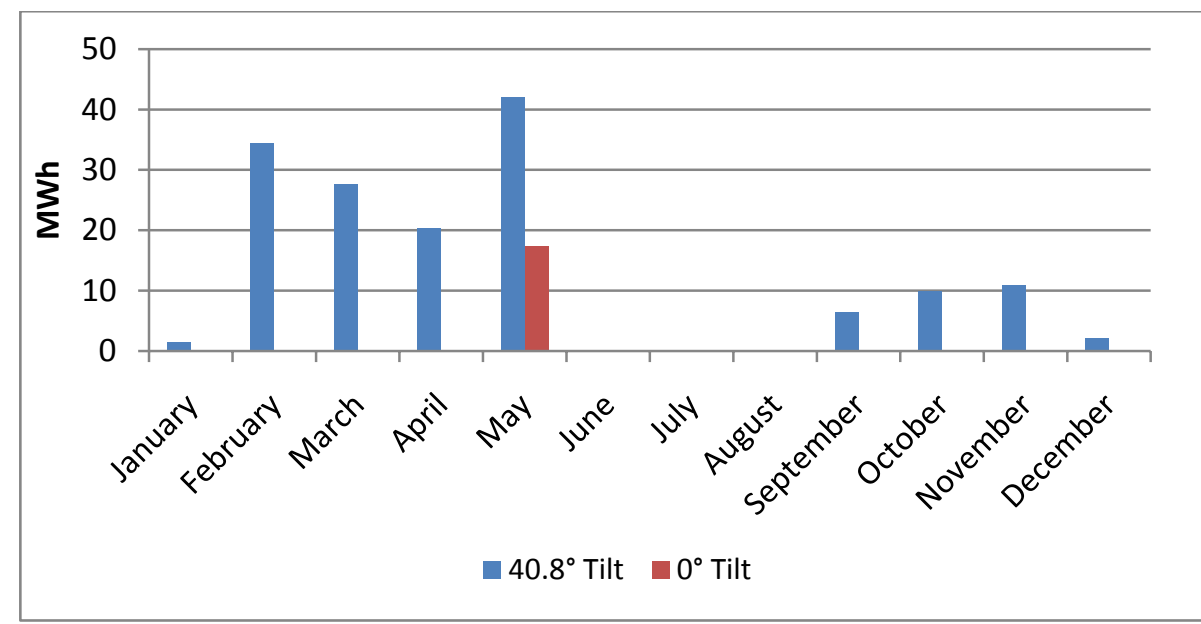

Figure 1-B-10. Amount of energy exported by month: Comparison of $40.8^{\circ}$ and $0^{\circ}$ tilt angles

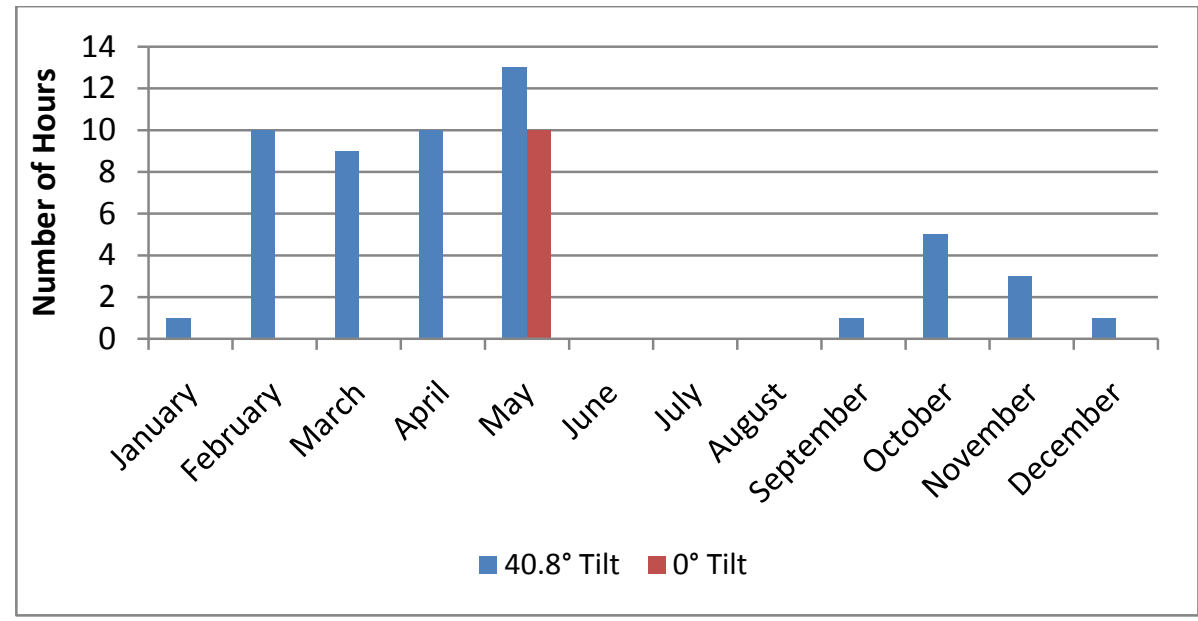

Figure 1-B-11. Number of hours of energy exported by month: Comparison of $40.8^{\circ}$ and $0^{\circ}$ tilt angles 


\section{Appendix 1-C: Individual Building Analysis}

We carried out the New York City PV deployment analysis at the macro level, comparing total loads and total PV generation across entire networks. This results in an estimate of net energy exported from the network, but utility operations require a more detailed understanding of energy exported at the individual building level.

To paint a better picture of which building types are most likely (or least likely) to export energy, we analyzed four types of buildings. Con Edison furnished four specific buildings in the New York area for this analysis: a primary school, a mid-rise apartment building, a stand-alone retail store, and a warehouse building. We used IMBY to estimate hourly annual PV generation for each building.

As in the overall network analysis, the rooftops were covered to the maximum extent possible. We estimated the load of each building based on NREL's benchmark buildings, which represent new commercial buildings meeting minimum ASHRAE 90.1-2004 standards. We used DOE's EnergyPlus whole-building annual simulation software to estimate load for each building type considered. ${ }^{6}$ Building size and climate zone were taken into account.

The analysis for each building type is described in the following sections.

\section{C.1 Primary School}

As shown in Figure 1-C-1, rooftop equipment on the school limits the space available for PV. The maximum PV system size would be $9 \mathrm{~kW}$. PV generation would be insignificant compared to the load (see Figure 1-C-2), and energy would never export to the grid.

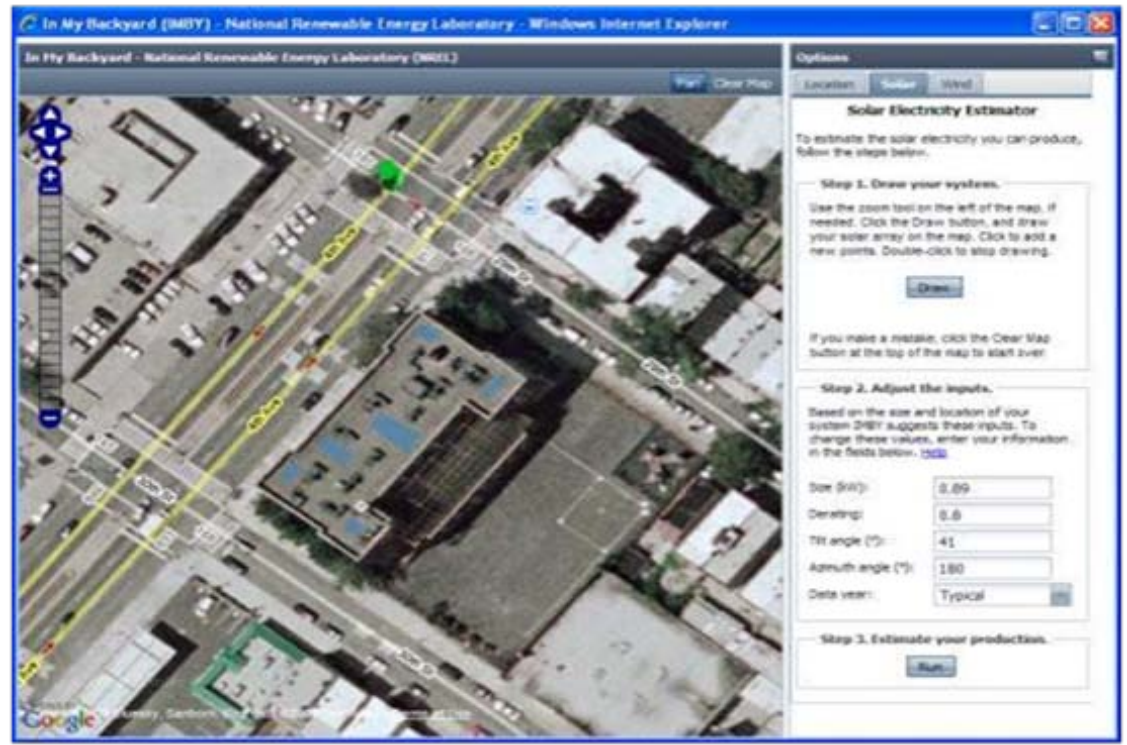

Figure 1-C-1. School PV system

\footnotetext{
${ }^{6}$ For more information on EnergyPlus, see http://apps1.eere.energy.gov/buildings/energyplus/.
} 


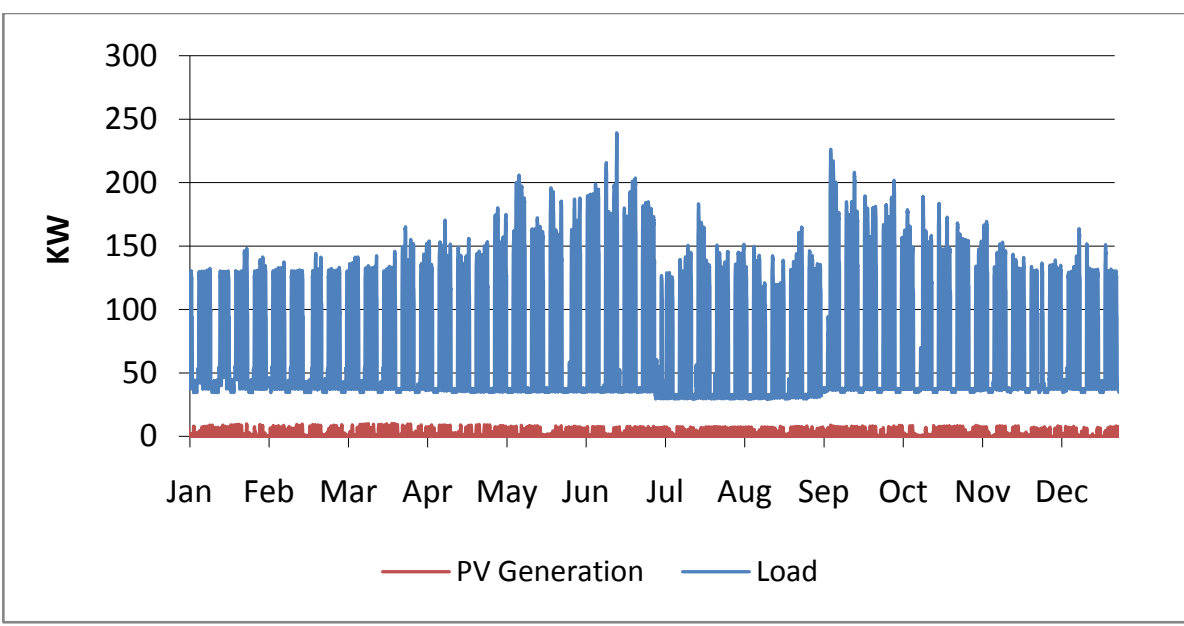

Figure 1-C-2. School load and PV generation (space limited by rooftop equipment)

If rooftop equipment did not limit space available for $\mathrm{PV}$, the entire roof could be covered with a 46-kW PV system, and PV generation would exceed loads at times - most commonly on the weekends (see Figure 1-C-3).

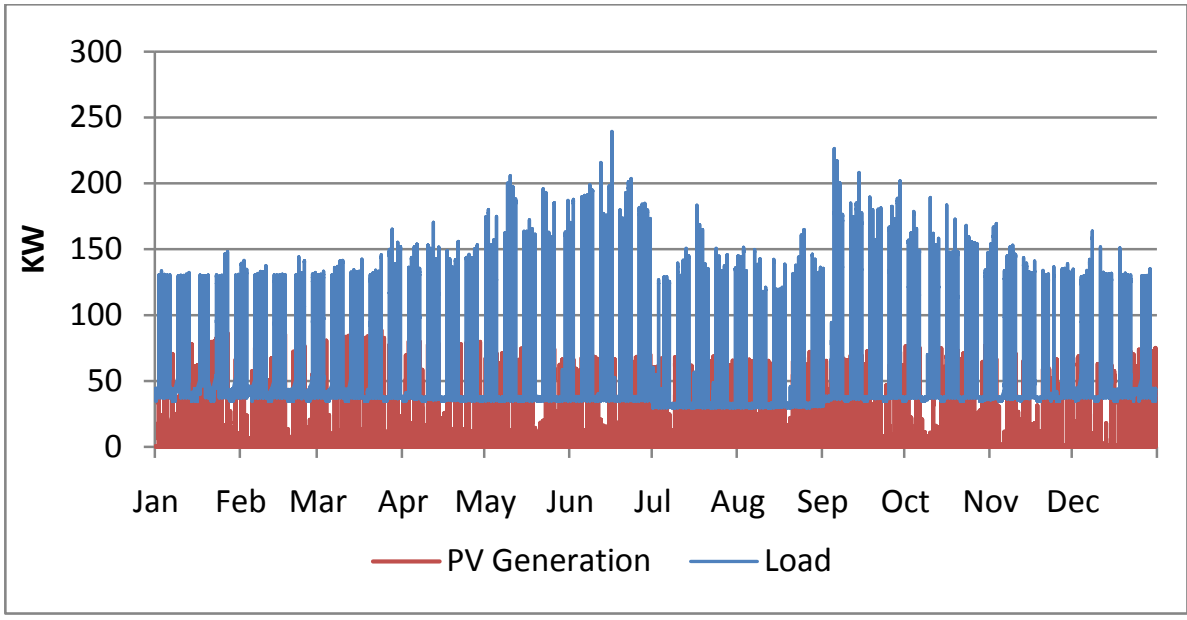

Figure 1-C-3. School load and PV generation (space not limited by rooftop equipment) 


\section{C.2 Mid-Rise Apartment Building}

Here, almost all roof space is available for PV, with room for a $64-\mathrm{kW}$ system (see Figure 1-C-4). Although loads exceed PV generation most of the time, energy would be exported for 154 hours during the year (see Figure 1-C-5).

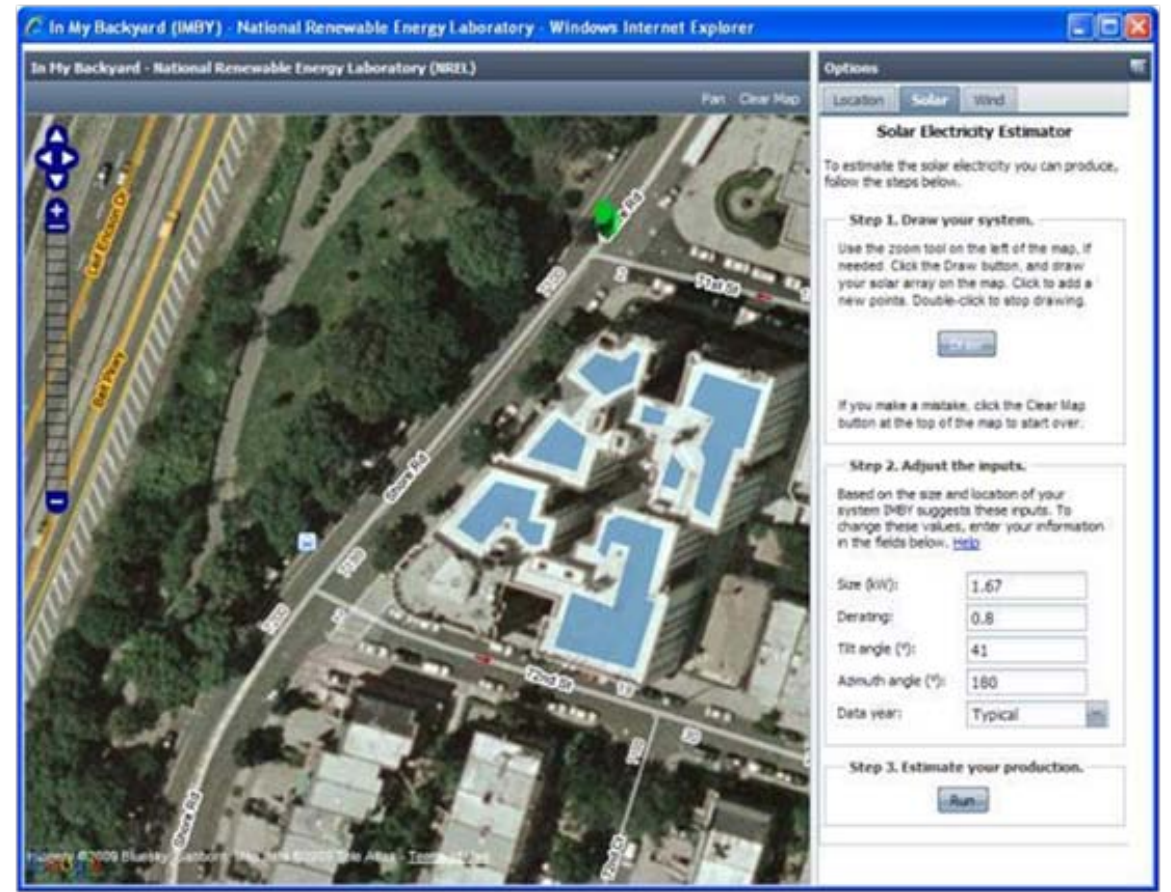

Figure 1-C-4. Apartment PV system

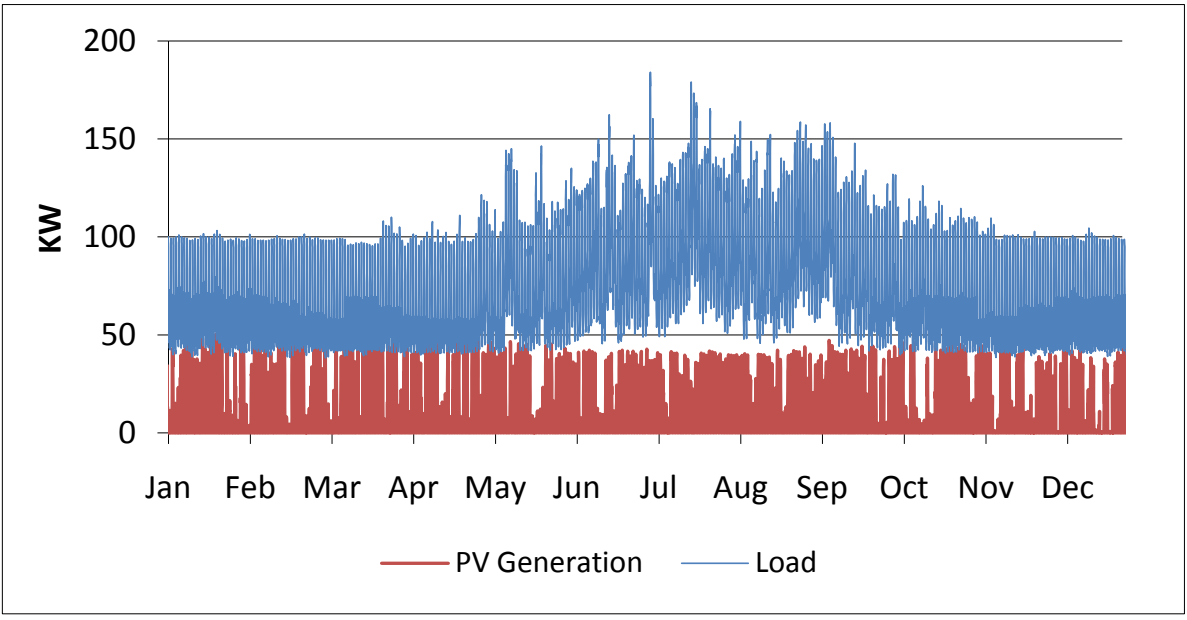

Figure 1-C-5. Apartment load and PV generation 


\section{C.3 Stand-Alone Retail Store}

About half of the roof space on this retail store is available for PV, with room for a 567kW system as shown in Figure 1-C-6. PV generation would exceed load during all months of the year, most significantly in spring, fall, and winter (see Figure 1-C-7).

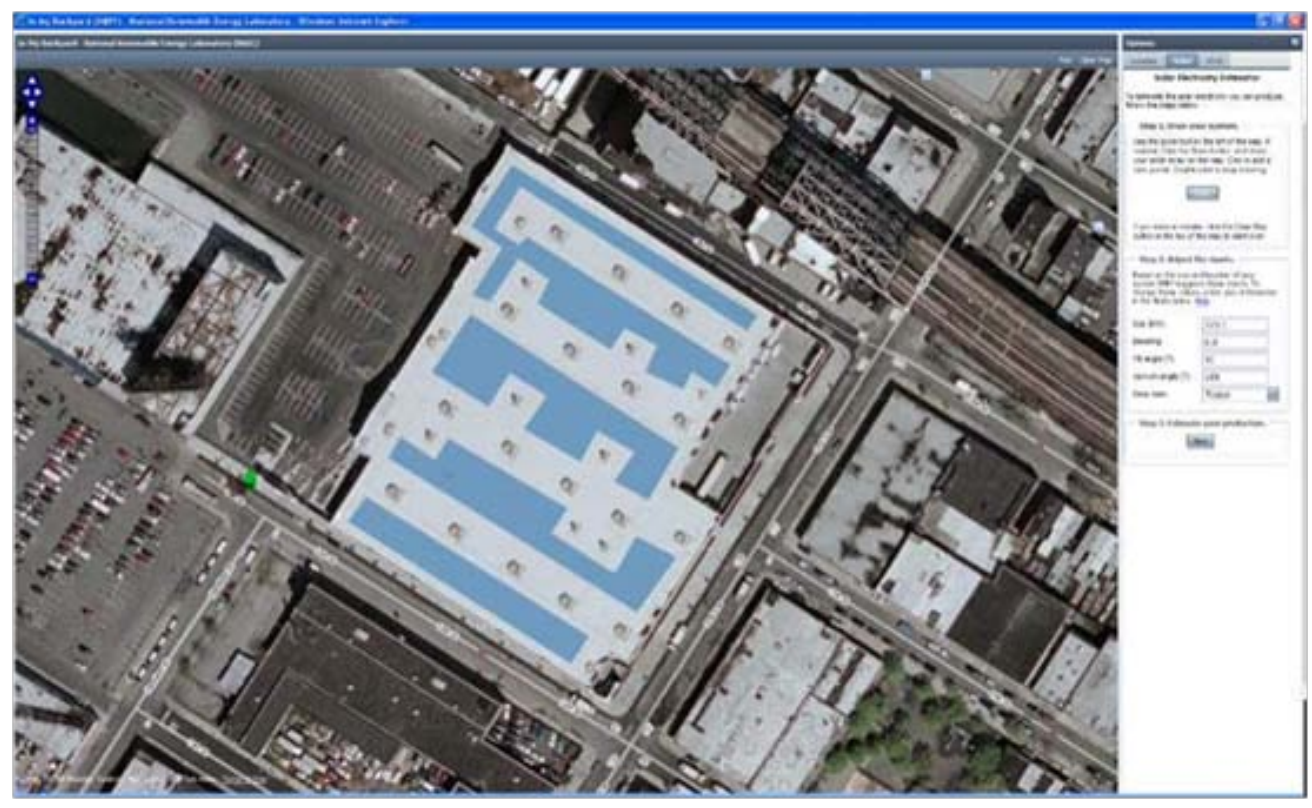

Figure 1-C-6. Retail store PV system

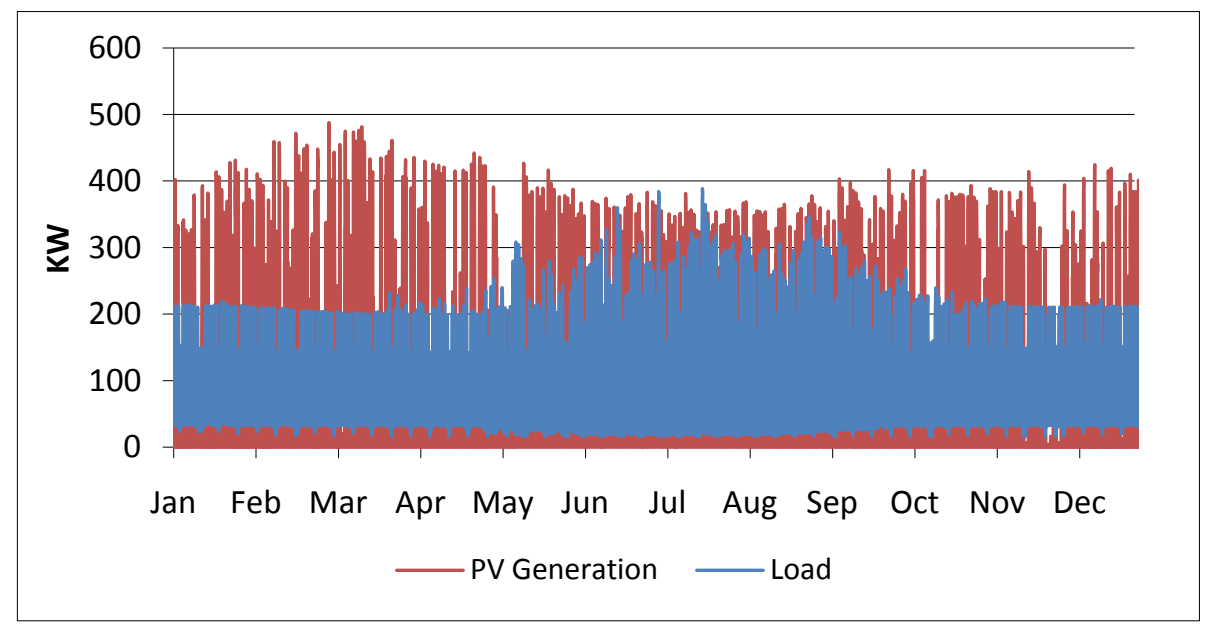

Figure 1-C-7. Retail store load and PV generation 


\section{C.4 Warehouse Building}

All the roof space on this warehouse is available for PV, with room for a $118-\mathrm{kW}$ system as shown in Figure 1-C-8. PV generation would significantly exceed load throughout the year (see Figure 1-C-9).

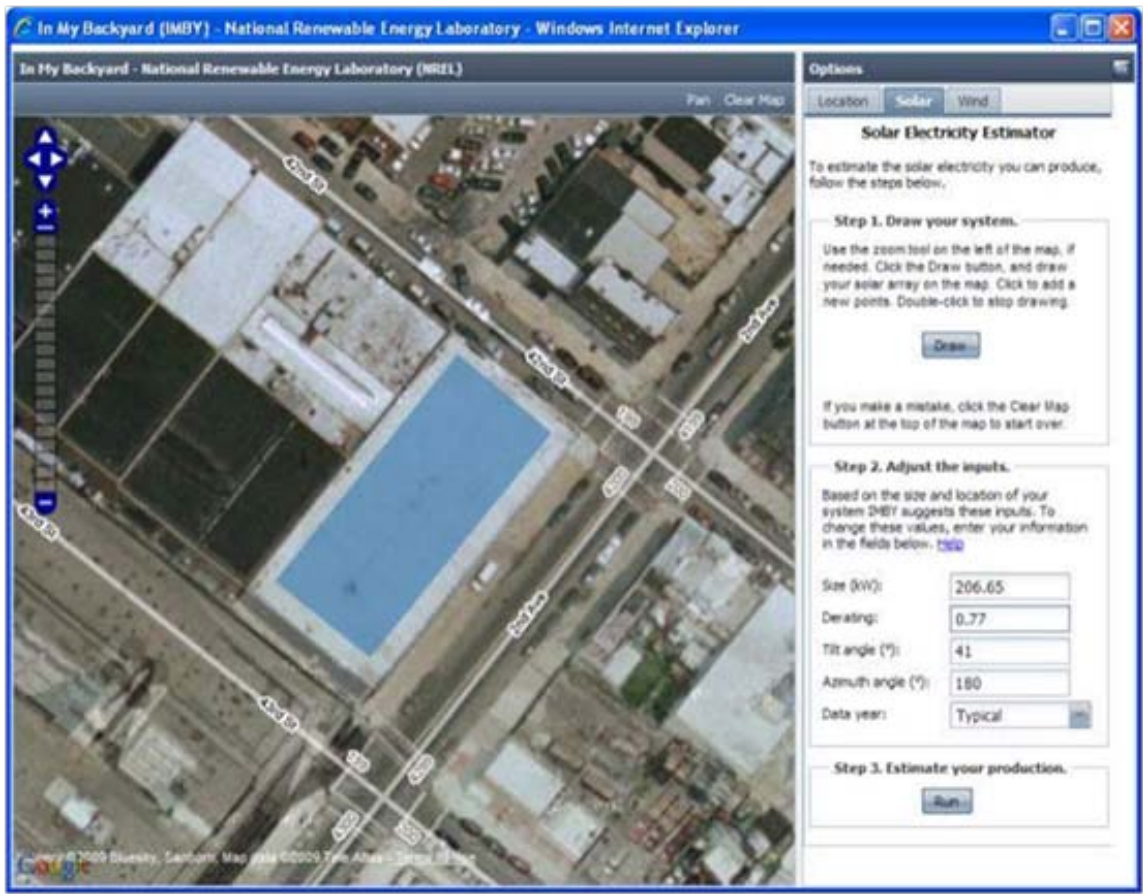

Figure 1-C-8. Warehouse PV system

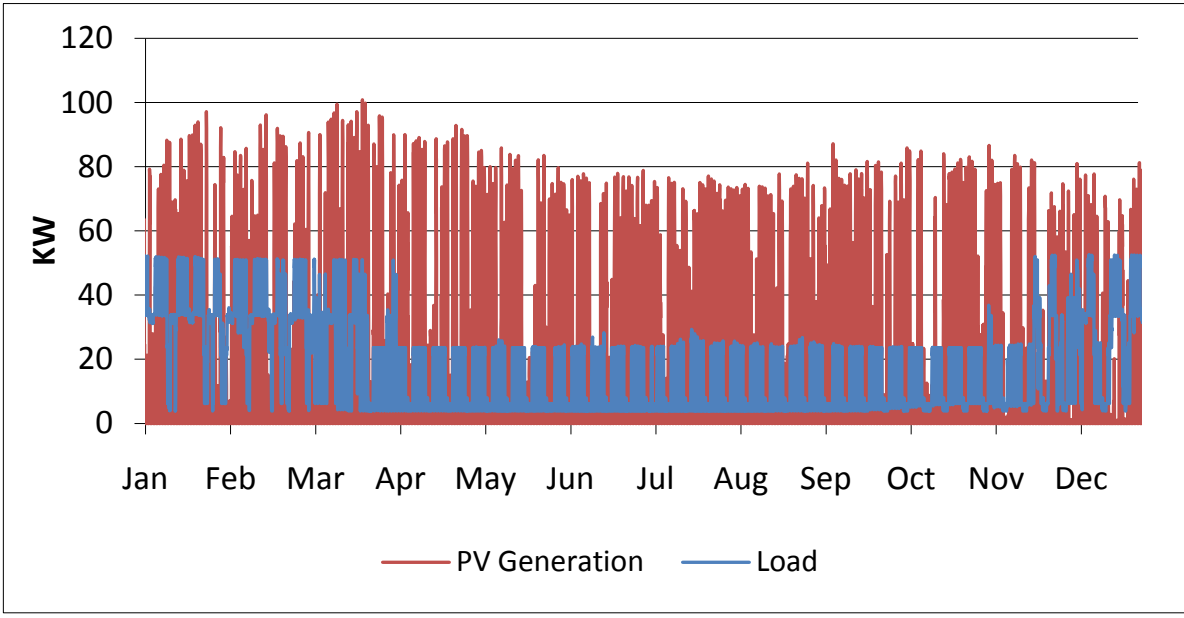

Figure 1-C-9. Warehouse load and PV generation 


\section{C.5 Conclusion}

Our analysis of these four buildings identifies the energy-exporting potential of the individual buildings studied, but it is insufficient for drawing conclusions about the energy-exporting potential of the broader building types. We recommend further analysis to identify whether certain building types are likely to export (or not export) energy. This information would assist Con Edison in evaluating interconnection applications for these building types. 


\subsection{A Briefing for Policy Makers on Connecting PV to a Network Grid}

This section is designed to educate urban planners and policy makers on the technical issues utilities face when interconnecting distributed photovoltaic (PV) systems to networks. The main technical concerns - network protector operation and cycling, load forecasting and planning, fault currents, reactive power requirements, harmonics, voltage flicker, voltage sag, and unintentional islands - are described, along with possible solutions. 


\section{Contents}

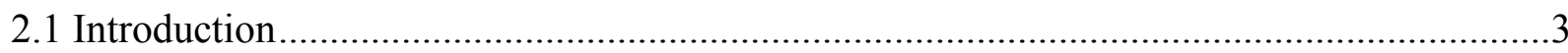

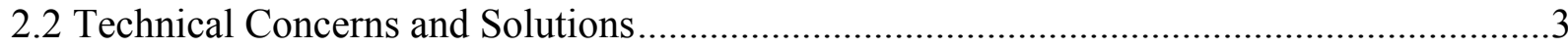

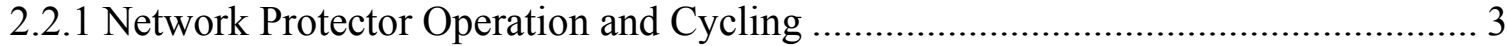

2.2.2 Load Forecasting and Planning Challenges ..................................................... 5

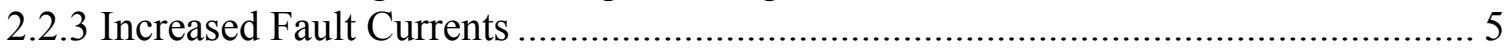

2.2.4 Increased Reactive Power Requirements..................................................... 6

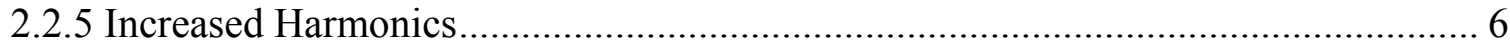

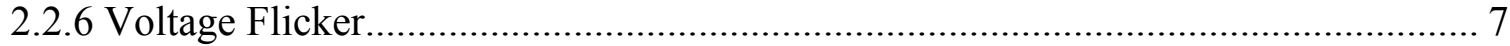

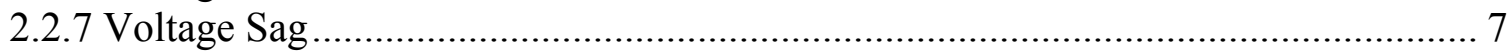

2.2.8 Impacts of Other Distributed Generation Systems on PV ................................... 7

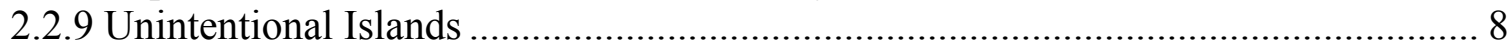

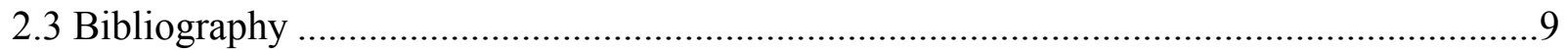




\subsection{Introduction}

Traditionally, energy is generated at large, centralized power plants. These power plants are connected to the transmission system, which carries energy over long distances and at high voltages from power plants to substations. From the substations, electricity moves on to individual customers through the distribution system, which operates over shorter distances and at lower voltages. Although most power is connected to the transmission system, small customer-sited generators can be connected to the distribution system (called "distributed generation"). Today, this includes a growing number of PV systems.

There are two main types of electrical distribution systems: radial and network. Most areas of the United States use simpler radial distribution systems to distribute electricity, but larger metropolitan areas like New York City typically use more complicated networks to increase reliability in large load centers. Unlike the radial distribution system, where each customer receives power through a single feeder and single transformer, a network delivers power to each customer through several parallel feeders and transformers. This redundancy improves reliability because the loss of a single line or transformer will not interrupt the power supply.

Networks use coordination and protection schemes that are based on the assumption that power flows in one direction - from the utility substation to the customer. With traditional power plants, this is true. When power sources like PV are connected to the distribution system at the customer's site, however, power can flow in the opposite direction - from the customer toward the utility substation. This can disrupt network protection schemes and threaten network reliability.

Although there are risks inherent in interconnecting PV systems to networks, there are benefits as well. Demand in New York City is increasing, and PV-generated electricity can help meet this demand and possibly reduce the capital costs associated with new conventional power plants. There is also the possibility for distributed PV systems to reduce distribution system requirements (if load forecasting and planning challenges are addressed) because they are located at the load. This is particularly important in New York City, where the distribution system is entirely underground. The existing system is costly to maintain, and space for new equipment is limited.

This briefing summarizes the main technical concerns associated with connecting distributed PV systems to networks and presents possible solutions to alleviate these problems.

\subsection{Technical Concerns and Solutions}

\subsubsection{Network Protector Operation and Cycling}

Networks are designed for power flow in one direction (from the utility's substation to the customer). Power flow in the reverse direction (called "reverse power flow") is indicative of an upstream supply feeder fault. Network protectors are designed to sense reverse power flow and physically disconnect the faulted supply feeder. This immediately isolates the fault, prevents equipment damage, and allows technicians to quickly repair 
and restore service. Network protectors are critical to maintaining robust network reliability.

Network-connected PV systems can upset this standard network protection scheme. When a PV system connected to the network at a customer's home or business generates more power than the customer can use, for example, the excess power is fed back into the network and produces reverse power flow. This causes network protectors to open unnecessarily and leads to wear on the equipment.

Network protectors are also responsible for reconnecting the faulted section once the fault has been cleared. They do this by sensing when power flow is in the correct direction (from the utility toward the customer). But when the network protector opens, the direction of the load flow changes. If the open network protector senses that power is flowing in the correct direction, it closes. When the network protector closes, the load flows will change again and the PV power could cause the network protector to open again. Repeated opening and closing of the network protector can eventually cause network protector failure.

\subsubsection{Solutions}

The simplest way to prevent unnecessary network protector operation is to ensure that PV systems do not export energy to the network, thus never producing reverse power flow. This can be accomplished in several ways. First, the customer can be required to maintain a minimum load at all times, to make sure that they are always drawing power from the network. Second, a minimum import relay (MIR) can be installed to trip the PV system offline if the customer load drops below a predetermined level. Third, a reverse power relay (RPR) can be installed. Similar to an MIR, an RPR trips the PV system offline if the customer load drops to zero or if the PV system begins to export power. Fourth, a dynamically controlled inverter (DCI) can monitor the load and curtail PV system output if the customer load drops below a predetermined level.

If PV systems are allowed to export to the network, a short-term solution is adjusting network protector settings to be less sensitive to reverse power flow. The network protectors can be set in a time-delayed mode, where they do not open immediately for low levels of reverse power (instead, they might wait two and a half minutes, and then open if the power is still flowing in the reverse direction). They can also be set to an insensitive mode where they do not trip at all for low levels of reverse power. In both cases, though, they still trip immediately for high levels of reverse power. Although an insensitive mode setting would necessitate fewer network protector operations, it could also result in network protectors not opening when they need to, leading to equipment damage, additional restoration time, and overall reduced system reliability at high PV penetrations.

At high PV penetration levels, utilities will need the ability to monitor, exchange information with, and control network protectors and PV systems. This will allow them to adjust network protector settings to allow reverse power, or to curtail PV production at times to reduce reverse power flow. These functions could be part of future smart grid technologies, but are not available in current utility systems. 


\subsubsection{Load Forecasting and Planning Challenges}

When PV systems supply part of a customer's energy needs, the load profile seen by the network changes. The difference between minimum and maximum load increases as daytime loads drop and nighttime loads remain the same. The variability of the load also increases because PV production is highly weather-dependent, and can drop off suddenly when clouds pass over. At low levels of penetration, these changes are not noticeable at the network level, but at high penetrations the utility will need to adjust generation from conventional power sources to meet these new load profiles. Conventional sources will have to be more flexible to quickly pick up the load when PV production drops off. Some conventional generation sources must be operated at a minimum load, and cannot be stopped and started quickly (i.e., coal-fired power plants). More flexible sources (natural gas) tend to be more expensive. The additional flexibility required to accommodate high PV penetrations can lead to higher generation costs.

\subsubsection{Solutions}

Utility operators can cope with load forecasting and planning challenges in a number of ways. The first solution should be to integrate renewable energy supply into the planning process and consider it during energy growth forecasting. Variable renewable generation should be viewed as a part of the load, and the variability should be characterized to ensure that the conventional generation portfolio has enough flexibility to cope with increased variability. This will allow for realistic plans for conventional generation and reasonable estimates of system operating costs.

As the penetration of renewable generation increases, conventional generation may no longer be flexible enough to handle the variability of renewable generation, and additional flexibility may be too expensive. In this case, variability can be reduced by controlling or shifting loads, using energy storage, and curtailing renewable generation sources.

Adjustments to the siting of renewable generation might also be able to reduce variability. Spreading renewable generation over a larger area can reduce the impact of passing clouds (although for a region as small as New York City, this may not be an effective strategy). Varying the orientation of PV panels (so some face east, some south, some west) will disperse maximum power production across the day (rather than concentrating it at midday if all were facing south), producing a more even load profile.

\subsubsection{Increased Fault Currents}

Network protective equipment (breakers and fuses) and substation equipment is designed to withstand a certain level of fault current. Adding additional sources of energy, like a PV system, can increase the level of available fault current beyond the equipment ratings, to the point where network protective devices will fail to protect the system from fault currents. This can result in catastrophic equipment failures that can threaten public safety. Additional sources of supply can also change the direction of fault current flows or add new flows, disrupting the coordination of protective devices. 


\subsubsection{Solutions}

Compared to other distributed generation sources, PV systems generate very little fault current. Because they are inverter-based, they typically can generate only twice the rated current for a short time. Synchronous generators, on the other hand, typically generate six to ten times their normal rating in fault current. Furthermore, PV systems are required by IEEE standards (see Bibliography) to drop offline quickly (within 0.16 seconds, or 6 cycles) in the event of a fault, which limits the amount of time in which they can inject any fault current. For these reasons, PV systems are not expected to contribute significantly to fault currents.

If increased fault current levels remain a concern, they can be mitigated by upgrading distribution system equipment to accommodate higher operation at fault levels (an expensive solution) or using fault mitigation controls ${ }^{1}$ to disconnect a PV system if it begins to supply current to a fault condition. Concerns about the coordination of protective devices can be addressed through utility short-circuit studies, which would determine if the PV system could potentially disrupt coordination. If the potential exists, the utility could modify the coordination scheme. Another solution is to set the PV inverters to monitor high-current conditions and automatically scale back their current when a spike in current over time is detected. Although they are not currently available, future smart grid systems will allow better coordination of relaying and protection schemes through communication with the PV system.

\subsubsection{Increased Reactive Power Requirements}

Electrical power is made up of real power (measured in watts) and reactive power (measured in volt-ampere reactive [VAR]). Most loads use both real and reactive power. IEEE standards (see Bibliography), however, require PV system inverters to produce only real power. This means other power generators will have to supply a higher percentage of reactive power.

\subsubsection{Solutions}

Capacitors can be installed to supply reactive power to inductive loads. They can be installed at the customer's site, or utilities can install them at feeders or substations. As the PV penetration increases, PV inverters may need to supply VARs.

\subsubsection{Increased Harmonics}

PV systems could reduce power quality by inducing harmonic distortion in the system, which could adversely affect operation of motors and electronics. Harmonics also cause undesirable heating in transformers and cables. This can cause circuit-breaker tripping, overvoltage problems, incandescent light blinking, and computer malfunctions.

\subsubsection{Solutions}

The inverters used in modern PV systems are required to meet minimum power quality standards and do not induce harmonic distortion. Future PV inverters might have the

\footnotetext{
${ }^{1}$ Fault current mitigation would be defined by the utility on a case by case basis but generally requires that the protection interrupt the fault current contribution within half a cycle.
} 
capability to actually improve the harmonics at the load by actively canceling load harmonics.

\subsubsection{Voltage Flicker}

Voltage flicker can occur when PV system output increases or decreases (in response to passing clouds, for example) faster than the remaining generators can compensate. This leads to voltage excursions that can become noticeable to customers as light flicker or variable motor speed performance. These variations can also wear down equipment that attempts to hold the voltage at a constant level.

\subsubsection{Solutions}

Voltage flicker can be reduced by adding storage systems that compensate for the variations in PV system output. Storage (like batteries) can be added to PV systems or to utility substations. PV systems can also be spatially distributed to reduce the impact of passing clouds. Although this might not be an effective solution for customer-sited generation, spatial distribution could be a consideration in utility-owned systems. Another solution would be to integrate cloud forecasting into future smart grid utility control systems, allowing the utility to predict PV output dips and to use voltage regulation methods to lessen the effects.

\subsubsection{Voltage Sag}

Current interconnection standards require PV systems to disconnect from the grid during grid faults. The sudden loss of PV generation can lead to unacceptably low voltages in parts of the system and subsequent increases in apparent load to the utility. This is less of a concern in secondary networks, which have numerous sources of power, although it could become more significant at very high PV penetration levels.

\subsubsection{Solutions}

In the short term, voltage sag issues can be mitigated by using energy storage systems and ensuring that utilities have adequate backup energy generation capacity that can be brought online quickly to make up the lost voltage while PV systems are offline. A better long-term solution is to allow PV systems to stay online during voltage sags caused by temporary faults, and to help restore the voltage after the fault is cleared. This is known as "fault ride-through capability." Adding this capability will require changes to existing interconnection standards for distributed generation and to current anti-islanding protection schemes.

\subsubsection{Impacts of Other Distribution System-Connected Equipment on PV}

Other distribution system-connected equipment, such as lighting ballasts, arc welding equipment, synchronous generators, or induction generators, could induce harmonics, high voltage, reduced voltage, and variations in frequency, noise, or surges in the local distribution system. These events could force the PV system to drop offline. The loss of the PV systems in the area could further exacerbate the voltage level and quality of the local distribution system. 


\subsubsection{Solutions}

A utility power quality expert can monitor power quality to determine if any of these issues exist. These aberrations might not be significant enough to cause any adverse operating condition for a PV system or the electric utility secondary network. If they are significant, though, operators must locate the source of the harmonics, abnormal voltages, and variations in frequency and eliminate the problem.

A second solution, similar to the solution for voltage sag, is to allow inverters to stay online through temporary aberrations like bumps or voltage dips. Again, this will require alternative methods of unintentional island protection and is unlikely to be implemented in the near future.

\subsubsection{Unintentional Islands}

Unintentional islands (which can be established when a network protector opens and isolates a section of the power system with an energy source) pose a threat to proper utility system operation for a number of reasons:

1. The upstream utility system might attempt to reclose into the island under unsuitable conditions, which can damage switchgear, power generation equipment, and customer loads.

2. An unintentional island can increase public exposure to unsafe, energized downed conductors.

3. Line crews working on power restoration following storms or other events may encounter unintentional energized islands, making their job more hazardous and slowing down the power restoration process.

4. Unintentional islands do not usually have their generators set up with the proper controls to maintain adequate voltage and frequency conditions to the customer loads.

5. Unintentional islands can increase the likelihood of dangerous spikes or surges in the system.

Because of the dangers of unintentional islands, the IEEE 1547-2008 standard (see Bibliography) and utility interconnection guidelines require PV systems connecting to the network to have anti-islanding protection. Inverters are set to disconnect in the event that the network voltage or frequency goes outside of predefined limits. As a result, unintentional islands are not currently considered a significant concern at lower levels of PV penetration. Under high penetration levels, though, current anti-islanding techniques may not adequately detect island formation and disable it within a suitable amount of time. Furthermore, current anti-islanding techniques require PV systems to drop offline during temporary faults, contributing to voltage drop problems. Alternative anti-islanding protection methods that allow PV systems to stay connected during temporary faults are needed. 


\subsubsection{Solutions}

A power line carrier communications (PLCC) system could replace current anti-islanding techniques. A PLCC would send out a constant signal from the utility to PV systems (and other DG systems) on the actual utility distribution conductors. As long as the utilitysupplied signal is present, the PV system knows that the network is operating nominally, and stays connected. If the utility service is disconnected, the PLCC signal is lost at the PV system's end of the line, and the PV system will disconnect resulting in the PV system disconnecting in order to prevent an unintentional island. A PLCC system would allow voltage and frequency trip settings to be widened to better accommodate system variations and allow PV systems to stay connected during temporary faults or for lowvoltage ride through. Implementing PLCC will require development of a rugged, lowcost PLCC transmitter and a low-cost (and preferably noninvasive) means of ensuring reliable signal availability at all end points.

A second solution is to integrate PV inverters into utility supervisory control and data acquisition (SCADA) systems or advanced metering infrastructure (AMI) systems. Inverters could be tied into utility communications systems, which would issue a disconnect command to inverters in sections of the utility system isolated from the utility. And although they are not currently available, future smart grid systems should be designed to allow this type of control and through communication with the PV system.

\subsection{Bibliography}

Achilles, S.; Schramm, S.; Bebic, J. Transmission System Performance Analysis for High-Penetration Photovoltaics. NREL/SR-581-42300. Golden, CO: National Renewable Energy Laboratory (NREL), 2008.

Bebic, J. Power System Planning: Emerging Practices Suitable for Evaluating the Impact of High-Penetration Photovoltaics. NREL/SR-581-42297. Golden, CO: NREL, 2008.

Behnke, M.; Erdman, W.; Horgan, S.; Dawson, D.; Feero, W.; Soudi, F.; Smith, D.; Whitaker, C.; Kroposki, B. Secondary Network Distribution Systems Background and Issues Related to the Interconnection of Distributed Resources. NREL/TP-560-38079. Golden, CO: NREL, 2005.

Coddington, M.; Kroposki, B.; Basso, T.; Lynn, K.; Sammon, D.; Vaziri, M.; Yohn, T. Photovoltaic Systems Interconnected onto Secondary Network Distribution SystemsSuccess Stories. NREL/TP-550-45061. Golden, CO: NREL, 2009.

Edison Electric Institute (EEI). Edison Electric Institute Distributed Resources Task Force Interconnection Study. Washington: EEI, June 2000.

IEEE. The Authoritative Dictionary of IEEE Standards Terms. IEEE 100, Seventh Edition. New York City: IEEE, 2000. 
IEEE. Standard Conformance Test Procedures for Equipment Interconnecting Distributed Resources with Electric Power Systems. IEEE Std, 1547.1-2005. New York City: IEEE, 2005.

http://ieeexplore.ieee.org/xpl/standardstoc.jsp?isnumber=32033\&isYear=. Accessed October 3, 2009.

IEEE. Application Guide for IEEE Standard 1547, IEEE Standard for Interconnecting Distributed Resources with Electric Power Systems. IEEE P1547.2-2008. New York City: IEEE, 2009. http://ieeexplore.iee.org/servlet/opac?punumber=4816076. Accessed October 3, 2009.

IEEE. Standard for Interconnecting Distributed Resources with Electric Power Systems. IEEE Std. 1547-2003. New York City: IEEE, 2003.

http://grouper.ieee.org/groups/scc21/1547/1547_index.html. Accessed October 3, 2009.

Liu, E.; Bebic, J. Distribution System Voltage Performance Analysis for HighPenetration Photovoltaics. NREL/SR-581-42298. Golden, CO: NREL, 2008.

McGranaghan, M.; Ortmeyer, T.; Crudele, D.; Key, T.; Smith, J.; Barker, P. Renewable Systems Interconnection Study: Advanced Grid Planning and Operations. SAND20080944 P. Albuquerque, NM: Sandia National Laboratories (SNL), 2008.

Underwriters Laboratories, Inc. (UL). Inverters, Converters, Controllers and Interconnection System Equipment for Use with Distributed Energy Resources. UL 1741. Northbrook, IL: UL, 2007. http://ulstandardsinfonet.ul.com/scopes/1741.html. Accessed October 3, 2009.

Whitaker, C.; Newmiller, J.; Ropp, M.; Norris, B. Renewable Systems Interconnection Study: Distributed Photovoltaic Systems Design and Technology Requirements.

SAND2008-0946 P. Albuquerque, NM: SNL, 2008. 


\subsection{Technical Review of Concerns and Solutions to PV Interconnection in New York City}

This section describes solutions to concerns commonly expressed by utility network engineers and industry experts when interconnecting photovoltaic (PV) systems onto secondary networks. Nine solutions are described in detail, including advantages and disadvantages, potential impacts, and road maps for deployment. We suggest the following solutions: maintaining minimum loads, minimum import relays, reverse power relays, dynamically controlled inverters, load flow studies, supervisory control and data acquisition (SCADA) system/inverter integration, energy storage devices, advanced protective schemes, and PV array orientation variations. 


\section{Contents}

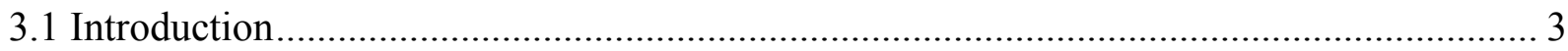

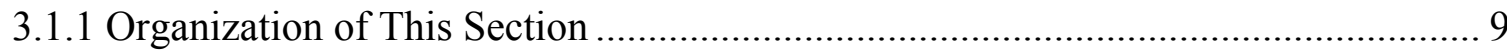

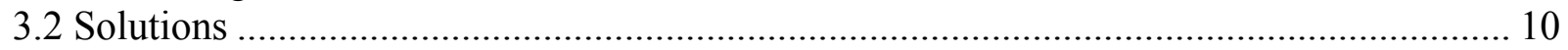

3.2.1 ML_Maintain Minimum Load ............................................................................ 10

3.2.2 MIR_Minimum Import Relay.................................................................... 11

3.2.3 RPR - Reverse Power Relay.................................................................... 15

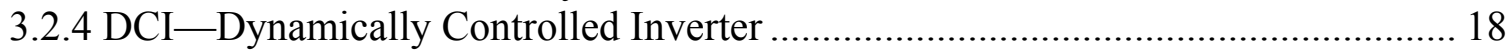

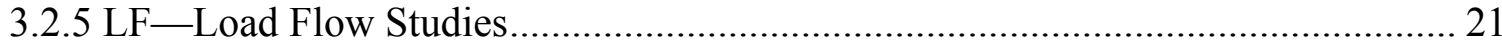

3.2.6 SCADA - Integrate Inverters with Communication Capabilities........................... 24

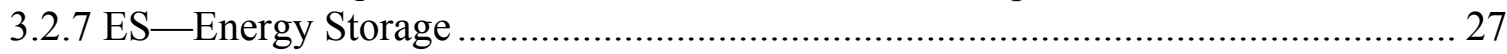

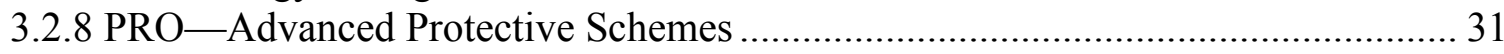

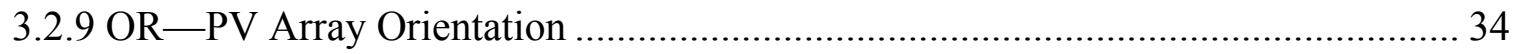




\subsection{Introduction}

In this section, intended for utility network engineers and industry experts, we focus on potential technical problems (called "concerns") that might arise when interconnecting PV systems onto secondary networks. Table 3-1 presents the concerns along with relevant solutions for each. The table lists the concerns in order of importance, loosely based on the most common issues described by utility network engineers and industry experts.

Each solution given in Table 3-1 is abbreviated, and Table 3-2 is the abbreviation key. Following Table 3-2, we examine each of the top nine solutions in detail, looking at the concerns it addresses, its effectiveness at various PV penetration levels, its advantages and disadvantages, its impacts, its financial considerations, and any associated smart grid issues. At the end of each solution discussion, we suggest a road map for deployment.

Note that, to date, PV deployment on secondary networks has been quite limited. As a result, many of the topics discussed in this section will need to be revisited to determine the validity of the concerns and the appropriateness of the solutions. 
Table 3-1. Concerns and Solutions for Interconnecting PV with Secondary Distribution Networks

\begin{tabular}{|c|c|c|}
\hline Concern & Explanation & Solution \\
\hline $\begin{array}{l}\text { Network Protector } \\
\text { Operation and Cycling }\end{array}$ & $\begin{array}{l}\text { Exporting PV systems produce reverse } \\
\text { power flow, which might cause network } \\
\text { protectors to operate and cycle. }\end{array}$ & $\begin{array}{l}\text { MIC, DCI, LF, SCADA } \\
\text { (exporting systems) } \\
\text { ML, MIR, RPR, DCl, LF, } \\
\text { SCADA (nonexporting } \\
\text { systems) }\end{array}$ \\
\hline $\begin{array}{l}\text { Power System Planning- } \\
\text { Generation Dispatch Impact }\end{array}$ & $\begin{array}{l}\text { Variability in PV generation might require } \\
\text { increased flexibility from conventional } \\
\text { generation. }\end{array}$ & GF, LC, SIT, OR \\
\hline $\begin{array}{l}\text { Power System Planning- } \\
\text { Load Profile Change }\end{array}$ & $\begin{array}{l}\text { PV generation might change the load profile } \\
\text { seen by the utility, impacting the scheduling } \\
\text { of conventional generation. }\end{array}$ & OR, FOR \\
\hline Increased Fault Current ${ }^{\mathrm{D}}$ & $\begin{array}{l}\text { PV systems add additional sources of } \\
\text { energy to the network, and might increase } \\
\text { the level of available fault current beyond } \\
\text { the equipment ratings. }\end{array}$ & $\mathrm{FCM}$ \\
\hline $\begin{array}{l}\text { Fault Current Coordination } \\
\text { Issues }^{\mathrm{a}}\end{array}$ & $\begin{array}{l}\text { PV systems add additional sources of } \\
\text { energy that can change the direction of fault } \\
\text { current flows or add new flows, disrupting } \\
\text { the coordination of protective devices. }\end{array}$ & MIC, PRO \\
\hline Voltage Rise ${ }^{c}$ & $\begin{array}{l}\text { Reverse power flow from exporting PV } \\
\text { systems can cause voltage levels to rise } \\
\text { above the maximum voltage limit. }\end{array}$ & ES \\
\hline $\begin{array}{l}\text { Increased Volt-Ampere } \\
\text { Reactive (VAR) } \\
\text { Requirements }\end{array}$ & $\begin{array}{l}\text { PV system inverters produce only real } \\
\text { power, so other power generators will have } \\
\text { to supply a higher percentage of reactive } \\
\text { power (VAR). }\end{array}$ & CAP \\
\hline Increased Harmonics & $\begin{array}{l}\text { PV systems could induce harmonic } \\
\text { distortion in the system. Harmonics could } \\
\text { adversely affect operation of motors and } \\
\text { electronics and cause undesirable heating } \\
\text { in transformers and cables. }\end{array}$ & $P Q, M I C$ \\
\hline Voltage Flicker & $\begin{array}{l}\text { When PV system output increases or } \\
\text { decreases (in response to passing clouds, } \\
\text { for example) faster than the remaining } \\
\text { generators can compensate, voltage flicker } \\
\text { can occur. This may result in light flicker, } \\
\text { variable motor speed performance, and } \\
\text { wear on equipment. }\end{array}$ & $\begin{array}{l}\text { DIS, ES, WEA (exporting } \\
\text { systems) } \\
\text { ES, WEA (nonexporting } \\
\text { systems) }\end{array}$ \\
\hline
\end{tabular}




\begin{tabular}{|c|c|c|}
\hline $\begin{array}{l}\text { Voltage Drop Resulting } \\
\text { from Sudden PV Loss }\end{array}$ & $\begin{array}{l}\text { The sudden loss of PV generation can lead } \\
\text { to unacceptably low voltages in parts of the } \\
\text { system and subsequent increases in } \\
\text { apparent load to the utility. }\end{array}$ & ES, VR, LVRT \\
\hline $\begin{array}{l}\text { Voltage Drop Caused by } \\
\text { Trips on Distribution } \\
\text { System }^{\mathrm{a}}\end{array}$ & $\begin{array}{l}\text { Interconnection standards require PV } \\
\text { systems to disconnect from the grid during } \\
\text { grid faults. Loss of PV generation may lead } \\
\text { to unacceptably low voltages. }\end{array}$ & LVRT, VR \\
\hline $\begin{array}{l}\text { Sudden PV Loss Due to } \\
\text { Inverter Tolerance Limits }\end{array}$ & $\begin{array}{l}\text { Customer equipment and other distributed } \\
\text { generators could induce harmonics or } \\
\text { variations in voltage and frequency that } \\
\text { push power outside inverter tolerances, } \\
\text { forcing PV systems to drop offline. The loss } \\
\text { of the PV systems could lead to } \\
\text { unacceptably low voltages. }\end{array}$ & PQM, INV \\
\hline Subtransmission Problems ${ }^{a}$ & $\begin{array}{l}\text { PV currents may feed from the distribution } \\
\text { system back up into the subtransmission } \\
\text { system, causing ground fault overvoltage, } \\
\text { interference with sectionalizing switching } \\
\text { schemes, and overcurrent protection } \\
\text { coordination issues on the subtransmission } \\
\text { system }\end{array}$ & PRO, LIM, INS \\
\hline Unintentional Islands ${ }^{a, d}$ & $\begin{array}{l}\text { When a network protector opens and } \\
\text { isolates a section of the power system with } \\
\text { a PV energy source, an unintentional island } \\
\text { might form. This endangers utility and } \\
\text { customer equipment and personnel. }\end{array}$ & PLC, SCADA \\
\hline
\end{tabular}

\footnotetext{
${ }^{a}$ This is only a concern at higher PV penetration levels. At this time, high PV penetration levels for secondary networks are not well defined. In this report, we consider high penetration to be above $5 \%$.

${ }^{\mathrm{b}}$ Fault current contribution from inverter-based systems is not considered significant.

${ }^{\mathrm{c}}$ Extremely unlikely with most small to medium PV systems. Very unlikely on any secondary network.

${ }^{\mathrm{d}}$ Underwriters Laboratories (UL)-approved inverters have an anti-islanding function per IEEE 1547-2003 [IEEE. Standard for Interconnecting Distributed Resources with Electric Power Systems. IEEE Std. 1547-2003. 2003. http://grouper.ieee.org/groups/scc21/1547/1547_index.html. Accessed October 3, 2009.]
} 
Table 3-2. Solution Key for Table 3-1

\begin{tabular}{|c|c|c|}
\hline Abbreviation & Definition & $\begin{array}{l}\text { Explanation } \\
\end{array}$ \\
\hline $\mathrm{ML}$ & Minimum load & $\begin{array}{l}\text { A minimum load is maintained at all } \\
\text { times. }\end{array}$ \\
\hline MIR & Minimum import relay & $\begin{array}{l}\text { A relay is set to trip PV offline if customer } \\
\text { load drops below a predetermined level. }\end{array}$ \\
\hline RPR & Reverse power relay & $\begin{array}{l}\text { A relay is set to trip PV offline if customer } \\
\text { load drops to zero or if the PV system } \\
\text { begins to export power. }\end{array}$ \\
\hline $\mathrm{DCl}$ & Dynamically controlled inverter & $\begin{array}{l}\text { A DCI monitors the load and curtails PV } \\
\text { system output if customer load drops } \\
\text { below a predetermined level. }\end{array}$ \\
\hline LF & Load flow study & $\begin{array}{l}\text { The utility runs a load flow study to } \\
\text { determine if there is any potential impact } \\
\text { to the coordination of protective devices. } \\
\text { If a potential exists, the utility can modify } \\
\text { the coordination scheme in most cases. } \\
\text { Load flow calculation for network systems } \\
\text { is highly complex. }\end{array}$ \\
\hline SCADA & $\begin{array}{l}\text { Supervisory control and data } \\
\text { acquisition }\end{array}$ & $\begin{array}{l}\text { PV inverters are integrated into utility } \\
\text { SCADA systems and/or advanced } \\
\text { metering infrastructure (AMI) systems. } \\
\text { The SCADA system controls inverters via } \\
\text { an available communications channel. }\end{array}$ \\
\hline ES & Energy storage & $\begin{array}{l}\text { Energy storage (most likely batteries) is } \\
\text { added at the PV site or the utility } \\
\text { substation to control fluctuations in PV } \\
\text { system output. The cost is significant, but } \\
\text { the storage could decrease ramp rates, } \\
\text { reduce flicker, and help manage voltage } \\
\text { levels. }\end{array}$ \\
\hline PRO & Advanced protection & $\begin{array}{l}\text { Advanced protective schemes-such as } \\
\text { directional overcurrent trip, blocking, and } \\
\text { high-speed transfer trip(s)-are used to } \\
\text { take equipment offline in the event of a } \\
\text { fault. }\end{array}$ \\
\hline OR & Orientation & $\begin{array}{l}\text { The orientation of some PV panels is } \\
\text { changed to shift timing of power } \\
\text { generation. }\end{array}$ \\
\hline MIC & $\begin{array}{l}\text { Monitoring information exchange } \\
\text { and control }\end{array}$ & $\begin{array}{l}\text { Utility monitoring, information exchange, } \\
\text { and control allow curtailment of PV } \\
\text { generation. }\end{array}$ \\
\hline GF & Generation flexibility & $\begin{array}{l}\text { The utility modifies the balance of } \\
\text { generation portfolio to maintain flexibility, } \\
\text { allowing the system to cope with }\end{array}$ \\
\hline
\end{tabular}




\begin{tabular}{|c|c|c|}
\hline & & increased variability. \\
\hline LC & Load control & $\begin{array}{l}\text { The utility uses load control, load shifting, } \\
\text { energy storage, and curtailment of PV } \\
\text { generation to manage a flexibility } \\
\text { shortage or voltage excursions. }\end{array}$ \\
\hline SIT & Siting & $\begin{array}{l}\text { Utilities, states, and cities evaluate } \\
\text { alternative siting options of PV systems to } \\
\text { reduce impacts on generation dispatch. }\end{array}$ \\
\hline FOR & Load forecasting & $\begin{array}{l}\text { The utility includes PV generation in the } \\
\text { energy growth forecast (integrated } \\
\text { resource plan) and plans for sufficient } \\
\text { flexibility in generation portfolio. }\end{array}$ \\
\hline CAP & Capacitor & $\begin{array}{l}\text { Capacitors are installed on customer PV } \\
\text { systems to maintain a power factor (PF) } \\
\text { of } 90 \% \text { or better (PV inverters currently } \\
\text { produce only real power). A utility might } \\
\text { also install feeder-level capacitors or } \\
\text { substation-sited capacitor banks to } \\
\text { maintain proper PF and VARs. }\end{array}$ \\
\hline$P Q$ & Power quality standards & $\begin{array}{l}\text { Power quality issues are addressed by } \\
\text { IEEE } 1547-2003 \text { and inverters must meet } \\
\text { the UL } 1741 \text { standard. }{ }^{1} \text { These standards } \\
\text { require distributed generation (including } \\
\text { PV) to maintain minimum power quality. }\end{array}$ \\
\hline WEA & Weather forecasting & $\begin{array}{l}\text { Tracking of weather patterns, especially } \\
\text { cloud cover, is integrated into utility } \\
\text { dispatch operations to ensure that } \\
\text { adequate spinning reserve or } \\
\text { dispatchable load is available. }\end{array}$ \\
\hline DIS & Spatial distribution & $\begin{array}{l}\text { Distributed resources (including PV) are } \\
\text { spatially distributed so that cloud cover } \\
\text { does not affect the system quickly. }{ }^{a}\end{array}$ \\
\hline VR & Voltage regulation & $\begin{array}{l}\text { The utility uses load tap changers or } \\
\text { other regulator devices to raise or lower } \\
\text { feeder voltage to keep it within normal } \\
\text { limits. }\end{array}$ \\
\hline LVRT & Low-voltage ride-through & $\begin{array}{l}\text { Inverters with ride-through capability } \\
\text { allow the PV system to maintain } \\
\text { operation during times when voltage sags } \\
\text { below normal operating range or when } \\
\text { there are temporary voltage drops caused } \\
\text { by faults. PV systems stay online during } \\
\text { minor system disturbances and support }\end{array}$ \\
\hline
\end{tabular}

\footnotetext{
${ }^{1}$ See UL 1741. [Underwriters Laboratories Inc. Standard for Inverters, Converters, Controllers and Interconnection System Equipment for Use with Distributed Energy Resources. UL Std. No. 1741, 1st Edition. 1999. http://ulstandardsinfonet.ul.com/scopes/1741.html. Accessed October 28, 2009.]
} 
voltage, rather than dropping off in bulk (causing a larger disturbance). Some existing inverters have the ability to ride through voltage irregularities, but current U.S. standards ${ }^{2}$ call for the inverters to drop offline and remain offline for 5 minutes once normal voltage returns.

PQM Power quality monitoring

Power quality monitoring devices are installed at the source of power quality problems. The utility works with the owner of problematic systems to bring that system into conformance as governed by the rules of the utility.

INV Inverter tolerance

LIM Limit penetration

INS Insulation

PLC Power line carrier communications

FCM Fault current mitigation

The inverter operates outside of the normally allowed voltage parameters. Many inverters on the market today can be programmed or adjusted to tolerate aberrations in voltage, frequency, and harmonics. Future standards (UL and IEEE) could allow for wider tolerances or for adjustments.

PV capacity is limited to a safely defined penetration limit. This requires tracking the total PV deployment level and comparing that number to the known system peak demand load.

Insulation coordination and surge/lightning arresters are increased on all cables and devices to handle ground fault overvoltages. This is applicable if system studies indicate that voltage levels could reach a level that could damage distribution equipment. ${ }^{\mathrm{b}}$

PLC communications (PLCC) tests the continuity of the line by injecting a lowfrequency signal (typically $5 \mathrm{kHz}$ or lower) onto the network to verify the presence of utility sources. Inverters "listen" for the signal and drop offline in the event of loss of signal (indicating loss of utility power). This prevents unintentional islanding.

Fault current mitigation equipment is installed at the generator. Fault mitigation requirements are defined by the utility on

\footnotetext{
${ }^{2}$ See IEEE 1547-2003, 4.2.3 Table 1 [IEEE. Standard for Interconnecting Distributed Resources with Electric Power Systems. IEEE Std. 1547-2003. 2003. http://grouper.iee.org/groups/scc21/1547/1547_index.html. Accessed October 3, 2009.]
} 
a case-by-case basis but generally require that the protection interrupt the fault current contribution within half a cycle. Examples of FCM include DC links, fast acting fuses, or series reactors.

\footnotetext{
${ }^{a}$ Spatial distribution opportunities within New York City are limited for customer-owned PV systems. Utility-owned PV systems may be located with reasonable spatial distribution.

${ }^{\mathrm{b}}$ This is highly unlikely for secondary network systems similar to those in New York City.
}

\subsubsection{Organization of This Section}

Each solution is further described in this section with the following components:

- Description: Offers information on how the solution might apply to one or more concerns.

- Discussion: Elaborates further on the main description if necessary.

- Concerns Addressed: Lists which concerns (identified in Table 3-1) are addressed by this solution.

- Ranking of Solutions: Ranks how well the solution addresses the concern. The ranking applies to both area and spot networks, unless otherwise stated. This ranking is subjective, and is based on the experience of National Renewable Energy Laboratory (NREL) staff and from information gleaned from other publications on this subject:

- Good - considered an acceptable or preferred approach to address specific concerns.

- Poor-considered an unacceptable solution for the concern being addressed. The technology may have been deployed in some manner and shown to be either unsuccessful or having significant shortcomings.

- Untested — not likely to have been applied on PV systems on secondary networks.

- Penetration Level: Discusses the appropriateness of the solution at low, medium, or high penetration levels. The level of penetration of PV systems on an electric distribution system is expressed as a percentage of peak PV generation power divided by the peak demand load for that system.

- Advantages: Presents some of the potential advantages of the solution to both PV system owners and the utility.

- Disadvantages: Presents some of the known or perceived disadvantages of the solution to both PV system owners and the utility.

- Financial Considerations: Covers financial issues, positive or negative, for both the PV system owner or installer and the utility.

- Impact of Solution: Examines the anticipated impact of this solution (may be based on historical experience).

- Location of Solution: Briefly describes where the solution might be physically located. 
- Smart Grid Issues: Describes how the solution would integrate with smart grid technology. Much of the discussion is hypothetical because the smart grid has not been fully defined or deployed.

- Road Map: Lists potential steps or issues to address in the future.

- Remarks: Serves as an area for additional comments.

We have also included graphs and examples where they help to illustrate the solution.

\subsection{Solutions}

\subsubsection{ML-Maintain Minimum Load}

Description: ML is a means to forecast that net customer load (including PV generation) will be greater than a specific minimum load. The expected power output of the PV system is compared to historical and projected customer loads, and the PV system is sized to ensure a minimum load is maintained at all times. All non-PV customer-sited distributed generation must also be included in the analysis.

Concerns Addressed: Network protector operation and cycling

Ranking of Solution: Network protector operation and cycling-good

Penetration Level: This is an appropriate solution for all levels of penetration.

\section{Advantages:}

- Relatively simple to estimate level of minimum load based on load data and type

- Good solution for PV systems that must remain nonexporting

- Can be validated by real-time monitoring

- Applicable to both area and spot networks

- Using ML might eliminate requirements for other protective relays like RPR, MIR, or DCI in situations where load is consistent and PV system peak output is less than half of the minimum daytime load.

- Can be used in conjunction with RPR, MIR, or DCI to prevent a system from exporting.

- The most appropriate solution for installations with minimum loads that are significantly greater than the output of the PV system.

Disadvantages: If the minimum daytime load at a facility is low (e.g., on weekends and holidays), the PV system size may have to be reduced in order to maintain a nonexporting system.

\section{Financial Considerations:}

For PV system installer/owner 
- Analysis cost (e.g., system monitoring)

- May be no equipment costs (unless ongoing monitoring is required or another technology — such as RPR, MIR, or DCI—is used in conjunction with ML)

- Cost of review of design and load data by the utility.

For the utility

- Significant internal coordination required among engineering, planning, operations, billing, and other departments

- May incur costs if the utility is to monitor or inspect the system at regular intervals. The cost of monitoring (via SCADA/smart grid system) may be recoverable in the rate base if approved by the Public Service Commission (PSC).

Impact of Solution: ML has no impacts other than a reduced daytime load for the customer with the PV system.

Location of Solution: This solution affects only the size of the PV system. No additional hardware is required.

Smart Grid Issues: Monitoring the status of minimum load during PV production hours via SCADA/smart grid might be beneficial for verifying the power generated and the load consumed at the site.

Road Map: ML can be calculated and the PV system sized based on historical and forecasted loads. An annual review of all ML systems might be worthwhile, though, in case loads drop significantly below historical or forecast levels. If loads are smaller than allowed for in the PV system design, the PV system owner might need to take steps to eliminate export (if required) or to reduce power production capability.

ML is a good solution for any spot network. It might also be a good approach for area networks where power exporting is not desired or allowed. ML may not require any system upgrades or hardware additions. To track annual loads for verification, however, the utility might require an interval or production meter.

Remarks: ML is based on limited PV system size and larger historical or projected site loads. ML has been implemented with several PV systems on networks with successful results. One very significant drawback to relying on ML alone is the nature of loads in any location. For example, buildings of any type can see large increases or decreases in load over time, and additional PV equipment might be installed on the buildings. ML relies on historical or forecast data, which may not be an accurate prediction of future data.

\subsubsection{MIR-Minimum Import Relay}

Description: Similar to an RPR, an MIR is designed to trip a circuit breaker (or perhaps control a DCI) when the customer's load drops below a predefined level. The MIR monitors the input at the point of common coupling (PCC) and issues a signal if customer's load drops below a preset threshold. Good solution for ensuring that the customer load does not approach zero and power is always being drawn from the network. 
Concerns Addressed: Network protector operation and cycling

Ranking of Solution: Network protector operation and cycling — good for spot networks. For area networks, an RPR should be considered instead of an MIR if zero customer load is acceptable.

Penetration Level: MIR is an appropriate solution for spot networks at all levels of penetration. For area networks, they may be used at any level of penetration, but it is unlikely that MIRs would be necessary to prevent disruptions of network protector operations at low penetration levels. At higher levels of penetration, the MIR solution will be a valuable method to ensure that network protectors remain closed.

\section{Advantages:}

- Technology exists today and is proven.

- Prevents customer's load from dropping below a specified threshold.

- Can be monitored by customer's energy management system (EMS) or utility-owned SCADA systems.

- Can be used in concert with other solutions (e.g., ML, RPR, and DCI).

\section{Disadvantages:}

- For smaller PV systems, MIR installation can be a significant percentage of overall system cost.

- Customer's loads must consume all power produced or risk an MIR lockout.

- Most MIRs must be reset manually. If not monitored, this could result in the PV system being offline for an extended period of time.

- Utility must review and accept calculations of settings for the level of current/power appropriate for each customer site. This could be time consuming and costly.

\section{Financial Considerations:}

For the PV system installer/owner

- Typically in the range of $\$ 10,000$ installed (traditionally paid by installer).

- Varying prices based on existing equipment configuration, integration constraints, size of PV system, size of MIR equipment, and service characteristics.

- Cost of review of design and load data by the utility.

For the utility

- May be a cost to the utility for testing, monitoring, or ongoing evaluation of the equipment. 


\section{Impact of Solution:}

For area networks, an MIR should eliminate any power flow onto the network, greatly reducing the likelihood of network protectors operating and cycling. At significant levels of penetration, reduced system loads from the presence of PV systems (and other distributed generation systems) could cause MIRs to operate frequently. This will result in PV systems going offline for extended periods.

For spot networks, an MIR will eliminate the PV system contribution before the customer's load drops too low. It is a good solution for spot networks, which require a minimum load to be present at all times to keep the network protectors closed.

Location of Solution: MIR monitoring sensors are located near the main utility meter equipment just downstream of the main disconnect (the PCC). This placement allows the utility to measure the service load. The MIR relay, typically located within a few feet of the monitoring sensors, controls a circuit breaker or contactor that ties onto the PV system branch circuit.

\section{Smart Grid Issues:}

- At higher penetration levels, smart grid controls might need to be incorporated into MIRs.

- Using SCADA to monitor larger PV MIR systems ${ }^{3}$ would be beneficial as a means of verifying operation and determining the relay's status. The utility would also be able to gain control of the MIR in the event of a significant network failure that would require remote operation of the MIR. Monitoring of smaller systems might not be required, although monitoring might have benefits to the utility and the system owner.

- Larger PV systems with MIR technology might have an option for utility control in case of severe problems on the network, but a highly secure communication link would be necessary.

- If AMI technology progresses sufficiently in the future, so that all customers have twoway communications in place, both the PV system owner and the utility might benefit from monitoring the status of all PV systems.

\section{Road Map:}

- MIR equipment, like RPR equipment, is often installed as a retrofit after PV systems are installed. Although feasible as a retrofit, it is easier to install this technology on new buildings.

- MIR equipment is a mature technology. The equipment is likely to evolve further and this solution will be employed for many years.

\footnotetext{
${ }^{3}$ IEEE 1547-2003 4.1.6 suggests monitoring provisions for systems of $250 \mathrm{kVA}$ or larger. [IEEE. Standard for Interconnecting Distributed Resources with Electric Power Systems. IEEE Std. 1547-2003. 2003. http://grouper.ieee.org/groups/scc21/1547/1547_index.html. Accessed October 3, 2009.]
} 
- MIRs are a good choice when a PV system is not allowed to export power. Spot networks should always be fitted with an MIR, unless the minimum load can be shown to be significantly higher than the PV power produced.

- MIR settings should be verified each year or when a significant load change occurs at the PV system location.

- The utility might consider monitoring MIRs on its network systems using SCADA or smart grid MIC. Larger PV systems should be monitored, but smaller systems might also be considered for monitoring (depending on location specifics).

- MIR is often financially practical to install, both from a cost perspective and from a technical perspective. Some facilities, though, will face significant challenges in retrofitting their electrical panels with this technology.

Figure 3-1 illustrates one example of how an MIR might be applied.

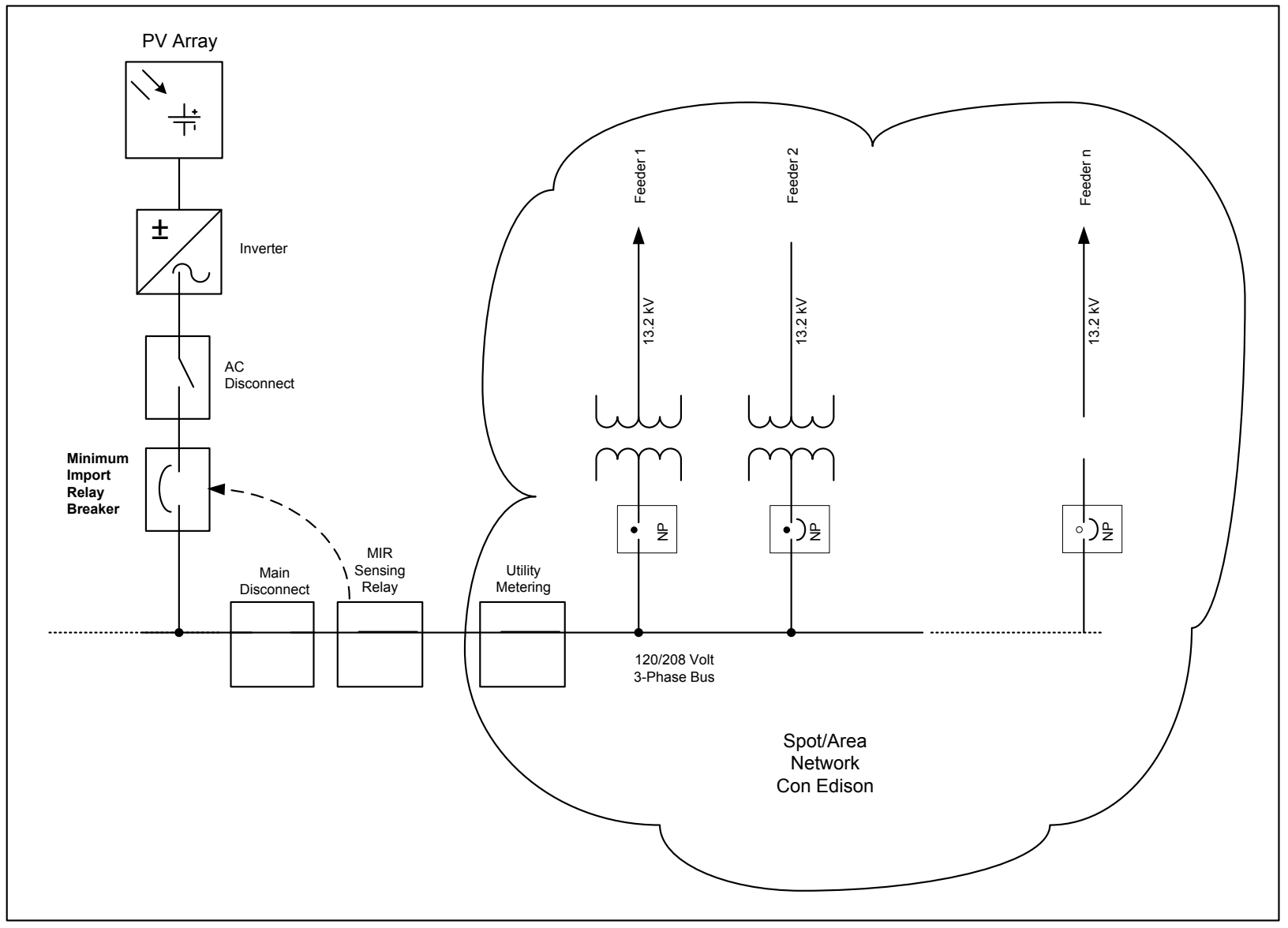

Figure 3-1. Schematic of a secondary network with MIR

Remarks: The MIR is commonly deployed on PV system installations at commercial or industrial locations, but infrequently on residential systems. The MIR is an excellent solution that, when installed properly, ensures that the customer load is always taking power from the network transformers, which tends to keep network protectors in a normal closed position. Spot 
networks would be better served by an MIR than an RPR because the MIR is capable of ensuring minimum power flow to the customer. In addition, the MIR is a proven technology, trusted by many electric utilities and customers, and can be monitored and controlled remotely as smart grid technology takes on a greater role in electric utility operations. Note that coordination between the MIR, customer circuit breakers, and the network protector must be considered during system design.

\subsubsection{RPR一Reverse Power Relay}

Description: An RPR is a special case of the MIR where the current is set at zero amps. It is designed to trip a circuit breaker (or perhaps control a DCI) when the customer's load drops below the predefined limit of zero amps. The RPR monitors the input at the PCC and issues a signal if the input current from customer load drops below zero amps.

Concerns Addressed: Network protector operation and cycling

Ranking of Solution: Network protector operation and cycling—-good for area networks. MIRs are preferred for spot networks.

Penetration Level: RPRs are an appropriate solution for maintaining a nonexporting PV system at all levels of penetration. At very low levels of penetration, they may not be needed to prevent network operations in area networks. At higher levels of penetration, they will likely be a valuable tool for ensuring network protectors do not open.

\section{Advantages:}

- Prevents PV systems from exporting energy to the grid.

- Technology exists today and is mature. Generally an acceptable solution for many utilities.

- Could be monitored by customer's EMS and utility-owned SCADA/smart grid systems.

\section{Disadvantages:}

- Might still allow some network protectors to open as the customer load approaches zero (MIR or CIS solutions are a preferred choice because the PV system can be reduced/decoupled before the customer load reaches zero).

- Cost, commensurate with the MIR, could be a significant percentage of cost for small PV systems ( $5 \mathrm{~kW}$ and below).

- Customers must consume all power produced or risk the RPR lockout.

- Most RPR circuit breakers must be reset manually and, if not monitored, could result in the PV system being offline for an extended time. This is a similar issue for MIR systems, and might pose a significant problem.

\section{Financial Considerations:}

For PV system installer/owner 
- Typically in the range of $\$ 10,000$ installed (traditionally paid by installer).

- Prices vary based on existing equipment configuration, integration constraints, size of PV system, and size of RPR equipment.

- Cost of review of design and load data by the utility.

For the utility

- Utility can incur costs if the system is to be monitored or inspected on an ongoing basis. The utility cost of monitoring (via SCADA or smart grid system) could be recovered through the rate base if approved by the PSC.

- If the installation labor and capital costs of the RPR are placed on the utility, those costs may be capitalized (if approved by the PSC) and could be recovered in one or more rate classes.

\section{Impact of Solution:}

An RPR eliminates power export from the customer PV system to an area network. This greatly reduces the likelihood of network protectors operating at low levels of penetration. At higher levels of penetration, network protectors are more likely to operate, owing to reduced network transformer loads from the aggregated effect of PV systems (and all distributed generation systems).

For spot networks, network protectors may still open or cycle under network transformer lowload conditions because these networks require a minimum load to be present at all times to keep the network protectors closed. RPRs prevent power from flowing back to the utility.

Location of Solution: The RPR is located on the customer side of the meter at the installation location. The RPR monitoring equipment (current transformers) is usually located near the main utility meter equipment or on the branch circuit that ties to the PV system. The relay controls a circuit breaker or contactor that connects to the PV system branch circuit.

\section{Smart Grid Issues:}

- Monitoring of larger RPR systems ${ }^{4}$ via SCADA or any hybrid system could be beneficial as a means of verifying operation, status of relay, and potential utility control of the RPR in the event of a significant network failure.

- Smaller PV systems might have provisions to allow monitoring by a local device that would report back to the utility when needed.

- Larger PV systems with RPR technology might also allow for utility control in case of severe problems on the network (per agreement by the utility and system owner).

\footnotetext{
${ }^{4}$ IEEE 1547-2003 4.1.6 Each DR unit over $250 \mathrm{kVA}$ shall have provisions for monitoring. [IEEE. Standard for Interconnecting Distributed Resources with Electric Power Systems. IEEE Std. 1547-2003. 2003. http://grouper.ieee.org/groups/scc21/1547/1547_index.html. Accessed October 3, 2009.]
} 


\section{Road Map:}

- Although RPRs are often installed as a retrofit system on PV systems, they are easiest to install where there is ample room or new construction. Some facilities will find installing RPRs difficult because of space constraints.

- RPR technology is mature, and utilities have installed RPRs successfully.

- As levels of penetration rise, RPRs may be required for systems of all sizes. Some PV proponents suggest that RPRs should not be required on PV systems smaller than $30 \mathrm{~kW}$ because small systems are unlikely to have significant impact on area networks. The requirement might have to be evaluated on a case-by-case basis.

- RPRs are a good choice when exporting power is not expected or allowed on area networks. Spot network operators should consider using MIRs or DCIs to maintain minimum load and ensure that network protectors remain closed.

- The utility might consider using SCADA/smart grid to monitor RPRs on its network systems.

- RPR installations are often practical from both a cost perspective and a technical perspective.

- For larger PV systems, utility monitoring (and perhaps supervisory control with agreement between the PV system owner and the utility) might be considered for both generation tracking and high-penetration controls. This would require the utility to upgrade its SCADA system or add other smart grid technologies, especially as penetration levels increase. The utility might ask that PV systems of all sizes be voluntarily monitored. The utility might also consider continuously monitoring PV systems using production meters.

Figure 3-2 illustrates one example of how an RPR might be applied. 


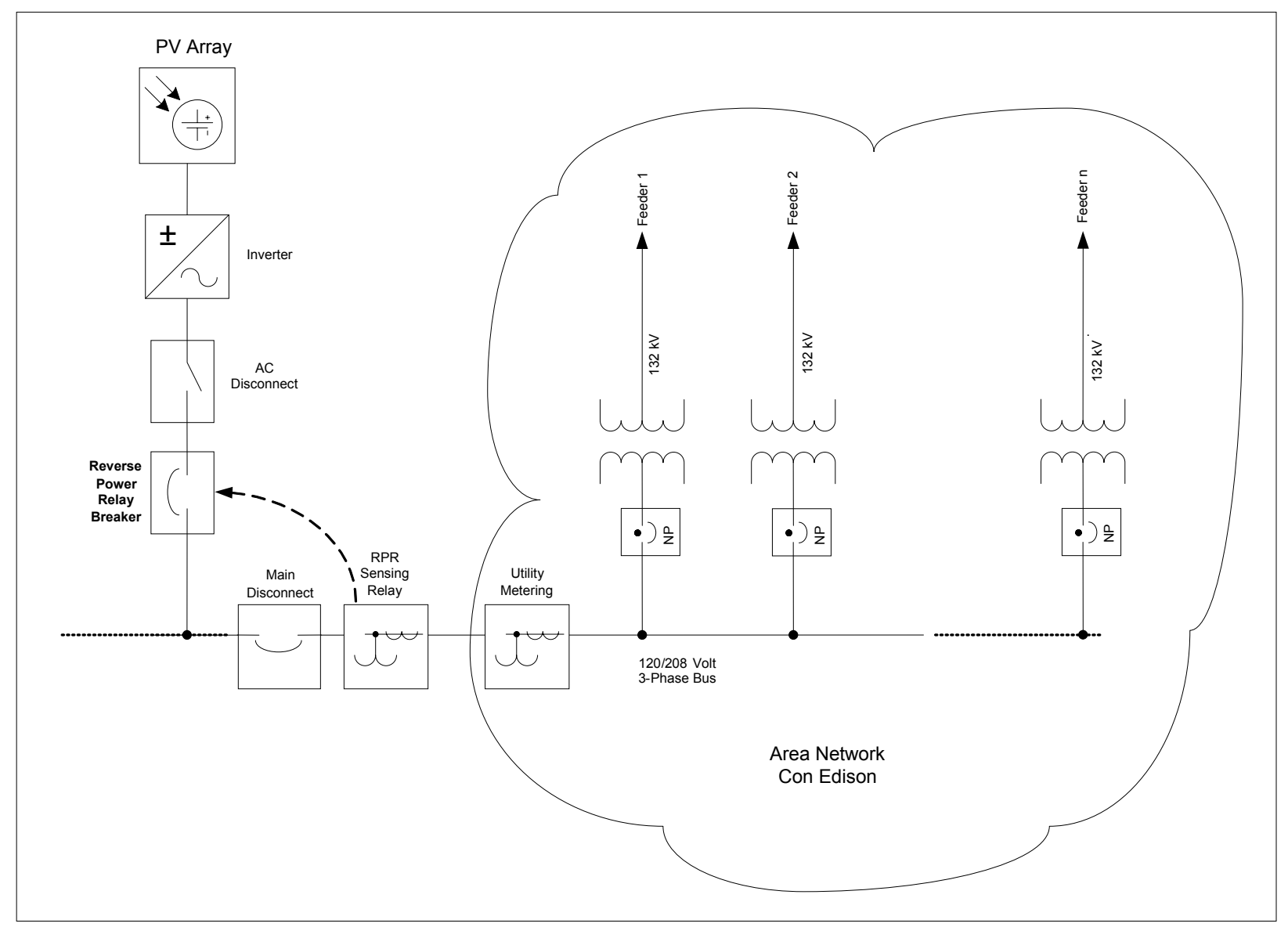

Figure 3-2. Schematic of a secondary network with RPR

Remarks: RPRs are a proven technology, trusted by many electric utilities and customers, and they can be monitored remotely using smart grid technology. RPRs are often deployed on PV system installations in commercial or industrial settings, but rarely on residential systems (an RPR is not typically a financially viable option for a smaller PV system). RPRs are considered costly for smaller PV systems $(<30 \mathrm{~kW})$, and usually considered economical for medium to large PV systems.

\subsubsection{DCl—Dynamically Controlled Inverter}

Description: A DCI is an electronic-based control system that monitors the load and curtails PV system output if the customer load drops below a predetermined level. DCIs would typically be integrated into the inverter, and have monitoring and control components that are external to the inverter. The major advantage of DCIs is the PV system is signaled to reduce output, instead of being dropped to zero power output as the RPR and MIR options require. DCIs are an emerging technology.

Concerns Addressed: Network protector operation and cycling

Ranking of Solution: Network protector operation and cycling-good 
Penetration Level: DCIs are an appropriate solution for low, medium, and higher levels of penetration. At very low penetration levels, DCIs would be unnecessary to prevent network protector from opening within an area network. At higher levels of penetration, DCIs are likely to be a valuable tool to ensure that network protectors do not open. Smart grid controllability might need to be incorporated into DCIs at higher penetration levels. DCIs would be a good solution on spot networks regardless of overall network penetration levels.

\section{Advantages:}

- Prevents PV systems from exporting, or from exporting under certain conditions, thus eliminating detrimental power flow onto the grid.

- Might be applied as a means to ensure minimum import requirements.

- Can be monitored by customer's EMS and utility-owned SCADA systems.

\section{Disadvantages:}

- Emerging technology. Successfully demonstrated in actual deployment, but not extensively field tested.

- Loss of generation for some PV system owners when the DCI reduces system power output.

- Only a few inverter manufacturers offer DCIs. ${ }^{5}$

- DCI operation could preclude PV system owners' awareness of reduced system output.

\section{Financial Considerations:}

For PV system installer/owner

- DCIs can be integrated into inverters for minimal additional cost.

- Costs are likely to drop as inverter manufacturers look at making this a standard option for inverters.

- DCIs will result in loss of generation for PV system owners when the DCI reduces system power output. This loss will reduce the amount of energy produced annually, which will impair the economic performance of the system and extend payback periods. New tariffs might compensate PV system owners for curtailed operations, similar to existing demand response provisions.

- Customer will incur a cost for the review of the design and load data by the utility.

For the utility

- Utility can incur costs if the system is to be monitored or inspected on an ongoing basis. The utility cost of monitoring (via SCADA or smart grid system) could be recovered through the rate base if approved by the PSC.

\footnotetext{
${ }^{5}$ At the time of this report, DCIs are not a commonly available option for all inverters. They are available commercially only on larger $(>100 \mathrm{~kW})$ inverters.
} 


\section{Impact of Solution:}

For area networks, a DCI can be set to eliminate all power flow onto an area network, greatly reducing the likelihood of network protector operations. An MIR would still be required to ensure network protectors do not operate. In high-penetration scenarios, the DCI could be monitored and potentially controlled by the utility smart grid system. That control could significantly reduce system problems when high levels of distributed generation negatively affect the distribution system.

For spot networks, because network protectors will open if their load drops below the minimum power threshold, DCIs would have to be programmed to prevent power from flowing back to the utility. Network protectors might still open or cycle under low-load conditions, but are far less likely to do so if the DCI assists by lowering PV system power production.

Location of Solution: A DCI would always be located on the customer side of the meter. DCI monitoring equipment would likely be located near the main disconnect, and most DCI electronics would be located within the inverter itself.

\section{Smart Grid Issues:}

- Monitoring of DCI systems via SCADA/smart grid would be beneficial as a means of verifying operation and status of output. Monitoring would also allow for emergency control of the DCI if the network suffered a significant failure that required remote inverter operation.

- Monitoring provisions should be installed on larger PV systems that include DCIs. ${ }^{6}$ This gives the utility the option to track the PV system's performance.

- Smaller PV systems with DCIs could also have an option for utility control in case of problems on the network.

\section{Road Map:}

- In comparison to RPRs or MIRs, which are protection systems, DCIs could be significantly easier to install in existing facilities. DCIs are worth consideration, particularly because they can be set to provide nonexporting functions.

- DCIs should be combined with an MIR in a spot network to ensure that network protectors remain in service. As a design philosophy, control and protection functions need to remain separate.

- DCIs have been installed in PV systems, though none to date in New York City.

- DCIs can be considered an option for PV systems of all sizes for both spot networks and area networks with higher levels of penetration.

- The utility might consider using SCADA to monitor DCIs on its network systems.

\footnotetext{
${ }^{6}$ IEEE 1547-2003 4.1.6 Monitoring Provisions [IEEE. Standard for Interconnecting Distributed Resources with Electric Power Systems. IEEE Std. 1547-2003. 2003. http://grouper.ieee.org/groups/scc21/1547/1547_index.html. Accessed October 3, 2009.]
} 
- DCIs are feasible to install, both from a cost perspective and a technical perspective. Not all manufacturers offer DCI at this time, however.

- For medium to large PV systems, utility monitoring and control should be considered for both generation tracking and for high-penetration controls. This might require upgrading the utility SCADA system or putting other smart grid technology in place.

Figure 3-3 illustrates one example of how a DCI might be applied.

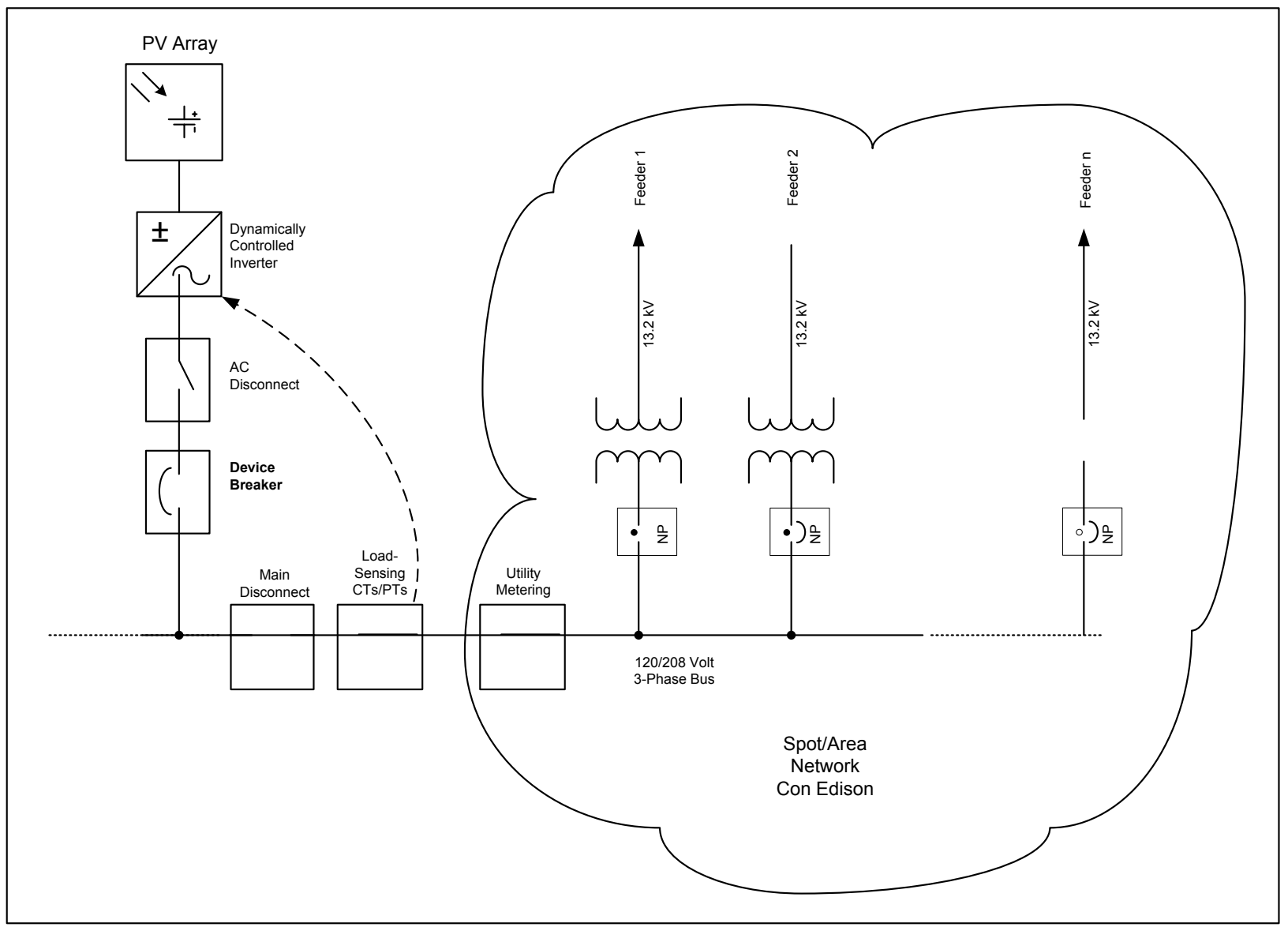

Figure 3-3. Schematic of a secondary network with DCI

Remarks: DCIs work well for ensuring that a PV system does not export power onto either an area or spot network. Because the output of the PV system would vary depending on the incoming utility power, the systems are ideal when the load status changes.

\subsubsection{LF-Load Flow Studies}

Description: A utility load flow study evaluates the effects of a proposed PV system - and other distributed generation systems - on a secondary network. In such studies, analysts use software tools to help the utility engineers understand if the proposed system would cause any reliability problems and whether any facilities would need to be upgraded. The studies, which are typically quite detailed, can be time-consuming and expensive. Where appropriate, both the utility and the PV system owner would prefer a simplified approach. 
Concerns Addressed: Network protector operation and cycling

Ranking of Solution: Network protector operation and cycling—-good

Penetration Level: Load flow studies are appropriate at all levels of network penetration. Because of the nature of secondary networks and their sensitivity to the direction of current flow, load flow studies are useful even when there are relatively few PV systems on a network. As penetration levels increase, concerns that PV systems will disrupt network operations grow, and load flow studies might need to be completed on all PV system installations.

\section{Advantages:}

- The utility engineers have the expertise to conduct load flow studies using computer models.

- Load flow studies allow engineers to evaluate potential PV systems at a specific location and design solutions appropriate for that system.

\section{Disadvantages:}

- A load flow study is a time-consuming process that can delay a project.

- Modeling tools for distributed generation systems are under development, but tools currently available are limited.

- It may be difficult to discern which potential installations require a load flow study.

- Secondary networks and load flow characteristics will change over time. As a consequence, recommendations that come from load flow studies might need to be reevaluated in the future.

\section{Financial Considerations:}

For the PV system installer/owner

- The cost of a load flow study is borne by the PV system owner up to cost limits set by the public utility commission. Costs may range from $\$ 500$ to $\$ 5,000$, and possibly more for more complicated systems.

- The study could indicate that specific relaying equipment, DCIs, or additional equipment is required, and these costs can be significant.

- Subsequent load flow studies could be required as the network changes and as PV systems are added.

For the utility

- After the cost limit set by the public utility commission is reached, further costs are borne by the utility.

- Analysts completing load flow studies can become overwhelmed during periods where there are large numbers of applications. 
- Results do not necessarily mitigate future network problems. Network changes may require the utility to run new load flow studies at their own cost.

\section{Impact of Solution:}

- A load flow study can uncover potential problems in a particular area and will help the engineers make reasoned recommendations.

- A load flow study can be time-consuming, which can have some impact on application processing.

- These studies are unlikely to be necessary for small- to medium-sized PV systems.

- The results of the study might indicate that special control equipment would be required (RPRs, MIRs, DCIs, or smart grid monitoring/controls). This equipment, if required, could have significant financial implications on the PV installer or owner.

Smart Grid Issues: Load flow studies help determine which PV systems can be sited using autonomous control and which systems might need external monitoring, information exchange, and control. Some network systems might require more smart grid solutions than others.

\section{Road Map:}

- A load flow study is not required for proposed nonexporting PV systems.

- As the number of studies of potential PV system installations increases over time, it should become clear that some PV systems do not need a load flow study. Need for studies may depend on PV capacity, penetration levels, location, and type of PV system.

- PV systems and other distributed generation equipment can be monitored using a database and mapping system. Data from this monitoring can then be incorporated into load flow studies of future PV systems.

- If a Web-based application process were available, it would be useful to consider a preliminary load factor study set of criteria for applicants. This might help them understand the constraints in their area based on their proposed design. In addition, PV system designers could find the resulting design parameters useful during their design process.

\section{Remarks:}

- Load flow studies are often critically important for any electric utility evaluating distributed generation systems.

- Numerous software packages are available for conducting load flow studies, although none assess the impacts of distributed generation on a three-phase networked system.

- Future software releases could reduce the time and cost of load flow studies, which would benefit customers and the utility.

- Lessons learned from studies of current PV systems could reduce the number, time, and cost of future load flow studies, which would benefit customers and the utility. 


\subsubsection{SCADA—Integrate Inverters with Communication Capabilities}

Description: SCADA and AMI systems could be configured, along with communication systems, to use inverter technology for monitoring and controlling PV systems. This would allow a utility to monitor the PV system's output, which in turn would enable curtailment or power diversion to, for example, a local storage system, load bank, or microgrid in the event of a grid problem.

\section{Concerns Addressed:}

- Unintentional islands

- Network protector operation and cycling

\section{Ranking of Solution:}

- Unintentional islands - untested

- Network protector operation and cycling - untested

Penetration Level: This is an appropriate solution for all levels of penetration.

\section{Advantages:}

- Integrating PV system inverters into SCADA or AMI systems could allow for continuous monitoring of PV system performance. AMI systems could collect data for geographical areas and report back to SCADA.

- If coupled with two-way communications technology, AMI systems could be used for communicating with PV systems when those systems were required to curtail power output.

- SCADA monitoring of PV inverters would allow for real-time monitoring by system operators responsible for dispatching generation resources. Real-time monitoring in many SCADA systems results in data that are updated every 1 to 5 seconds.

- Continuous monitoring of PV systems would be an important tool for understanding PV system performance and the ramp rates that would be associated with various weather phenomena.

- Understanding the overall power output of blocks of PV systems would allow for a significantly improved understanding of the benefits of PV on the utility networks.

\section{Disadvantages:}

- Utility systems are not in place to monitor real-time customer-side information.

- AMI systems, which are currently designed for billing customers, are often slow and are not designed for fast data collection.

- There may be data collection limitations on the number of PV systems that could be monitored via AMI. 
- SCADA system monitoring would not be practical for monitoring each individual PV system (especially residential systems). Using intermediary systems (e.g., grid agents and smart grid platforms) to accumulate data for blocks of PV systems would be necessary for managing the large amounts of data. This would negate the possibility of real-time monitoring.

- Costs to implement and maintain these systems would be high.

\section{Financial Considerations:}

For the PV system installer/owner

- AMI monitoring of a PV system is more expensive for the PV system owner because the inverter manufacturer adds costs for specific monitoring points or for smart grid communications capabilities (e.g., via Zigbee, Bluetooth, WAN, and IEEE 802.11x, among others).

- To maintain grid reliability, PV systems might be asked to curtail operations for any reason. These curtailments would reduce the amount of energy produced annually, which would impair the economic performance of the system and extend payback periods. New tariffs might compensate PV system owners for curtailed operations, similar to existing demand response provisions.

For the utility

- High cost to implement and maintain.

- Significant investment (likely in the billions of dollars) will be required as part of an overall smart grid investment. These investments will need to be paid both by the PV system owners and the ratepayers as a group, as well as other stakeholders. This may be considered part of an overall smart grid system investment that is paid for by all ratepayers. Investments would likely be needed with either SCADA or AMI system upgrades/additions as well.

\section{Impact of Solution:}

- Network operators will be able to track bulk PV system performance for specific areas within a network.

- Utilities would have the ability to monitor PV systems and notify owners if their PV systems cease to operate or sustain significant change in expected performance. If the utility is relying on PV system availability for operations and planning, SCADA systems would allow the utility to implement compliance measures, including penalties for nonperforming or underperforming systems. This may not be economically feasible or practical for monitoring smaller systems.

- SCADA, AMI, or smart grid systems could monitor the difference in load and power production and, through additional communications, could notify the system operator of a problem or send a control signal to the inverter to curtail operation. 
- Understanding overall PV system performance would allow the utility and distribution, transmission, and generation operators to better utilize the resource and to plan for future load growth.

- When the utility engineers know the characteristics of PV systems on their networks, they can design more accurate and timely tariffs.

- Understanding the measured profile of all PV systems in an area might help researchers establish the benefits of, for example, PV systems and battery storage.

\section{Location of Solution:}

- SCADA systems have both software and hardware components and are integrated with communications systems. SCADA equipment for monitoring PV systems would be located on the distribution system on a secondary network.

- AMI systems include utility revenue meters and one or more communications platforms. The communications platforms can be completely separate from the utility distribution system, or they can use the electric distribution systems via a power line carrier system.

\section{Smart Grid Issues:}

- SCADA integration may be impractical without additional communication systems or an intermediary (e.g., grid agent system) that could transfer bulk PV system information gathered in pockets of the network.

- Security and cyber security are of concern.

- AMI systems typically monitor utility revenue meters and report back to a central meter collection computer via PLC, radio signal, fiber optic system, or a combination of these. Some AMI systems have the capability to both monitor and issue commands to external devices (e.g., air conditioners or thermostats). PV systems with AMI would need to be monitored and commanded with the help of smart grid devices (such as grid agents) that have the ability to minimize the data movement in any direction. This would prevent the AMI system from being overwhelmed by large amounts of data.

- AMI systems that rely on slower reporting technology or those with unidirectional information exchange (from meter to utility) would likely have limited usefulness in monitoring PV systems (other than collecting production data). To be effective, an AMI system must have a low-latency communications backbone and the capability to monitor and control external devices.

Road Map: AMI systems should be chosen and deployed with several considerations, including

- Overall cost to install meters and communications

- Overall cost to read meters

- Quality of AMI system and track record with other utilities

- Adaptability to new technology (can the AMI devices integrate new devices?)

- Speed of data retrieval and speed of commands to meters (if available) 
- Ability to integrate distributed generation into their platform.

Figure 3-4 illustrates one example of how a SCADA/AMI system might be applied.

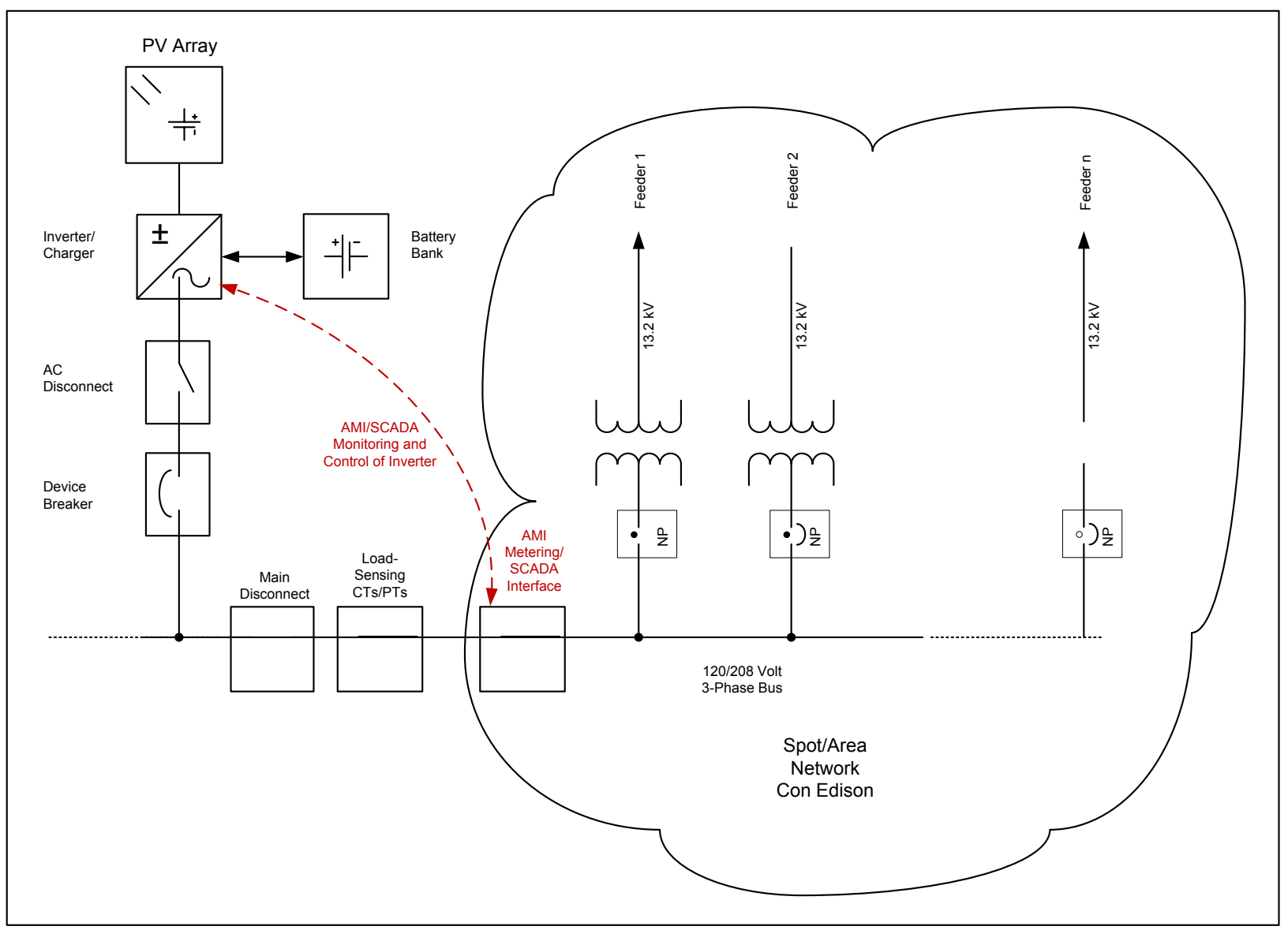

Figure 3-4. Schematic of a secondary network with SCADA or AMI interface to inverter (batteries optional)

Remarks: The utility will decide whether to add monitoring and control of PV systems - via AMI communications and control technologies - to its operations. SCADA system integration would likely be focused on bulk PV systems reporting to an intermediate control device.

Inverter manufacturers need to design inverters capable of interfacing with external systems. These inverters will need to have standardized outputs for monitoring power, energy, and status, along with inputs for control of chargers and curtailment.

\subsubsection{ES-Energy Storage}

Description: PV systems can be operated with batteries connected to the inverter. The batteries would be charged during periods when the power is not needed on the grid, and would be available to move that power back onto the grid when it is needed. Batteries could also be used as a backup system for a customer's home or business, or for other critical loads (streetlights, emergency radios, life safety apparatus, and emergency loads). Batteries could also be used to improve ramp rates of PV systems. 


\section{Concerns Addressed:}

- Voltage rise

- Voltage flicker

- Voltage drop resulting from sudden PV loss.

Note: PV system batteries might address other concerns because they have the potential to keep a PV system from exporting. They can also allow a PV system to shift its power output to periods that are most beneficial to the utility system (e.g., shifting power to peak demand times).

\section{Ranking of Solution:}

- Voltage rise - good. Voltage rise could occur when PV systems export power to the network. Batteries could prevent exporting by storing excess power rather than sending it back to the network.

- Voltage flicker-good. Flicker could occur when many PV systems drop offline because of sudden cloud cover. Batteries could maintain inverter power output in the event of sudden loss of DC power from the PV arrays.

- Voltage drop resulting from sudden PV loss - poor. Once a feeder or network drops offline, and then is restored, the inverters - with or without batteries - must remain offline (once normal voltage and frequency are restored) for a period up to 5 minutes. ${ }^{7}$

Penetration Level: ES is an appropriate solution for medium to high levels of penetration.

\section{Advantages:}

- Even small amounts of battery storage can smooth out and reduce the ramp rate of PV systems dropping out with cloud cover. Just one automotive-sized battery could improve system ramp performance.

- Larger storage systems might allow for shifting energy production to grid peak times.

- Customers could run inverters and batteries to lower their peak demands, potentially lowering monthly electric costs.

- Storage systems could be used to allow customers to operate in stand-alone mode during outages.

- For PV systems that are required to be nonexporting, batteries might store extra energy instead of cutting back production or installing a smaller PV system.

\section{Disadvantages:}

- Batteries are expensive and experience losses associated with charging and discharging.

- Lead-acid batteries require significant maintenance.

\footnotetext{
${ }^{7}$ Per IEEE 1547-2003 4.2.6 [IEEE. Standard for Interconnecting Distributed Resources with Electric Power Systems. IEEE Std. 1547-2003. 2003. http://grouper.ieee.org/groups/scc21/1547/1547_index.html. Accessed October 3, 2009.]
} 
- Storage of batteries can be difficult.

- Concerns about explosive gas and corrosive acids are significant.

- Batteries have a limited life expectancy.

\section{Financial Considerations:}

For the PV system installer/owner

- Inverters that also charge batteries typically cost more than standard inverters.

- Battery storage containers, cables, monitors, and venting all add to the balance of system cost.

- Batteries can reduce peak demand for commercial and industrial customers who pay a demand and energy component on their electric utility bill, with potential savings on monthly utility bills.

- Battery systems last only a few years under normal conditions and replacing them adds substantial costs to the PV system.

For the utility

- Battery systems integrated with PV could flatten system demands, lowering costs and potentially lowering requirements for generation reserves (at higher levels of integration).

- If significant levels of PV system penetration were attained in areas where the grid is congested, PV systems with batteries could be used to reduce grid congestion. This has the potential of reducing outages, deferring capital improvements, and lowering service calls.

\section{Impact of Solution:}

For area networks, PV systems with battery storage could flatten the load profile, which would benefit the utility. In addition, storage could be used to ensure that PV systems stay in a nonexporting mode.

For spot networks, storage could be a viable option to keep PV systems nonexporting (batteries could charge when notified by an MIR). Batteries would also allow for an overall larger system, especially if customer load is unpredictable and minimum customer demand load is low.

Location of Solution: Battery systems integrated with PV systems would typically be installed within a few feet of the PV system inverter. 


\section{Smart Grid Issues:}

- Battery systems could be monitored and possibly dispatched manually or automatically when needed.

- Sufficient quantities of battery storage on PV systems could have a positive impact on reserve requirements.

\section{Road Map:}

- Battery systems could be deployed in PV systems today because the inverter and battery technologies exist.

- Depending on system need, peak-reducing battery systems would need to be dispatched based on a predefined schedule or through SCADA/AMI systems.

- Smart grid equipment could be deployed that would charge batteries if there is insufficient load on the network. Conversely, batteries could be discharged during peak times.

Figure 3-5 illustrates one example of how batteries might be applied.

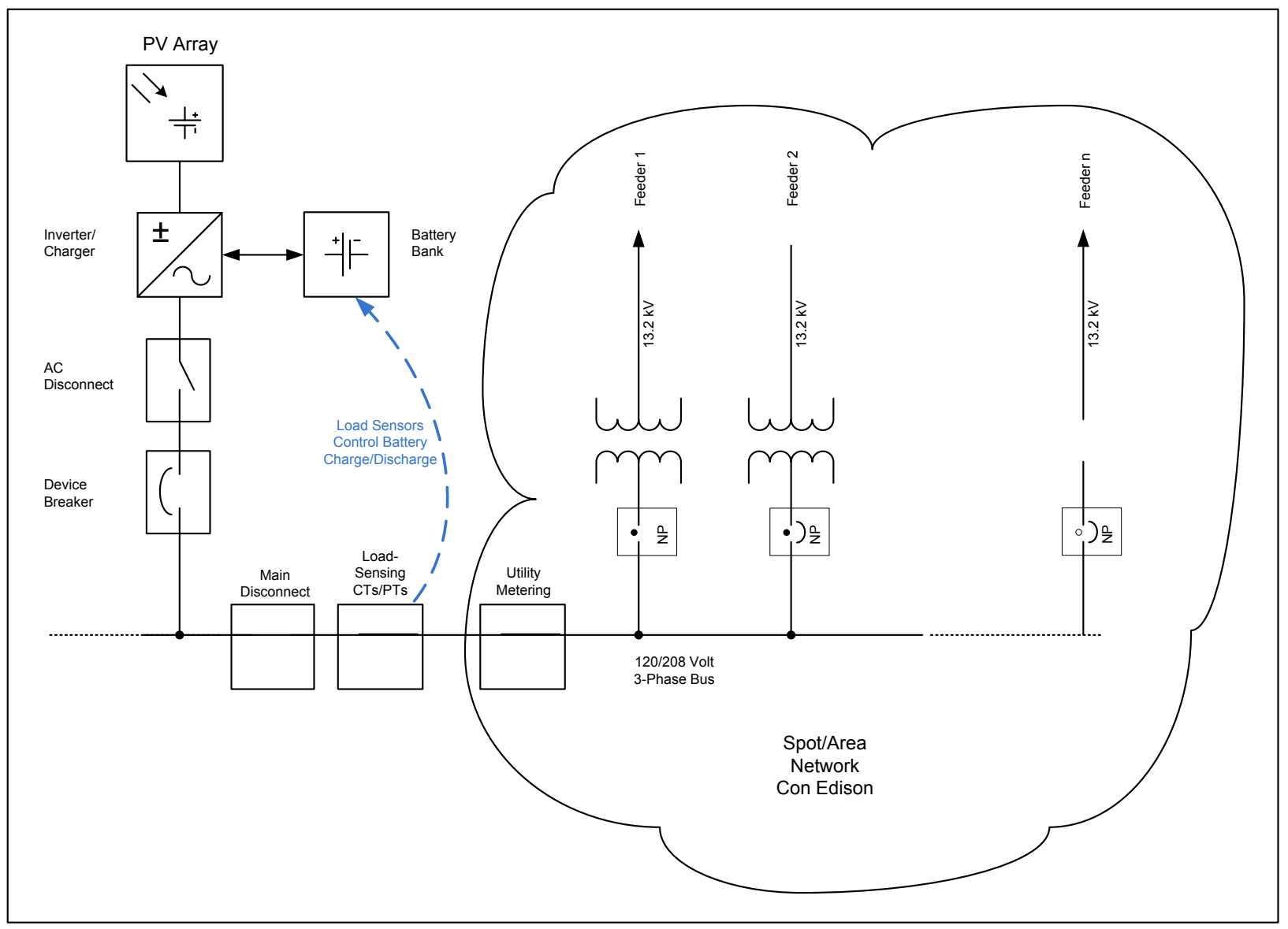

Figure 3-5. Hypothetical design of a secondary network with MIR and battery technology 


\section{Remarks:}

- For grid-connected PV systems, batteries are currently very expensive. Adding one or two batteries, though, could improve overall system performance.

- Batteries might also be available for emergency systems, traffic lights, and emergency radios, among other applications.

- Battery power might also support smart grid components in the event of an outage by keeping information moving even if utility power is absent.

- Using battery systems to perform multiple tasks will increase the value of the battery, thus improving the economics.

\subsubsection{PRO—Advanced Protective Schemes}

Description: Advanced protective schemes ${ }^{8}$ allow the customer to ensure proper operation of circuit breakers and other protective equipment during instances of equipment failures (when fault currents are present). Some PRO already exist and are in place for distributed generation systems; others are under development.

Concerns Addressed: Fault current coordination issues

Ranking of Solution: Fault current coordination issues—untested

Penetration Level: PRO is an appropriate solution for low and medium levels of penetration. The equipment might need to incorporate smart grid controllability, especially at higher penetration levels.

\section{Advantages:}

- Although the technology exists today, much more development can be done to make these schemes technically and financially feasible (for customers and for the utility).

- PRO technologies can be monitored by utility-owned SCADA systems.

\section{Disadvantages:}

- Systems might cost more to install, for both the customer and the utility.

- In the case of transfer trip schemes, or other similar schemes in which protective devices communicate with other systems, there may be significant distances between the monitored equipment and the controlled equipment. Communications could be unreliable and might require upgrades.

- Protective schemes might need to be evaluated and changed as the network changes (e.g., as new PV systems or new loads or both are added).

\footnotetext{
${ }^{8}$ Includes directional overcurrent tripping, blocking, and high speed transfer trip (HSTT), among others.
} 


\section{Financial Considerations:}

For the PV system installer/owner

- High Speed Transfer Trip (HSTT) might require system modification and new or additional control equipment, which would increase PV system installation costs.

- The PV system could be forced offline and not produce energy on occasion, causing loss of energy production and revenue.

- Cost of review of design and load data by the utility.

For the utility

- The utility incurs costs when the protective scheme equipment is monitored or inspected on regular intervals. Those costs are justified only if recovered through approval of the PSC.

- If the installation and material costs of the advanced protective schemes are paid by the utility, those costs may be capitalized, if approved by the PSC.

\section{Impact of Solutions:}

Advanced protective schemes might prevent fault current from being injected into the system in the event of a fault. PV system fault current contribution is not considered problematic, however, because of the behavior of the inverters. Therefore, installing these advanced protective schemes for PV systems might have little effect on networks other than, perhaps, to add more equipment that requires maintenance, inspection, and adjustment.

In addition, HSTT schemes may drop PV systems offline unnecessarily if not carefully installed and maintained.

\section{Location of Solution:}

- These devices reside on the distribution system and components can be installed at the substations, on the feeders, at network protectors, or at a customer's service equipment or inverter location.

- Some solutions will require components that are located at various points on the distribution system, which will necessitate communications links among multiple components.

\section{Smart Grid Issues:}

- Special protective devices might be monitored and or controlled by smart grid technology.

- Smart grid-enabled devices might be programmed to change characteristics based on the status of the network during specific times of the day or particular seasons of the year. 
- Smart grid communications systems would likely be an important component in monitoring, operating, coordinating, programming, and maintaining protective equipment.

\section{Road Map:}

- The utility will continue to study fault current contribution from inverters and determine if they are a threat to the protective schemes.

- If load flow studies conclude that advanced protective schemes are needed, and worth the financial expenditures, a list of viable schemes would be developed.

- Viable protective schemes should be rolled out for PV systems over a specific size or at a specific penetration threshold.

Figure 3-6 illustrates one example of how an HSTT scheme might be applied.

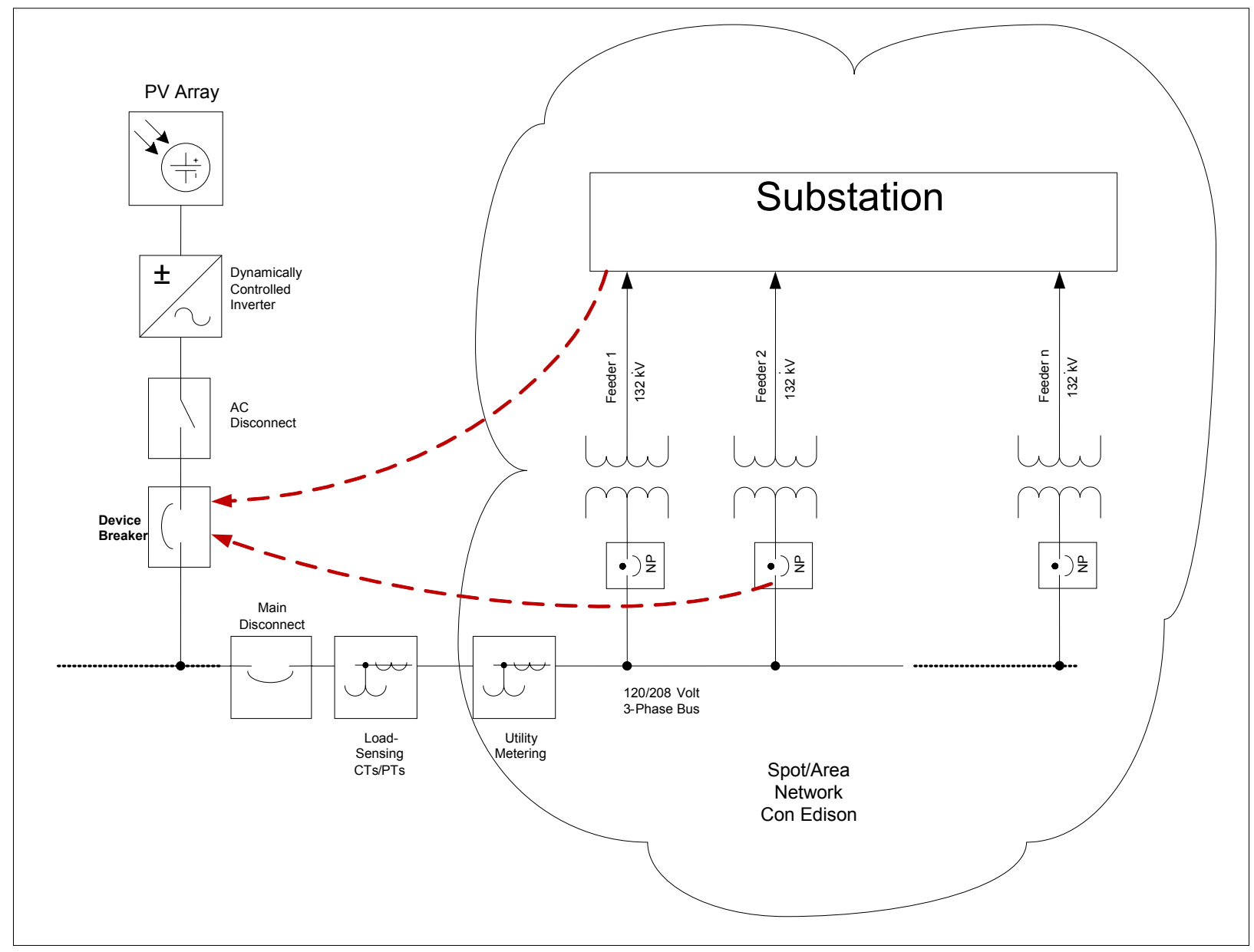

Note: Signal to trip breaker can be initiated by, for example, network protectors or substation relays.

Figure 3-6. Schematic of a secondary network with transfer trip protective scheme

Remarks: Addition of new distributed generation systems on a network, as well as load changes, will affect advanced protective schemes. 


\subsubsection{OR-PV Array Orientation}

Description: PV panels can be oriented at different tilt angles (horizontal, vertical, or an angle in between) and different azimuths (facing east, south, west, or an angle in between). They can be fixed, or they can track the sun across the sky in one or two axes. Variations in tilt angle, azimuth, and tracking affect daily and seasonal output.

Discussion: Tilt angle affects the PV system power production over the course of the year. Mounting systems with a tilt angle equal to the site's latitude maximizes spring and fall power production. Increasing the tilt angle to a more vertical position increases production during the winter months, and decreasing the tilt angle to a more horizontal position increases production during the summer months (often the most desirable).

Azimuth affects the PV system power production over the course of a day. South-facing systems produce the most power at midday. East-facing systems have better morning production, and west-facing systems have better afternoon production. Tracking systems have fairly steady production during all daylight hours. Tracking systems are more expensive than fixed systems, however, because they have higher installation and maintenance costs.

PV systems are usually designed to minimize the cost per kilowatt-hour of energy by maximizing annual energy production while minimizing installation and maintenance costs. A $\mathrm{PV}$ array can also be designed to maximize power output during certain hours of the day and months of the year, but this may increase the cost per kilowatt-hour of energy.

\section{Concerns Addressed:}

- Power system planning - load profile change

- Power system planning - generation dispatch impact

\section{Ranking of Solution:}

- Load profile changes - good at low penetration, untested at high penetration. These changes might help match the PV system power output to the load profile, but can shift the output only during daylight hours. Because customers will change their tilt and azimuth only with an incentive from the utility or if paid the higher market price of peaking power, we do not know whether this solution will be cost-effective in terms of overall grid performance.

- Generation scheduling flexibility — untested. Modifying the power output hours will have limited effects on daytime power output from PV systems.

Penetration Level: This solution could be incorporated in some PV systems (some PV arrays will have limited adjustability), and could have some impact at all levels of penetration.

\section{Advantages:}

- Several online tools can be used to determine the power output profile of a PV system based on tilt and azimuth. Models such as IMBY ${ }^{9}$ can inform the utility and the PV

\footnotetext{
${ }^{9}$ For more information on the IMBY (In My Backyard) tool, see http://www.nrel.gov/eis/imby/.
} 
system owner about the implications on system performance. Figures 3-7 through 3-11 show an example of one system.

- These angles can be adjusted in many cases to best fit the needs of the utility based on the average daily load profile.

\section{Disadvantages:}

- Adjusting tilt and azimuth of a PV array may be possible for some PV systems, but at a cost of reduced annual PV system energy production and increased balance of system cost.

- Some systems do not have flexibility on the tilt and/or azimuth setting and must conform to the environment in which they are placed. Building-integrated PV (BIPV) systems generally have little flexibility with regard to panel orientation.

\section{Financial Considerations:}

For the PV system installer/owner

- Many PV arrays can be adjusted to required or desired tilt and/or azimuth angles. The cost can be minimal or significant, depending on the situation. Each PV array must be evaluated for panel orientation flexibility.

- Overall energy production will vary depending on the chosen angles. Loss of annual energy production might reduce the financial benefits of the PV system unless utility incentives were available.

- Cost of review of design and load data by the utility.

For the utility

- Overall annual energy output might be lowered depending on the tilt and azimuth of the panels. If the utility adopts requirements for the PV system load shape, the utility might need to offer financial incentives to the PV system owner.

- Time-of-day or time-of-year rates could cause PV system owners to adjust their systems to maximize their financial position, which could in turn create shifted load profiles. In this case, the utility might need to readjust its system resource mix.

- Flattening of combined PV production output could be useful when committing generation reserves.

- Cost of committing generation reserves might increase as PV system generation profiles change.

- Time-of-day or time-of-year rates for PV systems might have a significant effect on the PV array orientation design, which may or may not benefit the utility. 


\section{Impact of Solution:}

- Adjusting panel orientation — tilt, azimuth, or both - will change the PV energy production. Doing so can help shape the load profile of the customer and the secondary network.

- Panels may be oriented to produce more power during summer months or they may be oriented to generate more power during spring and fall.

- Panel orientation optimization can be encouraged by offering customers incentives to contribute power and energy during specific times of the day and/or specific months of the year.

Location of Solution: This solution would be sited at the PV array.

Smart Grid Issues: A smart grid system, capable of monitoring PV system power output, could be employed to track the system performance on one system or for an entire network.

Examples: A model of a 4.2-MW (DC) PV system, located in Manhattan, was evaluated based on a summer-peaking tilt angle ( $0^{\circ}$ flat) as well as a spring-fall peaking tilt angle $\left(\sim 45^{\circ}\right)$. Additionally, the system was evaluated for morning-peaking azimuth angle $\left(90^{\circ}\right)$ and an evening-peaking azimuth angle $\left(270^{\circ}\right)$. Figures 3-7 through 3-11 illustrate the results.

- Figure 3-7 is an example of an array installed tilted $41^{\circ}$ with an azimuth of $180^{\circ}$ (southern orientation for optimal annual production).

- Figure 3-8 is an example of an array installed tilted $41^{\circ}$ with an azimuth of $90^{\circ}$ (easterly orientation for enhanced morning power production).

- Figure 3-9 is an example of an array installed tilted $41^{\circ}$ toward the south with an azimuth of $270^{\circ}$ (westerly orientation for enhanced afternoon power production).

- Figure 3-10 is an example of an array installed with $0^{\circ}$ tilt (flat array installation) for maximized power production during summer months.

- Figure 3-11 is an example of an array installed with $45^{\circ}$ tilt (toward due south) for maximized power production during spring and fall months. 


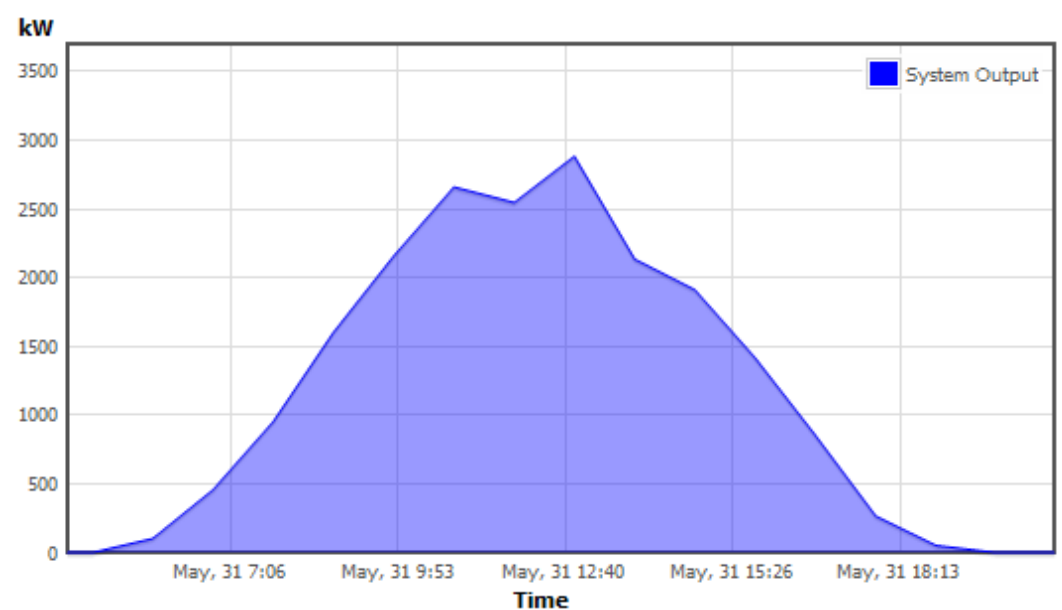

Figure 3-7. IMBY/PVWatts results for $41^{\circ}$ tilt and $180^{\circ}$ azimuth (typical system profile for flat panel installation)

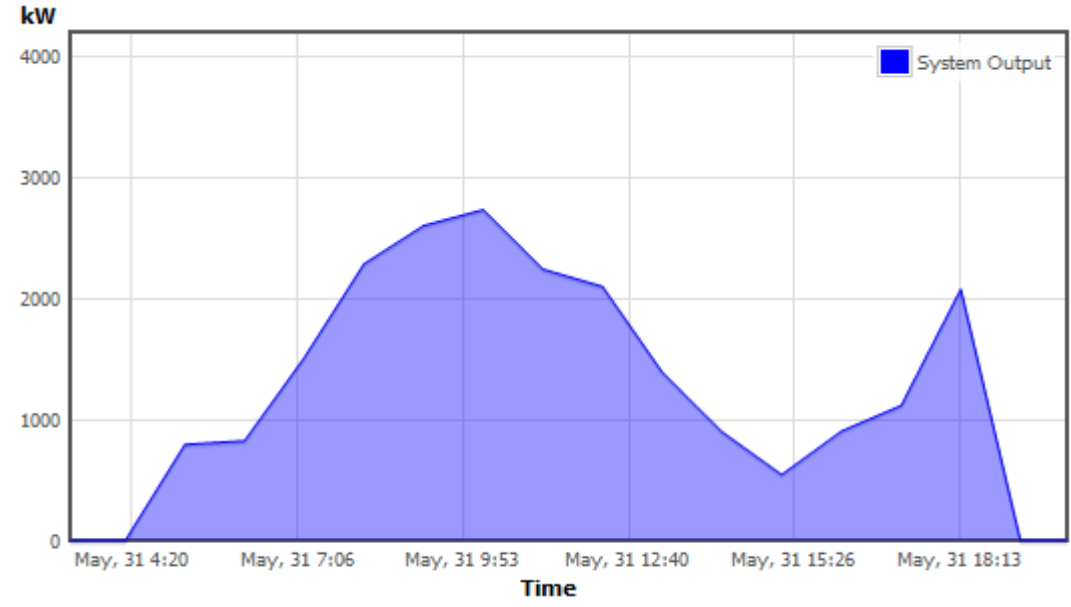

Figure 3-8. IMBY/PVWatts results for $41^{\circ}$ tilt and $90^{\circ}$ azimuth (panels adjusted for morning peak)

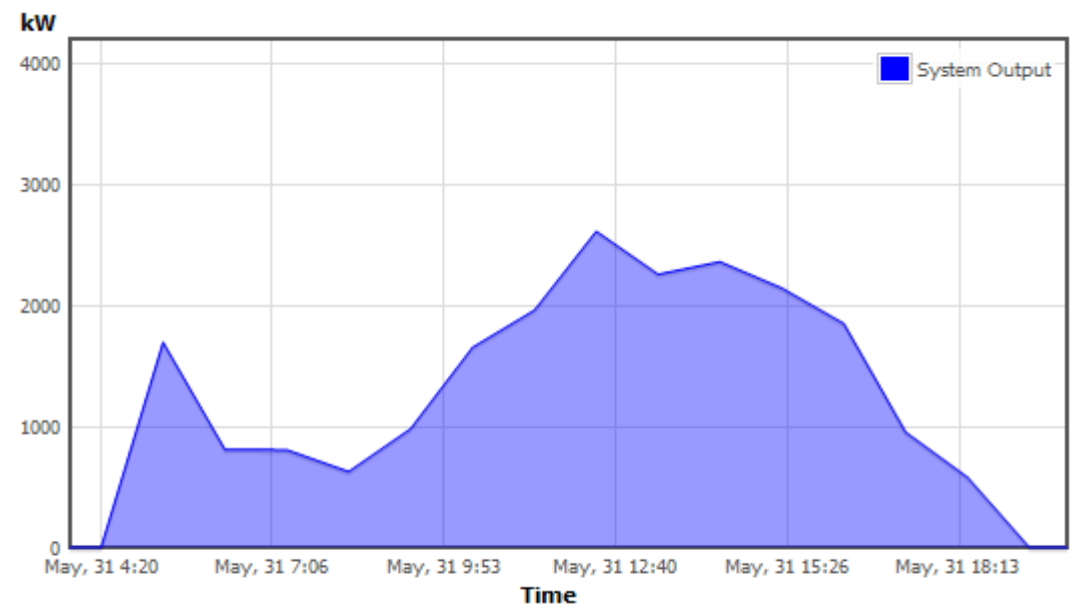

Figure 3-9. IMBY/PVWatts results for $41^{\circ}$ tilt and $270^{\circ}$ azimuth (panels adjusted for afternoon peak) 


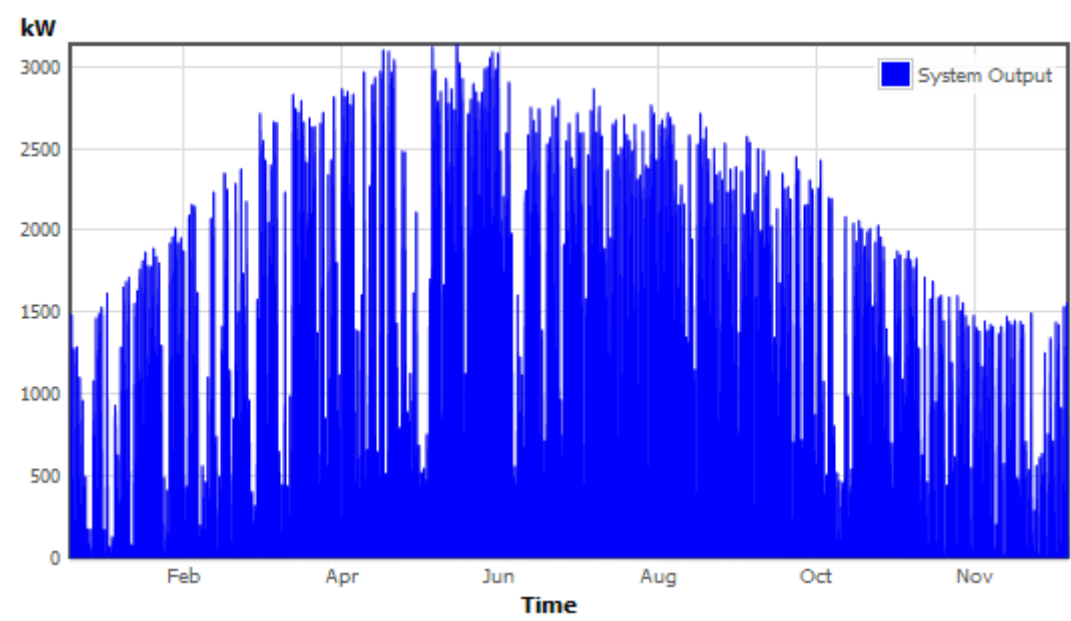

Figure 3-10. IMBY/PVWatts annual hourly PV simulation profile for $0^{\circ}$ tilt (note the peak in spring/summer)

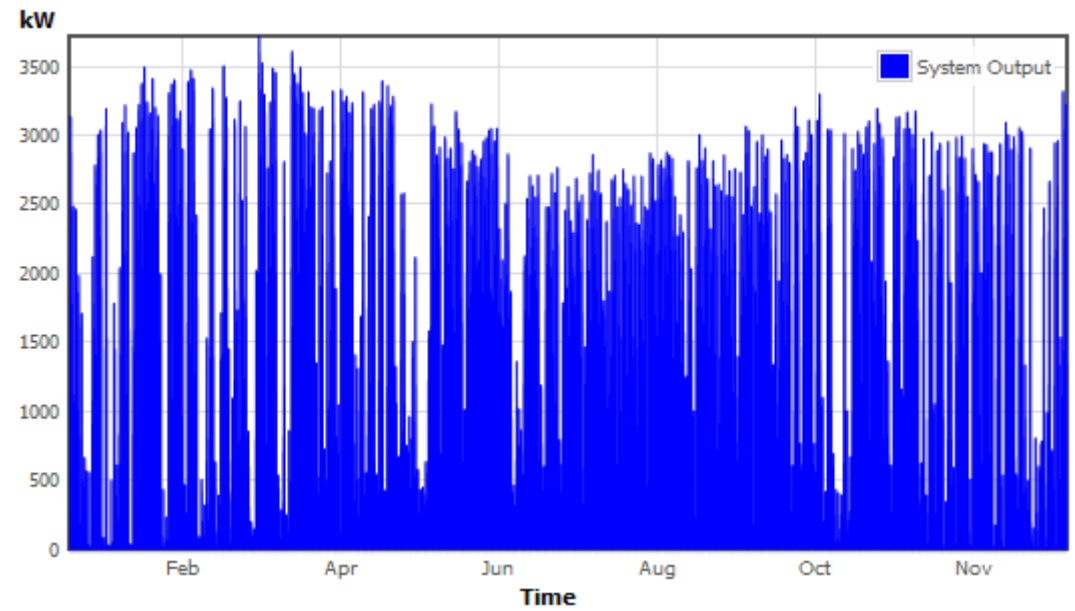

Figure 3-11. IMBY/PVWatts annual hourly PV simulation profile for a south-facing array with a $45^{\circ}$ tilt (note higher output in spring and fall months)

\section{Road Map:}

- Future PV system installations might be considered for modified panel orientation by offering PV system owners incentives to increase power production during specific times of the day and the year.

- Financial models will need to be developed and tariffs evaluated in order to encourage PV system owners (with incentives) to orient their arrays in a manner that best meets the generation needs of the utility.

Remarks:

- PV systems that track the sun will produce the most power and energy over the course of a year, but tracking systems for rooftop design are expensive and may not be practical. Most rooftop systems are designed and installed with a fixed tilt and azimuth, and can often be installed with the panels oriented for greater power production during time intervals chosen by the system installer or with input from the utility. 
- Networks with low penetration potential would not see a significant change in their load profile based on PV system installations, and modifications to panel orientation would have little effect. The utility may choose, however, to work with PV system owners to modify panel design orientation regardless of their location. 


\subsection{Utility Application Process Review}

As applications for distributed generation systems (like photovoltaic [PV] installations) increase nationwide, public utilities are facing mounting delays in the application process. This section describes surveys conducted on the interconnection processes of U.S. utilities that are connecting distributed generation systems to networks. It also identifies ways in which utilities could streamline the application process.

Recommendations from this review include making application documentation available on the utility's Web site; establishing an online tracking system to inform the contractor/homeowner about the status of an application; creating qualified equipment and contractor lists; removing application fees; and offering training and outreach programs to contractors and homeowners. 


\section{Contents}

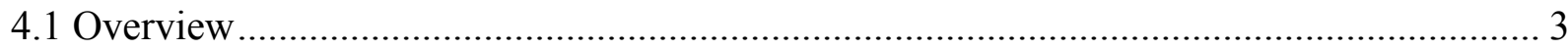

4.1.1 Application Distribution Process ............................................................................ 3

4.1.2 Tracking System Requirements ........................................................................ 3

4.1.3 General Application Review Process..................................................................... 4

4.1.4 Requirements for a Full Utility Engineering Study ............................................... 4

4.1.5 Inspection and Verification Test Requirements..................................................... 4

4.1.6 Outreach Education Program and Training ………................................................ 5

4.2 New York State Application Process............................................................................ 5

4.2.1 Discussion of Proposed Application Process............................................................... 6

4.3 Summary of Recommended Practices ……………….................................................. 7

Appendix 4-A: List of Questions on Application Process ..................................................... 8

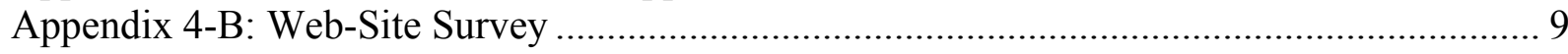

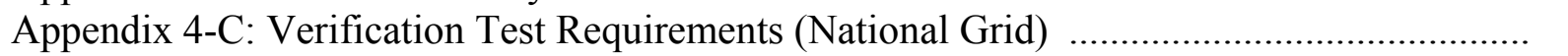




\subsection{Overview}

To heighten the efficiency of the application process for distributed generation systems like PV, the New York Solar America City Program partnered with the U.S. Department of Energy's (DOE) National Renewable Energy Laboratory (NREL) to conduct a survey of public utilities around the country. The survey - conducted for New York City's utility, Con Edison-explored ways to streamline the application process without sacrificing the quality of PV system installations. The NREL team conducted phone interviews with various utility companies to discuss their application review process. The six utilities surveyed by phone were Seattle City Light, Xcel Energy, Pacific Gas \& Electric (PG\&E), Sacramento Municipal Utility District (SMUD), National Grid, and Public Service Enterprise Group (PSEG). The survey questions (contained in Appendix 4-A) focused on the following areas of the review process:

- Application distribution process (Web-based or mail)

- Tracking system requirements

- General application review process

- Requirements for a full utility engineering study

- Inspection and/or verification requirements

- Outreach education program and training.

We also reviewed ten utility Web sites, and the Excel spreadsheet in Appendix 4-B gives additional information we gleaned from these reviews.

In the subsections that follow, we briefly summarize the interviews for each area of the survey.

\subsubsection{Application Distribution Process}

We learned that, for the most part, applications are distributed via the utility's Web site. At the time of the interviews and the Web site review, SMUD was the only utility with mail-in applications. As of June 8, 2009, however, SMUD's applications became available online. The applications are generally categorized by the size of the distributed generation system rather than the type. All six utilities surveyed indicated that most applications are for residential installations sized at $<10 \mathrm{~kW}$.

\subsubsection{Tracking System Requirements}

Xcel Energy was the only utility company surveyed that tracked applications online. Xcel's application process is done entirely through the Web, e-mail, and fax. The applications are all online and can be filed by either the homeowner or the contractor installing the system. Once the application is approved, the applicant receives an e-mail outlining the next step in the application process. All the steps in the application review process are dated and tracked in Xcel's online database. Other utilities we interviewed designate a representative as an applicant's point of contact. 


\subsubsection{General Application Review Process}

Once the applicant fills out the application, it is sent-along with a one-line diagram and a list of equipment - to the utility for review. If the application is for a single-phase system sized below 15 to $30 \mathrm{~kW}$, there is no major review. For large, three-phase, $480-\mathrm{V}$ systems, though, the application process requires review and approval by a licensed electrical professional engineer. Both Xcel Energy and PG\&E reported that about $90 \%$ of all their net energy metering (NEM) projects are sized below $10 \mathrm{~kW}$. In the majority of utilities surveyed, applications for small PV systems $(<10 \mathrm{~kW})$ are reviewed by the "office specialist" and the one-line drawings are generally reviewed by an engineer. Applications using equipment from an approved list (certified by a qualified independent testing laboratory) will move through the system more quickly. Certified equipment lists are located on the New York State Web site at http://www.dps.state.ny.us/distgen.htm and the Go Solar California Web site at http://www.gosolarcalifornia.ca.gov/equipment/index.html. The California state Web site also has a list of certified contractors at http://www.gosolarcalifornia.ca.gov/retailers/search-new.php. To be listed on this Web site, California requires that the contractor have a $\mathrm{C} 10$ (EE license) or a $\mathrm{C} 45$ (solar license). Contractors must also supply references along with a minimum of five PV systems they have installed previously.

Once the application is approved, the utility company or the city electrical inspection (permitting) office schedules an inspection of the PV system. After the inspection is signed off, the interconnection can take place with the installation of an advanced net meter. Some utilities, including SMUD and Xcel, are then required to send out the rebates within 30 days.

\subsubsection{Requirements for a Full Utility Engineering Study}

We found that utilities typically approve PV systems without a full utility engineering study when the aggregate generation is below 10 to $50 \mathrm{~kW}$ on a single-phase branch of a distribution circuit, or if the aggregate generation is below $150 \mathrm{~kW}$ on a single threephase distribution feeder.

\subsubsection{Inspection and Verification Test Requirements}

In general, the utilities surveyed require that a qualified individual perform a verification test on the initial parallel operation of a generating system. Qualified individuals include professional engineers or certified technicians and licensed electricians with experience in testing protective equipment. The test requires removing power to the inverter, and then visually checking the inverter to ensure it is not producing energy. Voltage may be removed by one of the following methods, as approved by the utility: 1) opening the AC disconnect (if present); 2) opening the main disconnect; 3) opening the circuit breaker tied to the inverter output; or 4) removing the fuse tied to the inverter output. More formal test plans for complex systems are determined on a case-by-case basis.

The utility usually reserves the right to witness verification testing or to require written certification that the testing was successfully performed. Xcel Energy requires only that the city electrical permit be issued before it places a net meter on the system. Xcel does not inspect any of its systems, relying solely on the city's permitting process. 


\subsubsection{Outreach and Education Programs and Training}

Our review of the ten utility Web sites indicated that many of the utilities have posted documentation online, including a wide range of educational resources for contractors, homeowners, and design professionals. SMUD and National Grid indicated that they hold advanced training sessions for contractors once or twice a year. They hire a company to present advanced design and installation workshops. They also hold a workshop four times a year called "PV for Homeowners." Our utility Web site review also showed that many utilities have an FAQ section to help their customers with common problems.

\subsection{New York State Application Process}

The New York State Standardized Interconnection Requirements (SIRs) and the application process for new distributed generators of $2 \mathrm{MW}$ or less were updated in February 2009 by the New York State Public Service Commission. ${ }^{1}$ There are two distinct application processes - one for distributed generation systems of $25 \mathrm{~kW}$ or less and an additional process for systems $>25 \mathrm{~kW}$ and $<2 \mathrm{MW}$.

Using the updated application standard requirements and the information from our survey, we constructed a detailed outline of recommended practices. Table 4-1 reviews the application process and recommends practices that might help streamline the process. We discuss these recommendations in Section 4.2.1, referencing the processes from the utilities surveyed.

Table 4-1. Recommended Practices

New York State Application Process $(<25 \mathrm{~kW})$

\section{Recommended Practice}

Step 1: Initial communication from the potential applicant

Step 2: Utility review of the inquiry to determine project's nature

Step 3: Applicant files formal application

Step 4: PV system installed

\author{
Customer makes initial contact through an online \\ tracking system. Customer inquiry takes place \\ primarily through documentation on the utility's \\ Web site.
Customer files formal application online. The utility's online tracking system contains links to all documents, which include
1. Letter of authorization from the customer
2. Standard one-page application form
3. One-line diagram with manufacturer model number
4. Verification test (see Appendix 4-C) to ensure that SIRs are met.

Utility's office specialist conducts a review of the application. Engineering group reviews the oneline diagram.

The local inspection authority that handles the permits should inspect the PV system.

\footnotetext{
${ }^{1}$ New York State Public Service Commission, New York State Standardized Interconnection Requirements and Application Process for New Distributed Generators $2 \mathrm{MW}$ or Less Connected in Parallel with Utility Distribution System, February 2009. http://www.dps.state.ny.us/Final_SIR_02-12-09_Clean.pdf. Accessed October 8, 2009.
} 
Step 5: Applicant's system tested in accordance with the SIR. Verification testing must be performed at least once every four years.

Step 6: Final acceptance and company cost reconciliation
The utility should reserve the right to witness verification testing or require written certification that the testing was successfully performed.

Rebates and incentives are handled under the state solar incentive program, separately from the utility's interconnection process.

\subsubsection{Discussion of Proposed Application Process}

Step 1: We recommend implementing an online tracking system similar to the one Frontier Associates ${ }^{2}$ developed for Xcel Energy. The user-friendly tracking system allows all the application steps to be done online, and all forms are available on the Web site. Customers can follow their applications through the entire process, and e-mail messages update the customer on the next step. According to the New York SIRs, the utility Web site is required to give applicants with systems $25 \mathrm{~kW}$ and below the ability to submit their application for interconnection via the Web. The Web-based application process must include the ability to attach associated documentation or drawings associated with each project.

Step 2: The main part of the application is submitted in this step. A complete application package consists of a signed letter of authorization by the customer (the customer can scan or fax the signed document, or use the electronic signature feature available in some programs). The completed standard application should be submitted with a one-line diagram, and the drawing should contain the manufacturer's model number for the PV panels and inverter. The equipment must be Underwriters Laboratories (UL)-certified, and should also be listed as standard equipment on the list on New York State's Web site. If the application design meets the SIRs, the application is approved and the tracking system sends out an e-mail message that indicates approval and date of approval. Note that the utility can require the installer to carry out a verification test procedure.

Step 3: The utility's nontechnical person should be responsible for reviewing the application to ensure that all the forms are filled out and that the equipment specified in the design is on the certified equipment list. An engineer should review the one-line diagram. The nontechnical preliminary review of the application and design should help reduce the engineer's review time.

Step 4: The system is installed and tested. Inverter-based systems are allowed to interconnect to the utility system for no more than two hours for verification testing. The utility can either dispatch a witness to the verification test or simply request written certification that the system was installed and tested in compliance with the SIRs.

\footnotetext{
${ }^{2}$ Frontier Associates LLC. http://www.frontierassoc.com/about.html. Accessed September 15, 2009.
} 
Step 5: According to the New York SIRs, the single-phase inverters and inverter systems rated $25 \mathrm{~kW}$ and below must be verified on initial parallel operation and then once every four years. The homeowner must interrupt the utility source and verify that the equipment automatically disconnects and does not reconnect for at least 5 minutes after the utility source is reconnected. The owner should maintain the $\log$ and results from testing for inspection by the utility. National Grid provided an example of a verification test (see Appendix 4-C).

Step 6: Once the interconnection has been verified, the utility should finalize acceptance and do its company cost reconciliation promptly. Rebates and incentives should be handled under the state solar incentive program and separate from the utility's interconnection process. Currently, the New York State Energy Research and Development Authority (NYSERDA) handles the rebates.

\subsection{Summary of Recommended Practices}

As detailed earlier in this section, the survey brought to light some recommended practices that might help speed up the application process:

- Make applications documentation available on the utility's Web site.

- Institute an online tracking system to inform customers about the status of their applications.

- Post a qualified equipment list for PV modules and inverters.

- Post a qualified contractor list and make sure that contractors meet the certification requirements that qualify them to be on the list.

- Offer training and outreach programs for both contractors and homeowners. These help to build awareness of the application process and should improve the quality of the applications submitted. 


\section{Appendix 4-A: List of Questions on Application Process}

Here is a list of general interconnection questions for utilities approving PV systems.

1. Does your company install distributed generation systems by size and type? Are there different processes for PV installations versus other distributed generation installations?

2. How long does it take an application for PV installation to move through your system today compared to when you were first approving new systems? If the process is faster, what do you attribute that to?

3. Does your company have all documents (applications, procedures, guidelines) available online? Is this a change from your first installations?

4. What types of PV systems are approved without any full utility engineering studies? How is this different from a few years ago?

5. Does your company inspect all systems that are installed? If you do an inspection, what does it consist of? What test do you run on an installation or is it just a visual check?

6. If some systems are not inspected, is this because of the experience you have had with other installations?

7. What equipment has a fast-track process?

8. What procedures have been streamlined since PV systems were first being installed? If they were streamlined, how?

9. Have these streamlined processes been successful? Have they

A. Reduced the time to install a system?

B. Reduced the cost to the customer and/or your utility?

C. Improved time spent by the utility engineers?

D. Revised the processes more than once?

10. Does your company have an online tracking process in place? If not, how does a customer determine the status of their installation?

11. Do you have outreach education for your communities? Do you mainly target installers/developers or customers? 
Appendix 4-B: Web-Site Survey 


\begin{tabular}{|c|c|c|c|c|c|}
\hline \multicolumn{6}{|c|}{ Utility } \\
\hline & $\begin{array}{c}\text { Sempra includes } \\
\text { San Diego Gas \& Electric (SDG\&E) and } \\
\text { Southern California Gas Company }\end{array}$ & Pacific Gas \& Electric (PG\&E) & Xeel Energy & $\begin{array}{l}\text { Sacramento Municipal } \\
\text { Utility District (SMUD) }\end{array}$ & Seattle City Light (SCL) \\
\hline Web Site & hitp://www.sdge.com/business/netMetering.shtml & \begin{tabular}{|l} 
hhtp://www.pge.com/myhome/saveenergymoney/solaren \\
ergy//
\end{tabular} & \begin{tabular}{|l} 
hittp://www.xcelenergy.com/XLWEB/CDA/0,3080,1-1- \\
2735 257709-23075-2 424 756-0,00.html
\end{tabular} & http:///www.smud.org/community-environment/solar/ & hhtp://www.seattle.gov/light/Conserve/cgen// \\
\hline \begin{tabular}{|l} 
Location \\
\end{tabular} & California & California & Colorado & California & Washington State \\
\hline Point of Contact & \begin{tabular}{|l} 
Ken Parks \\
San Diego Gas \& Electric \\
8316 Century Park Ct, CP52F \\
San Diego, CA 92123-1582 \\
kparks@@emprautilitis.com \\
Phone: 858-636-5581
\end{tabular} & 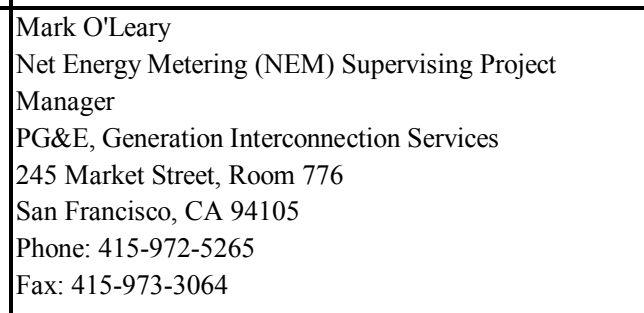 & $\begin{array}{l}\text { Pam Newell } \\
\text { Phone: 507-457-1249 } \\
\text { pamela.j.newell@xcelenergy.com }\end{array}$ & \begin{tabular}{|l} 
Hector Ortiz \\
Energy Specialist II \\
Residential/Commercial Solar PV \\
Phone: 916-732-6882
\end{tabular} & 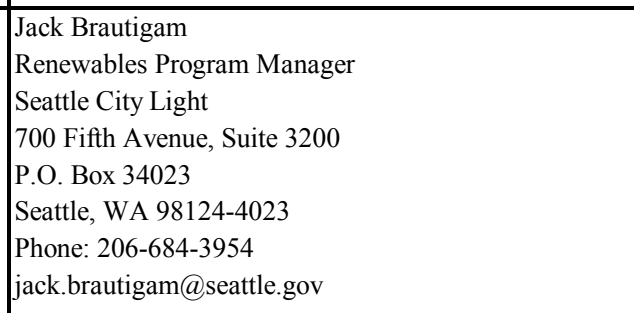 \\
\hline \multirow[t]{2}{*}{ State Tiers } & $<10 \mathrm{~kW}$. & $<10 \mathrm{~kW}$. & $10 \mathrm{~kW}$. & $<10 \mathrm{~kW}$ & $<300 \mathrm{~kW}$. \\
\hline & $10 \mathrm{~kW}-10 \mathrm{MW}$. & $10 \mathrm{~kW}-10 \mathrm{MW}$. & $10 \mathrm{~kW}-2 \mathrm{MW}$. & $10 \mathrm{~kW}-10 \mathrm{MW}$. & $300 \mathrm{~kW}-2 \mathrm{MW}$. \\
\hline \multirow[t]{2}{*}{ Utility Tiers } & $<30 \mathrm{~kW}$. & $30 \mathrm{~kW}$ & $0.5-10 \mathrm{~kW}$. & None specified. & $<100 \mathrm{~kW}$. \\
\hline & $30 \mathrm{~kW}-1 \mathrm{MW}$ & $30 \mathrm{~kW}-1 \mathrm{MW}$. & \begin{tabular}{|l}
$10 \mathrm{~kW}-100 \mathrm{~kW}$. \\
$100 \mathrm{~kW}-1 \mathrm{MW}$.
\end{tabular} & & $>100 \mathrm{~kW}$. \\
\hline \multicolumn{6}{|c|}{ PV System Connection Requirements: Utility Tier 1} \\
\hline Size Limit & $30 \mathrm{~kW}$. & $<30 \mathrm{~kW}$. & $0.5-10 \mathrm{~kW}$. & None specified. & $<100 \mathrm{~kW}$. \\
\hline Application Fee & None. & None. & None. & None. & $\$ 100$ \\
\hline Application & $\begin{array}{l}\text { Three pagess. Requires name and contact info for owner } \\
\text { and contractor, along with description of solar panels, } \\
\text { invertercontroller, disconnect, and any other customer } \\
\text { generation system. }\end{array}$ & $\begin{array}{l}\text { Eight-page combined application and interconnection } \\
\text { agreement. Requires contact information for nowner and } \\
\text { contractor, insurance information, rate selection, and a } \\
\text { description of the generating facility (including solar } \\
\text { panels, inverters, and disconnects). }\end{array}$ & $\begin{array}{l}\text { Oolline application requires contact info for owner and } \\
\text { contractor, alang with description of system including } \\
\text { PV panel manufacturer and model, nameplate capacity, } \\
\text { azimuth/orientation, tilt anglel tracking system, single- } \\
\text { or three-phase electrical service, and inverter } \\
\text { manufacturer and model. }\end{array}$ & $\begin{array}{l}\text { Ten-page application requires contact information and } \\
\text { generating system information. Available online but } \\
\text { must be submitted by mail. }\end{array}$ & $\begin{array}{l}\text { Six-page combined application and interconnection } \\
\text { agreement requires contatat information and generating } \\
\text { system information. Separate two-paga application for } \\
\text { electric service required to request a production meter if } \\
\text { applying for the Washington State Renewable Energy } \\
\text { Production Incentive. SCL electrical service } \\
\text { representatives available to visit customer's property to } \\
\text { review submitted forms and system design. }\end{array}$ \\
\hline $\begin{array}{l}\text { Interconnection Agreement } \\
\end{array}$ & $\begin{array}{l}\text { Eight pages. Agreement must be signed. Agreement } \\
\text { summarizes generating facility, interconnection and } \\
\text { design requirements, metering and billing, } \\
\text { disconnection, interruption or reduction of deliveries, } \\
\text { access to premises, indemnity and liability, and } \\
\text { insurance. }\end{array}$ & Included in application. & $\begin{array}{l}\begin{array}{l}\text { Fifteen pages. Requires a signed agreement that outlines } \\
\text { the terms for connecting the } \mathrm{PV} \text { installation to the utility } \\
\text { grid. }\end{array}\end{array}$ & $\begin{array}{l}\text { Two agreements: Electrical Interconnection Agreement } \\
\text { and Net Metering Agreement. }\end{array}$ & Included in application. \\
\hline Electrical Diagram & $\begin{array}{l}\text { One-line diagram (one page). The general arrangement } \\
\text { and relationship of the system components and the make } \\
\text { and model of each component must be shown. }\end{array}$ & 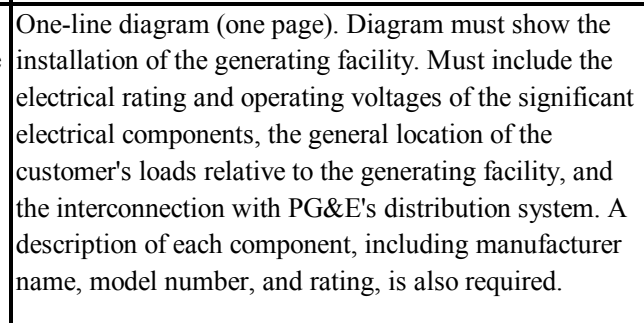 & $\begin{array}{l}\text { A one-page installation diagram must show the } \\
\text { arrangement of system components. }\end{array}$ & One-line electrical diagram (one page). & One-line electrical diagram (one page). \\
\hline Description of Materials & $\begin{array}{l}\text { Requires bill of materials with item description, vendor, } \\
\text { part number, and quantity. }\end{array}$ & Included in electrical diagram. & $\begin{array}{l}\text { Requires serial numbers of the PV panels and inverters } \\
\text { to verify that the equipment is new. }\end{array}$ & \begin{tabular}{|l|} 
Included in application and electrical diagram. \\
\end{tabular} & $\begin{array}{l}\text { Inverter specification sheet required, also with } \\
\text { production meter socket installation. }\end{array}$ \\
\hline AC Disconnect & $\begin{array}{l}\text { A visible, open, lockable disconnect must be installed } \\
\text { adjacent to electric service panel. Brand name and model } \\
\text { number must be given to the utility. }\end{array}$ & $\begin{array}{l}\text { Requires a description and location of visible, lockable } \\
\text { AC disconnect switth if present. Switch is required only } \\
\text { for inverter-based interconnections having a transformer- } \\
\text { rated meter or noninverter- based generators. }\end{array}$ & An AC disconnect is not required for $<10 \mathrm{~kW}$. & Not specified. & $\begin{array}{l}\text { Requires a UL-approved safety disconnect switch. This } \\
\text { requirement may be waived if interconnection equipmen } \\
\text { physically disconnects generating equipment supply } \\
\text { internally, and applicant agrees that service may be } \\
\text { disconnected entirely if generatating equipment must be } \\
\text { disconnected for any reason. }\end{array}$ \\
\hline
\end{tabular}




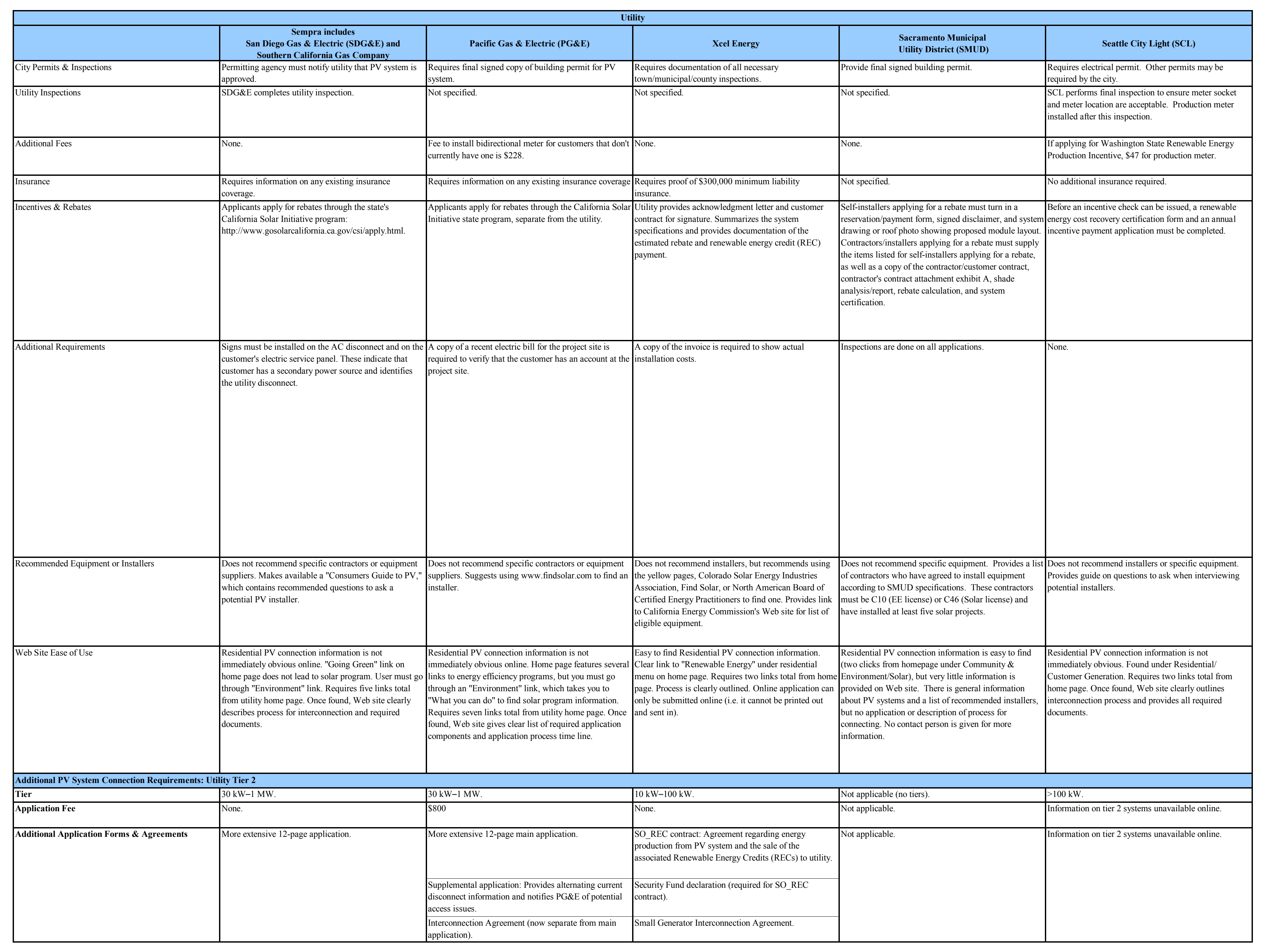




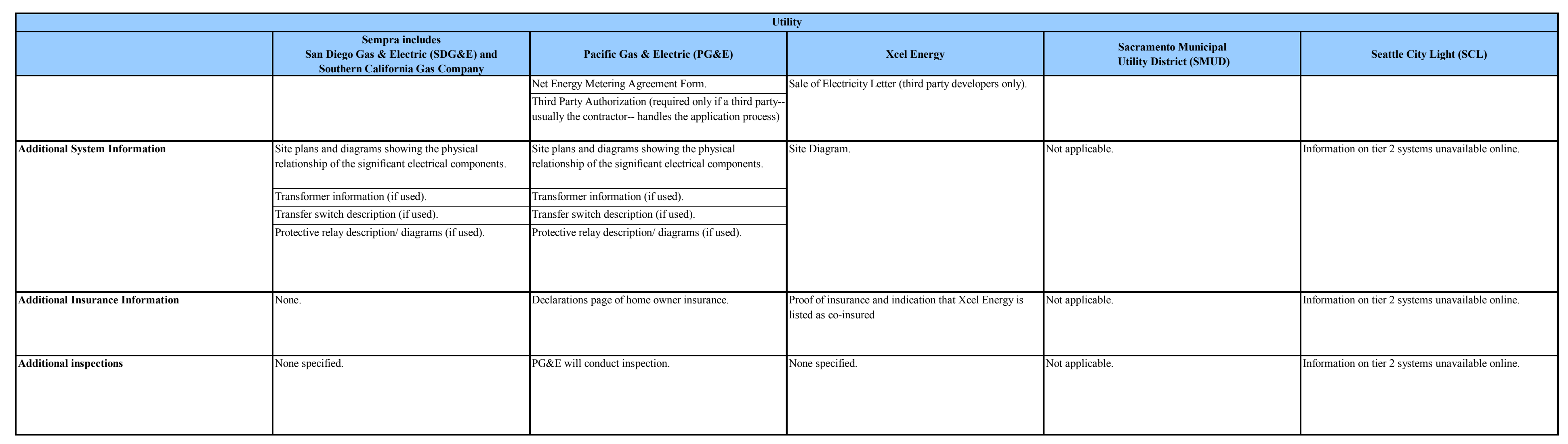




\begin{tabular}{|c|c|c|c|c|}
\hline & \multicolumn{4}{|c|}{$\begin{array}{llll}\text { Utility } \\
\end{array}$} \\
\hline & NSTAR & Entergy & Con Edison & $\begin{array}{c}\text { Public Service } \\
\text { Enterprise Group (PSE\&G) }\end{array}$ \\
\hline Web Site & htpp://www.nstar.com/business/interconnections/ & $\begin{array}{l}\text { hitpp///www.entergy- } \\
\text { neworleans.com/your_home/net_metering.aspx }\end{array}$ & http://apps.coned.com/dg/applications/applications.asp & hitp:///www.pseg.com/customer/solar/procoess 1.jsp \\
\hline Location & \begin{tabular}{|l|l} 
Boston, Massachusetts \\
\end{tabular} & Arkansas, Louisiana, Mississippi \& Texas & New York & New Jersey \\
\hline Point of Contact & \begin{tabular}{|l} 
Jan Gudell \\
Program Manager \\
Phone: 781-441-8366 \\
Fax: $871-441-8721$ \\
jan.gudell@nstar.com \\
Joe Feraci \\
Senior Engineer \\
Phone: 781-441-8196 \\
Fax: 781-441-8721 \\
joseph.feraci@nstar.com
\end{tabular} & \begin{tabular}{|l|} 
Entergy New Orleans, Inc. \\
Customer Relations, Net Metering \\
P.O. Box 61000/LMAG-44 \\
New Orleans, LA 70161-1000 \\
1 1-800-368-3749
\end{tabular} & \begin{tabular}{|l} 
Margarett Jolly \\
DG Ombudsman \\
$212-466-3328$ \\
jollym@coned.com
\end{tabular} & \begin{tabular}{|l} 
Don Cooke \\
Distribution Team Leader, New Business \\
PSE\&G Ilectric Delivery Asset Management \\
80 Park Plaza, T12 \\
Newark, NJ 07102 \\
Phone: $973-430-7419$ \\
Mobile: $973-390-7026$ \\
Fax: 973-621-8410 \\
Donald.Cooke@pseg.com
\end{tabular} \\
\hline \multirow[t]{2}{*}{ 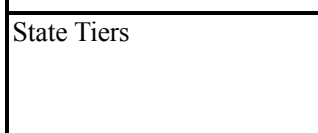 } & $<10 \mathrm{~kW}$ one-phase or $<25 \mathrm{~kW}$ three-phase. & $<25 \mathrm{~kW}$ residential, $<100 \mathrm{~kW}$ commercial. & $<15 \mathrm{~kW}$. & $<100 \mathrm{~kW}$. \\
\hline & $>10 \mathrm{~kW}$ one-phase or $>25 \mathrm{~kW}$ three-phase & & $15 \mathrm{~kW}-2 \mathrm{MW}$. & $>100 \mathrm{~kW}-2 \mathrm{MW}$ \\
\hline \multirow[t]{2}{*}{ 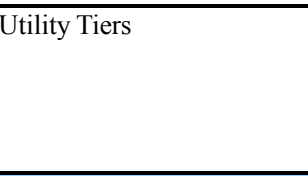 } & $<10 \mathrm{~kW}$ one-phase or $<25 \mathrm{~kW}$ three-phase. & $<25 \mathrm{~kW}$ residential, $<100 \mathrm{~kW}$ commercial. & 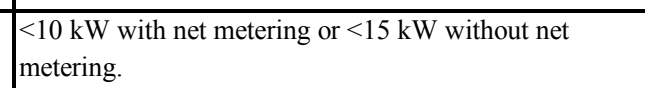 & \multirow[t]{2}{*}{$<10 \mathrm{~kW}$ single-phase or $<25 \mathrm{~kW}$ three-phase. } \\
\hline & $>10 \mathrm{~kW}$ one-phase or $>25 \mathrm{~kW}$ three-phase. & No other tiers. & $\mid$ & \\
\hline \multicolumn{5}{|c|}{ PV System Connection Requirements: Utility Tier 1} \\
\hline Size Limit & $<10 \mathrm{~kW}$ one-phase or $<25 \mathrm{~kW}$ three-phase. & $<25 \mathrm{~kW}$ residential, $<100 \mathrm{~kW}$ commercial. & 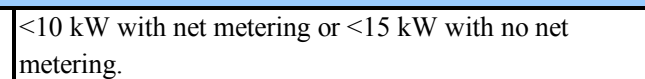 & $<100 \mathrm{~kW}$. \\
\hline Application Fee & $\begin{array}{l}\text { None. } \\
\end{array}$ & None & $\begin{array}{l}\begin{array}{l}\text { A } \$ 350 \text { fee is refunded to net metering customers unless } \\
\text { applied to transformer. }\end{array} \\
\end{array}$ & $\begin{array}{l}\text { \$10 per installed kilowatt up to a maximum fee of } \\
\text { \$2,500 per application. }\end{array}$ \\
\hline Application & $\begin{array}{l}\text { Six-page combined application and interconnection } \\
\text { agreement. Requires contact information, generating } \\
\text { facilitity information, and inverter UL1741 listing } \\
\text { information. }\end{array}$ & $\begin{array}{l}\text { Four-page application requires contact information and } \\
\text { generating facility information. }\end{array}$ & $\begin{array}{l}\text { One-page application. Addditional addendum application } \\
\text { (five pages) required for confinuurations that do not } \\
\text { qualify for net metering. Must attach protection } \\
\text { schematics and generator control description to } \\
\text { addendum application. }\end{array}$ & $\begin{array}{l}\text { Three page application requires contact information, } \\
\text { system information, and contractor information. }\end{array}$ \\
\hline Interconnection Agreement & Included in application. & Six-page interconnection agreement. & \begin{tabular}{|l} 
Six-page New York State Public Service Commission \\
Standardized Interconnection Agreement.
\end{tabular} & $\begin{array}{l}\text { Requires copies of project design documents; project } \\
\text { operation and maintenance plan, including warranty } \\
\text { documents; and all documents/agreements between } \\
\text { applicant and solar developer. }\end{array}$ \\
\hline \begin{tabular}{|l|l} 
Electrical Diagram \\
\end{tabular} & $\begin{array}{ll}\text { Not specified. } \\
\text { nate }\end{array}$ & One-line electrical diagram & $\begin{array}{l}\text { One-line electrical drawing. Wiring and schematic } \\
\text { drawings sealed by a licensed professional engineer in } \\
\text { New York State. }\end{array}$ & $\begin{array}{l}\text { Project design documents including one-line electrical } \\
\text { diagram. }\end{array}$ \\
\hline Description of Materials & $\begin{array}{l}\text { Not required. } \\
\text {. }\end{array}$ & Not required. & $\begin{array}{l}\text { List of all interconnection devices; must provide specs } \\
\text { for this equipment upon utility request. }\end{array}$ & $\begin{array}{l}\text { Copies of the manuffacturer's specification sheets for the } \\
\text { equipment comprising the project. }\end{array}$ \\
\hline AC Disconnect & NSTAR may require an external disconnect switch. & AC disconnect required. & External disconnect switch required. & $\begin{array}{l}\text { All generating equipment must be capable of being } \\
\text { isolated from PSE\&G system by means of an external, } \\
\text { manual, visible, gang-operated, load breaker (except for } \\
\text { systems of } 10 \mathrm{~kW} \text { ). }\end{array}$ \\
\hline
\end{tabular}




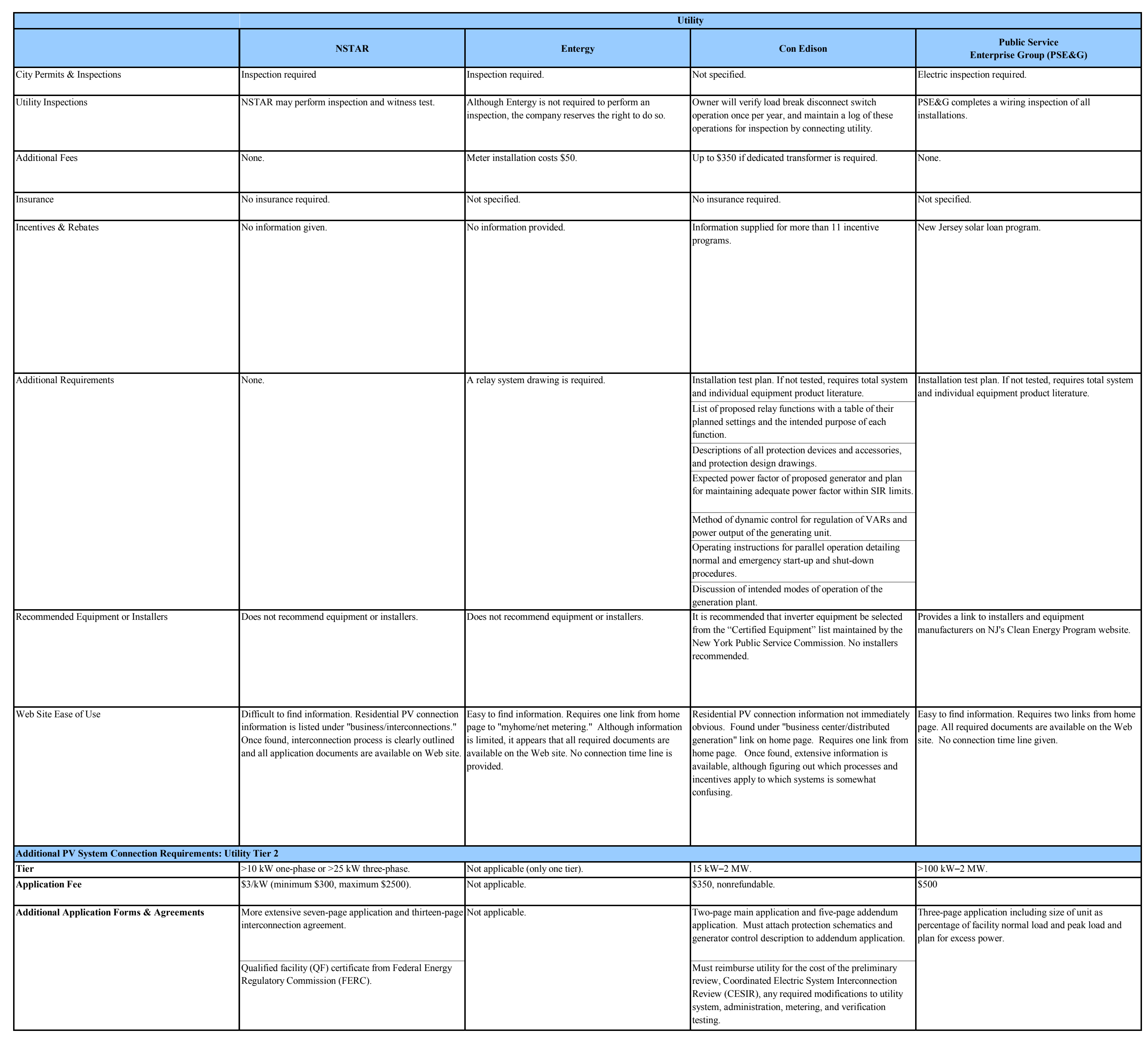




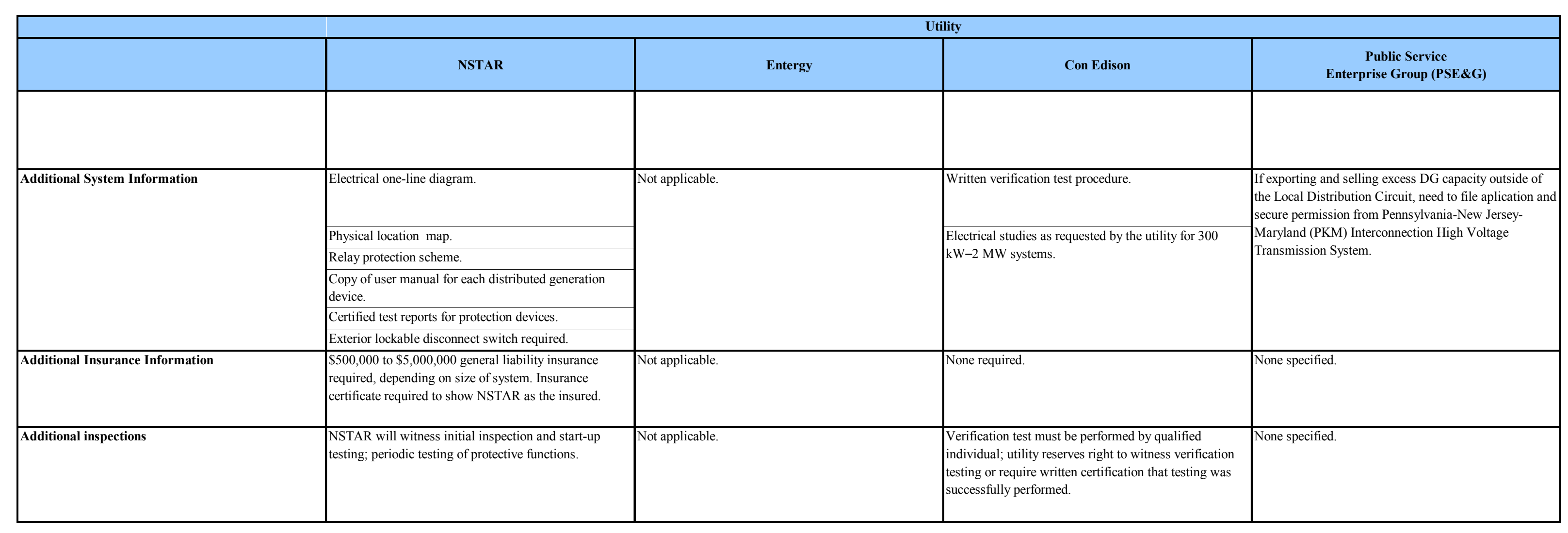




\section{Appendix 4-C: Verification Test Requirements (National Grid)}




\section{Net-metered Type-tested DG Installation Compliance Verification Check List}

Account Number:

Customer Name:

Phone \#

Last

First

Work Phone \#

Service Address:

Number Street Town/City $\quad$ Zip

Billing Address:

Number Street

Town/City

Zip

Qualified Installer:

Last First

License \#

Phone \#

Address:

Number

Street

Town/City

(if available)

Cellular \#

FAX \#

Pager \#

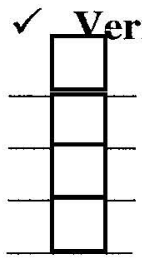

erify One-Line Diagram (installed equipment)

Inverter Model or Intertie Multifunction Relay Model

Software version

Company billing meter $\mathbf{s} / \mathbf{n}$

Inspection received? YES Number

NO $\square$ then stop and await inspection approval.

Net-meter One Meter Option: YES $\square$ NO (attach copy of approval certificate)

\section{$\checkmark$ Verify Plot Plan (equipment's location)}

\begin{tabular}{l|l}
\hline & \\
\hline & \\
\hline & \\
\hline
\end{tabular}

"Generator Disconnect Switch" is at agreed location: YES $\square$ NO $\square *$

"Generator Disconnect Switch" is labeled as such: YES $\square \mathrm{NO} \square *$

Label is at meter location to identify location of Generator Disconnect: YES $\square \mathrm{NO} \square$ *

* Attach photo or digital photo of utility-designated generator disconnect location.

\section{$\checkmark$ Verify DG System Is Operating (producing power)}

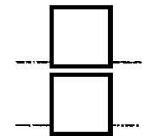

Verify "Generator Disconnect Switch" is Open.

Verify voltage is zero volts on DG side of open "Generator Disconnect Switch":

YES $\square$ NO

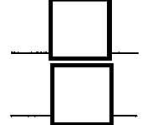

Close "Generator Disconnect Switch".

Verify DG Inverter or Intertie Multifunclion Relay alarms and voltage present on utility side of "Generator Disconnect Switch": YES $\square$ NO

\section{$\checkmark$ Restoration of Utility Power Test}

$\square$ Open "Generator Disconnect Switch", pause at least 1 to 2 minutes, then Close "Generator Disconnect Switch". Record time when "Generator Disconnect Switch" is closed:

_ Record time when DG starts producing power: Is the time between the "Generator Disconnect Switch" closure and when DG Inverter or Intertie Multifunction Relay permits synchronization to utility source greater than 5 minutes? YES

\section{Hour Telephone Number Contact}

Name:

Number ( $(2)$ -

Performed by: signature:

Date: Name (Company witness or Customer's qualified installer.)

Witnessed by: signature: Date: Property Owner Name (If test is performed by Customer's qualified installer.) 


\subsection{Conclusion}

To help accelerate the widespread implementation of solar energy in the United States, the U.S. Department of Energy (DOE) has teamed with cities around the country through its Solar America Cities (SAC) partnership program. New York City's team is working with DOE's National Renewable Energy Laboratory (NREL) and the city's utility, Con Edison, to develop a roadmap for photovoltaic $(\mathrm{PV})$ installations in the five boroughs. City leaders set a goal to increase the installed PV capacity in New York City from 1.1 MW in 2005 to 8.1 MW by 2015 (the maximum allowed in 2005). The complexity of the interconnection process with the local utility, though, presents unique challenges that must be addressed if the city's goals are to be met.

Although most areas of the country use simpler radial distribution systems - where each customer receives power through a single line - to distribute electricity, larger metropolitan areas typically use secondary network distribution systems (simplified to "networks" in this report) to increase reliability in large load centers. Networks deliver power to each customer through several parallel circuits and sources, and although this redundancy does improve reliability, it also requires more complicated coordination and protection schemes. These schemes can be unintentionally disrupted by energy exported from distributed PV systems. Today, Con Edison evaluates the network impact of each proposed PV system in New York City, but this is time consuming for utility engineers and may delay the customer's project or add cost for larger installations. The city's leaders would like to streamline this process to facilitate faster, simpler, and less expensive PV system interconnections.

With support from DOE, NREL conducted a four-part study to assess ways to improve the interconnection process. We then compiled the final reports from each study into this report, which is intended not only to document our work in New York City, but also to assist other utilities that are interconnecting distributed PV systems to their networks.

\subsection{A Brief Summary of Each Report Section}

In Section 1, we analyze the technical potential for rooftop PV system in ten Con Edison networks. The study spans various boroughs of New York City and different building densities, ranging from high-density apartments to lower density single family homes. Next, we compare the potential power production to network loads to determine where and when PV generation is most likely to exceed network load and disrupt network protection schemes. The results of this analysis may assist Con Edison in evaluating future PV interconnection applications and in planning future network protection system upgrades.

Section 2 is an overview intended for nontechnical stakeholders. Here we describe the issues associated with interconnecting PV systems to networks and present possible solutions. At higher deployments, for example, distributed PV systems can disrupt network protection, complicate load forecasting and power system planning, increase the potential for unintentional islands, and cause power quality problems like voltage flicker. Section 2 ends with a brief summary of potential solutions for these issues. 
In Section 3, we summarize common concerns of utility engineers and network experts about interconnecting PV systems to secondary networks. This section also contains detailed descriptions of nine solutions, including advantages and disadvantages, potential impacts, and road maps for deployment.

Section 4 describes our review of the administrative interconnection processes of utilities across the country and identifies ways to streamline the distributed generation application process. A list of administrative best practices for efficient PV interconnection is included in this section.

\subsection{Future Research}

To build on what we learned in this four-part study and gain a better understanding of the effects of distributed PV systems on networks, we recommend additional research in the following areas:

- Identify system-level impacts of high PV penetration in networks: Although the effects of individual PV system connections to networks have been comprehensively examined, we currently know little about how the entire system is affected at high penetrations of PV.

- Identify maximum penetration levels in network systems: PV penetration levels of $20 \%$ to $30 \%$ are generally considered to be the maximum allowable level in radial distribution systems before changes to the system are necessary. The maximum allowable penetration level on a network system, however, is unclear. Additional research is crucial for establishing maximum acceptable penetration levels in networks.

- Improve modeling of distributed generation in network systems: Current modeling solutions do not adequately address the system impacts of distributed generation in network systems. Further research and development should be directed at improving modeling solutions for network systems.

- Develop smart grid technologies: Smart grid technologies, which are currently in their infancy, could potentially offer intelligent monitoring and control of PV systems, allowing for better integration into network systems. Research and development of smart grid technologies, with a particular focus on their applicability in network systems, should continue. 


\subsection{Glossary}

Area network: A type of secondary network distribution system that is typically used in larger metropolitan areas. It can serve hundreds to thousands of electric customers of all types and sizes (e.g., residential, commercial, and industrial). Area networks are also known as street networks or grid networks. Area networks have two or more feeders and two or more transformers networked together (see Figure 6-1), to provide redundancy. Typical area networks can include as few as 10 transformers to more than 1,000 transformers, and be served by 3 to 35 distinct electric distribution feeders. Some area networks can serve up to several square miles. Area networks are designed to serve all network customer loads, during a peak-demand day, with one to two feeders out of service. And many networks could operate with additional feeders out of service during times of nonpeak demand.

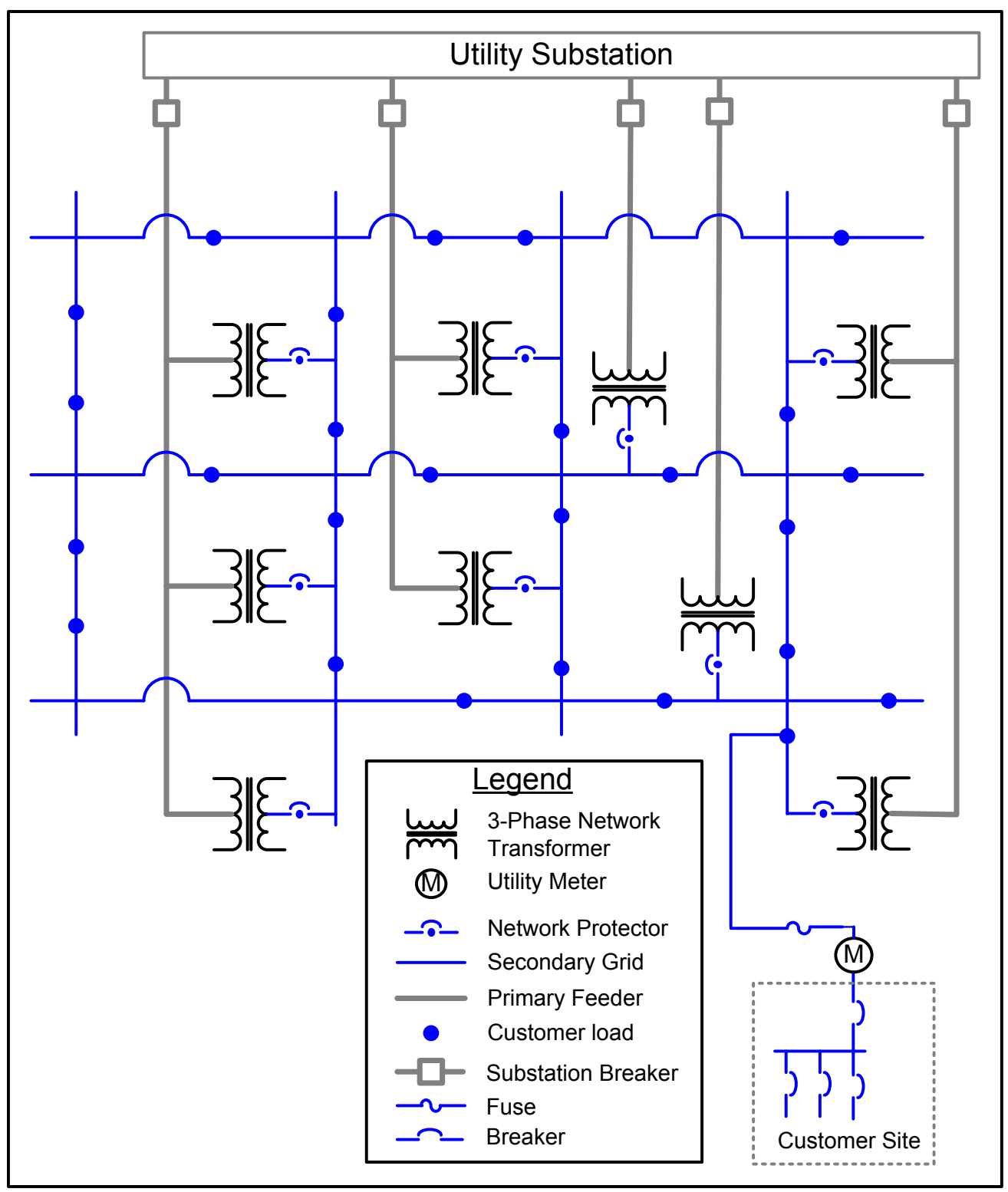

Figure 6-1. A typical area network 
Circuit breaker ("breaker"): A device designed to open the circuit automatically on a predetermined overload of current. It is typically manually reset to the closed position. A circuit breaker is usually intended to operate infrequently, although some types are suitable for frequent operation.

Cycling: The undesirable cyclical opening and closing of a network protector because of external (load) conditions. Left unchecked, cycling can eventually lead to failure of the network protector.

Reverse power flow from exporting photovoltaic (PV) systems can cause cycling. The network protector opens initially when it senses reverse power. Once it has opened, the load flow changes direction, and the open network protector may sense this as a "re-close" condition. When the network protector closes, the load flows will again change direction and could once again cause the network protector to open. This could lead to repeated opening and closing of the network protector, eventually causing it to fail.

Electrical distribution system: The system that carries electricity from the substations to the individual customers. The two main types of electrical distribution systems are radial and network.

Electrical transmission system: The system that carries electricity from the power plants to the substations. The transmission system operates over longer distances and at higher voltages than the distribution system.

Fault current: The current that results from the accidental connection between an energized and a grounded or other conductive element. Faults can be caused by a range of events, including lighting strikes, overhead lines breaking in storms, and workers digging through cables. Fault currents can be very large and the distribution system must be designed to withstand these currents and to disconnect the faulted section quickly, allowing the rest of the system to continue operating with a minimum of disturbance. Because PV systems add an additional source of energy to the network, they can increase the amount of fault current in the network. Increased fault current caused by individual PV systems is generally very small, but it could exceed equipment ratings at high $\mathrm{PV}$ penetrations.

Feeder: The circuit that carries electricity from the electrical substation to the customers. A feeder typically supports several hundred to several thousand electric utility customers.

Fuse: An overcurrent protective device that detects faults and opens the circuit by melting a wire component.

Grid network: See area network.

Harmonic distortion: The change in the waveform of the supply voltage from the ideal sinusoidal waveform. Harmonics cause undesirable heating in transformers and cables, which can lead to circuit breaker tripping, overvoltage problems, incandescent light blinking, and computer malfunctions. 
Islanding: A condition in which a portion of the utility system that contains both load and distributed resources remains energized while isolated from the rest of the utility system.

Meter: The device that measures and records electricity consumption.

Net metering: A practice that enables customers to use their own generation to offset their consumption over a billing period by allowing their electric meters to run backward when they generate electricity that exceeds their demand. This offset means that customers receive retail prices for the excess electricity they generate. Without net metering, a second meter is usually installed to measure the electricity that flows back to the provider, with the provider purchasing the power at a rate much lower than the retail rate.

Network: See secondary network distribution system.

Network protector (NP): Special protective devices used in secondary network distribution systems (networks), but not in radial distribution systems. Networks were originally designed for one-way current flow from the electric utility to the consumer, and NPs are usually set to prevent current from flowing back toward the utility. NPs, which consist of a relay and breaker pair, are installed on the low-voltage side of each network transformer. When they sense reverse current flow, they open to prevent current from flowing back through the transformer from its lowvoltage side to its high-voltage side. This prevents current flow in the event of a faulted or deenergized circuit, and allows the network to maintain uninterrupted service to utility customers even if a piece of equipment fails.

Because NPs are set to prevent reverse current flow, net metering is often difficult to implement in systems with NPs. Most NPs, though, can be programmed to allow reverse current, even by up to half the power rating of the transformer.

Pumping: The rapid, uncontrolled, unintentional, and intolerable repetitive opening and closing of a network protector, normally because of a failure in the network protector control circuitry. If not detected and corrected, pumping will quickly lead to failure of the network protector.

Radial distribution system: The most common design used by electric utilities. Radial distribution systems are the least expensive to plan, construct, and maintain. They generally consist of an electrical substation (typically at medium voltage in the $15-\mathrm{kV}$ class); a feeder (which may be a few miles to a few dozen miles in length); and a transformer that converts the $15-\mathrm{kV}$ voltage to a utilization level (120/240, 120/208 or 277/480; see Figure 6-2.) Several hundred to several thousand electric utility customers are typically on a feeder, and anywhere from 1 to 20 customers are served by a single transformer. Although radial distribution systems are simpler and less expensive than their network counterparts, they are also the least reliable because of the radial nature of the design. If any part of the system experiences a failure, some customers will be without power until a repair is completed. An auto-loop distribution system is a special type of radial distribution system that is differentiated by having two feeders that tie to a customer load. The auto-loop system automatically senses the loss of one source of voltage and quickly and automatically switches the load to the second feeder. This type of system increases reliability by keeping outages to a few seconds (or faster), but requires two sets of utility 
equipment at one location (which can add thousands to hundreds of thousands of dollars to an installation).

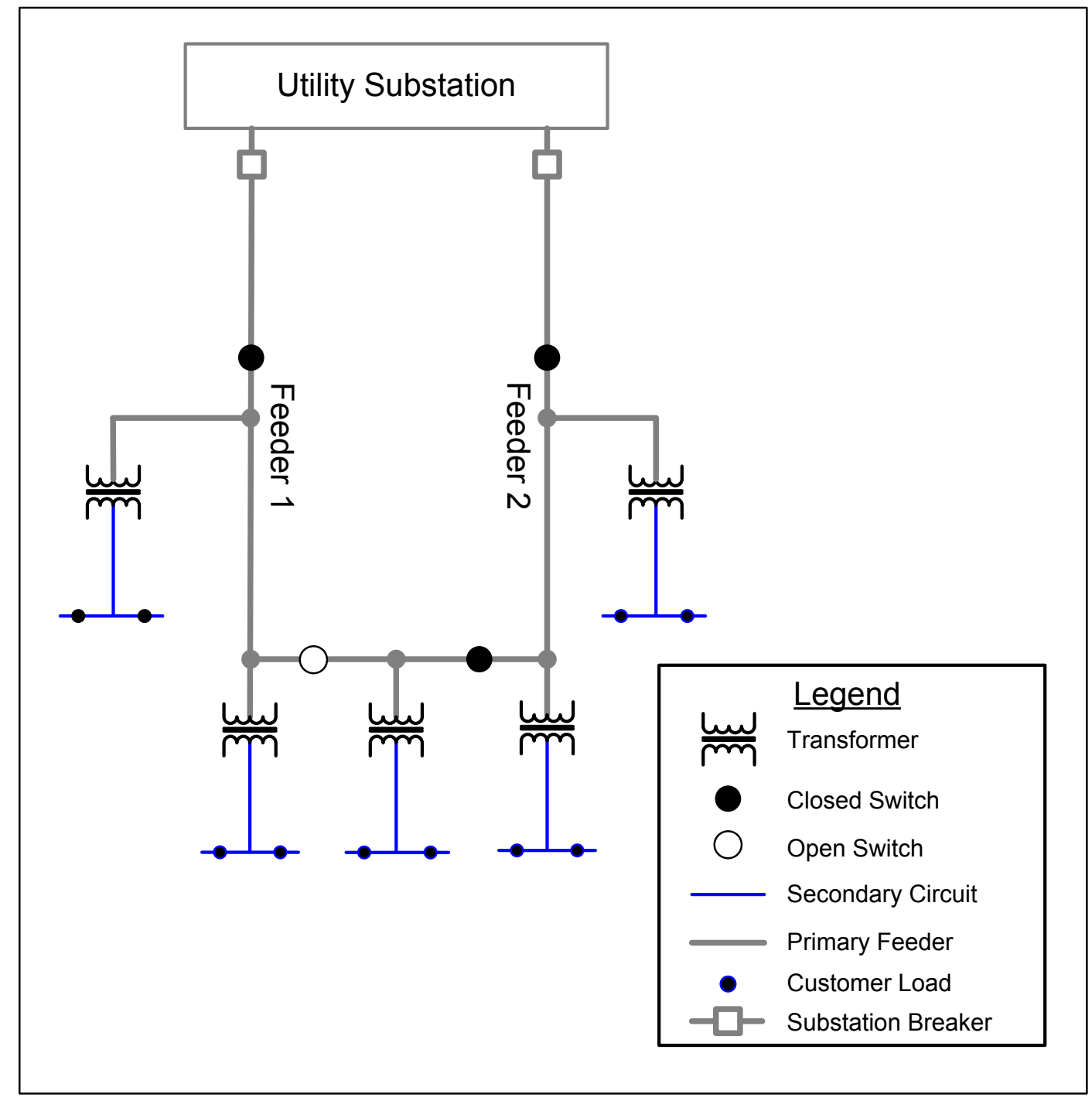

Note: Any transformer/customer load can be served by either feeder, depending on the switch positions.

Figure 6-2. A typical radial distribution system

Reactive power: Represents the alternating exchange of stored energy (inductive or capacitive) between two areas. Unlike real power, it does not deliver energy to a load, but it is necessary for the operation of induction motors.

Relay: A switch that opens and closes electrical contacts to control another device. In the case of an NP, a relay controls the circuit breaker.

Secondary network distribution system ("network"): The most sophisticated type of distribution system used by larger electric utility companies. Networks bring electricity to customers in areas where there are large concentrations of load and where greater reliability 
(than that of a radial system) is needed. A network is designed so that each load receives its power and energy from several parallel circuits and sources. This is achieved using a grid of interconnected primary and secondary lines to serve the connected loads. Engineers design networks with redundant transformers and redundant feeders, which is a distinguishing characteristic of a network. Redundant feeders and transformers can be taken out of service without affecting customers. Network feeders, transformers, and NPs can be taken out of service for maintenance or to add new equipment. Other reasons to take them out of service include equipment failures that result in a feeder or transformer outage, and significant drops in load on the network. Because there are multiple sources of power, "n," network engineers often design the networks to operate at "n-1" or "n-2" contingency mode. The n-1 indicates that the network will be fully functional with one less feeder in service, and $n-2$ indicates that the network will be fully functional with two less feeders in service.

The two types of secondary network distribution systems are spot networks and grid networks.

Spot network: A type of secondary network distribution system that is frequently used to serve a single customer. Spot networks will have two or more feeders and two or more transformers networked together at an electric consumer's site (see Figure 6-3). Electric consumers who are served by spot networks are typically located in very large buildings with major electric loads.

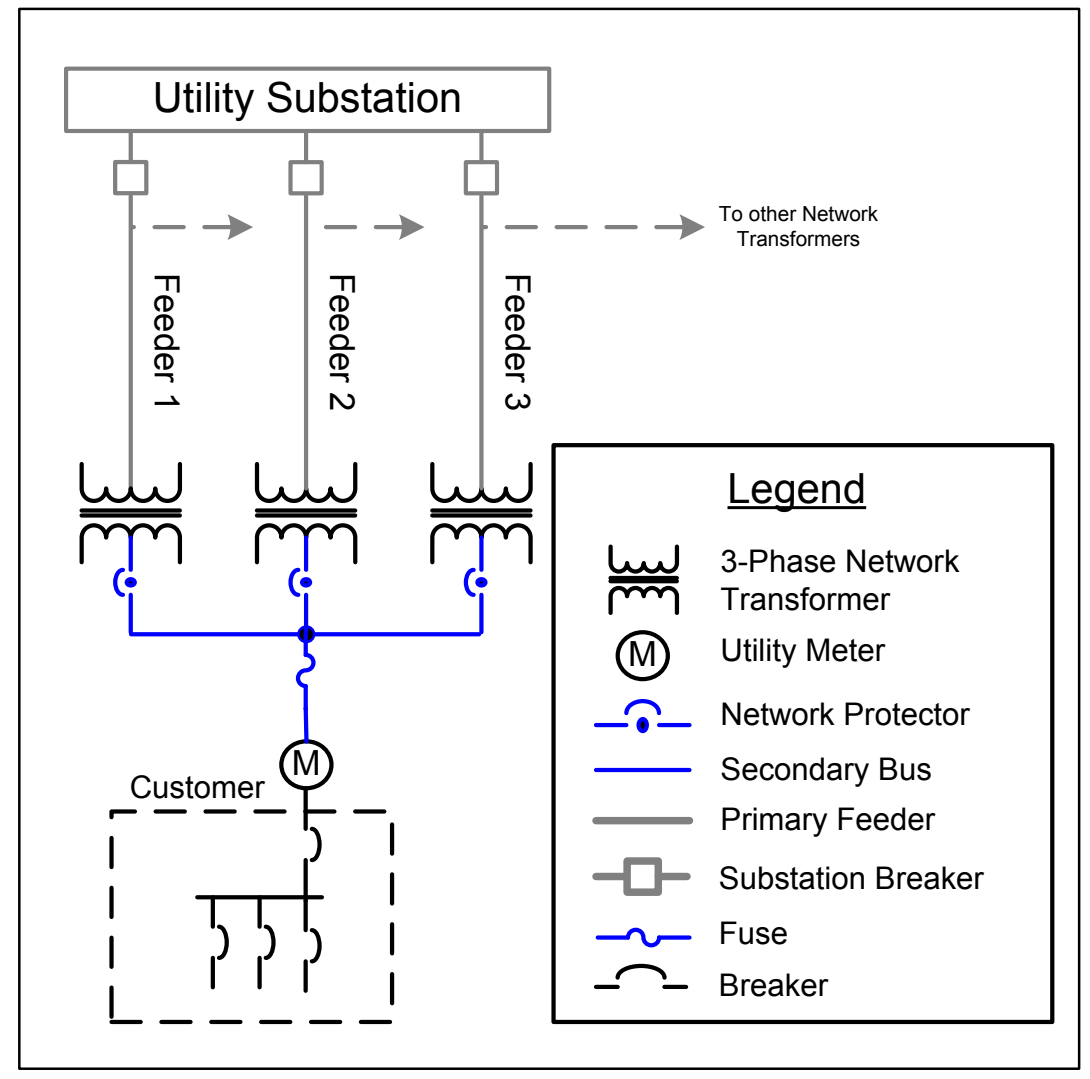

Figure 6-3. A typical spot network 
Street network: See area network.

Substation: A group of switches, circuit breakers, buses, and transformers that switch power circuits and transform power from one voltage to another or from one system to another. A substation connects the electrical transmission system and the distribution system, and transforms the power from high to low (or the reverse) using transformers. Electricity may flow through several substations between the power plant and the consumer, and the voltage may be changed in several steps.

Transformer: A device that raises or lowers voltage and current levels in a circuit.

VAR: Volt-ampere-reactive, the unit of reactive power. 


\section{REPORT DOCUMENTATION PAGE}

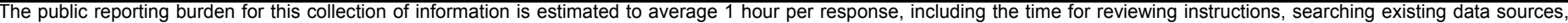

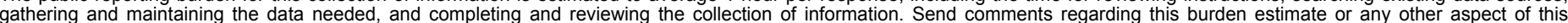

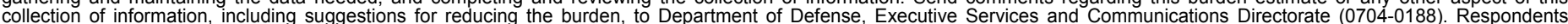

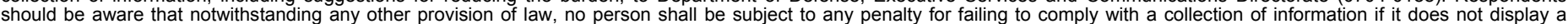

should be aware that notwithstandind

PLEASE DO NOT RETURN YOUR FORM TO THE ABOVE ORGANIZATION.

\begin{tabular}{l|l|l|l} 
1. REPORT DATE $(D D-M M-Y Y Y Y)$ & 2. & REPORT TYPE & 3. DATES COVERED (FrOm - TO)
\end{tabular}

December 2009

Technical Report

4. TITLE AND SUBTITLE

Interconnecting PV on New York City's Secondary Network

Distribution System 5a. CONTRACT NUMBER

DE-AC36-08-GO28308

5b. GRANT NUMBER

5c. PROGRAM ELEMENT NUMBER

5d. PROJECT NUMBER

NREL/TP-7A2-46902

5e. TASK NUMBER

PVC9.92GA

5f. WORK UNIT NUMBER
7. PERFORMING ORGANIZATION NAME(S) AND ADDRESS(ES)

National Renewable Energy Laboratory

1617 Cole Blvd.

Golden, CO 80401-3393
8. PERFORMING ORGANIZATION REPORT NUMBER

NREL/TP-7A2-46902

9. SPONSORING/MONITORING AGENCY NAME(S) AND ADDRESS(ES)

10. SPONSOR/MONITOR'S ACRONYM(S)

NREL

11. SPONSORING/MONITORING AGENCY REPORT NUMBER

12. DISTRIBUTION AVAILABILITY STATEMENT

National Technical Information Service

U.S. Department of Commerce

5285 Port Royal Road

Springfield, VA 22161

13. SUPPLEMENTARY NOTES

14. ABSTRACT (Maximum 200 Words)

This study describes technical assistance provided by NREL to help New York City and Con Edison improve the interconnection of distributed PV systems on a secondary network distribution system.

15. SUBJECT TERMS

Photovoltaic (PV) Interconnection; secondary network distribution system; New York City; Con Edison; utility networks

\begin{tabular}{|c|c|c|c|c|}
\hline \multicolumn{3}{|c|}{ 16. SECURITY CLASSIFICATION OF: } & \multirow{2}{*}{$\begin{array}{l}\text { 17. LIMITATION } \\
\text { OF ABSTRACT } \\
\text { UL }\end{array}$} & \multirow{2}{*}{$\begin{array}{l}\text { 18. NUMBER } \\
\text { OF PAGES }\end{array}$} \\
\hline $\begin{array}{l}\text { a. REPORT } \\
\text { Unclassified }\end{array}$ & $\begin{array}{l}\text { b. ABSTRACT } \\
\text { Unclassified }\end{array}$ & $\begin{array}{l}\text { c. THIS PAGE } \\
\text { Unclassified }\end{array}$ & & \\
\hline
\end{tabular}

19a. NAME OF RESPONSIBLE PERSON

19b. TELEPHONE NUMBER (Include area code) 